\title{
REFURBISHED AND 3D MODELED THERMAL VACUUM CHAMBER
}

\author{
A Thesis \\ presented to \\ the Faculty of California State University, \\ San Luis Obispo \\ In Partial Fulfillment \\ of the Requirements for the Degree \\ Master of Science in Aerospace Engineering
}

by

Lauren M. Glenn

March 2017 
(C) 2017

Lauren M. Glenn

\section{ALL RIGHTS RESERVED}




\section{COMMITTEE MEMBERSHIP}

TITLE:

AUTHOR:

DATE SUBMITTED:

COMMITTEE CHAIR:

COMMITTEE MEMBER:

COMMITTEE MEMBER:

COMMITTEE MEMBER:
Refurbished and 3D Modeled Thermal Vacuum Chamber

Lauren M. Glenn

March 2017
Kira Abercromby, Ph.D.

Associate Professor of Aerospace Engineering

David Marshall, Ph.D.

Professor of Aerospace Engineering

Jordi Puig-Suari, Ph.D

Professor of Aerospace Engineering

Roland Coelho

VP Launch Services, Tyvak NanoSatellite Systems 


\begin{abstract}
Refurbished and 3D Modeled Thermal Vacuum Chamber
\end{abstract}

Lauren M. Glenn

Spacecraft testing includes acoustics, vibrations, and thermal vacuum. Cal Poly's Space Environments Lab is equipped with multiple vacuum chambers, but no thermal vacuum chamber. The purpose of this thesis is to incorporate an ATS Chiller system with the HVEC vacuum chamber so students are able to experiment with a thermal vacuum chamber. The ATS Chiller had leaky pipes that needed to be refurbished and a shroud was implemented to improve thermal capabilities of the system. The full system was able to reach temperatures as low as $-38^{\circ} \mathrm{C}$ and as high as $58^{\circ} \mathrm{C}$ at a pressure of $10^{-6}$ Torr. The ATS Chiller was able to absorb up to 500W of heat dissipation from a component mounted to the platen inside of the vacuum chamber.

Thermal modeling of the apparatus was performed in Thermal Desktop. The model was incorporated with the test data to extract interface resistance information between connected surfaces. Another model is used to analyze a theoretical component inside the apparatus to evaluate mounting methods and determine theoretical temperatures of the component. The model adjusts for material properties, including thermal conductivity and emissivity to accurately simulate testing conditions within $+/-3^{\circ} \mathrm{C}$.

Platen and shroud adjustments were able to accommodate a peak bake out temperature of $130 \pm 2.2^{\circ} \mathrm{C}$ of any component without damage to the system. Three temperature cycles were performed by the thermal vacuum chamber to reach extreme temperatures of $58^{\circ} \mathrm{C}$ and -38 . A 300 Watt heater was used to simulate component heat dissipation for the duration of the test.

Furthermore, this thesis lays out further possibilities for thermal testing using the HVEC Vacuum chamber and ATS chiller as a thermal vacuum chamber. 


\section{ACKNOWLEDGMENTS}

I would like to thank all members of my committee for working with me and answering questions as they came up and for reviewing my Thesis every at every step.

Another thanks goes to Dennis Weber at ATS for answering questions for the operation of the chiller, even though it is 16 years old. He was able to help with the hook ups, answer questions about each channel, and provide input on other quirks that came up along the way. Thanks to him I was able to save time and energy getting the ATS Chiller up and running again.

Thank you to SSL Company and Randy Pon for helping me learn thermal desktop modeling. Without a summer internship I would be much less effective in my modeling and analysis of thermal desktop. On that note, a huge thank you to Cindy Beer at C\&R Technologies for being extremely helpful by getting me a temporary license for thermal desktop.

I want to thank Cody Thompson for helping with all kinds of questions and also refitting the pipe to the plate. His encouragement is also greatly appreciated.

Thank you to my family for always offering support and thank you to my wonderful counterpart Will Meek for always being there when I needed him, even at 2am to check on a TVAC test.

Dr. Kira Abercromby, I certainly can't thank you enough. You've helped so much rom learning how to work the equipment in the lab to pointing to excellent resources for the project. I would not have any clue where to even begin if it weren't for you and without your encouragement I don't know if I would've known how to end this Thesis either. 
LIST OF TABLES. viii

LIST OF FIGURES ix

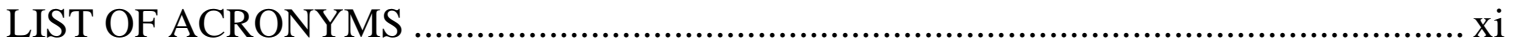

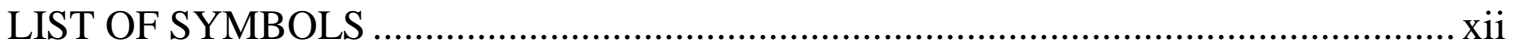

\section{CHAPTER}

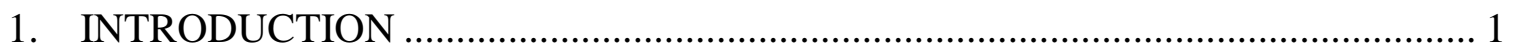

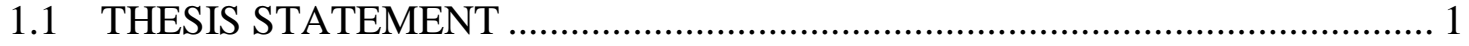

1.2 SPACECRAFT THERMAL ENVIRONMENT BACKGROUND ..................... 1

1.3 THERMAL TESTING .............................................................................. 2

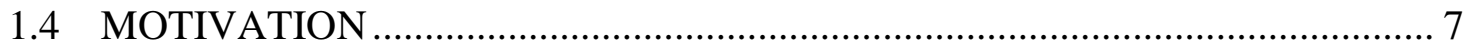

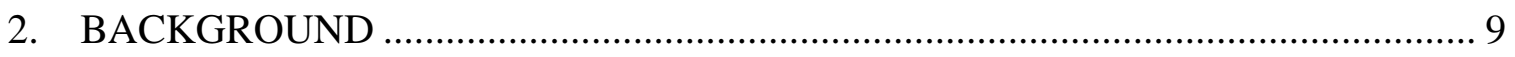

2.1 THERMAL HEAT TRANSFER .............................................................. 9

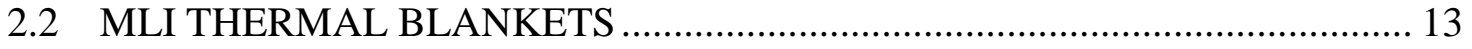

2.3 THERMAL DYNAMICS OF THE ATS CHILLER ........................................ 15

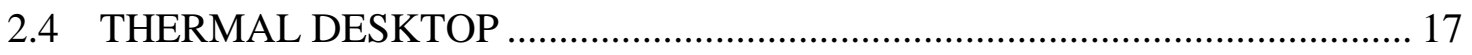

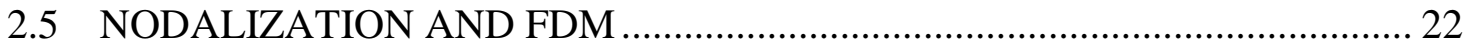

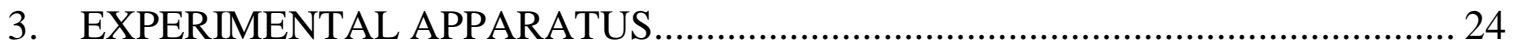

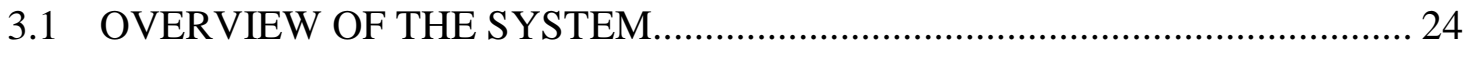

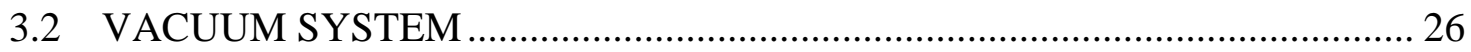

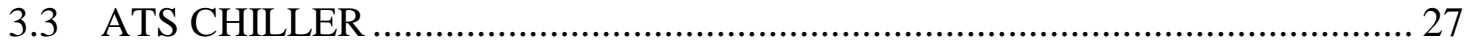

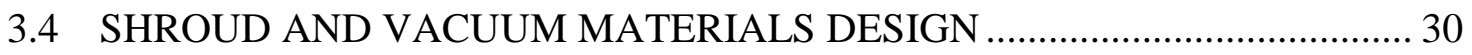

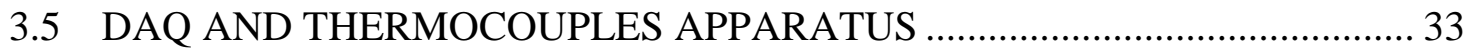

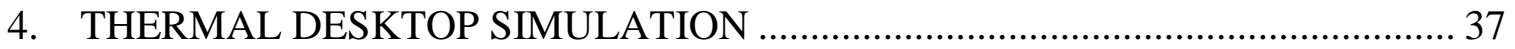

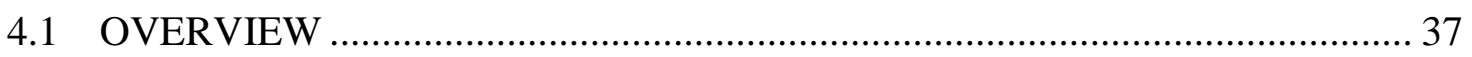

4.2 MATERIALS AND IMPLEMETATION INTO THE MODEL........................ 37

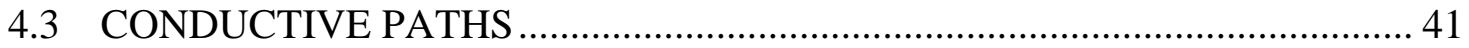

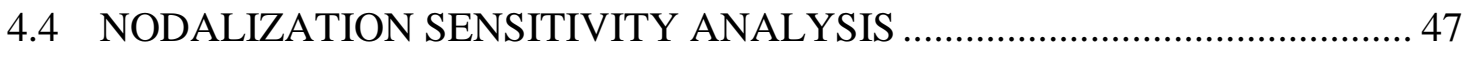

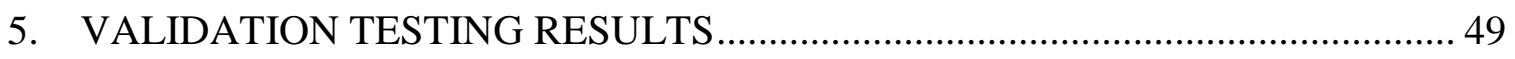

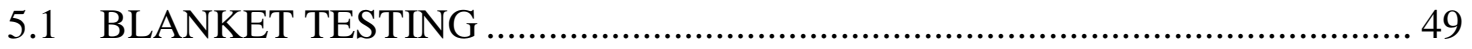


5.2 APPPARATUS TESTING AND DESIGN METHOD 51

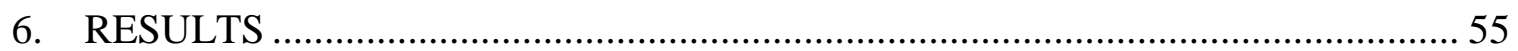

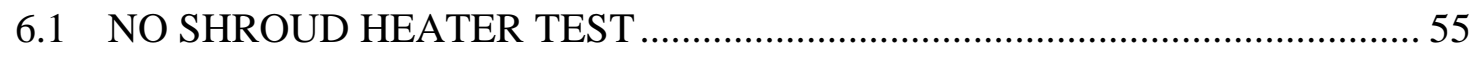

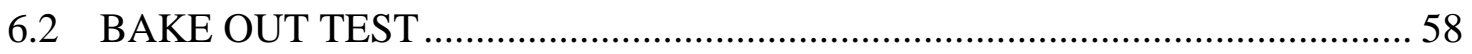

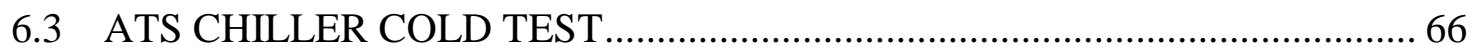

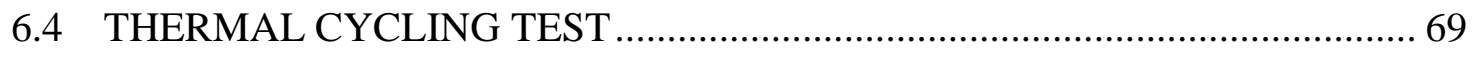

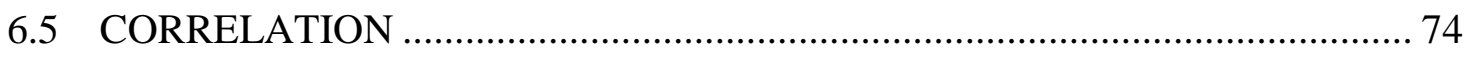

6.6 COMPONENT THERMAL DESKTOP MODELS …………………………..... 78

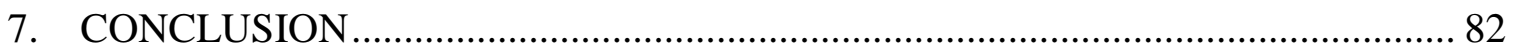

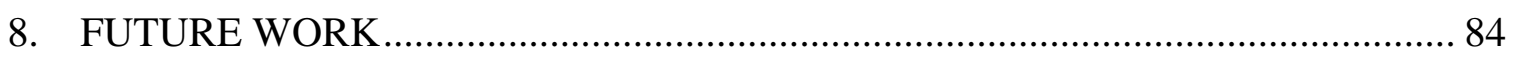

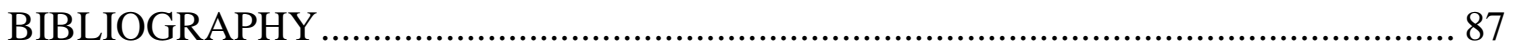

APPENDICES

A. LESSONS LEARNED AND RECOMMENDATIONS …….............................. 89

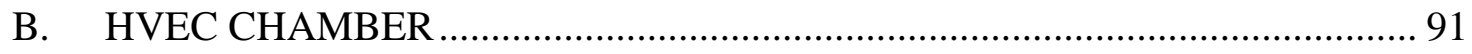

C. CRYOPUMP/COMPRESSOR PROCEDURE ……...................................... 95

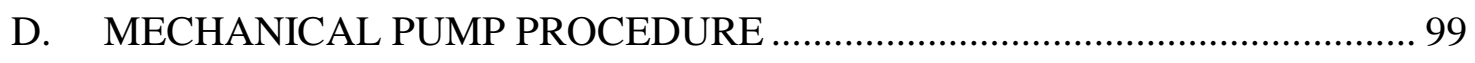

E. BLANKET CREATION PROCEDURE ……............................................. 103

F. DAP SOFTWARE PROCEDURE ………………................................... 105

G. PLATEN INSTALLATION WITH SHROUD ............................................... 108

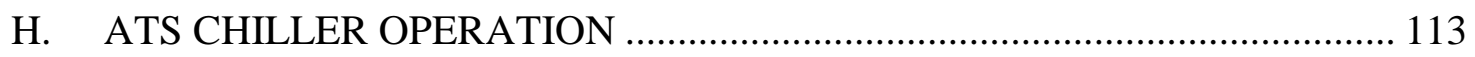

I. THERMAL DESKTOP/SINDA OVERVIEW ............................................... 127

J. MATLAB CODE: CONVERT OUTPUT TO TEMPERATURE...................... 132 


\section{LIST OF TABLES}

Table Page

Table 1. Development Test Example Legend .............................................................. 4

Table 2. Type of Nodes Used in SINDA and Descriptions of Each.[3] ......................... 20

Table 3. ATS Chiller Specifications ...................................................................... 28

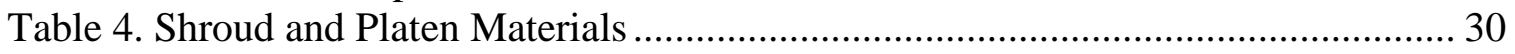

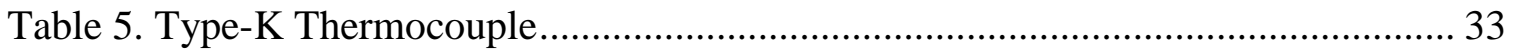

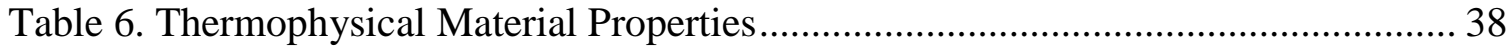

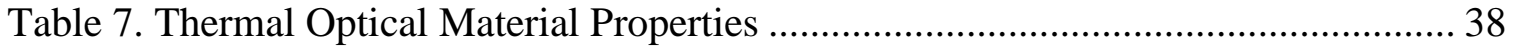

Table 8. Thermal Conductance Design Guideline from TRW Inc. [3] ............................ 42

Table 9. Contact Conductance and Interface Material for the Component. ..................... 43

Table 10. Braze Filler Material Conductance Calculation............................................ 45

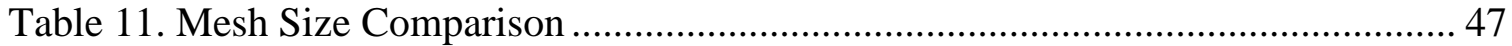

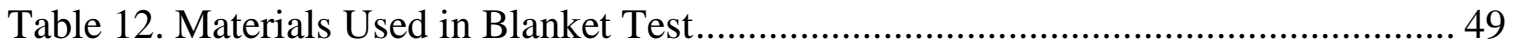

Table 13. Thermal Blanket Test Results ................................................................. 51

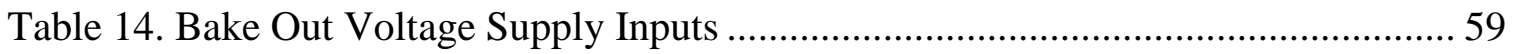

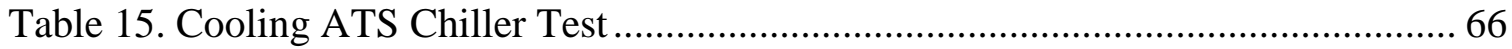

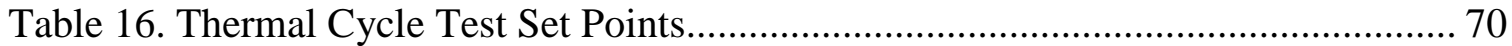

Table 17. Heater and Platen Test no Shroud Temperature Correlation .......................... 75

Table 18. Correlation Bake Out Shroud, All Temperatures in ${ }^{\circ} \mathrm{C}$ and with $\pm 2.2^{\circ} \mathrm{C} \ldots \ldots . . .76$

Table 19. Cold Test ATS Chiller Correlate Nodes When the Heater is Off..................... 77

Table 20. Hot Cycle Test ATS Chiller Correlate Nodes When Heater is On................... 77

Table 21. Cold Cycle Test ATS Chiller Correlate Nodes When Heater is On ................. 78

Table 22. Bake Out Component Thermal Model Temperatures in ${ }^{\circ} \mathrm{C}$............................ 79

Table 23. Hot Cycle Component Thermal Model Temperatures in ${ }^{\circ} \mathrm{C}$............................ 79

Table 24. Cold Cycle Component Thermal Model Temperatures in ${ }^{\circ} \mathrm{C}$.......................... 80 


\section{LIST OF FIGURES}

Figure $\quad$ Page

Figure 1. Development Test Example ..................................................................... 4

Figure 2. Thermal Uncertainty Margins on Prediction Temperatures[3] ........................... 6

Figure 3. Qualification and Flight Acceptance TVAC Temperatures[17] ........................ 6

Figure 4. Emittance and Absorptance as a Function of Wavelength[1] ......................... 12

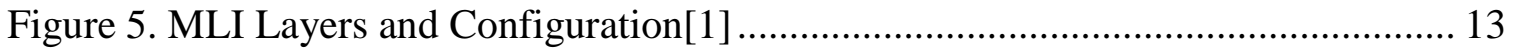

Figure 6. Multilayer Insulation Effect of Gas Pressure on Thermal Conductivity[3] ...... 14

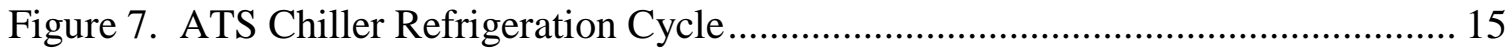

Figure 8. T-S Diagram of Ideal Vapor-Compression Cycle[6] ..................................... 16

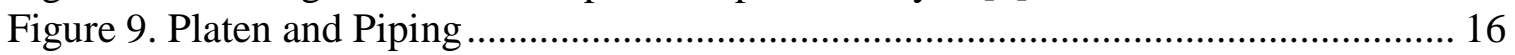

Figure 10. ATS Chiller Dual Refrigerant System..................................................... 17

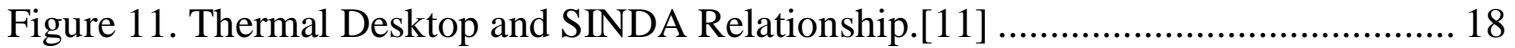

Figure 12. Nodes in Thermal Desktop ................................................................. 19

Figure 13. Conductors Automatic (left) and Manually Added (right) ........................... 20

Figure 14. Space Environment Nodal Network ........................................................ 22

Figure 15. Finite-Difference Two-Dimensional Mesh with Uniform Spacing [3] .......... 23

Figure 16. Thermal Cycling HVEC Vacuum Chamber and ATS Chiller ........................ 24

Figure 17. Shroud and Blanket ........................................................................... 24

Figure 18. Piping and Heat Strip Secured Under the Platen...................................... 25

Figure 19. ATS Chiller, Vacuum Chamber and DAQ Computer ................................. 25

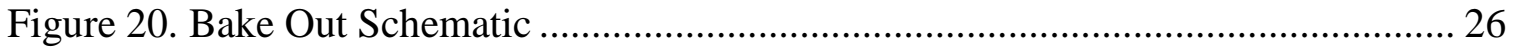

Figure 21. High Vacuum Equipment Corporation (HVEC) Bell Jar Chamber.[13] ........ 27

Figure 22. ATS Chiller Front and Back Views.......................................................... 28

Figure 23. Wrong Attachment Glued to Channel 1, Capped (right).............................. 29

Figure 24. Correct Attachment From ATS Attached to Channel 2. .............................. 29

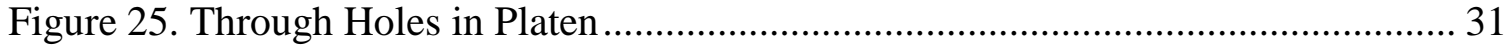

Figure 26. Thin Copper Shroud Design ..................................................................... 31

Figure 27. Copper Shroud Screw Joints: Two Screws (left) Three Screws (right) .......... 32

Figure 28. Copper Shroud Heater Cut Out ................................................................... 32

Figure 29. MLI Over the Shroud to Insulate the Copper.............................................. 32

Figure 30. Detailed Wiring on Adafruit AD8495 Breakout Amplifier. .......................... 34

Figure 31. Electric Schematic of Thermocouple and DAQ System. ............................... 35

Figure 32. Adafruit Amplifiers, TCs, BNC Cables, and Power Supply ......................... 35

Figure 33. TCs and Computer System by TVAC Chamber ............................................ 36

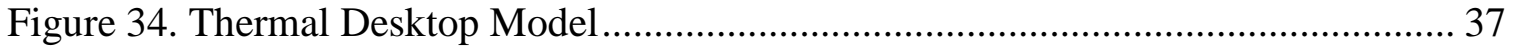

Figure 35. ATS Chiller Pipes: Real Dimension (left) and Modified (right) ................... 39

Figure 36. Shroud Thermal Model Compared to Real Model ....................................... 40

Figure 37. Component Thermal Model in the Shroud .................................................. 40

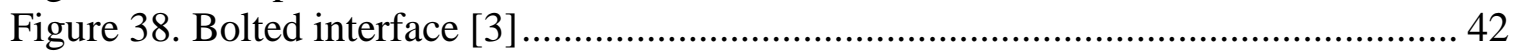

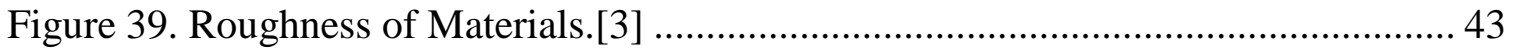

Figure 40. Uneven Brazing of the Pipes to the Platen ................................................. 44

Figure 41. Filler Material Between SS Piping and Platen ......................................... 45

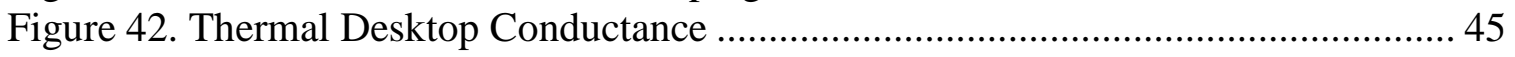

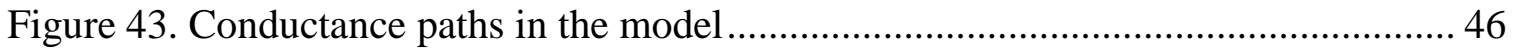

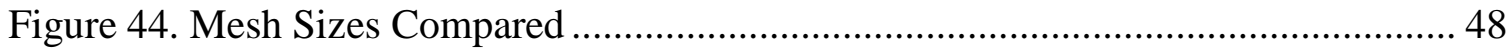




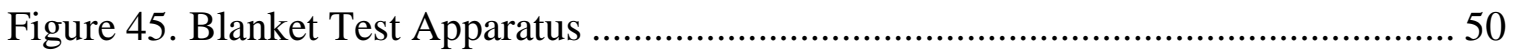

Figure 46. Thermal Blanket Verification Results …………………………………..... 50

Figure 47. Thermocouple Tape Down with Aluminum and Kapton Tape ........................ 53

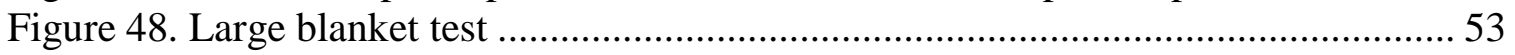

Figure 49. Large blanket test, burnt blanket ................................................................ 54

Figure 50. Heater Test Without a Shroud Thermocouple Locations ................................ 55

Figure 51. Heater Test Without a Shroud ................................................................... 56

Figure 52. Detail on the Warmer TCs of Heater Test without a Shroud .......................... 57

Figure 53. Thermal Desktop Model Heater with No Shroud............................................ 58

Figure 54. Bake Out Shroud Test Thermocouple Locations ............................................. 60

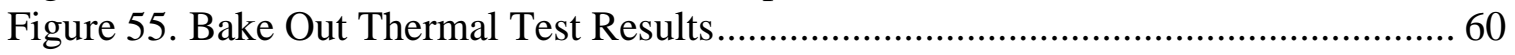

Figure 56. Bake Out TD Results, Shroud and Pipes...................................................... 61

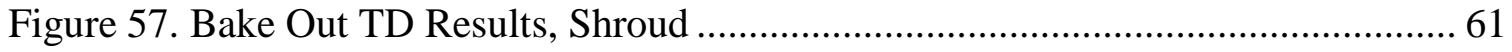

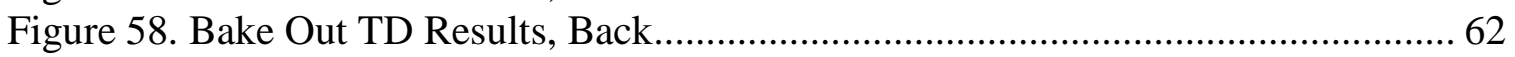

Figure 59. Back Blanket That Came Off During Bake Out Test..................................... 63

Figure 60. Bake Out Thermal Test Results of TC 13 on MLI Exterior............................. 64

Figure 61. Vacuum Chamber Pressure during Bake Out Test.......................................... 65

Figure 62. Detail of Steady-State Bake Out Results...................................................... 66

Figure 63. Cold ATS Chiller Test Thermocouple Locations.............................................. 68

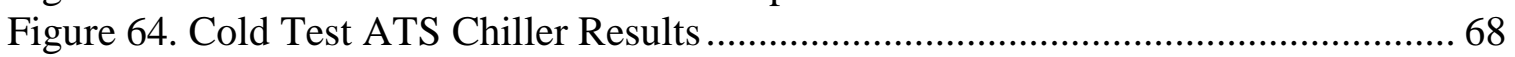

Figure 65. Detailed Cold Test Results, 300W Heater (left) and 0W (right) .................... 69

Figure 66. Cycle ATS Chiller Test Thermocouple Locations .......................................... 72

Figure 67. Thermal Cycle Test Temperature Results ..................................................... 72

Figure 68. Detail of Cycling Max Limit (left) and Minimum Limit (right) ..................... 72

Figure 69. Step Detail Lower From $60^{\circ} \mathrm{C}$ to $58^{\circ}$........................................................ 73

Figure 70. TD ATS Chiller Cold Test With Heater Power (left) and Without (right) ..... 73

Figure 71. TD ATS Chiller Hot Test With Heater Power (left) and Without (right) ....... 74

Figure 72. Piping Gradient from the Platen to the Chamber Wall.................................... 75

Figure 73. Bake Out Component Thermal Model (Kera-therm Pink 86/50).................... 79

Figure 74. Hot Cycle Component Thermal Model (Kera-therm Pink 86/50)................... 80

Figure 75. Cold Cycle Component Thermal Model (Kera-therm Pink 86/50)................. 80 


\section{LIST OF ACRONYMS}

$\begin{array}{ll}\text { ATS } & \text { Advanced Thermal Sciences } \\ \text { BNC } & \text { Coax Cable } \\ \text { DAP } & \text { Data Acquisition Processing } \\ \text { DAQ } & \text { Data Acquisition System } \\ \text { FDM } & \text { Finite Difference Method } \\ \text { GEVS } & \text { General Environment Verification Standard } \\ \text { HVEC } & \text { High Vacuum Equipment Corporation } \\ \text { IR } & \text { Infrared } \\ \text { MIL-STD } & \text { Military Standard } \\ \text { MLI } & \text { Multi-Layer Insulation } \\ \text { NASA } & \text { National Aeronautics and Space Administration } \\ \text { SS } & \text { Stainless Steel } \\ \text { TC } & \text { Thermocouple } \\ \text { TCS } & \text { Temperature Control System } \\ \text { TD } & \text { Thermal Desktop } \\ \text { PVAC } & \text { Thermal Vacuum } \\ & \text { Programmable Gain Amplifier } \\ & \end{array}$




\section{LIST OF SYMBOLS}
A Area $\left[\mathrm{m}^{\wedge} 2\right]$
C Capacitance or thermal mass $[\mathrm{J} / \mathrm{K}]$
$\mathrm{c}_{\mathrm{p}} \quad$ Specific heat capacity $[\mathrm{J} / \mathrm{kg}-\mathrm{K}]$
$\mathrm{e}^{*} \quad$ Effective emissivity [0 to 1$]$
F View Factor [0 to 1]
G Conductance $[\mathrm{W} / \mathrm{K}]$
h Convective heat transfer coefficient $\left[\mathrm{W} / \mathrm{m}^{2}-\mathrm{K}\right]$
$\mathrm{k} \quad$ Thermal conductivity $[\mathrm{W} / \mathrm{m}-\mathrm{K}]$
L Thickness for thermal conductivity equation [in]
$l_{\text {pipe }} \quad$ Length of the pipe that touches the platen [in]
$\mathrm{N} \quad$ Number of blanket layers
Q Power [W]
$\dot{Q} \quad$ Heat flux density $\left[\mathrm{W} / \mathrm{m}^{2}\right]$
$\dot{\mathrm{Q}}_{\mathrm{V}} \quad$ Volumetric heat generation $\left[\mathrm{W} / \mathrm{m}^{3}\right]$
$\mathrm{R} \quad$ Resistance [ohms]
$\mathrm{T} \quad$ Temperature $\left[{ }^{\circ} \mathrm{C}\right.$ or $\left.\mathrm{K}\right]$
$\mathrm{t} \quad$ Time [sec, min, hour]
$\alpha \quad$ Absorptance [0 to 1]
$\alpha_{\lambda} \quad$ Spectral absorptance at given wavelength [0 to 1]
$\varepsilon \quad$ Emissivity [0 to 1]
$\varepsilon_{\lambda} \quad$ Spectral emittance at given wavelength [0 to 1]
$\lambda \quad$ Wavelength of light
$\rho \quad$ Density $\left[\mathrm{kg} / \mathrm{m}^{3}\right]$
$\sigma \quad$ Stefan-Boltzmann constant $\left[\mathrm{W} / \mathrm{m}^{2} \mathrm{~K}^{4}\right]$ 


\section{INTRODUCTION}

\subsection{THESIS STATEMENT}

There are many aspects to the space environment that offer possibilities for failure of the spacecraft mission. Engineers must understand the space environment and do extensive testing on the ground in order to mitigate failure and ensure survivability. Thermal aerospace engineers use vacuum chambers to test equipment in a simulated space environment. Each component, subsystem, instrument, and full space vehicle system must be cycled through hot and cold temperatures expected in orbit.

There are two purposes for this thesis. The first purpose is to refurbish the Advanced Thermal Sciences (ATS) Chiller and integrate it into the High Vacuum Equipment Corporation (HVEC) Vacuum Chamber in the Space Environments Laboratory on the California Polytechnic State University Campus. The second purpose is to create a fully modeled test apparatus in Thermal Desktop with updated material properties that reflect the testing. The full thermal vacuum system will provide aerospace undergraduate or graduate students the ability to run material tests, thermal design tests, and thermal cycling tests to further their understanding of thermal engineering.

\subsection{SPACECRAFT THERMAL ENVIRONMENT BACKGROUND}

For this thesis both thermal control and the thermal spacecraft environment are taken into account. A low earth orbit (LEO) of $100 \mathrm{~km}$ altitude is considered a vacuum environment measuring $10^{-6}$ Torrs of pressure, six orders of magnitude below the pressure on Earth's surface.[2] Higher altitudes have even lower pressure.

The low pressure environment in space inhibits any convection, the primary mode of heat transfer on Earth, where the air is a working fluid. The other two modes of heat transfer are conduction and radiation. Therefore, the vacuum chamber simulates the thermal environment by limiting convective heat flow. 
In space, the thermal environment experienced by a spacecraft includes: [1]

1) direct solar radiation

2) albedo radiation

3) thermal energy radiated by nearby celestial bodies

4) deep space at 4 Kelvin

5) onboard heat sources

Energy will enter the spacecraft through any of these five methods. The onboard heat sources and solar radiation environment are the main driver when designing thermal control. Thermal control is a process of managing the input and output of energy.[3] The sun is eclipsed for parts of the orbit and thermal controls must be put in place to warm up the spacecraft so that it does not freeze, such as heaters or multi-layer insulation. When the spacecraft is not eclipsed the absorptance of the solar arrays and the large heat dissipations by the components must radiate back out into space or else the spacecraft will over heat causing failures to components that may not recover. The use of heat pipes, conductive materials, and radiators all help to emit heat into space.[3] Passive controllers include the external optical properties of the spacecraft. These will dictate both the solar absorptance and infrared emittance. Absorption is used to calculate how much heat is absorbed from solar radiation and albedo radiation. The emittance of the external material dictates how much heat the spacecraft radiates back into space.

Each orbit will have different space environments for the spacecraft and typically the worst cases for hot and cold must be analyzed. This depends on eclipse times, the distance from the sun, and the spacecraft orientation.[2] Testing is used to validate the components can reach and exceed expected on orbit temperatures.

\subsection{THERMAL TESTING}

Before designing the spacecraft thermal control system the temperature requirements of the components and the heating environment to which the spacecraft will be exposed must be 
known.[2] The system can then be analyzed in Thermal Desktop, SINDA, or another method to evaluate the maximum and minimum temperatures of the spacecraft or a component on the spacecraft. The raw prediction temperatures are used to determine the hot and cold environments to test the component in the thermal vacuum (TVAC) chamber. A vacuum chamber is able to pump out the air to simulate low earth pressure.

Testing is an extremely important part of engineering because it is a way to validate designs and correlate analytical models. In aerospace thermal engineering extensive measures are taken to mitigate risk by demonstrating the performance of units, subsystems, payloads, and vehicles. A unit is an item such as a thruster or electronic box that is tested before being assembled onto the spacecraft. A subsystem is an assembly of functionally related units, such as thermal control, or attitude control.[3] Finally, the space vehicle is an integrated set of subsystems and units that support an operational role in space. A Cubesat is a space vehicle that can be potentially tested in the refurbished TVAC system.

There are three types of thermal test categories: development tests, qualification tests, and acceptance tests. Development tests are conducted to validate a design concept, such as new bonding material between the spacecraft panel and the component, thermal heat straps, or other material testing. Whenever a new design involves a temperature gradient across a material, developmental tests are required to understand the material thermal properties. No military or commercial standard documents can be used for development tests because they are unique to the design.[3] Thermal testing of materials requires a temperature controlled platen in a vacuum chamber to provide a constant boundary temperature. A platen is a large plate composed of a highly conductive metal like copper. With the platen acting as a large heat sink, it should not vary in temperature which is extremely useful for development thermal testing. Such testing was not included in the thesis, but by verifying the platens capabilities it is possible for any engineering student to develop a test procedure for a development thermal test. 
An example scenario is shown in Figure 1 and Table 1. A known material with known thermal conductivity can be compared to a thermal material with an unknown thermal conductive path. The known material is used as a control for the test and the red material is also modeled in an analytical thermal model. Heat travels from the heater (black), through the material, and to the platen (orange) because the platen is a heat sink, so it is constantly being cooled. Thermocouples (green) are used at any critical points to verify the analytical model. To ensure the heat path is through the material, each material can be wrapped in a thermal blanket. According to Eq. 1 the thermal conductivity can be evaluated once the system is at equilibrium.

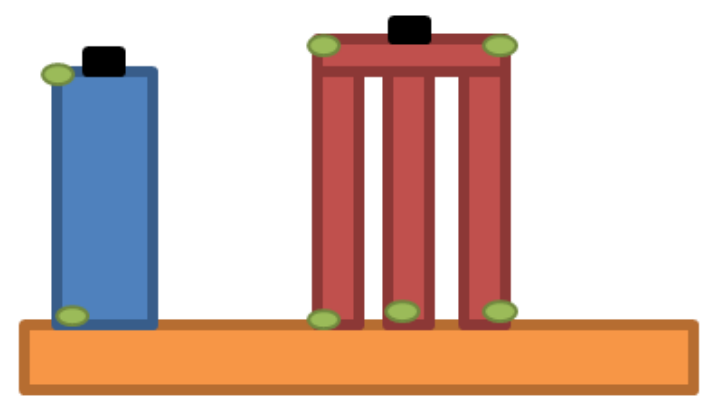

Figure 1. Development Test Example

Table 1. Development Test Example Legend

\begin{tabular}{cc}
\hline \hline Colors & Material \\
\hline Blue & Known Material \\
Black & Heater \\
Green & Thermocouples \\
Orange & Platen \\
Red & Unknown thermal path \\
\hline \hline
\end{tabular}

Qualification and acceptance testing are similar to each other in that the testing is specifically used for the spacecraft units and components. Formal tests must be done before spaceflight to reduce risk once in orbit. Qualification tests are more severe than acceptance tests because they push the hardware beyond maximum limits seen on orbit and increase maximum cycles. Therefore, qual-tested equipment cannot be flown. Acceptance testing demonstrates the capability of an item that will be flown, so the maximum and minimum temperatures are less 
severe than qualification tests.[3] The nature of these tests require strict documentation using MIL-STD 1540 guidelines or other guidelines.[4]

The General Environment Verification Standard (GEVS) document GSFC-STD-7000A is the NASA guideline used for flight programs and projects.[5] This thesis will ensure the test apparatus is compatible with NASA GEVS acceptance thermal cycle testing. One cycle includes a low and a high temperature at the times specified in the document depending on the assembly of the component. The unit or instrument must continue operation between extremes and at the extremes to check performance. Temperatures are continuously monitored to ensure the equipment does not exceed acceptance temperatures which would invalidate the component from spaceflight.

According to thermal cycling guidelines in section 2.6.2.4 of GSFC-STD-7000A the following testing times are used for temperature cycling tests.[5] At an instrument level the test procedure must have four TVAC cycles. Each steady state extreme must be 12 hours. The hardware must be operating for the duration of the test and show performance. For example, a camera must show it can perform by taking pictures. Component or unit testing requires a minimum of eight TVAC temperature cycles before installation onto the payload. Each extreme must be 4 hours for each cycle. The hardware must be operating to prove performance. The pressure must be less than $1 \times 10^{-5}$ Torr throughout testing.

The entire spacecraft with all temperature critical components must be modeled in the expected orbit in order to estimate the temperature extremes for each component. Uncertainty margins are added to the expected temperature on either end of the hot and cold raw temperature prediction extremes as shown in Figure 2. The margin can be as large as 17 to $40^{\circ} \mathrm{C}$ at the beginning of design, but as the design progresses the margin reduces to the minimum amount of $\pm 11^{\circ} \mathrm{C}$ according to MIL-STD- 1540 . 


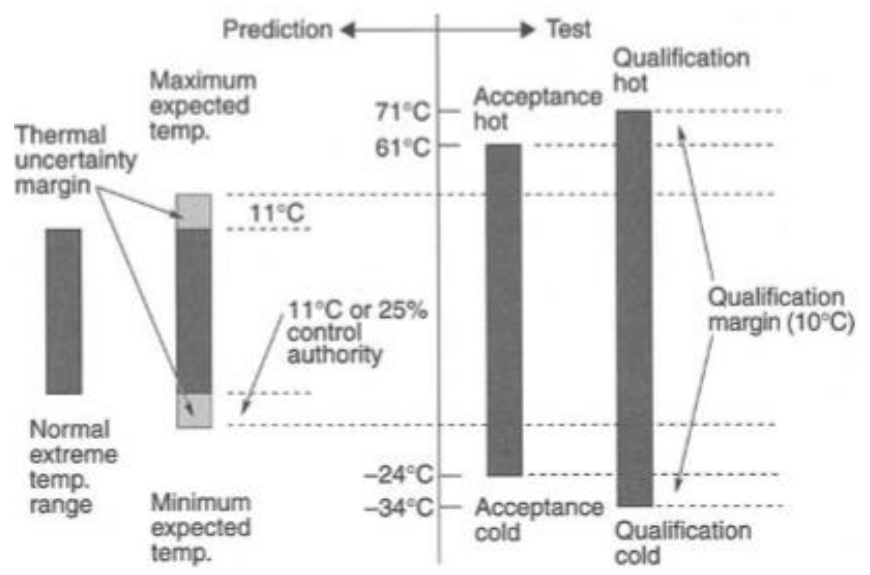

Figure 2. Thermal Uncertainty Margins on Prediction Temperatures[3]

Temperatures for testing the equipment come from the acceptance guidelines shown in Figure 3. An additional $\pm 5^{\circ} \mathrm{C}$ is added to the uncertainty margin to create even more margin to ensure the best risk mitigation. This means even if the thermal model is incorrect by $\pm 16^{\circ} \mathrm{C}$ there should be no problems on orbit because the component was tested to such extremes. Different guidelines can be used depending on the program, but the requirements described here are typical values that are unclassified.

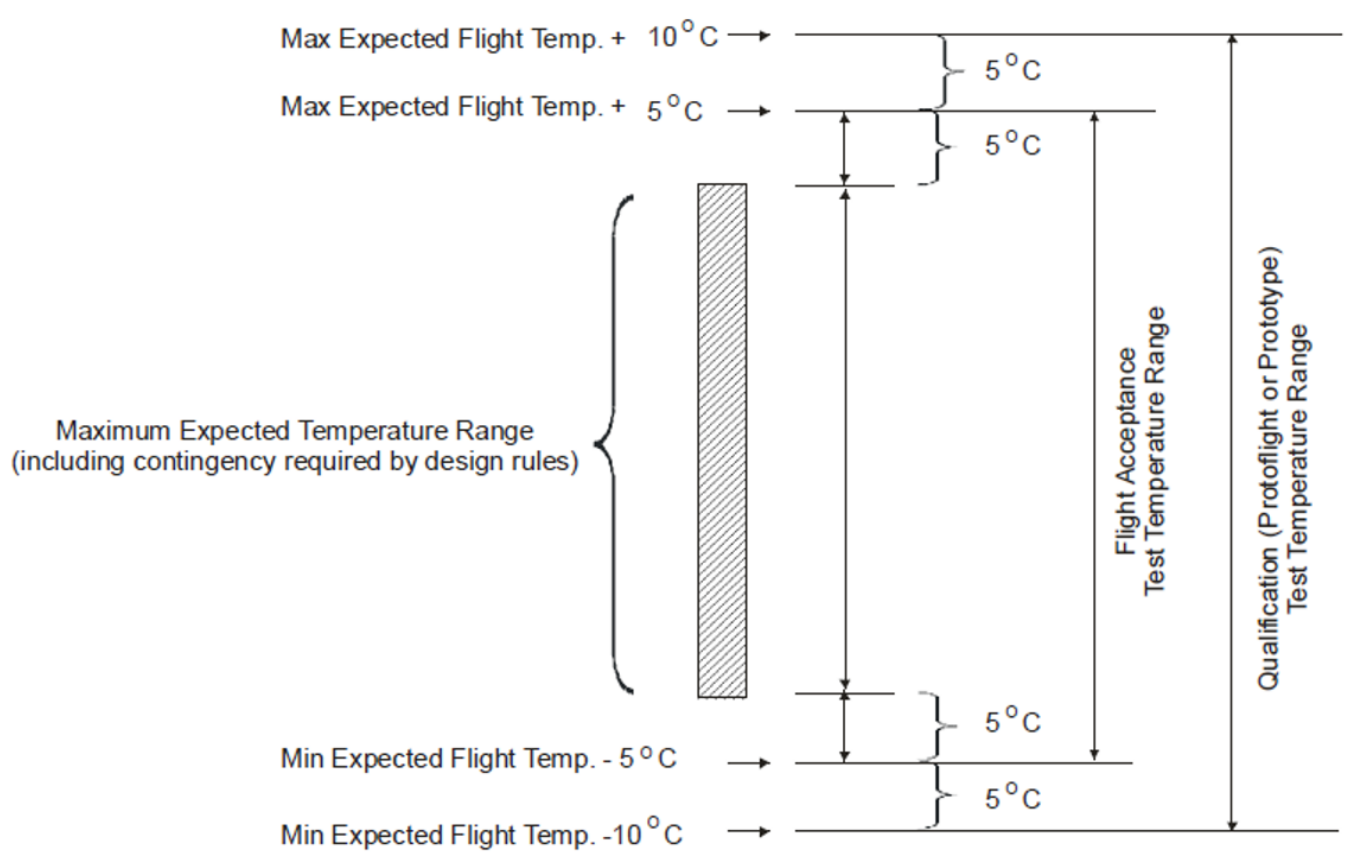

Figure 3. Qualification and Flight Acceptance TVAC Temperatures[17] 
Another thermal test specified in the GSFC-STD-7000A document is a thermal vacuum bake out test. This test uses thermal equipment to elevate the temperatures in the vacuum chamber, but does not test the thermal control system or the hardware to acceptance temperatures. A full bake out helps to prevent contamination of sensitive instruments after launch. Materials in a vacuum environment outgass, meaning gasses from the material release into the space environment and can accumulate on sensitive instruments.[1] Contamination can also come from particles in the manufacturing room settling on the equipment. Clean rooms are used to control the environment and lower the particulate contamination to levels appropriate for the mission. A bake out test is another safeguard to contamination and is especially useful on campuses where there is no clean room for student projects.

Most effective bake out tests are performed at the parts level before assembly because allowable temperatures are often higher than after assembly. Warming the equipment under vacuum increases the outgassing rate, so hardware should be heated at the highest temperature possible without going over allowable limits. The duration depends on the material. A bake out test only requires heating and does not require any power to the equipment.

\subsection{MOTIVATION}

Cal Poly Campus has one thermal vacuum chamber that is operational for Cubesats. It uses liquid nitrogen, a copper shroud, and heaters in order to cycle the Cubesat through expected orbital temperatures. This is useful for the Cubesat team, but a more accessible thermal vacuum chamber for other aerospace students will provide hands thermal design testing and hands on TVAC operation. The HVEC and ATS Chiller system is reliable, understandable, and safe for undergraduate and graduate work. The ATS Chiller is hard to break and the HVEC has been in the hands of students for many years, so there is less risk for student experimentation. Such experimentation for thermal testing is not possible in the Cubesat TVAC chamber because of the risks involved and it is primarily used for Cubesat. 
This second vacuum chamber can be used for bake outs, thermal component testing, or any project involving thermal heat transfer in a vacuum. The platen system is versatile and the use of Galden ${ }^{\circledR}$ fluid instead of Liquid Nitrogen is more manageable for students. This thesis will also cover the Thermal Desktop design and basics of the program that are used by thermal engineers. The merging of hardware testing and computer model analysis is important for a broad understanding of thermal aerospace engineering. 


\section{BACKGROUND}

\subsection{THERMAL HEAT TRANSFER}

Thermodynamics and heat transfer are used in engineering sciences to analyze and design equipment intended to meet human needs. For this thesis, an in depth analysis of heat transfer will be used. Heat transfer is a the transfer of energy in a closed system that cannot be categorized as work. [6] Only two modes of heat transfer, radiation and conduction, are analyzed for the thermal model.

Conduction is the transfer of more energetic particles to adjacent less energetic particles. The change in energy is in the form of a temperature gradient. The equation, from Fourier's Law, is as follows, where $Q_{x}$ is the heat energy transferred per second in the x direction, $k$ is the

thermal conductivity, $A$ is the area of the cross seciton, and $\frac{d T}{d x}$ is the temperature change in the $\mathrm{x}$ direction. [1] This is for steady-state, one dimensional calculations.

$$
Q_{x}=-k A \frac{d T}{d x}
$$

Conduction is necessary to transfer heat from the interior of the spacecraft to the external panels which then radiate to space. The thermal conductivity, $k$, is an important parameter for spacecraft thermal engineering because it is a property of the material. This is why a material like copper is used for thermal control, because the thermal conductivity is extremely high. Conversely, ceramics can be used to insulate components because the material has a very low thermal conductivity. Insulation slows heat transfer across adjacent materials.

Although useful for back of the envelope analysis, Eq. 1 is not enough to perform multidimensional or transient analysis. Transient analysis solves the heat equation over a set amount of time. From the conservation of energy for a small element the heat equation for conduction becomes Eq. 2, where $\rho$ is the density of the material, $c_{p}$ is the specific heat capacity, $t$ is time, and $\dot{Q}_{v}$ is the volumetric heat generation as opposed to $\dot{Q}$ which is just heat flux density. The 
material is assumed to be uniform so the material properties, specific heat, density and thermal conductivity, are constant as a function of space..

$$
\frac{\partial T}{\partial t}=-k\left(\frac{\partial^{2} T}{\partial x^{2}}+\frac{\partial^{2} T}{\partial y^{2}}+\frac{\partial^{2} T}{\partial z^{2}}\right)+\frac{\dot{Q}_{v}(x, y, z, t)}{\rho c_{p}}
$$

It is important to know the density and specific heat of the material when conducting transient analysis, but comparing to Eq. 1, these properties are not used in steady state analysis. The specific heat is the amount of heat energy that it takes to raise one unit of mass of the material by one unit of temperature.[3] The higher the specific heat the more energy a material can absorb without affecting the temperature. Galden ${ }^{\circledR}$ Fluid has a high heat capacitance in order to effectively absorb heat from the chamber, discussed more in section 2.3 . Equation 2 can be discretized to solve the heat equation numerically as shown in section 2.5.

Convection is the transfer of heat between a surface and a moving fluid. This mode of heat transfer is used extensively on Earth to cool hot systems because the atmosphere acts as the moving fluid. The few molecules in space make convection a negligible mode of heat transfer, so convection is not modeled or analyzed in the TVAC chamber. Convection by means of heat pipes are used to transfer heat within the spacecraft, just not to emit heat into space. Convection is more effective than conduction, so replacing some of the panel material with a heat pipe greatly increases the ability to transfer heat evenly across the panel which can then radiate to space.[3] For the thermal vacuum chamber convection is used to heat and cool the platen as described in section 3. Galden ${ }^{\circledR}$ Fluid in the pipes contacts the surface of the pipe and conducts to the paten to transfer heat effectively as shown in Eq. 3, where $\dot{Q}_{x}$ is the heat flux density, and $h$ is the convective heat transfer coefficient of the fluid in $\mathrm{W} / \mathrm{m}^{2} \mathrm{~K}$.

$$
\dot{Q}_{x}=h\left(T_{\text {fluid }}-T_{\text {surface }}\right)
$$


Due to the high heat transfer coefficient of the working fluid shown in Table 3, it is assumed that the pipe is a constant temperature with an infinite heat sink, so it is modeled as a boundary node in the thermal model, explained further in section 4 . This eliminates the need for convective computation in Thermal Desktop which is not as essential for aerospace engineering and also requires more licensing to use.

Thermal radiation is the smallest mode of heat transfer on Earth. In the vacuum of space radiation is the only way to transfer heat from the sun, the Earth, and the spacecraft by way of a photon. How much heat is radiated into space depends on temperature and surface properties of the body. Radiation is emitted by matter as a result of changes in the electronic of the atoms or molecules within it. Photons carry the energy from a hot surface to a colder surface.[3]

The equation for thermal radiation is from the Stefan-Boltzmann Law and quantifies the rate at which energy is emitted, $Q$, from a surface of area $A .[6]$ Note that the temperature is absolute, in Kelvin or Rankin. Another complication of radiation is that the heat transfer rate depends on the temperature to the fourth power.

$$
\mathrm{Q}=\varepsilon \sigma A T_{a b s}^{4}
$$

The emissivity, $\varepsilon$, is an optical property of the material that affects radiation, just like the conductivity is a material property that affects conduction. Emissivity can only be from 0.0 to 1.0 , indicating how effectively the surface radiates or absorbs IR radiation. The Stefan-Boltzmann constant, $\sigma$, is a constant value used to find radiation.

Kirchhoff's law states the spectral emittance, $\varepsilon_{\lambda}$ and absorptance, $\alpha_{\lambda}$ at any given wavelength are equal.[1] Figure 4 shows an example of optical properties over wavelength. The solar band wavelength is between $0.3 \mu \mathrm{m}$ and about $3 \mu \mathrm{m}$, encompassing visible light that comes from the sun or reflects off of other planets. The infrared band is invisible to humans and extends from $3 \mu \mathrm{m}$ to $8 \mu \mathrm{m}$. This radiation energy comes from Earth, other planets, and the spacecraft itself. In thermal engineering it is important to distinguish between the different wavelengths. To 
differentiate the $\alpha$ and $\varepsilon$ terms it is common practice to call the absorptance and emittance over the solar band the absorptance, $\alpha$, and over the infrared (IR) band the emittance, $\varepsilon$. Such terminology will be used throughout this report, with much more emphasis on IR emittance.

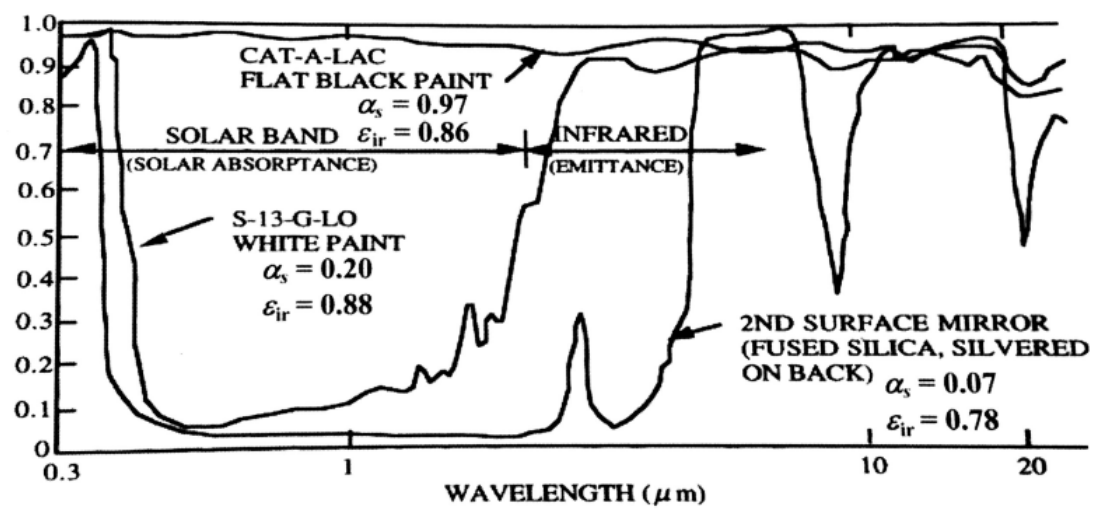

Figure 4. Emittance and Absorptance as a Function of Wavelength[1]

Equation 4 can be modified to include the net heat transfer from a hot surface to a relatively colder surface. Heat transfers from a surface, $i$, to another surface, $j$. Following the first law of thermodynamics: energy in, $Q_{j}$, must equal energy out, $Q_{i}$. The following is a special case is for a small emittance area to a large surrounding surface, such as a component inside of a vacuum chamber.

$$
\begin{gathered}
Q_{i}=\varepsilon \sigma A_{i} T_{i}^{4}=Q_{j}=\varepsilon \sigma A_{j} T_{j}^{4} \\
Q_{i}-Q_{j}=\varepsilon \sigma A_{i} T_{i}^{4}-\varepsilon \sigma A_{j} T_{j}^{4}
\end{gathered}
$$

Assume all of the heat that leaves surface $i$ is incident on surface $j$. Due to the significantly larger size of what is being emitted to, the emissivity of surface $j$ is assumed to be the same as surface $i$.

$$
Q_{i}-Q_{j}=Q_{n e t}=\varepsilon \sigma A_{i}\left(T_{i}^{4}-T_{j}^{4}\right)
$$

More detailed thermal heat transfer analysis is required when there are similar sized objects in a vacuum environment. The properties of each surface and the orientations with respect to each other must be taken into account.[5] The orientations between radiating surfaces are called view factors, $F$, and are dependent on the distance and angle between surfaces. The geometries for hand calculations are explained further in The Space Environment and its Effects on Space Systems.[1] 


\subsection{THERMAL BLANKETS}

Thermal blankets, also known as multilayer insulation (MLI) are used in the apparatus to insulate the testing platen from the ambient temperature of the chamber. This will limit the radiation effect of the chamber walls on the component being tested and create a more uniform internal environment. This is the same use in space for these blankets. During eclipse the spacecraft is insulated to limit the loss of heat. [2]

MLI is composed of multiple layers of low-emittance films. Each layer is insulated from the next layer with a thin layer of Dacron netting to inhibit the thermal conductive path. The schematic is shown in Figure 5. MLI is an essential part of thermal aerospace engineering because it is among the most common thermal-control elements due to the completely passive control, light weight, and verification in space.[3] MLI uses a vacuum to its advantage because it is only effective in low pressure environments, below $10^{-5}$ Torr, where radiation is the primary mode of heat transfer. Without gas to use convection and conduction between each layer, there is little to no conductance between the layers. As seen in Figure 6, thermal conductivity through the MLI decreases as pressure decreases.

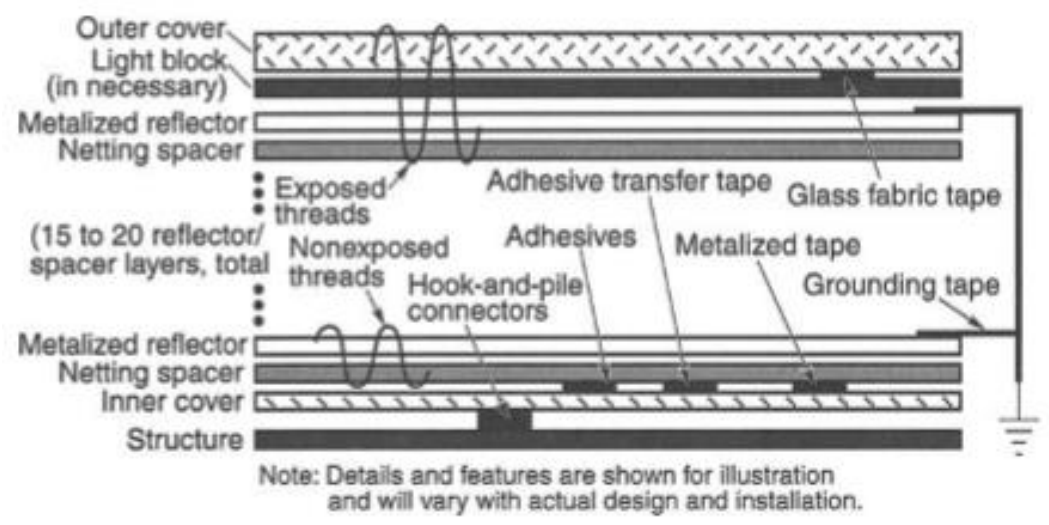

Figure 5. MLI Layers and Configuration[1]

Each layer has an emittance on each side of the sheet that varies depending on the surface material, but modeling the individual layers is not efficient or effective. Much more useful for 
analysis is the total emittance or equivalent emittance, $e^{*}$, of the blanket theoretically found from Eq. 8. This equation assumes the layers have the same emittance properties on each side. [3]

$$
e^{*}=\frac{1}{\frac{1}{\varepsilon_{1}}+\frac{1}{\varepsilon_{2}}-1}\left(\frac{1}{N+1}\right)
$$

In equation $8 N$ is the number of layers, and $\varepsilon 1$ and 2 is the emittance of each side of the layers. Experimental blanket tests with a minimum gas pressure of $10^{-5}$ Torr calculate emittance shown in Eq. 7. This equation is the rearranged radiative heat transfer equation from Eq. 4. Individual layer properties are not necessary inputs to find the equivalent emittance for a test blanket. As stated earlier, temperature must be in absolute units of Kelvin for radiation equations. Net heat transfer through the blanket is described by $Q$, area, $A$ is the total area of the blanket, and $\sigma$ is the Stephan-Boltzmann constant.

$$
e^{*}=\frac{Q}{A \sigma\left(T_{H}^{4}-T_{C}^{4}\right)}
$$

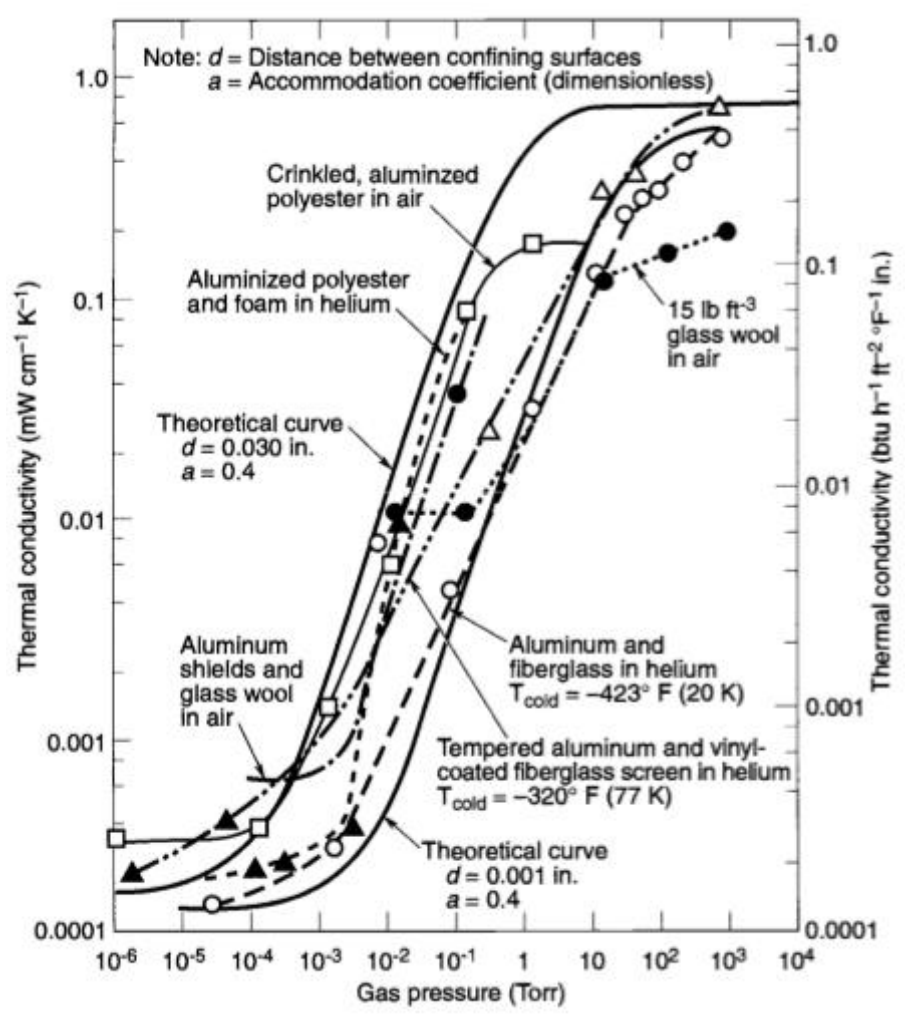

Figure 6. Multilayer Insulation Effect of Gas Pressure on Thermal Conductivity[3] 
Depending on the external material of the blanket it can either absorb solar light or reflect it away. The property to determine the absorption of sunlight in the optical wavelength is absorptance, $\alpha$. For this thesis only the emittance is needed because there is no light from the solar band inside the chamber. The external property is not a driver for the MLI, but the inner blanket is a driver. This blanket is black because a black surface has a very high emittance and will help to re-emit radiation back to the interior component.

\subsection{THERMAL DYNAMICS OF THE ATS CHILLER}

The ATS chiller has a temperature control system (TCS) that uses a refrigeration cycle and a heater to keep the working fluid at the controlled temperature. A schematic of the system is shown in Figure 7. Galden ${ }^{\circledR}$ HT-110 fluid is used as a heat transfer fluid to control the temperature of the SEMI TOOL, which is the platen. Galden ${ }^{\circledR}$ fluid is a line of highperformance, perfluorinated, inert polyether fluids used for temperature management in various high-tech applications.[7] The fluid is kept at a nominal pressure of $100 \mathrm{psi}$ and flow is nominally 5 gallons per minute.[8]

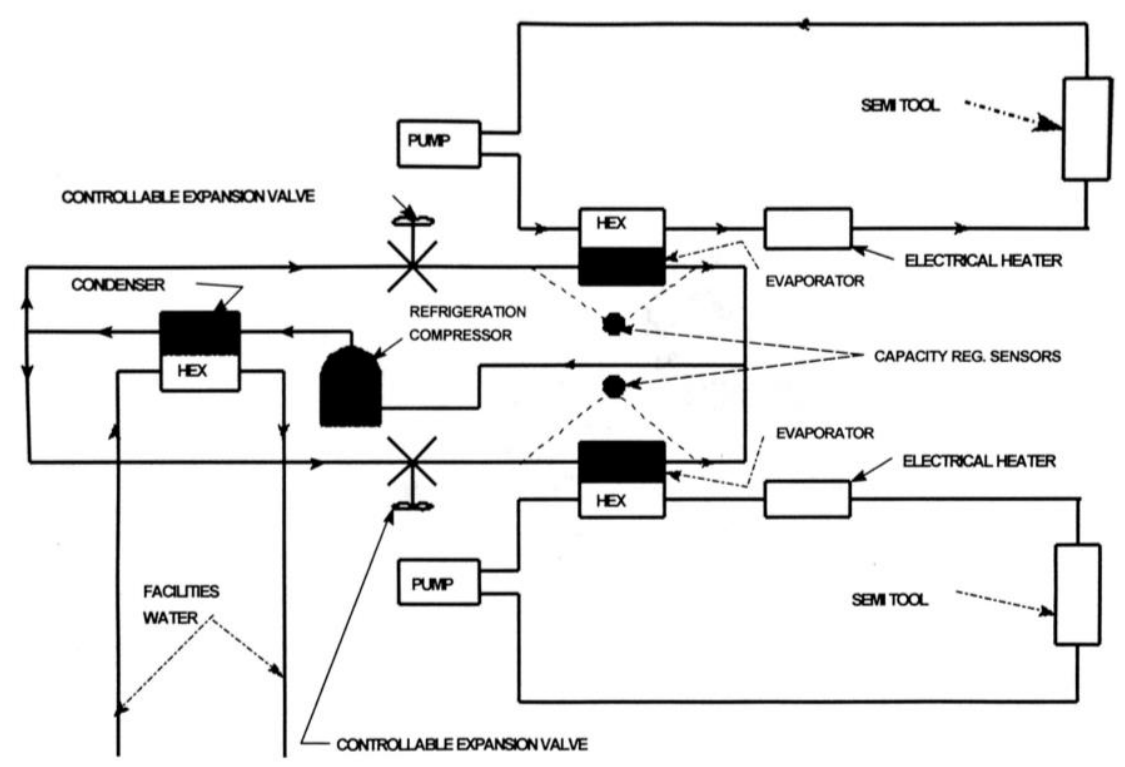

Figure 7. ATS Chiller Refrigeration Cycle 
The refrigerant cycle is shown in Figure 8 and can be controlled from $-38^{\circ} \mathrm{C}$ to $+58^{\circ} \mathrm{C}$. The vapor pressure table is shown to the right of Figure 8 where 1-2 is the compressor, 2-3 is the condenser, 3-4 is the expansion valve, and 4-1 is the evaporator.[6]

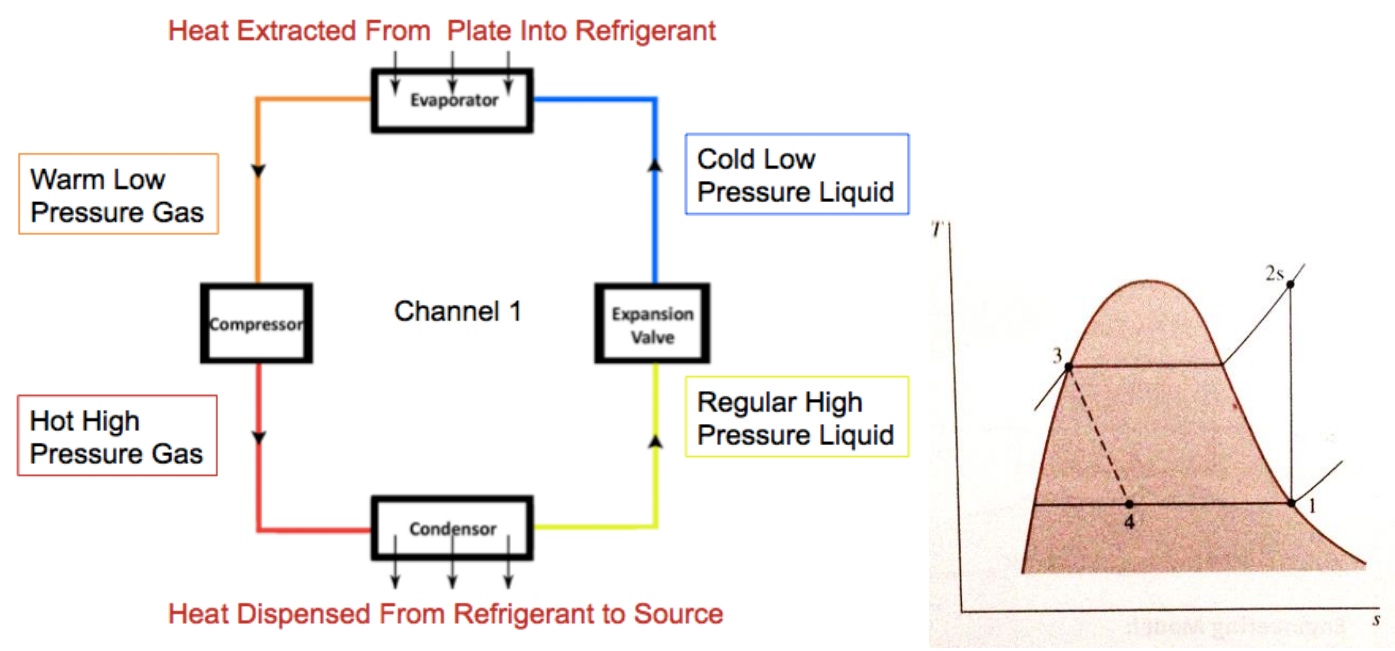

Figure 8. T-S Diagram of Ideal Vapor-Compression Cycle[6]

The system must have water that runs through the chiller to dispense heat from the refrigerant at the condenser. A typical expansion valve makes the high pressure refrigerant liquid (internal to the chiller) a low pressure liquid. The evaporator that extracts heat into the fluid is from the Galden® Fluid loop. It is important to note the refrigerant is not the Galden® Fluid; Galden® is used as a heat transfer liquid and is only present in the refrigeration cycle at the evaporator where it dumps heat into the cycle. A pump continually loops Galden® Fluid across the platen along the area shown in Figure 9. Galden ${ }^{\circledR}$ is an excellent heat transfer fluid because of the specific heat capacity is $962 \mathrm{~J} / \mathrm{kg}-\mathrm{K}$.

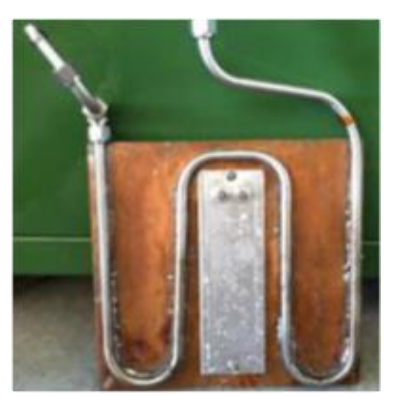

Figure 9. Platen and Piping 
The ATS Chiller is unique in that there are actually two refrigerant cycles, which means there two condensers, two expansion valves, and two evaporators. Another evaporator can be used to extract even more heat from another platen independent of the first channel. This system can be seen in Figure 10 below. At this time the first channel leaks too much to be used, but it is possible to refurbish further for another project.

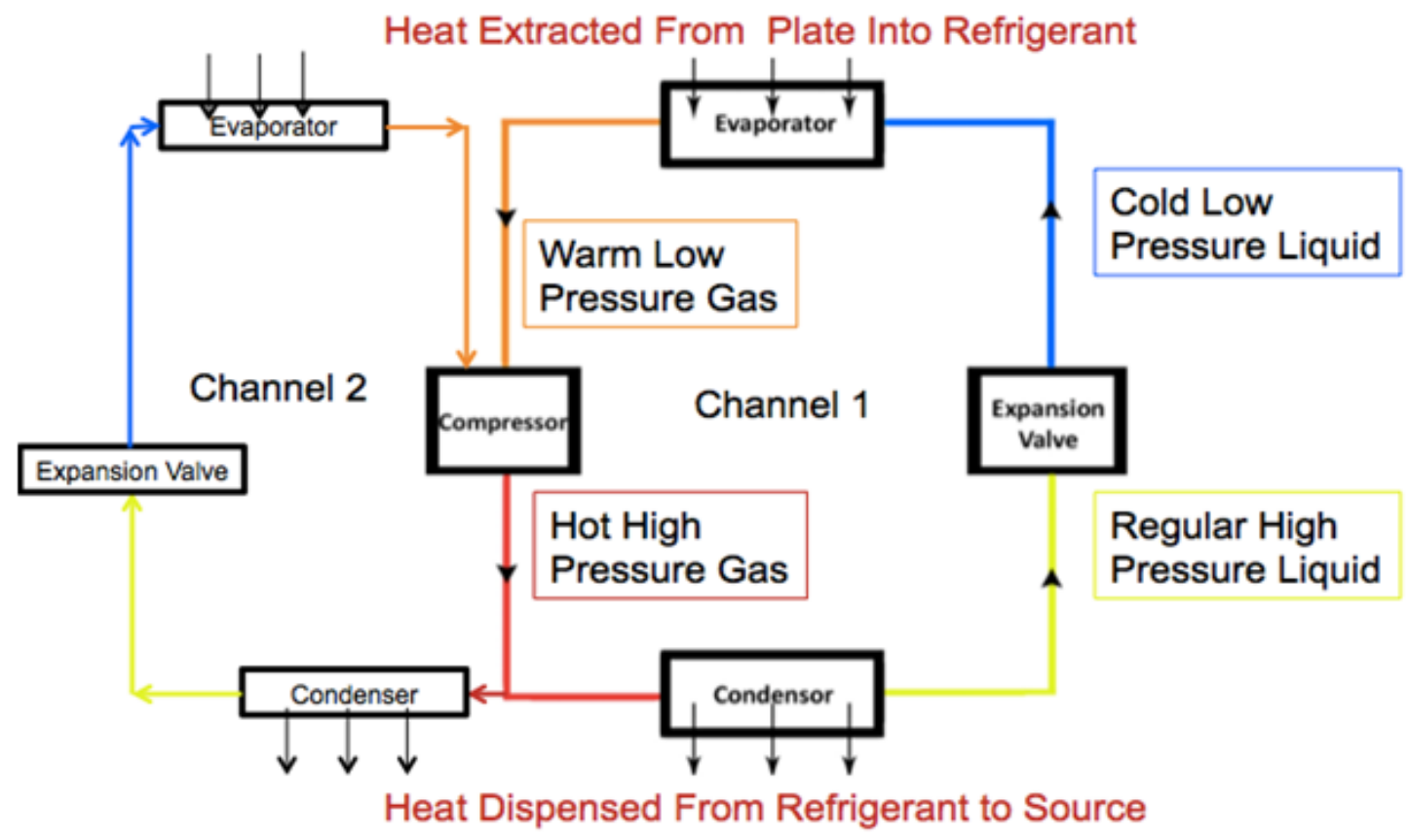

Figure 10. ATS Chiller Dual Refrigerant System

\subsection{THERMAL DESKTOP}

A significant portion of this thesis is dedicated to the thermal modeling design. Thermal engineers rely heavily on Thermal Desktop for its excellent radiation properties and orbit creation. The basic approach to thermal control begins with requirements, then an iterative process of analysis, design, and re-analysis to meet those requirements. The end result is a physical test of the design after manufacturing to verify acceptable performance.[2] Analysis is done through 3D modeling because there are many iterations of the design and manufacturing hardware for each iteration is not feasible. Once the design is chosen and tested in TVAC the 
model can be correlated to match the hardware. This makes it possible to run more analysis after launch. Therefore, learning how to use $3 \mathrm{D}$ modeling for analysis is essential for thermal aerospace engineering.

Thermal Desktop (TD) is an overlay of Autocad. It is a graphical user interface for the SINDA solver. TD then computes the dimensions, material properties, and distances between surfaces to create SINDA code. SINDA is the core batch-style solver of thermal/fluid design or simulation problems posed as networks, where "networks" can represent finite element models(FEM), finite difference models(FDM), or both.[10] TD is able to run radiation models faster than other programs because of the finite difference method, explained in section 2.5. Other programs rely on finite element models which take longer to iterate to a conclusion, especially with thermal radiation because of the fourth power used in the equation, Eq. 4. The SINDA/FLUINT and Thermal desktop relationship is shown in Figure 11.

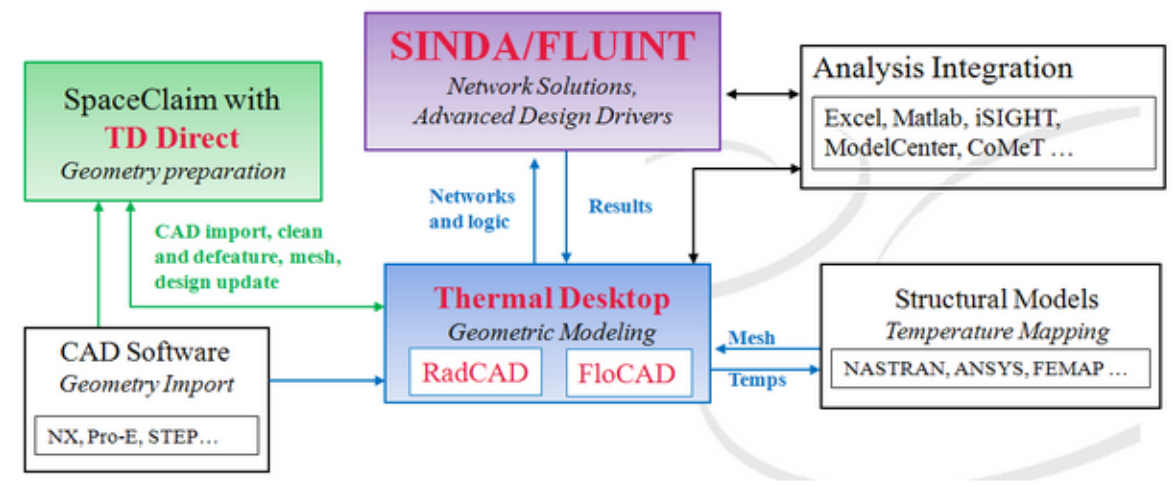

Figure 11. Thermal Desktop and SINDA Relationship.[11]

It is possible to use SINDA directly if thermal desktop is not available. SINDA code is written as a text input file and based on Fortran coding. SINDA has a preprocessor that reads the input file and constructs a FORTRAN executable which is explained in the SINDA Manual.[12] For this thesis only the very basic functions of thermal desktop are used or are even necessary. See Appendix I for a step-by-step approach to Thermal Desktop and the basics of SINDA coding.

This computer program requires the user to define a system thermal network similar to an electrical circuit because the mathematical equations describing the behavior of the systems are 
similar.[3] The network is composed of finite subvolumes called nodes. The discretization of the heat equation allows the model to solve finite difference equations numerically. Each node represents two elements, the temperature and the thermal mass, also called the capacitance. Capacitance, $C$, is a function of the subvolume and material properties, density and specific heat. The material properties do not change over time for a specific node with homogeneous material.

$$
C=-c_{p} * \rho * V
$$

The full network of nodes evaluates the average mass temperature of the volume assigned to a node.[3] As shown in Figure 12, the node is a section of the material. Simple geometric error introduced by nodalization of the material is discussed in section 2.5.
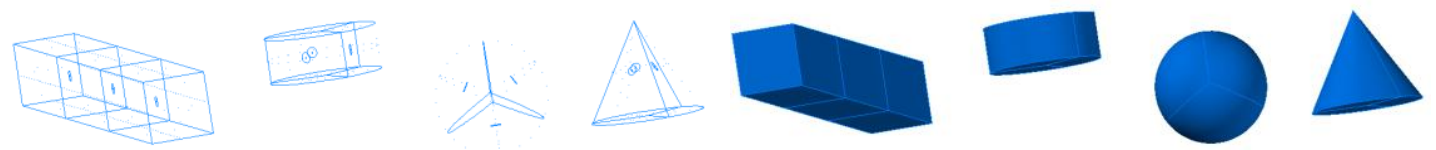

Figure 12. Nodes in Thermal Desktop

SINDA allows the user to use three different types of nodes shown in Table 2. A diffusion node represents a normal material that has mass. The boundary and arithmetic nodes are not physically possible, but both are used to improve the model performance. Arithmetic nodes are useful for MLI because the layers have almost no thermal mass when compared to the rest of the system. By converting the relatively small capacitance diffusion nodes to arithmetic nodes the computer run-time is reduced because the equation becomes less stiff.[3] Boundary nodes are necessary for any thermal model whether it is the sun, space, a high capacitance component, or a spacecraft panel. Without a boundary the solver can't establish an equation and Thermal Desktop will be unable to solve the equations. 
Table 2. Type of Nodes Used in SINDA and Descriptions of Each.[3]

\begin{tabular}{cccc}
\hline \hline Node Type & Capacitance & \multicolumn{1}{c}{ Description } & $\begin{array}{c}\text { Mathematical } \\
\text { Expression }\end{array}$ \\
\hline Diffusion Node & Finite thermal mass & $\begin{array}{l}\text { Normal material that changes } \\
\text { temperature as a result of heat } \\
\text { flow into or out of the node }\end{array}$ & $\sum \dot{Q}-\frac{C \Delta T}{t}=0$ \\
Arithmetic Node & Zero thermal mass & $\begin{array}{l}\text { Physically unreal, respond } \\
\text { instantly to its surroundings }\end{array}$ & $\sum \dot{Q}=0$ \\
Boundary Node & $\begin{array}{c}\text { Infinite thermal } \\
\text { mass }\end{array}$ & $\begin{array}{l}\text { Represents a boundary or sink } \\
\text { with a fixed temperature }\end{array}$ & $T=$ constant \\
\hline \hline
\end{tabular}

Conductors are used to create a thermal path between nodes. These are automatically created for the nodes in a finite difference element from the default geometries, but in order to make a thermal path between the different mediums that are in physical contact a conductor must be manually created. Figure 13 shows the conductor, $G$, between each node for one medium and between two separate mediums.[3]
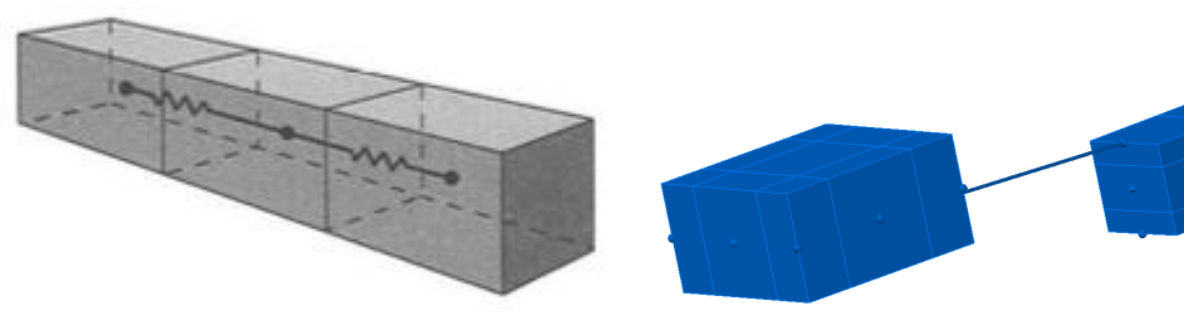

Figure 13. Conductors Automatic (left) and Manually Added (right)

Two types of conductors are used. The first is a linear conductor that represents conduction or convection, where the conductance is a function of thermal conductivity, area, and length between each node.

$$
\begin{gathered}
Q=G_{i j}\left(T_{i}-T_{j}\right) \\
G_{i j}=\frac{k A}{L}
\end{gathered}
$$

The second type of conductor is a nonlinear radiation conductor. It is nonlinear because the heat flow is a function of the temperature difference to the fourth power.[3] The conductance is a 
function of Stephan-Boltzmann constant, emissivity, view Factor, $F$, and area of the radiating surface. In SINDA, the conductance of a radiation path is differentiated from a conduction path by putting a minus sign in front of it.

$$
\begin{gathered}
Q=-G_{i j}\left(T_{i}^{4}-T_{j}^{4}\right) \\
-G_{i j}=-\sigma \varepsilon F_{i j} A_{i}
\end{gathered}
$$

The conductance is the inverse of the resistance, $R$, which is also used to explain thermal model networks. Just like the conductance and resistance in electrical models both follow the same physic rules when combining across networks. Resistors add together in series to create more resistance to the heat transfer flow, but the inverses are added when in parallel. Conductors add together in series to increase the thermal path for the transfer of heat, but the inverses are added in series. To continue the comparison, capacitance is also used as a storage of thermal energy in a large thermal mass, just like capacitors for electrical systems store energy.

Heat loads are used to represent a heat source, $Q$, from a component or heating element. The heat load is applied directly to the diffusion nodes to simulate heat dissipation.

A typical space environment consists of the sun, earth, and spacecraft as shown in Figure 14. When in view of the sun the spacecraft absorbs solar heat, but the earth eclipses the sun so the only way to heat the spacecraft is with component heat dissipation or heaters. The conductance between the space node and the spacecraft node is shown in the figure. This is a very simple nodal network, but useful for finding steady state information without software. As detail is added to the model and many more nodes of the spacecraft are needed the use of software becomes important, but the basis of how nodal networks are created remains the same. 


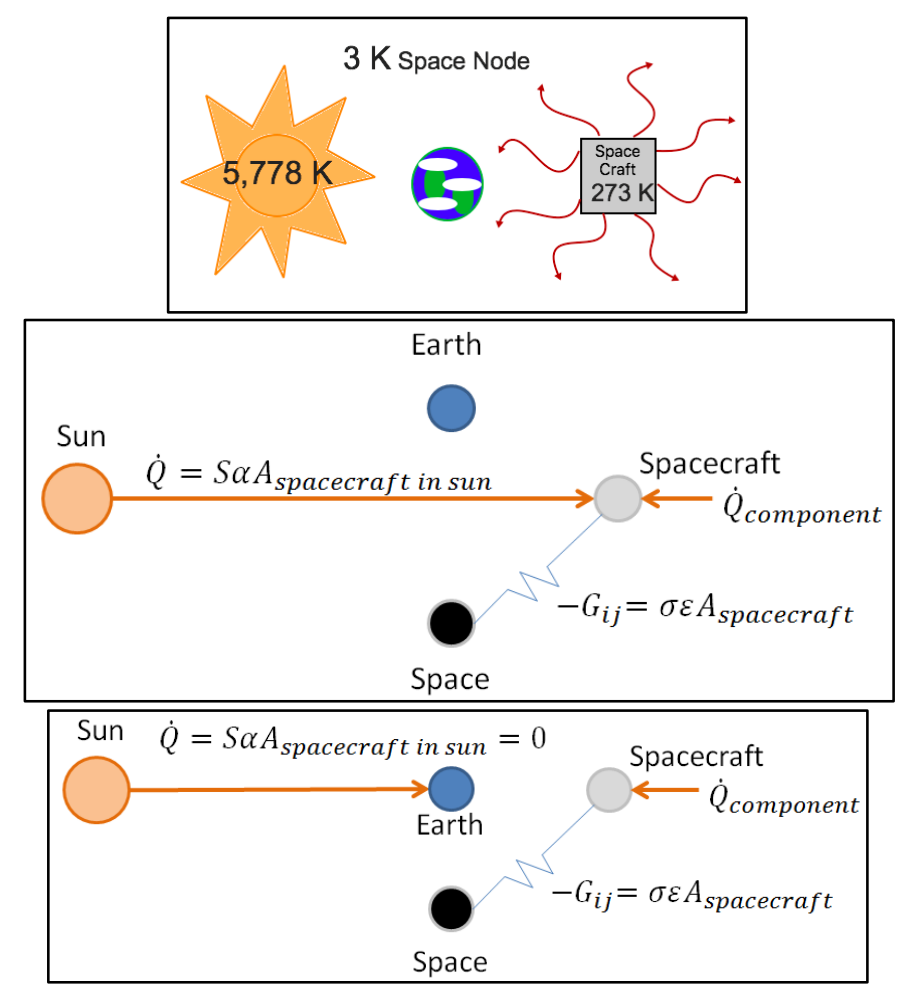

Figure 14. Space Environment Nodal Network

\subsection{NODALIZATION AND FDM}

Exact analytical solutions to the nonlinear heat conduction equation are not possible for most applications. Thermal desktop and many other software programs take advantage of the Finite Difference Method to approximate solutions numerically by discretizing space by an integer number of spatially distributed points and time by an integer number of discrete time steps.[1] This creates a nodal mesh of the material which is further discussed in the Thermal Desktop section of this thesis.

The heat equation from Eq. 2 can be manipulated to replace the differentials with finite differences following the Taylor series approximation. The two dimensional heat equation reduces to the following equation and is visualized in Figure 15.

$$
\frac{\partial T}{\partial t}=-\frac{k}{\rho c_{p}}\left(\frac{\partial^{2} T}{\partial x^{2}}+\frac{\partial^{2} T}{\partial y^{2}}\right)+\frac{\dot{Q}_{v}}{\rho c_{p}}
$$




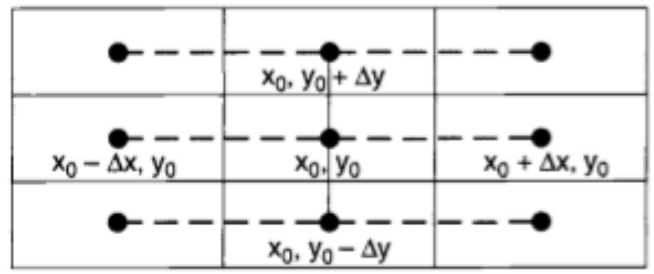

\section{Figure 15. Finite-Difference Two-Dimensional Mesh with Uniform Spacing [3]}

SINDA is able to solve complicated 3D and time dependent FDM which is why there is so much emphasis on the Thermal Desktop model. With more and more complex designs the use of programs like SINDA have become common. FDM errors occur from truncation errors, instability in the numerical solution, and computer rounding error. Truncation errors are minimized from increasing the number of nodes in the model, but there is no specific rule for mesh size. There is no instability if the Thermal Desktop model solves the solution. Rounding error is generally not a problem with 64-bit computers.[3] All this considered, in general, a course mesh is the best option to reduce the run time of large spacecraft models. A sensitivity analysis of the model is done in section 0 . 


\section{EXPERIMENTAL APPARATUS}

\subsection{OVERVIEW OF THE SYSTEM}

The HVEC and ATS Chiller system shown in Figure 16 together create a TVAC testing apparatus. The chiller input and output line is connected through two feed-throughs of the vacuum chamber to the copper platen. The ATS Chiller cools Galden® Fluid using an internal refrigeration system discussed in section 2.3. The fluid exits the chiller through one pipe, travels along the bottom of the copper platen, and returns to the chiller through the other pipe. Galden ${ }^{\circledR}$ Fluid can either heat or cool the platen as the fluid absorbs heat from the copper through the brazed pipes. For clarity, the shroud is shown in Figure 17, it consists of thin copper and MLI blanketing. A testing component can be bolted or bonded to the platen in order to dissipate the heat from the component to the plate.

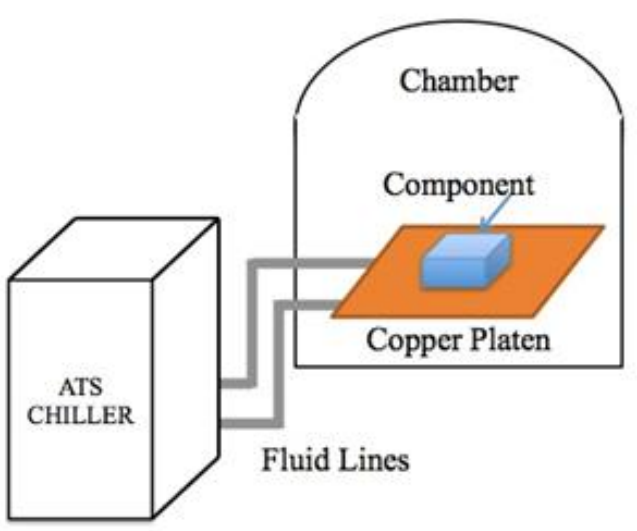

Figure 16. Thermal Cycling HVEC Vacuum Chamber and ATS Chiller
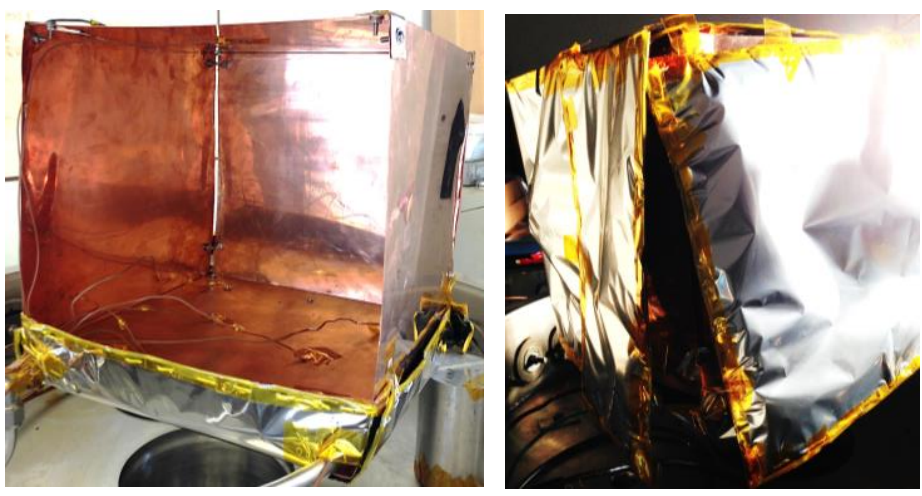

Figure 17. Shroud and Blanket 


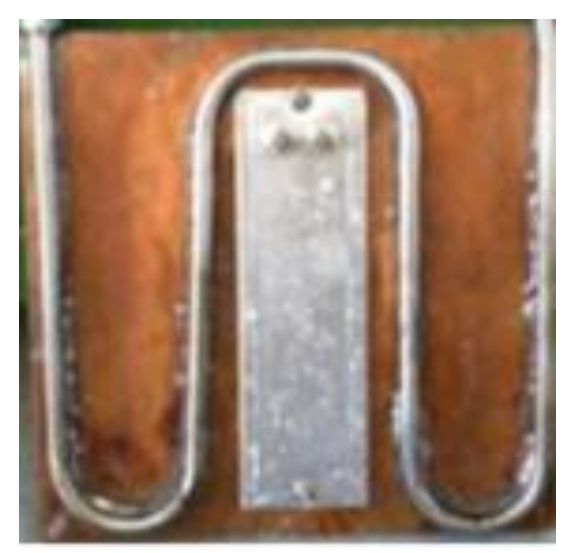

Figure 18. Piping and Heat Strip Secured Under the Platen.

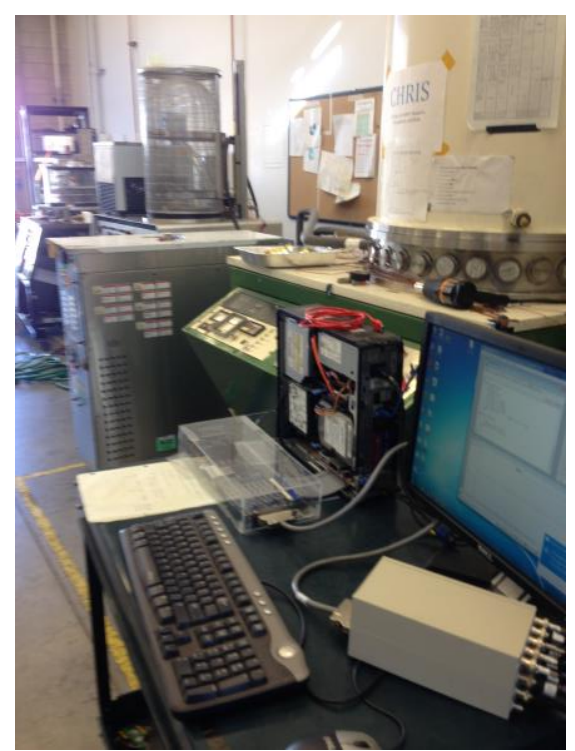

Figure 19. ATS Chiller, Vacuum Chamber and DAQ Computer

The bake out test only required the platen and shroud, the ATS Chiller was not used. No fluid could be in the lines for danger of boiling the Galden®fluid in this test set up. The heat strip was secured to the platen and the shroud was mounted to protect the blankets from the heat strip. An electrical feed-through was used to power the heat strip. A sample schematic is shown below in Figure 20. 


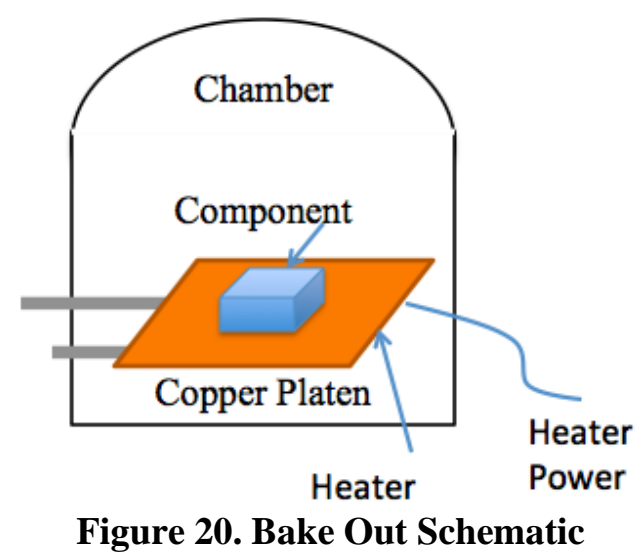

\subsection{VACUUM SYSTEM}

All testing for this thesis was performed in the Cal Poly Aerospace Engineering Space Environments Laboratory. The vacuum chamber is a High Vacuum Equipment Corporation (HVEC) 350 liter bell jar chamber, shown in Figure 21. The chamber measures 30 inches in diameter and about 30 inches high.[13] This chamber was already fitted with two Swaglok feedthroughs for the ATS Chiller. One feed-through has been used specifically for k-type thermocouples. The other feed-throughs are used to supply power to either the heat strip or an electrical component to be tested. It is also the largest chamber in the lab so it was able to fit the shroud and platen the best. Finally, the chamber is able to reach pressures below $10^{-5}$ Torr which is a requirement for thermal cycling. Both a mechanical pump and a cryopump had to be used for the chamber to reach such low pressures. The mechanical pump, a Welch 1374 Duo-Seal Vacuum Pump, was only needed to lower the pressure from atmospheric pressure to between $50-100$ mTorr. This was low enough for the cryopump, CTI-Cryogenics Cryo-Torr 8 High Vacuum Pump, to take over without harming the cold head. The Model 1020R Helium Compressor is needed in conjunction with the cryopump to cool the cold head to 10 Kelvin. Understanding how to operate and fix both of these pumps was another huge endeavor to complete this thesis. For an overview of the procedures and common problems solved for both machines refer to Appendices $\mathrm{B}, \mathrm{C}$, and D. 


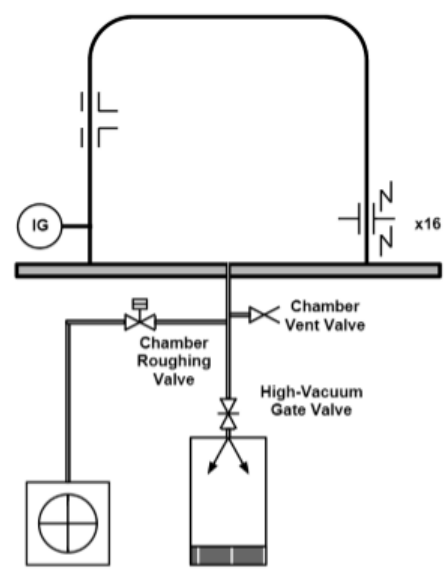

Figure 21. High Vacuum Equipment Corporation (HVEC) Bell Jar Chamber.[13]

\subsection{ATS CHILLER}

An ATS Chiller system was donated to Cal Poly's spacecraft environments lab and has been used in multiple projects. Chelsea Barackman, Steven Jackowski, and Leila Tebyani all did a senior project involving the use of the chiller in the HVEC Chamber. This thesis is meant to build on procedures created from their papers, to fix problems with the chiller, and to perform more complete testing. $[13,14]$ The chiller is a versatile machine that can be used in different vacuum chambers for different applications. In the most basic terms the purpose of the unit is to control the working fluid to a temperature set by the user and absorb a heat load applied to the platen. From previous projects, the main concern was the chiller leaking fluid, the platen not being evenly heated or cooled, and the testing not being verified. This section includes a summary of changes and fixes that were made to make the chamber operational. The ATS Chiller is shown in Figure 22 next to the vacuum chamber. Specifications are shown in Table 3. All information can be supplemented with the ATS Operating Manual.[8] In addition, a step by step procedure is outlined in Appendix $\mathrm{H}$. 


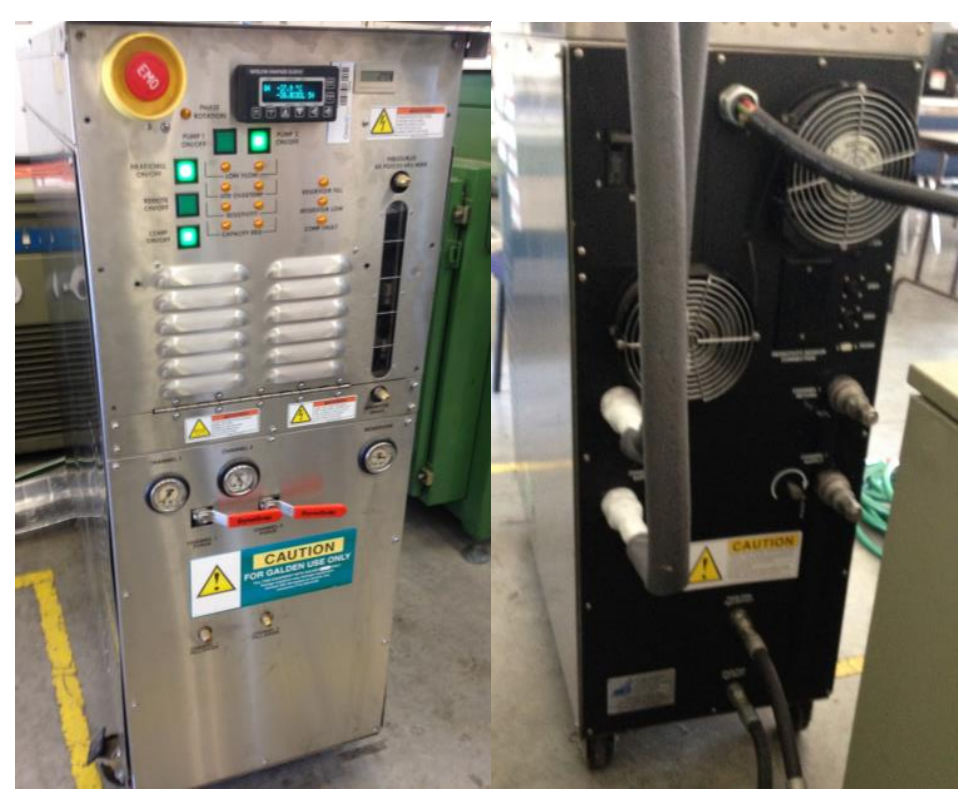

Figure 22. ATS Chiller Front and Back Views

Table 3. ATS Chiller Specifications

\begin{tabular}{ll}
\hline \hline Part Number & $1231-\mathrm{CCN}-\mathrm{GL}-003$ \\
\hline Serial Number & $0238 \mathrm{~W} / \mathrm{EP}$ \\
\hline Fluid & Galden ${ }^{\circledR} \mathrm{HT}-110$ \\
\hline Fluid Boiling Piont & $110^{\circ} \mathrm{C}$ \\
\hline Fluid heat transfer coefficient & $0.065 \mathrm{~W} / \mathrm{m}-\mathrm{K}$ \\
\hline Fluid Specific Heat Capacity & $962 \mathrm{~J} / \mathrm{kg}-\mathrm{K}$ \\
\hline Pressure & $100 \mathrm{psi}$ \\
\hline Flow & 5 gallons per minute \\
\hline Temperature Range & $-40^{\circ} \mathrm{C}$ to $60^{\circ} \mathrm{C}$ \\
\hline Absorbed heat load & Max 500 Watts \\
\hline Controller & Watlow Anafaze CLS200 Series \\
\hline \hline
\end{tabular}

First and foremost, the leaking of the ATS Chiller had to be addressed. It was possible to capture the leaked fluid in aluminum trays, but the leaks were causing a significant amount of spills of the expensive fluid. An attempt was made to remove the incorrect piping on channel 1, but the old bonding material would not come off. After discussing with Denis Webster from ATS it was determined to close off channel 1 and only use channel 2.[9] He also helped to supply the proper pipe attachment that would hold a small vacuum seal which was purchased from ATS. The part is a welded $1 / 2$ " face seal nut to a $3 / 4,-1 / 2, "$ pipe reducer. Figure 23 shows where the leaks were coming from and Figure 25 shows the better attachment that was made for channel 2. 


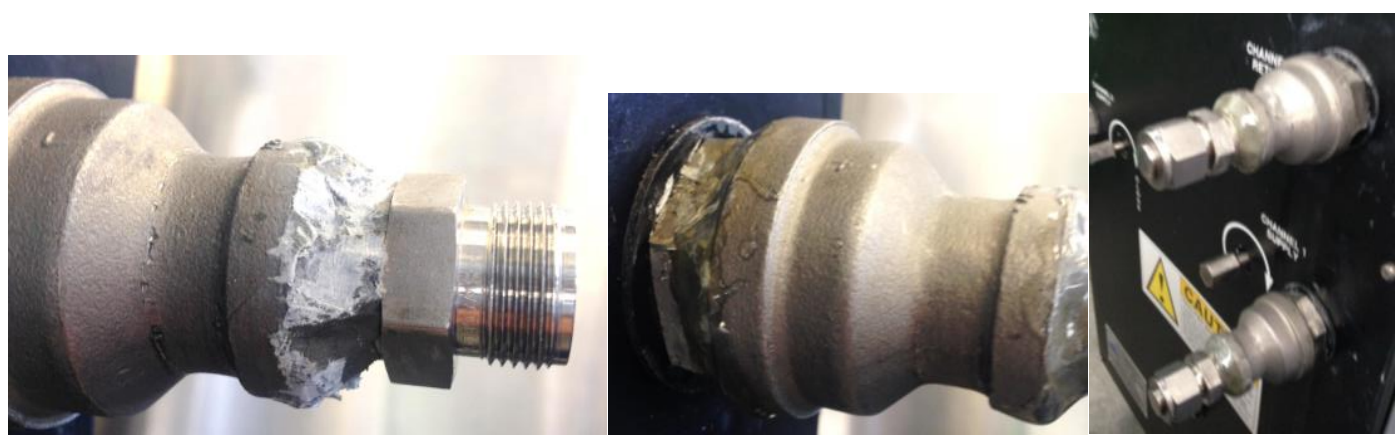

Figure 23. Wrong Attachment Glued to Channel 1, Capped (right)

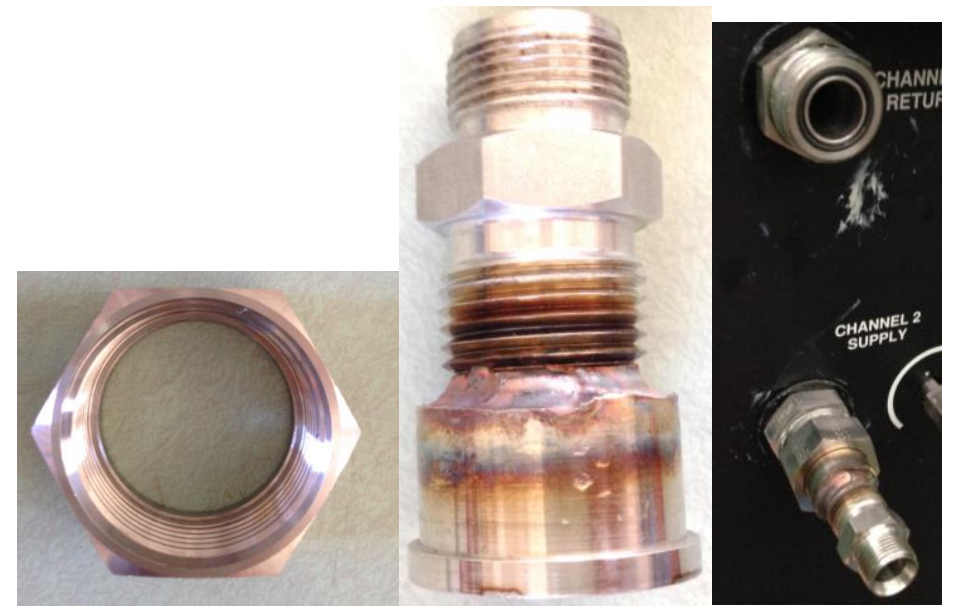

Figure 24. Correct Attachment From ATS Attached to Channel 2.

There were other problems with the ATS chiller that had to be overcome as well. The heater in channel 1 was not working properly, but using channel 2 fixed this problem. The controller was disconnected inside the chiller so the top was removed to reconnect it. The entire fill/drain process was re-documented from Leila's procedure and the fill/drain manual and is explained in detail in Appendix H.[16] The ATS Chiller should not need to be opened up unless it is assumed that a fuse broke because a button won't light up or the controller won't turn on.

In conclusion, each fix to refurbish the ATS Chiller was permanent. There are no longer any leaks, no faulty wiring, and more of the operational procedure has been added to Leila's procedure. 


\subsection{SHROUD AND VACUUM MATERIALS DESIGN}

With input from committee member Roland and using the information from researching papers it was deemed necessary to design a shroud to work with the platen.[17] The shroud needed to be easier to control than shrouds that have cooling piping all around the exterior because such shrouds are significantly more complex. For a student run chamber the shroud only needed to insulate the testing material from ambient temperatures of the vacuum chamber. It also had to work with the current platen and heater system already in use from previous work on the ATS Chiller system. The shroud and platen materials are shown in Table 4. A thin copper encasing was used to create a structure for the shroud and MLI is used all around the encasing. Passive MLI insulates the components without requiring further piping. See Figure 17 to visualize the shroud. The platen, stainless steel pipes, heat strip, and voltage supply were already available in the lab.

Table 4. Shroud and Platen Materials

\begin{tabular}{lll}
\hline \hline Material & Specifications & Manufacturer \\
\hline Platen & $12 \times 12 \times 0.25$ inch copper & n/a \\
SS Pipes & 0.5 ' diameter, total length along the platen 55.5, & n/a \\
Heat Strip & $3 \times 8$ inch heat strip from McMaster Carr, 195 Ohms & McMaster Carr \\
110 Copper Sheet & 0.21 " thick, 36x48” & McMaster Carr \\
SS Screws & $6-32$ thread, 1-1/4" long & McMaster Carr \\
MLI & 20 layers & Sheldahl \\
Voltage Supply & Powerstat Variable Autotransformer, Type 116B, & n/a \\
& Model E1830, 300W & \\
\hline \hline
\end{tabular}

To attach the copper shroud to the platen six extra through holes had to be machined into the platen using a drill press in the Cal Poly machine shop. The placement of the screw holes dodged the piping as shown in Figure 25. More through holes can be machined for future work if necessary to secure components onto the platen. Copper was used for the shroud to help create an even distribution of temperature across the shroud and reach steady state temperatures faster. According to the "Design and construction of a low-cost economical thermal vacuum chamber for spacecraft environmental testing" paper thin copper was used over the coolant piping to increase conductivity to the platen.[17] The design of the thin copper sheet is shown in Figure 26. 
The copper shroud folds into a 12 " cube with the front open. The shroud is bolted onto the platen with stainless steel screws so that they are able to be used under vacuum conditions. The length of the screws were imperative in order to reach through the platen. Along the sides of the copper shroud a joint of copper was made to combine two sides of the shroud or a corner as shown in Figure 27. Finally, a cut out was made for the heater electric wiring as shown in Figure 28.
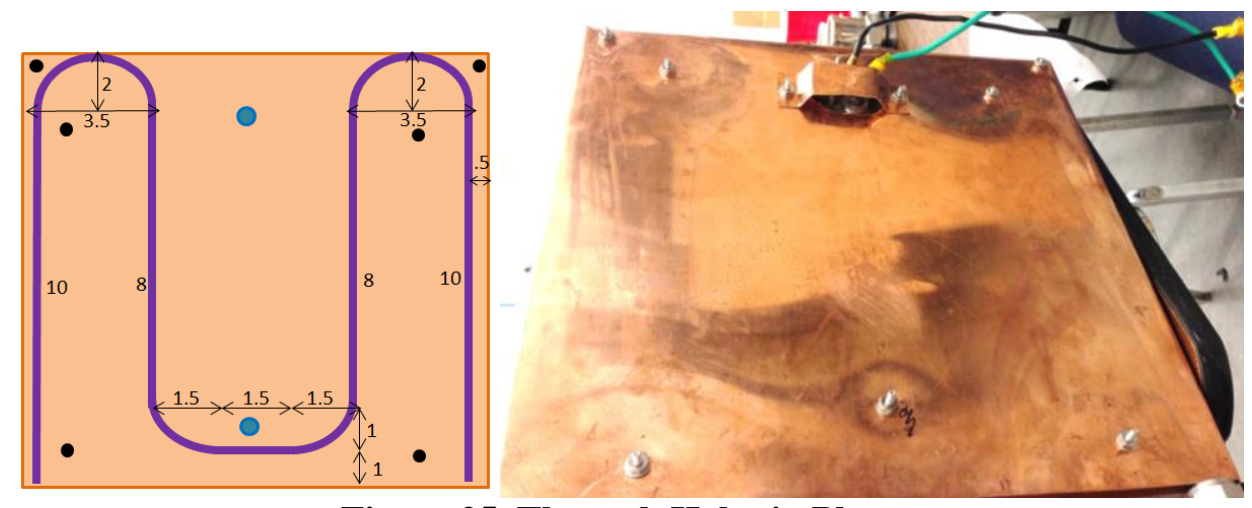

Figure 25. Through Holes in Platen

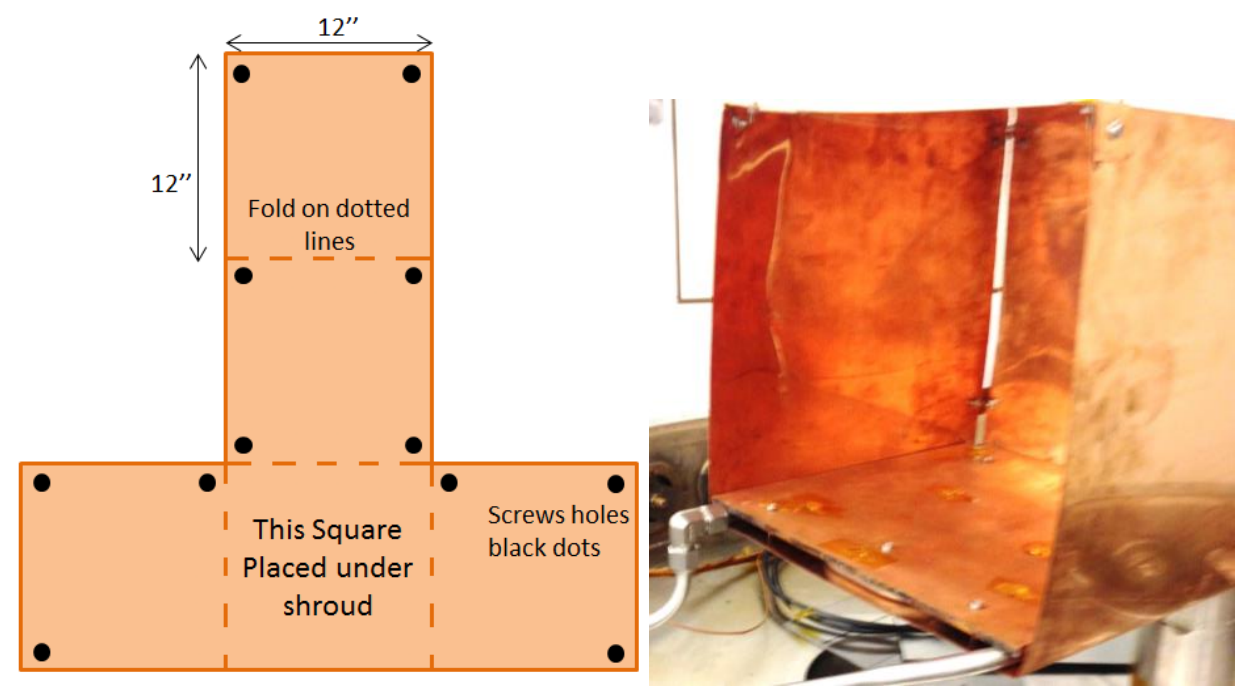

Figure 26. Thin Copper Shroud Design 


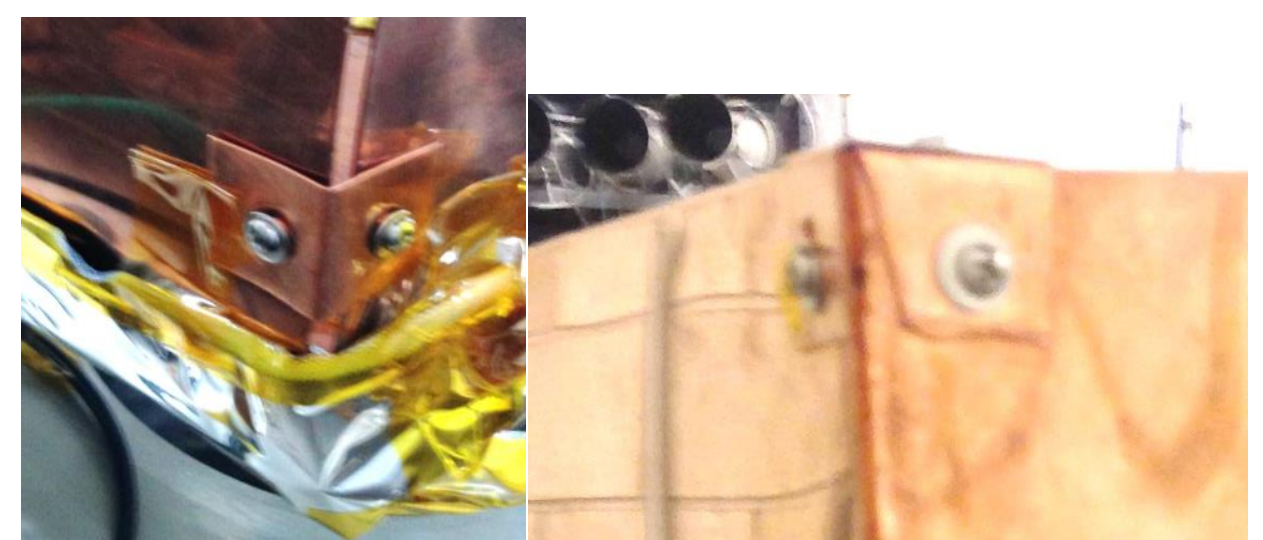

Figure 27. Copper Shroud Screw Joints: Two Screws (left) Three Screws (right)

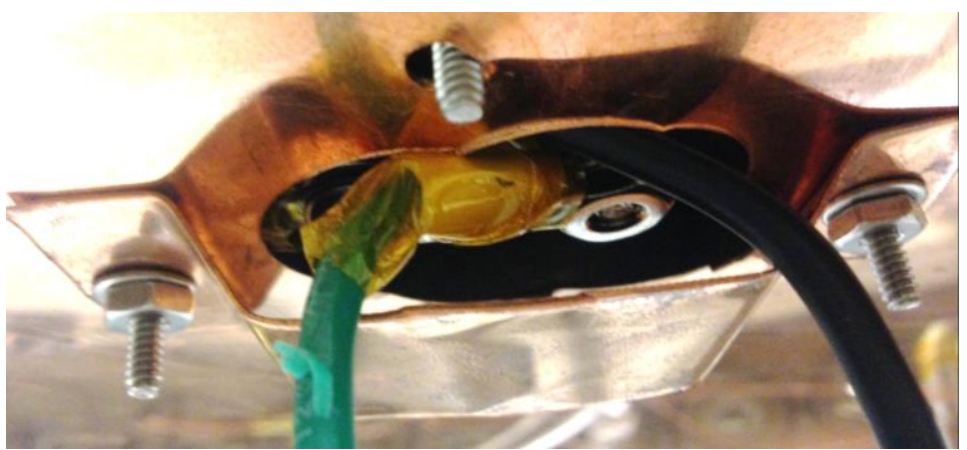

Figure 28. Copper Shroud Heater Cut Out

The copper shroud heats or cools by conducting heat from the ATS Chiller piping or the heater, but an MLI blanket is used to keep the heat from radiating to the ambient temperature chamber. For more information on the blanket design see Appendix E. Four pieces of blankets were sewn together to fully cover the shroud shown in Figure 29. The installation of the entire shroud is reviewed in the Appendix G.

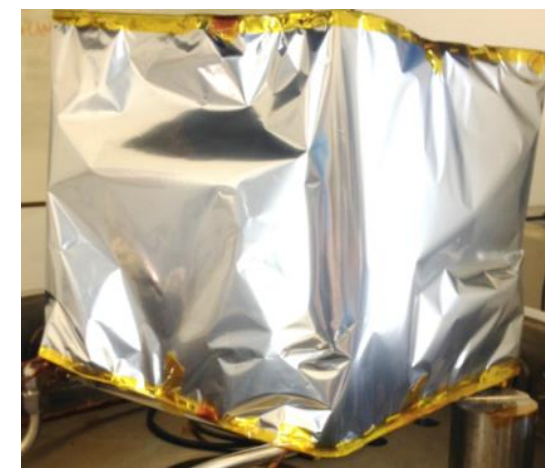

Figure 29. MLI Over the Shroud to Insulate the Copper. 


\subsection{DAQ AND THERMOCOUPLES APPARATUS}

Microstar Laboratories data acquisition system was used to record temperatures at a constant rate. The system includes a Data Acquisition Processing (DAP) board DAP5380aC and a signal interface stand-alone board MXTB 009-09-A2C-B. The DAP is connected to the computer and can be used with different signal interface boards. For this thesis type-k thermocouples were used to measure temperature inside the vacuum chamber; type-k is a standard thermocouple for most applications. Other types of thermocouples are better used for much higher temperatures over $121^{\circ} \mathrm{C}$ or lower temperatures, but come with other problems such as corrosion.[18]

Thermocouples use the Seebeck Effect or thermoelectric effect where a small current flows through the metal when each end is at different temperatures. Thermocouples are standardized by type following recommendations from Standards ASTM E 230 -ANSI MC 96.1. Type-k information is shown in Table 5.

\section{Table 5. Type-K Thermocouple}

\begin{tabular}{ll}
\hline \hline \multicolumn{1}{c}{ Description } & \multicolumn{1}{c}{ Value } \\
\hline Temp Range & -270 to $1260^{\circ} \mathrm{C}$ \\
Tolerance Value & $\pm 2.2^{\circ} \mathrm{C}$ or $\pm 0.75 \%$ \\
Positive Metal & Nickel-Chromium \\
Negative Metal & Nickel-Aluminum \\
Positive Coloring & Yellow \\
Negative Coloring & Red \\
Exterior Color & Brown \\
\hline \hline
\end{tabular}

The board is a 16 bit DAQ and the smallest voltage range is -5 to +5 Volts. From the resolution formula in Eq. 16 there are $15 \mathrm{mV}$ per count. This resolution is not fine enough for temperatures between $-60^{\circ} \mathrm{C}$ and $100^{\circ} \mathrm{C}$ where the thermocouple voltage output range is $2.243 \mathrm{mV}$ to $2.851 \mathrm{mV} .[18]$

$$
V / \text { Count }=V_{\text {range }} / 2^{\text {bits }}
$$

The voltage must be amplified to be read by the board with either a gain or an external amplifier. The board does not have a Programmable Gain Amplifier (PGA), so amplifiers from Adafruit, model number AD8495 Breakout, were used to increase the signal. Amplifiers require a 
separate power source with a voltage of 3-5 and a single k-type thermal couple input. The output of the amplifier is volts, but to get a temperature in centigrade the following equation must be used as provided by Adafruit.[19]

$$
T=\left(V_{\text {out }}-1.25\right) / 5 m V
$$

A power supply module from JBTek Breadboard Power Supply Module 3.3V/5V was attached to the breadboard to provide 5 Volts to the board. Any power adapter above 5 Volts can be used to supply power from a wall socket. Figure 30 shows a detail of the breadboard with wiring for the Adafruit amplifier. Figure 31 shows the electrical schematic of the system. All wires are connected through a bread board. More thermocouples can be used, but more than 10 thermocouples will require the purchase of more amplifiers and BNC cables.

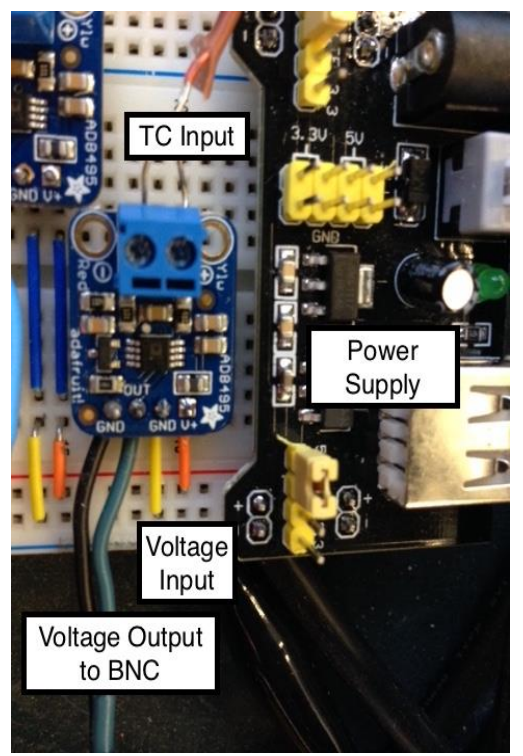

Figure 30. Detailed Wiring on Adafruit AD8495 Breakout Amplifier. 


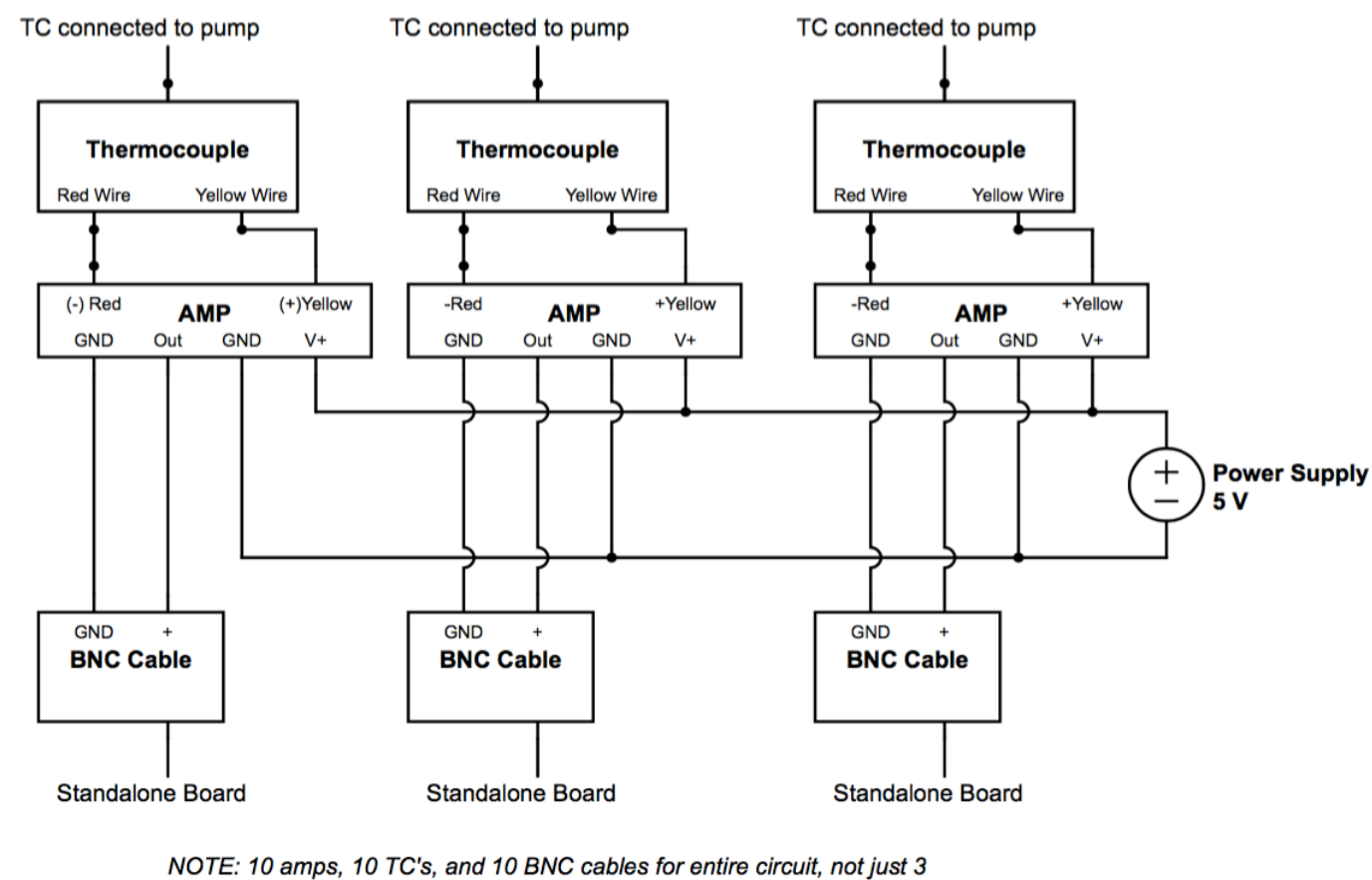

Figure 31. Electric Schematic of Thermocouple and DAQ System.

All of the equipment is shown in Figure 32. Each BNC cable was either stripped to expose both wires on one end (positive and ground) or the BNC cable was purchased with a positive and ground wire on one end and BNC connector on the other end.

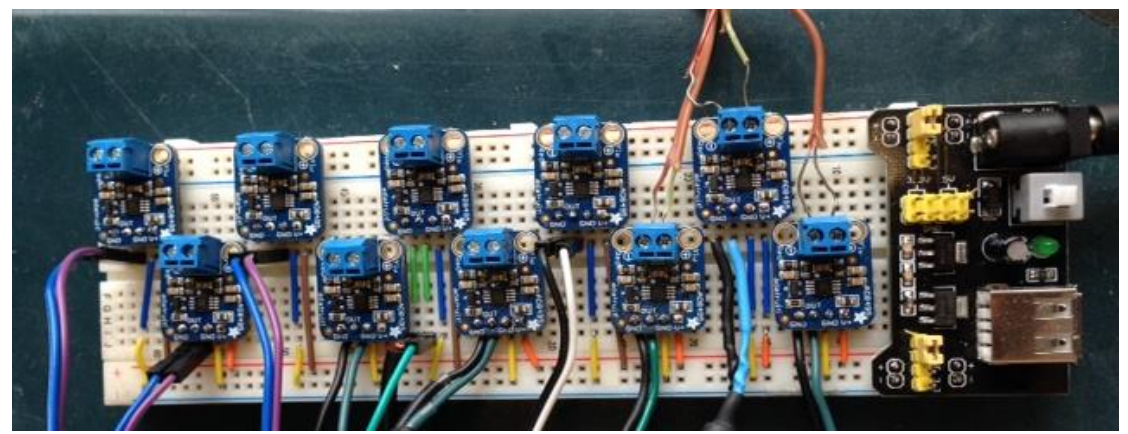

Figure 32. Adafruit Amplifiers, TCs, BNC Cables, and Power Supply

The lab computer had to be placed in close range of the vacuum chamber in order for the thermocouples to reach it. The full set up is shown in Figure 33. The desk is on rollers so it can be used for other experiments or moved out of the way when the TVAC system is not in use. 

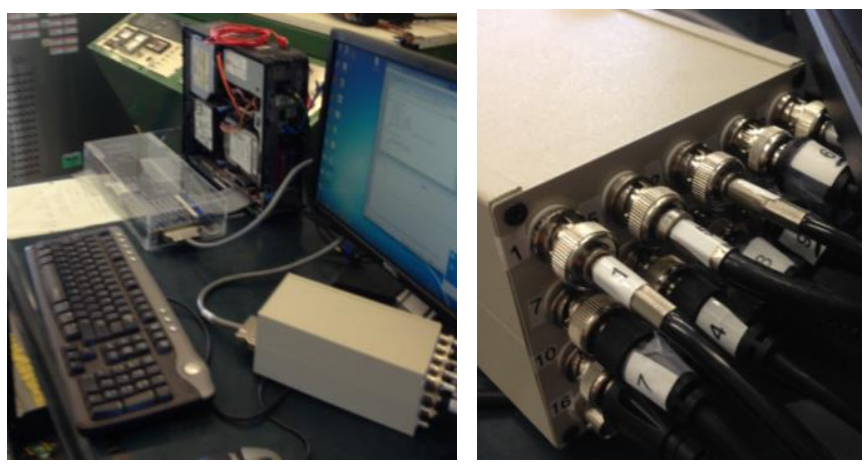

Figure 33. TCs and Computer System by TVAC Chamber 


\section{THERMAL DESKTOP SIMULATION}

\subsection{OVERVIEW}

Five thermal models are used to analyze the system. First, there is a simple model with only the platen and a heater. It was used to validate the heater. Second, there is a bake out model that includes the heater, shroud, platen, and does not include the ATS chiller cooling or heating. The third model was created to analyze the cycling testing and it included the heater, shroud, platen, and the ATS chiller cooling or heating conditions. In this case the heater was used to act as a component and test how much energy the ATS chiller can absorb. These three models are used to correlate to testing conditions. Then, the models are adapted to support a component. The fourth and fifth thermal models are used to predict the temperature of a component inside the apparatus, where the component is an aluminum finite difference brick four inch cube. For the bake out case the heater is used, but there is no heat dissipation on the component because the testing guidelines do not require power on the unit. For the thermal cycling case no heater is used because it is required to apply power to the component to test operation during the cycling.

The final Thermal Desktop model is 1060 nodes. Mesh size is discussed in section 0. The model is shown in Figure 34.

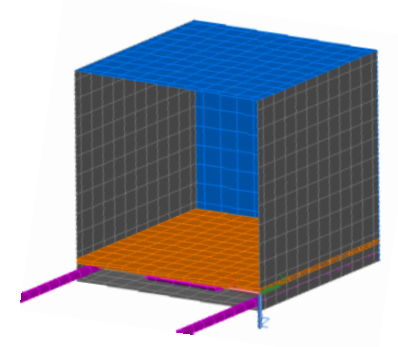

Figure 34. Thermal Desktop Model

\subsection{MATERIALS AND IMPLEMETATION INTO THE MODEL}

Each material property is shown in Table 6 and Table 7. These were inputs for the thermal desktop model and also explain where the material was used. The copper material property was taken from Engineering Tool Box. [20] Mylar optical information was taken from 
the manufacturer, but the effective emissivity, $e^{*}$, value was used from the blanket testing. The type of metal for the tubing was found to be stainless steel 304 (SS 304) as shown by the manufacturer, Swagelok.[21] Engineering Tool Box also has the material properties for the standard stainless steel type 304 which is a minimum $18 \%$ chromium and $8 \%$ nickel. Aluminum 6061-T6 is the most common aluminum used in the aerospace industry so the instrument or unit was modeled with this material. The heater, purchased by McMaster-Carr, is sheathed in steel.[22] For simplicity the mica-insulated interior of the strip heater is not modeled.

Table 6. Thermophysical Material Properties

\begin{tabular}{cccccc}
\hline \hline Material & Use In Model & $\begin{array}{c}\text { Thermal } \\
\text { Conductivity } \\
(\mathrm{W} / \mathrm{m}-\mathrm{K})\end{array}$ & $\begin{array}{c}\text { Specific } \\
\text { Heat } \\
\mathrm{c}_{\mathrm{p}} \\
(\mathrm{kJ} / \mathrm{kg}-\mathrm{K})\end{array}$ & $\begin{array}{c}\text { Density } \\
\rho \\
\left(\mathrm{kg} / \mathrm{m}^{3}\right)\end{array}$ & $\begin{array}{c}\text { Effective } \\
\text { Emissivity } \\
\mathrm{e}^{*}\end{array}$ \\
\hline SS 304 & Pipes, Heater & 16 & 0.502 & 8030 & $\mathrm{n} / \mathrm{a}$ \\
Copper & Platen, Shroud & 386 & 0.390 & 8940 & $\mathrm{n} / \mathrm{a}$ \\
Aluminum & Component/Unit & 167 & 0.896 & 2700 & $\mathrm{n} / \mathrm{a}$ \\
Mylar & MLI Blanket & $\mathrm{n} / \mathrm{a}$ & $\mathrm{n} / \mathrm{a}$ & $\mathrm{n} / \mathrm{a}$ & 0.0014 \\
\hline \hline
\end{tabular}

None of the absorptance values were recorded because it was not necessary to analyze in this test which is exclusively IR radiation with no solar heat source.

Table 7. Thermal Optical Material Properties

\begin{tabular}{cccc}
\hline \hline Material & Use In Model & Absorptance $\alpha$ & Emittance $\varepsilon$ \\
\hline SS 304 & Pipes, Heater & $\mathrm{n} / \mathrm{a}$ & 0.4 \\
Aluminum & Component/Unit & $\mathrm{n} / \mathrm{a}$ & 0.09 \\
Copper & Platen, Shroud & $\mathrm{n} / \mathrm{a}$ & 0.7 \\
Mylar & MLI Blanket & $\mathrm{n} / \mathrm{a}$ & 0.035 \\
Kapton & MLI Blanket & $\mathrm{n} / \mathrm{a}$ & 0.85 \\
\hline \hline
\end{tabular}


Each material was converted into a model in thermal desktop through various methods for a final result shown in Figure 34. The platen is orange, the pipes are pink, and the shroud is black and blue. Thermal Desktop steps are shown in more detail in Appendix I. To start the modeling process, the platen was created as a solid finite difference brick with a length and width of 12 inches and a thickness of 0.25 inches. The holes for the screws were not considered because the holes make up a very small area in relation to the platen.

The pipes were then modeled after a simplified version without curves, the differences between realistic pipes and the model pipes are shown in Figure 35. It is common to simplify curves and abstract geometry for thermal spacecraft analysis.[3] The pipes are made of finite difference solid cylinders with boundary nodes instead of diffusion nodes.
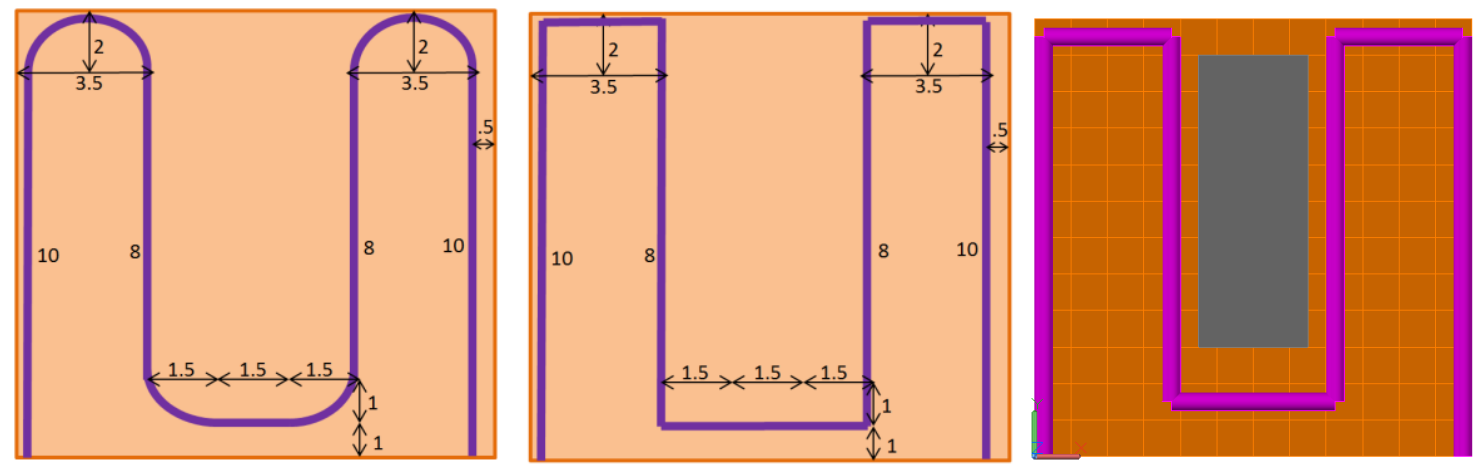

Figure 35. ATS Chiller Pipes: Real Dimension (left) and Modified (right)

The heater is modeled as a finite difference thin shelled rectangle with a thickness of 0.025 '. Similar to the copper platen, there was not much manipulation that needed to be done to the basic square shape. A heat load was used on the heat strip nodes to simulate the heat strip power dissipation. More details on the use of heat loads can be found in Appendix I : Thermal Desktop/SINDA Overview.

Next, the copper shroud was created with 5 finite difference thin shelled rectangles. The thickness of the copper sheet is determined inside the editor as 0.021 inches. The copper shroud completely covered the platen except for the front. It was a solid piece of copper, but is not welded together at some of the edges shown in Figure 36. Along the edges where the copper is 
only bent and still one solid piece the nodes are merged together, simulating a solid piece of sheet metal. The merged solid copper sides are shown in blue and the non-merged nodes are shown in black. Although the thermal model looks like the nodes are merged at the other edges, the thermal graphs in the results show that the copper is not continuous because the heat map breaks along the edge.
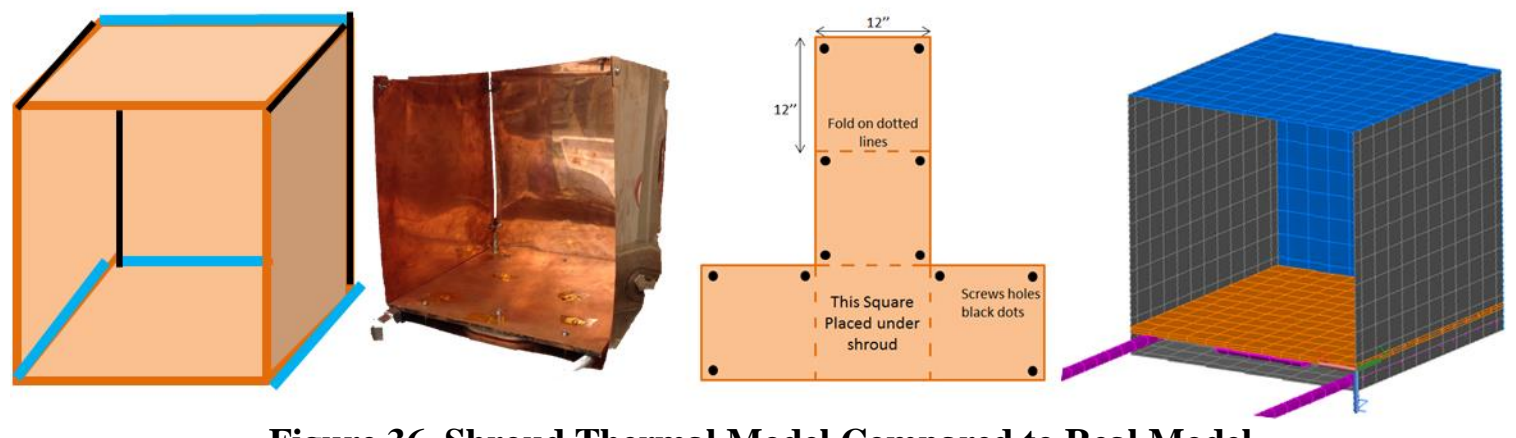

Figure 36. Shroud Thermal Model Compared to Real Model

The creation of each layer of the MLI blanket in thermal desktop would be both time consuming and unnecessary. For this reason a single insulation node was used with the effective emissivity blanket properties on the outside of the copper shroud to simulate all the layers. The Mylar property only has the $e^{*}$ value in the thermophysical property inputs because it is only used as an arithmetic node with no thermal mass.

The component was modeled as a very simple finite difference brick because no real test component was used. In a real design this would be the most detailed part of the thermal desktop model because it normally requires detailed analysis and correlating. Since no component was tested, it was only implemented to predict values a small component would experience inside the thermal vacuum chamber.

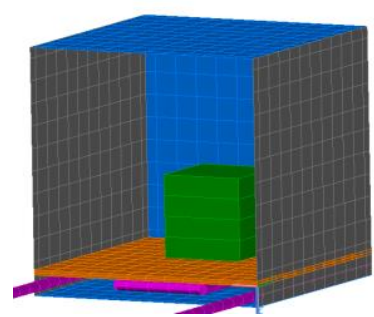

Figure 37. Component Thermal Model in the Shroud 
Materials not outlined here include the screws, braze, TC's, thermal kapton tape, and vacuum chamber walls. The screws and the braze between pipes and platen are only in the model as conductors explained in section 4.3. Thermocouples are a small thermal mass that do not have heat dissipation, so these were excluded from the model. Instead, a node of the material at the approximate location of the TC is used to represent the temperature at that location. Similarly, the kapton tape used over the blanket edges and on the TC's was not considered critical for the thermal model results due to the small area in relation to the entire assembly. Instead of modeling a chamber wall that encloses the structure the ambient temperature was set to room temperature, $22^{\circ} \mathrm{C}$, instead of the default space node temperature of 0 Kelvin. Such a model is acceptable because the thermal mass of the chamber is significantly large with respect to the platen. Since the chamber was in the ambient air temperature, no change in temperature is expected. Results in section 6.2 show this assumption to be true.

\subsection{CONDUCTIVE PATHS}

Accurate conductive paths between materials is arguably one of the hardest parts of thermal modeling and is the primary reason for correlating the data. Thermal conductivity throughout a solid material is well documented for most materials, but the thermal contact resistance between adjoining materials varies significantly based on what materials are joined and how they are joined. Other variables include gap thickness of the interface material, type of interface material if used, average temperature of the interface, and surface roughness of the joined materials. No universal model exists to predict the joint resistance between any two surfaces, so thermal engineers assess the conditions and make best approximations based on previous models and experiments.[3] Sensitivity analysis can be done by using a range of joint resistance values and comparing thermal results in order to get a better understanding of the thermal behavior of that particular joint on the system. 
For this thesis three important interface conductivities are researched. The first is the solder between the ATS Chiller pipe and the copper platen. A better conductive path through this interface results in a platen temperature closer to the set temperature on the ATS Chiller. Second, each screw has a bolted interface value between the shroud to the platen. Lastly, multiple interface values were examined for the theoretical component that is tested in the prediction models for both bake out and thermal cycling testing.

The bolted interface does not have any thermal paste filler, so, the Thermal Control Handbook has a standard value for each bolt size.[3] To illustrate what the material does under the stress of the screw see Figure 38.

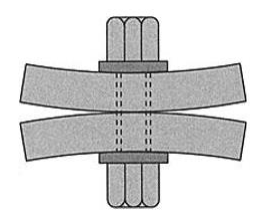

\section{Figure 38. Bolted interface [3]}

A useful study was done with different sized stainless steel screws that bolted two sheets of aluminum together and found experimental results of each conductance. The small stiff surface is used for the heat strip and the large thin surface type is used for the screws bolting the shroud to the platen. The values 0.42 and 0.132 for $6-32$ screws in Table 8 should be less than what is expected in real life because copper sheets are more conductive than aluminum. Therefore, the conductance between the two materials should be greater, but the testing will show a better correlation for this interface.

Table 8. Thermal Conductance Design Guideline from TRW Inc. [3]

\begin{tabular}{ccc}
\hline \hline Screw Size & Small Stiff Surface $(\mathrm{W} / \mathrm{K})$ & Large Thin Surface $(\mathrm{W} / \mathrm{K})$ \\
\hline $2-56$ & 0.21 & 0.105 \\
$4-40$ & 0.26 & 0.132 \\
$6-32$ & 0.42 & 0.176 \\
$8-32$ & 0.80 & 0.264 \\
$10-32$ & 1.32 & 0.527 \\
\hline \hline
\end{tabular}


A typical spacecraft design mounts each component to the spacecraft panels which act as the temperature sink for the component heat dissipation. When the component or unit is mounted to the platen, it experiences a similar temperature sink. How well the component is mounted will affect the temperature greatly, for example using an interface material with high conductivity will create a better conductive path from the component to the platen than using no filler and only bolting the component to the platen. The filler materials improve contact conductance because the material fills the micro scale voids present in surface roughness as shown in Figure 39.

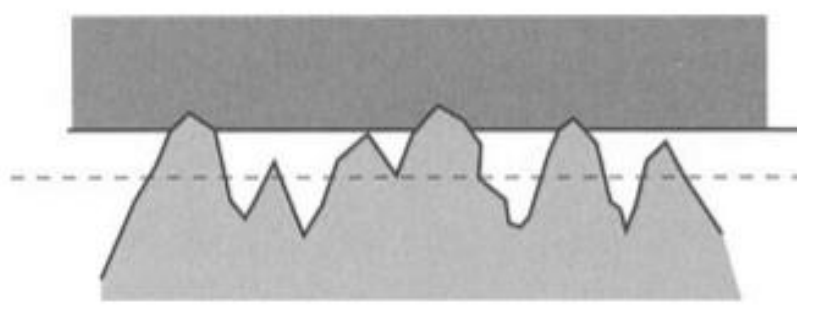

Figure 39. Roughness of Materials.[3]

As with all applications in aerospace engineering each improvement to the thermal design has other implications for other subsystems that must be traded. A filler material creates complications for outgassing, contamination, and difficulty in removing the mounted component for rework. Since there isn't an actual design to consider for mounting the theoretical component to the platen multiple interfaces were analyzed. These are all outlined in Table 9 and found in Appendix C of the Thermal Control Handbook.[3] The area of the component contacting the platen was $16 \mathrm{in}^{2}\left(0.0103 \mathrm{~m}^{2}\right)$ which was used along with conductivity and thickness to find conductance. Four screws were assumed to bolt down the component, so the parallel conductance paths were added together from Table 8 .

Table 9. Contact Conductance and Interface Material for the Component.

\begin{tabular}{|c|c|c|c|}
\hline Material & $\begin{array}{c}\text { Thermal Conductivity } \\
(\mathrm{W} / \mathrm{m}-\mathrm{K})\end{array}$ & Thickness (mm) & $\begin{array}{c}\text { Conductance } \\
(\mathrm{W} / \mathrm{K})\end{array}$ \\
\hline 4 6-32 Screws & $\mathrm{n} / \mathrm{a}$ & $\mathrm{n} / \mathrm{a}$ & 1.68 \\
\hline T-Putty 502 Series $^{\mathrm{TM}}$ & 3 & 5 & 6.18 \\
\hline Kera-therm Pink 86/50 & 2.9 & 0.225 & 132.75 \\
\hline
\end{tabular}


In a previous project the stainless steel pipes were brazed to the copper plate, but the application was done again to make a better contact between pipe and copper. As seen in Figure 40 the filler material is not evenly distributed and the cylinder pipe to the flat copper plate creates a variable interface thickness. There is no model to support or estimate the contact resistance through the filler material, so a hand calculation was done to get a prediction before correlating the model. This is a great example of how important testing is to get more accurate contact resistance information.

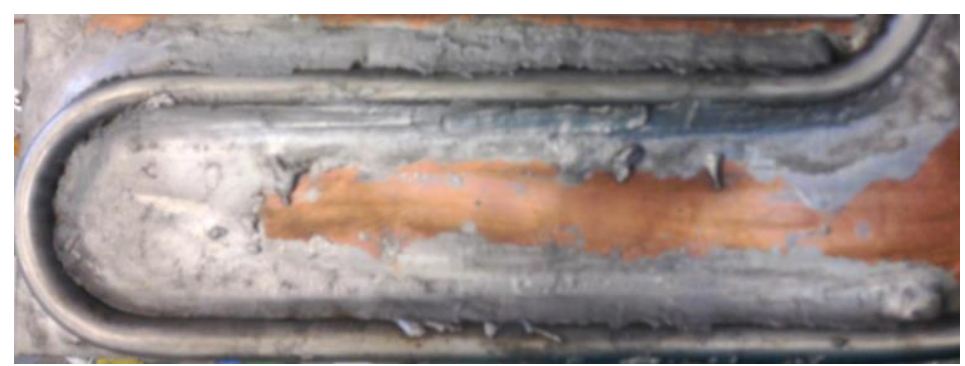

Figure 40. Uneven Brazing of the Pipes to the Platen

The filler material is a tin and lead alloy with thermal conductivity $50 \mathrm{~W} / \mathrm{m}-\mathrm{K}$. Note, it is important to only handle the platen with gloves because of the lead. To find the conductance of the filler material it was necessary to calculate the area, $A$ and the thickness, $L$ as shown in Eq. 12. Figure 41 illustrates the variable thickness across the pipe and the five sections in dark grey that were analyzed. To better estimate the conductance the sections were calculated individually, then added together because conductors in series add together, which can be investigated further in the electrical network analogy from section 2.4.[3] It is assumed the smallest length from the pipe to the platen is 0.05 inches thick. With this information and knowing the pipe is 0.5 inches in diameter each length and area were calculated as shown in Table 10. The area is a function of the total length of the piping, $\boldsymbol{l}_{\text {pipe }}$, where the estimated length was 55.5 inches and was the same for each section of braze filler. The area was based off of assuming half the pipe was in contact with the material for a total of 0.785 inches which is half the circumference of the 0.5 inch diameter pipe. There are a lot of assumptions to calculate the interface conductivity and still, the roughness 
of the materials were not even taken into account. In engineering conservative values are estimated to make sure the component does not go over acceptance temperatures, but a better method is to accurately perform tests to better understand the materials used.

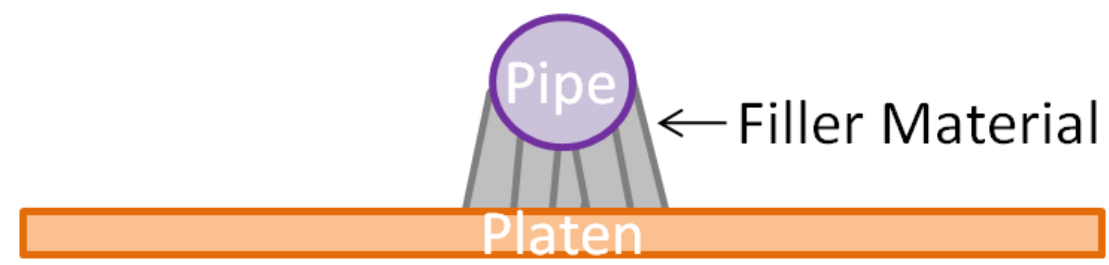

Figure 41. Filler Material Between SS Piping and Platen

Table 10. Braze Filler Material Conductance Calculation

\begin{tabular}{cccccc}
\hline \hline \multirow{2}{*}{ Section } & $\begin{array}{c}\text { Number } \\
\text { Used }\end{array}$ & L (in) & A $\left(\right.$ in $\left.^{2}\right)$ & $\mathrm{k}(\mathrm{W} / \mathrm{m}-\mathrm{K})$ & $\mathrm{G}(\mathrm{W} / \mathrm{K})$ \\
\hline Outer & 2 & 0.332 & $0.157 * l_{\text {pipe }}$ & 50 & 28.5 \\
Middle & 2 & 0.156 & $0.157 * l_{\text {pipe }}$ & 50 & 60.7 \\
Center & 1 & 0.05 & $0.157 * l_{\text {pipe }}$ & 50 & 189.4 \\
\hline \hline
\end{tabular}

As expected, the conductance increases as thickness, $L$, of the material decreases. Adding all the conductances from Table 10 shows that the final conductance for the bonding of the pipes to the copper is $367.8 \mathrm{~W} / \mathrm{K}$. The length is included for a total conductance value which helps to keep the Thermal Desktop user completely in control of the interface value. Alternatively, the thermal conductivity and the thickness can be used in Thermal Desktop with an interface material to reduce the need for hand calculations, but it is harder to determine how area is measured and what the final conductance value calculated by Thermal Desktop is. Also, during correlation knowing an absolute conductance value made adjusting and comparing the results easier. The conductive paths from pipe and heat strip to platen are highlighted in yellow in Thermal Desktop as shown in Figure 42.

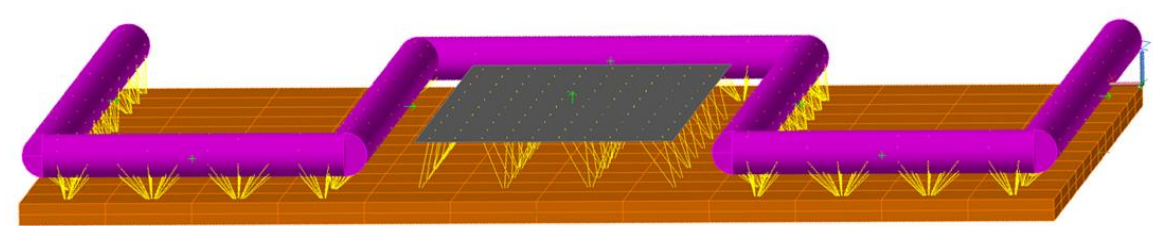

Figure 42. Thermal Desktop Conductance 
Radiative conductive paths utilize a vacuum medium, so no interface conductance was hand calculated. Thermal Desktop is able to accurately use the areas of the 3D models and the emittance from the input of the user to calculate complicated view factors and radiation paths between each piece of the model. To create a better radiation analysis two radiation groups are used in Thermal Desktop. The radiation groups tell TD what parts of the model radiate to each other. Run times were faster because the program did not have to analyze the view factor of every component, just the ones in a group. The first group included the interior of the shroud, the platen, the heater, and the component when used. The second group consisted only of the exterior shroud which was MLI optical properties and the ambient temperature node.

To summarize, a simple network of the conductance paths is shown in Figure 43. There are many more nodes in the model as shown in Figure 34, but the general concept is better explained with a simplified nodal network. The thermal model has one heat source, the heater or component, and two heat sinks. These heat sinks include the pipes and the "space" node which were modeled as boundary nodes with infinite thermal mass. There were two main radiation paths, the exterior of the shroud emits to the ambient temperature node and the interior component and platen radiate to the interior of the shroud. To denote a radiative conductance path, $G$, was given a negative value. The linear conductor is shown between the pipe and the platen. When a component was modeled there is another linear conductor between platen and component.

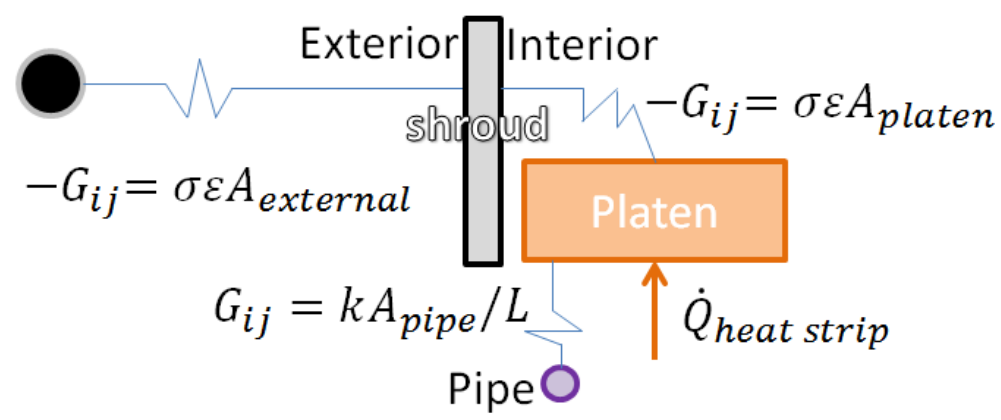

Figure 43. Conductance paths in the model 


\subsection{NODALIZATION SENSITIVITY ANALYSIS}

To test the thermal model various mesh sizes were used for the platen. The data was adapted from the platen and heater test without a shroud. The temperature of the upper left node was compared as the mesh refined. Comparisons are shown in Table 11 and visually shown in Figure 44. A mesh size of one inch was chosen because it was the courses mesh that was able to capture the temperature differences reflected in the testing apparatus. Thermocouples only needed to be accurate within a 1" square for the apparatus test. Thermal models can be so course that something like the platen is just one node. This isn't unreasonable from the mesh analysis results where the variance is less than a degree. There are no rules for thermal design meshing, it just depends on what needs to be analyzed and how much time or computation power is available to run the model.[3] More nodes can be used to extract more detailed information from a thermal model.

The thermal model was meant to be a representation of the testing apparatus. Verification of the model came from the test results in section 6 . The correlation of the model within $+/-3^{\circ} \mathrm{C}$ at each thermal couple lactation was able to prove the model was verified as a realistic representation of the apparatus.

Table 11. Mesh Size Comparison

\begin{tabular}{ccc}
\hline \hline Mesh Size & $\begin{array}{c}\text { Number of } \\
\text { Nodes }\end{array}$ & $\begin{array}{c}\text { Temp } \\
\left({ }^{\circ} \mathrm{C}\right)\end{array}$ \\
\hline $6 "$ & 4 & 159.9 \\
$4 "$ & 9 & 159.1 \\
$3 "$ & 16 & 159.3 \\
$2 "$ & 36 & 159.1 \\
$1 "$ & 144 & 159 \\
$0.5 "$ & 576 & 159 \\
\hline
\end{tabular}



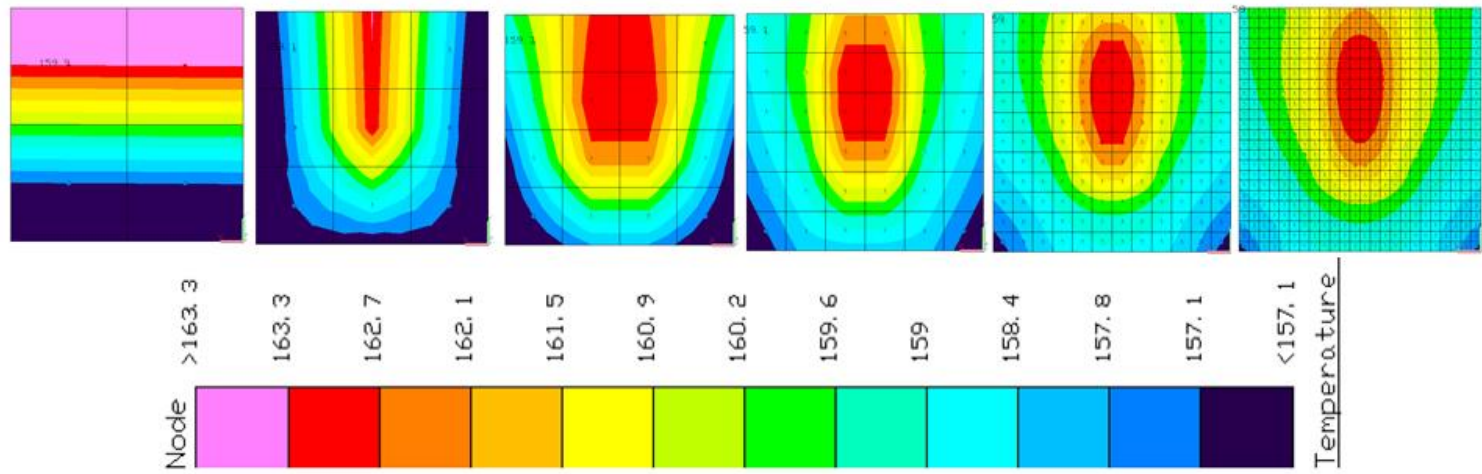

Figure 44. Mesh Sizes Compared 


\section{VALIDATION TESTING RESULTS}

\subsection{BLANKET TESTING}

To validate the thermal blanket method from section 2.2, a smaller piece of blanket was created and tested. Due to the new materials and the sewing method it was necessary to prove the blanket could insulate heat before a larger blanket was made. The design, test, and results are shown in this section, and the blanket creation is shown in the Appendix E.

Table 12. Materials Used in Blanket Test

\begin{tabular}{cc}
\hline \hline Material & Manufacturer and Properties \\
\hline 9 Layers of Mylar (5 by 8 inches) & Sheldahl, $\varepsilon=0.035$ \\
1 Layer Black Kapton (5" by 8") & Sheldahl, $\varepsilon=0.82$ \\
18 Layers Dacron (5 by 8 inches) & Nylon Tool From Micheal's \\
Nylon Thread, .01 inch diameter & Michael's \\
Strip Heater & McMaster Carr, 96 Ohms \\
Stainless Steel Wires & n/a \\
Power Supply & Powerstat Variable Autotransformer, Type 116B, Model \\
Kapton Tape & E1830 \\
Thermocouple (4) & n/a \\
\hline \hline
\end{tabular}

Once the blanket was made the four thermocouples were taped first with aluminum tape, then with kapton tape. Each pair had the same orientation with one on the outside and one on the inside of the blanket as close as possible to the same location. If there was no blanket the thermocouples would be on top of each other. There were two pairs for redundancy, so if one of the TC's failed, the other pair was able to provide data.

Wire was used to hang the strip heater to limit conduction as much as possible to the chamber. The platen was only used as a stand, there was no heating or cooling from it. The blanket wassecured around the strip heater with kapton tape. Schematic is shown in Figure 45. 


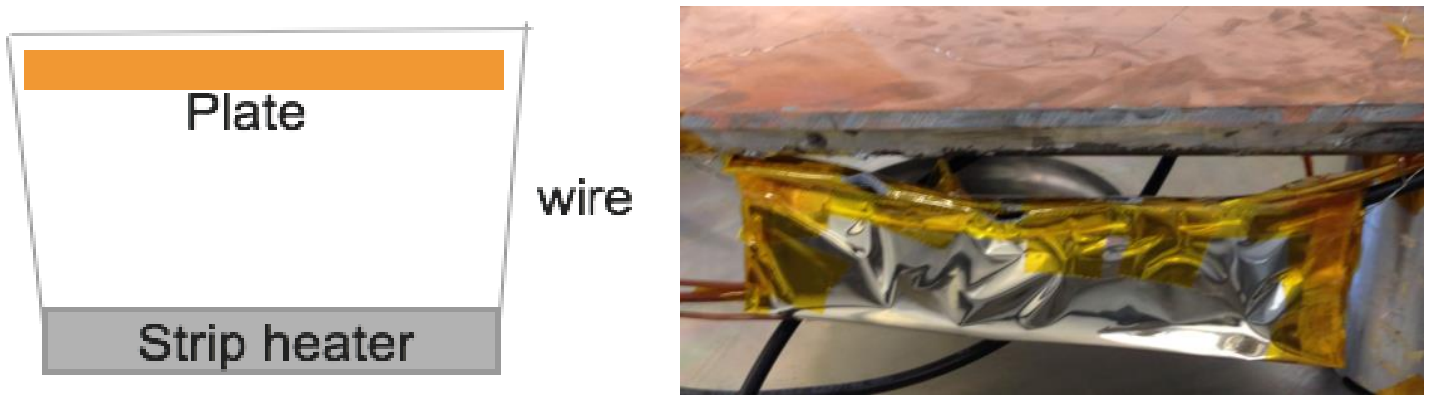

Figure 45. Blanket Test Apparatus

The vacuum was pumped down to $3 \times 10^{-6}$ Torr, then the power supply connected to the strip heater was turned on to supply 31 Volts. Using ohms law shown in Eq. 18 the power was derived from the known voltage and heat strip resistance.

$$
Q=V^{2} / R
$$

The 31 Volts equates to $10 \mathrm{~W}$. The temperature rose very fast as can be seen in Figure 46 so the voltage was lowered to $5 \mathrm{~V}$ on the power supply (0.26 Watts). Steady state temperatures were reached after 5.5 hours in vacuum.

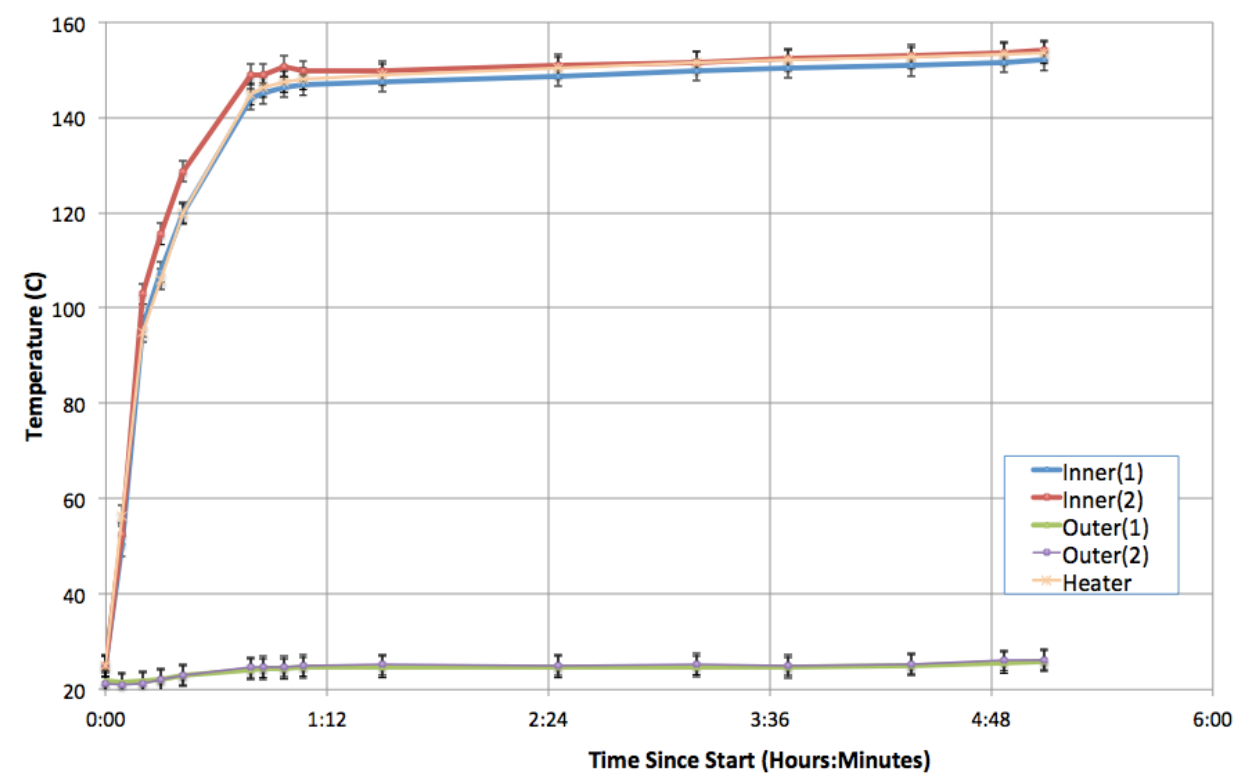

Figure 46. Thermal Blanket Verification Results

The two inner thermocouples and the heater thermocouple recorded temperatures all within the $\pm 2.2^{\circ} \mathrm{C}$ error bars. The same is true for the outer thermocouples which did not deviate far from ambient temperatures. Most extreme temperatures on the outside of the blanket were $26.3 \pm 2.2^{\circ} \mathrm{C}$ 
and $26.7 \pm 2.2^{\circ} \mathrm{C}$. Inner temperatures of the blanket recorded values up to $154.4 \pm 2.2^{\circ} \mathrm{C}$. From Eq. 8 and Eq. 9 from section 2.2 both the theoretical and experimental equivalent emittance were evaluated and compared as shown in Table 13. The total area used was $0.132 \mathrm{~m}^{2}$. For the theoretical approach, 10 layers were used with both sides having an emissivity of 0.035 . The black kapton was disregarded for this equation because it was only one layer and the equation does not consider different emittances for different layers.

\begin{tabular}{ccc}
\multicolumn{3}{c}{ Table 13. Thermal Blanket Test Results } \\
\hline \hline Calculation & $\mathrm{e}^{*}$ & Error \\
\hline Theoretical & $1.97 \mathrm{E}-3$ & $\mathrm{n} / \mathrm{a}$ \\
Experimental & $1.37 \mathrm{E}-3$ & $\pm 4.86 \mathrm{E}-5$ \\
Difference & $1.4 \mathrm{E}-3$ & $\pm 4.86 \mathrm{E}-5$ \\
$\%$ Difference & $35.9 \%$ & $\mathrm{n} / \mathrm{a}$ \\
\hline \hline
\end{tabular}

Although the percent difference between experimental and theoretical results were different by over $30 \%$, the test was still considered successful. The blanket experimental value of effective emissivity is even lower than the theoretical calculations, so the blanket performed better than expected. Both experimental and theoretical equivalent emissivity were within expected emissivity values of MLI.[3] Typical on orbit blankets have an $e^{*}$ of 0.03 due to the many angles and vent holes that keep the blankets from aligning perfectly.[3] The 30\% difference between the theoretical and experimental results was most likely due to the black kapton sheet on the inside of the blanket that emitted large amounts of heat back to the interior of the heater. By this logic the temperature inside the blanket enclosing is hotter for the experimental set up than the predicted theoretical calculations, which was exactly the case. The materials and sewing method proved to effectively insulate heat from the strip heater, so the larger blankets were created in a similar design.

\subsection{APPPARATUS TESTING AND DESIGN METHOD}

There are multiple aspects of the testing apparatus including chamber, blankets, ATS chiller, electrical wiring, and Swagelok piping, so each was carefully tested before construction of 
the shroud and assembly of the entire thermal vacuum chamber. Similar to the concept of spacecraft design each component was tested before putting each piece together. This allowed faults in each part to be fixed before assembly. Otherwise, it would have been significantly more difficult to find the problem after all the parts were put together. As testing progressed the design of the shroud slowly matured to the final product. Throughout the testing, multiple errors in the system were found and fixed so the final product would not include any confusion in the procedure. At the end of the design a streamlined process was created to work the TVAC chamber to perform thermal testing. Procedure is found in Appendix H.

Initially, the platen was tested alone with the heater because no test data was available from previous projects. This showed that the heat strip worked properly with the voltage supply and that the heater was thermally coupled to the platen. The test was done in ambient air to save time because pumping down to low vacuum takes roughly 24 hours. A single thermal couple or even a touch test showed the heat strip increased in temperature from the voltage supply. Each BNC cable was tested to make sure it was functioning properly and not shorting from a faulty connection. This was also done in ambient conditions with the chamber open.

Each one of the ten thermocouples was tested before every pump down. This was critical because the pump down and thermal test is very time consuming and losing more than one thermocouple of temperature data would be significant. After setting up the DAP system with all ten thermocouples they were attached to the system. This was done using a two tape method. First, aluminum tape was used to increase conductivity from the thermocouple to the platen for a better reading. Second, kapton tape is put over the aluminum tape to better secure it in place, shown in Figure 47. Once all TC's were in place on the testing apparatus a heat gun was used over each TC to test for a spike in temperature. A normal touch test did not apply enough heat to show up clearly and quickly on the DAP tables. The platen and heater were tested with results given in section 6.1 . 


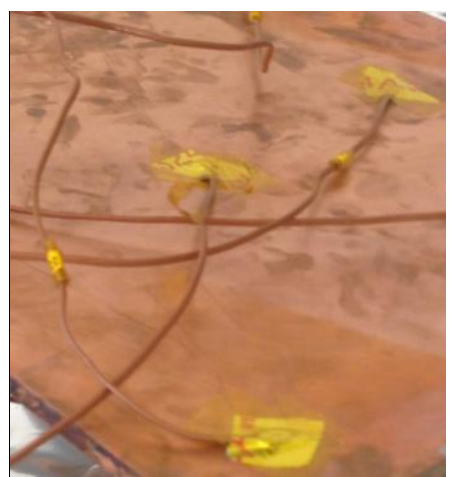

\section{Figure 47. Thermocouple Tape Down with Aluminum and Kapton Tape}

To test the heater further a blanket was placed around the entire platen with thermocouples on each side. No ATS Chiller coolant fluid was used because only the heater and larger blanket were to be tested. Unfortunately, the test was unsuccessful because half way through the test the thermocouples showed temperatures dropping in the chamber. After pumping down and opening the blanket the problem was clear. As shown in Figure 49 the heat strip burned through the blanket. Unlike the small blanket test, this heat strip was supplying a much higher heat load of 50V. It became obvious that direct contact of the blanket to the heat strip was not possible, so the copper shroud encircling the heat strip and the chiller piping was designed. The one good part about this test was that the hot temperatures of $+80^{\circ} \mathrm{C}$ lasted for over 5 hours before failing, so a lot of the brazing residue was able to outgass onto the failed blanket.

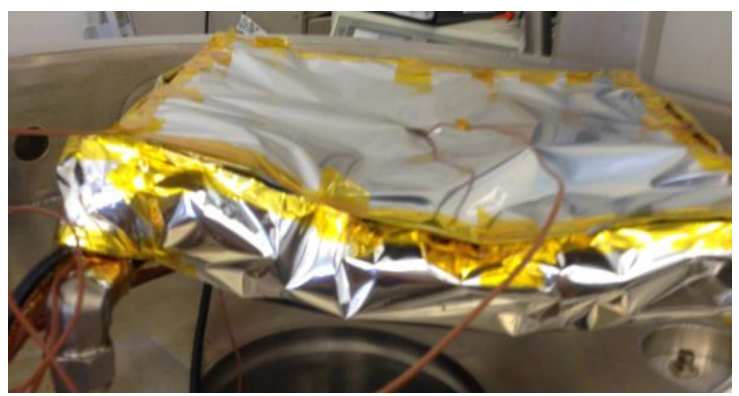

Figure 48. Large blanket test 


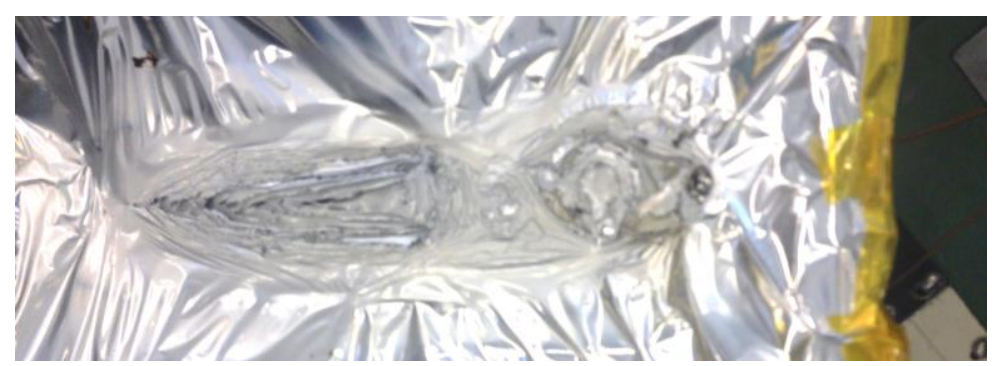

Figure 49. Large blanket test, burnt blanket

The shroud was created to enclose the heat strip to protect the blankets from the large heat dissipation of the heater. The results from the hot temperature test are given in section 6.2.

Once the shroud was tested at the hot end another test was done to verify the ATS Chiller cooling properties. There were significant problems with attaching the shroud and fluid pipes without causing leaks in the chamber while pumped down. The fix was finding a method to secure the platen that was clearly denoted in Appendix G. Another problem was keeping the chiller filled with enough liquid. The fill process and refill process was also documented for future use. The recorded results from the cold test are shown in section 6.3. 


\section{RESULTS}

\subsection{NO SHROUD HEATER TEST}

A test was performed of the platen and heater system without a blanket in order to verify the heater set up and compare to a blanketed platen. This test started the supply voltage at $100 \mathrm{~V}$, but had to reduce to $80 \mathrm{~V}(130 \mathrm{~W})$ because the temperature reached over $100^{\circ} \mathrm{C}$. There should not be a problem with going over $100^{\circ} \mathrm{C}$ as long as the Galden ${ }^{\circledR}$ Fluid lines are not filled with fluid. The thermal couple locations are outlined in Figure 50. Each thermocouple is a blue circle with the appropriate number next to it. The red dot thermocouples are placed underneath the platen. TC 13 has an asterisk because there were not enough DAP inputs to have it recorded automatically, instead manual temperatures were taken of the heater temperature to make sure the heater did not exceed maximum allowable temperatures of $480^{\circ} \mathrm{C}$. The maximum recorded value was $213^{\circ} \mathrm{C}$, well within the upper limits. TC 4,5 , and 6 are all directly connected to the stainless steel piping. Results are shown in Figure 51.

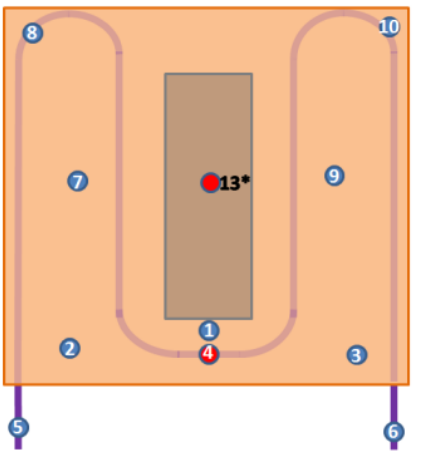

Figure 50. Heater Test Without a Shroud Thermocouple Locations 


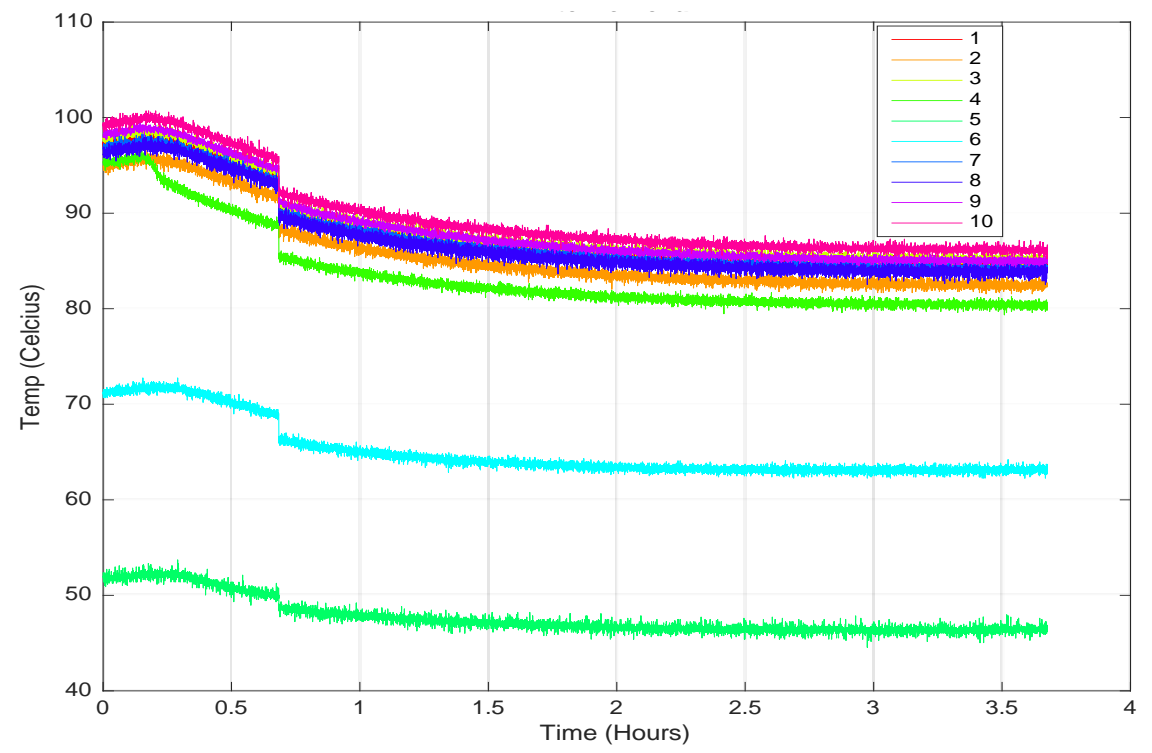

Figure 51. Heater Test Without a Shroud

The data stopped recording for a half hour, so the results are slightly shortened which can be seen at time 0.7 hours. This was one of the first tests conducted with the DAP system so there was still some work to be done to get the procedure streamlined. Regardless, the results were still valuable because the test takes a long time to reach steady-state temperatures. Each TC records the temperature every $1 / 33$ seconds so there is a lot of noise in the data. Most TVAC applications only need a recording every 1 second or longer, but this system has multiple uses in the Cal Poly Lab so it was used for this thesis, too. The noise recorded by the DAP encompasses about $\pm 1^{\circ} \mathrm{C}$, but the known $\mathrm{TC}$ error is $\pm 2.2^{\circ} \mathrm{C}$ so the noisy temperature is not considered a problem when analyzing the data.

As expected, TC 5 and 6 were the lowest temperatures because they were furthest from the platen. The conductive path was from the heater, to the platen, then through the piping. The hollow pipes were filled with ambient air and also connect to the ambient chamber walls which act as a giant sink. The sink creates a temperature gradient from ambient temperatures all the way to the heated pipes. TC 5 and 6 are along that path. TC 4 is the third coolest because it, too, is on the pipes instead of the conductive copper, but with a proximity significantly closer to the heater TC4 is warmer than TC 5 or 6 . To get a better look at the closer TC's see results in Figure 52. 
The order from coolest TC to warmest TC is TC 2, 8, 7, 1, 9, 3, 10 at steady-state. The largest recorded temperature was $86 \pm 2.2^{\circ} \mathrm{C}$. The values from coldest to warmest directly correlate with the distance from the heater. The hottest nodes in the model were closest to the heater with the cooler nodes closer to the Swagelok piping as shown in Figure 53. This correlates well with test results with only a few changes to the model that are documented in section 6.5. Including thermocouple error, the test steady state temperature variance across the plate from TC2 to TC10 is $80.3^{\circ}$ to $88.5^{\circ}$ for a total of $8.2^{\circ} \mathrm{C}$. The model was more uniform in temperature because the copper was modeled as a perfect homogenous plate and the piping conductivity to the platen did not vary along the thermal path. The trends were the same for the model and the test. The hottest part on the platen was above the heat strip, the platen does have variable temperature across it because of the localized heat load, and $80 \mathrm{~V}$ from the voltage supply to dissipate $130 \mathrm{~W}$ at the heat strip provided a steady-state temperature of at most $88^{\circ} \mathrm{C}$. The test was successful because the model was better correlated for other tests and there was strong reasoning to create a shroud to help insulate heat and reduce the variable temperature across the plate.

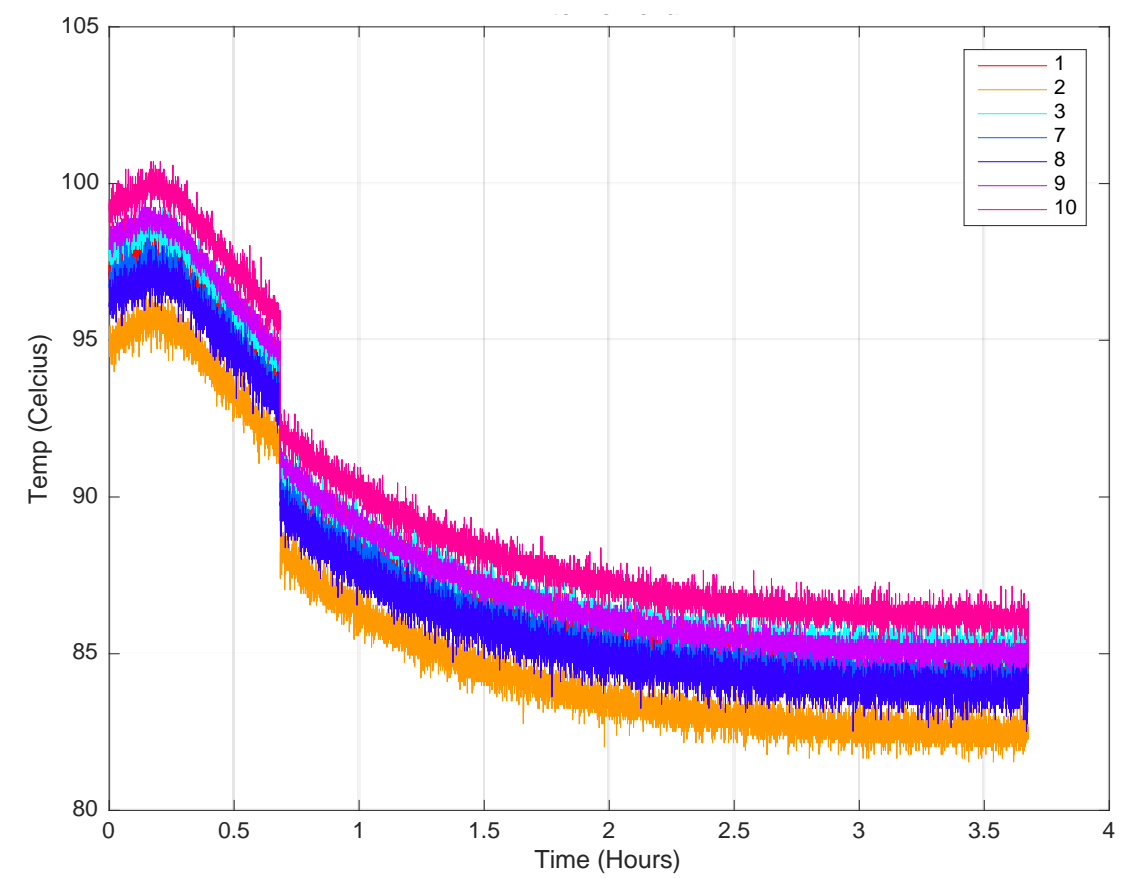

Figure 52. Detail on the Warmer TCs of Heater Test without a Shroud 57 


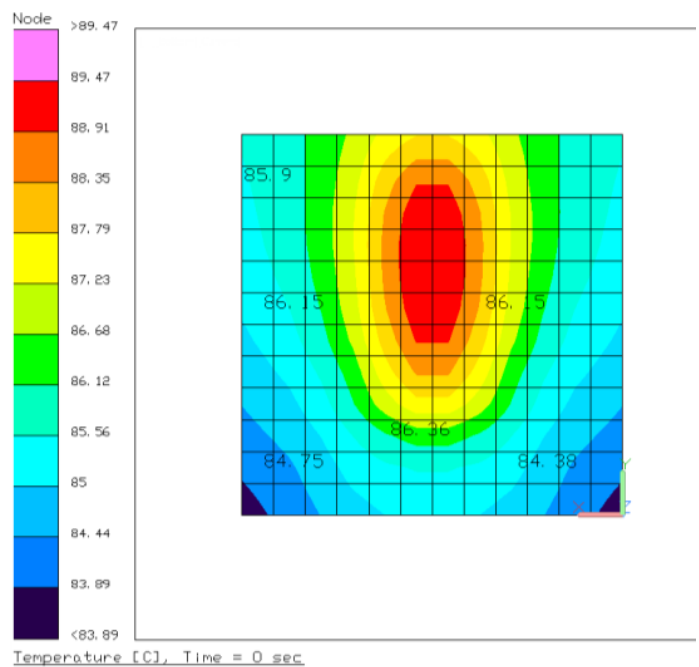

Figure 53. Thermal Desktop Model Heater with No Shroud

\subsection{BAKE OUT TEST}

The improved shroud from section 5.2 was tested to prove the design decreased variability across the platen when compared to the platen heater test without a shroud. The test lasted almost 42 hours to get a good reading on the steady-state temperatures. Throughout the test, variable voltages were used in order to keep the temperatures below $100^{\circ} \mathrm{C}$, shown in Table 14. The hottest temperature during the test was a peak temperature of $130 \pm 2.2^{\circ} \mathrm{C}$. The Galden ${ }^{\circledR}$ Fluid was not connected to the chamber with the Swagelok piping, so there was no fear of harming the ATS chiller system or boiling off the expensive fluid. 
Table 14. Bake Out Voltage Supply Inputs

\begin{tabular}{ccc}
\hline \hline $\begin{array}{c}\text { Time Since } \\
\text { Start (hr) }\end{array}$ & Voltage & Watts \\
\hline 0 & 100 & 208 \\
1.5 & 80 & 133 \\
2 & 70 & 102 \\
2.1 & 60 & 75 \\
2.2 & 50 & 52 \\
2.4 & 40 & 33 \\
2.5 & 30 & 19 \\
4.5 & 0 & 0 \\
6.8 & 40 & 33 \\
7.4 & 20 & 8 \\
7.5 & 15 & 5 \\
20.7 & 40 & 33 \\
21 & 30 & 19 \\
\hline \hline
\end{tabular}

The thermal couple locations are outlined in Figure 54. Each thermocouple is a blue circle with the appropriate number next to it. The red dot thermocouples are placed underneath the platen. TC 13 has an asterisk because there were not enough DAP inputs to have it recorded automatically, instead manual temperatures of the outer shroud temperature were recorded to test the effectiveness of the MLI, this TC temperature graph is show in Figure 60. TC 4 was directly connected to the stainless steel piping. At the top of the shroud in the center was placed TC 1,2, and 13 which is demonstrated in Figure 54. The placement was used to better understand the temperature distribution at the furthest point from the heater and to verify the thermal blanket effective emittance. The rest of the TC's were distributed across the platen, but TC 8 failed during the test and is not included in the thermal results. The failed TC was cut in a previous project so that the metals at the end were no longer secured together. An attempt to solder the TC back together was made, but soldering TCs is extremely difficult because of the type of metal. TC 8 was beyond repair and therefore permanently retired from use in favor of a more reliable TC. Temperature testing results are shown in Figure 60 and Thermal Desktop results are shown in Figure 56. 


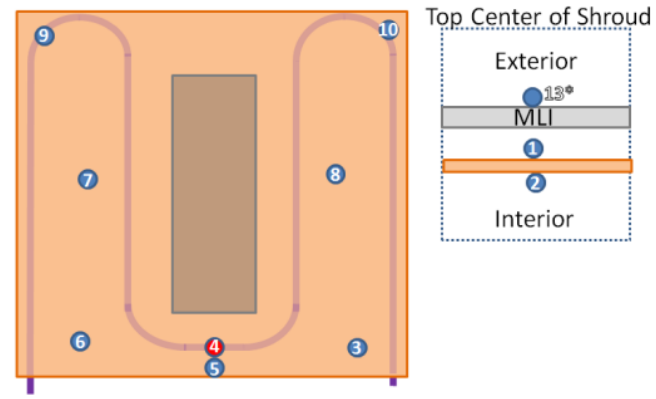

Figure 54. Bake Out Shroud Test Thermocouple Locations

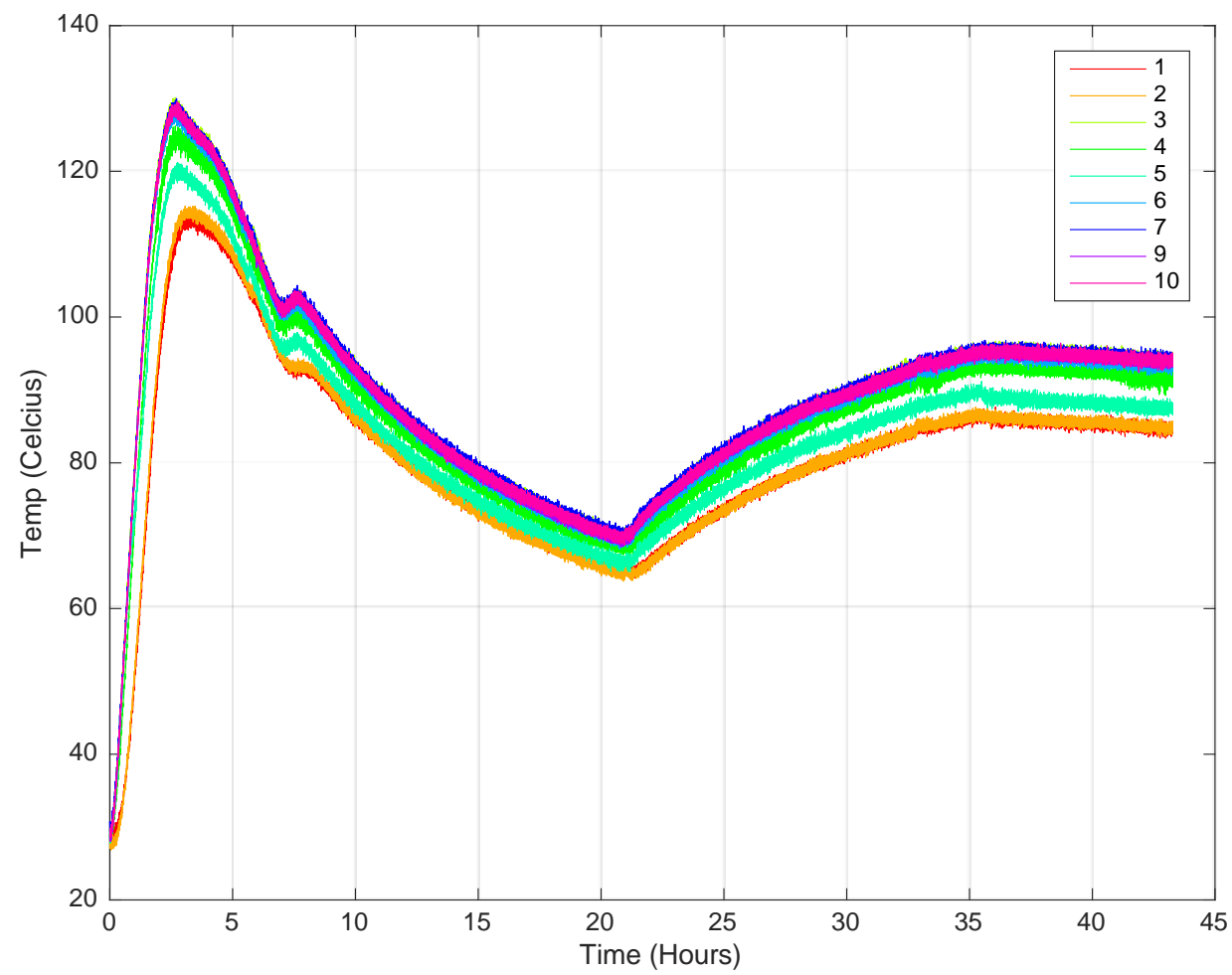

Figure 55. Bake Out Thermal Test Results 


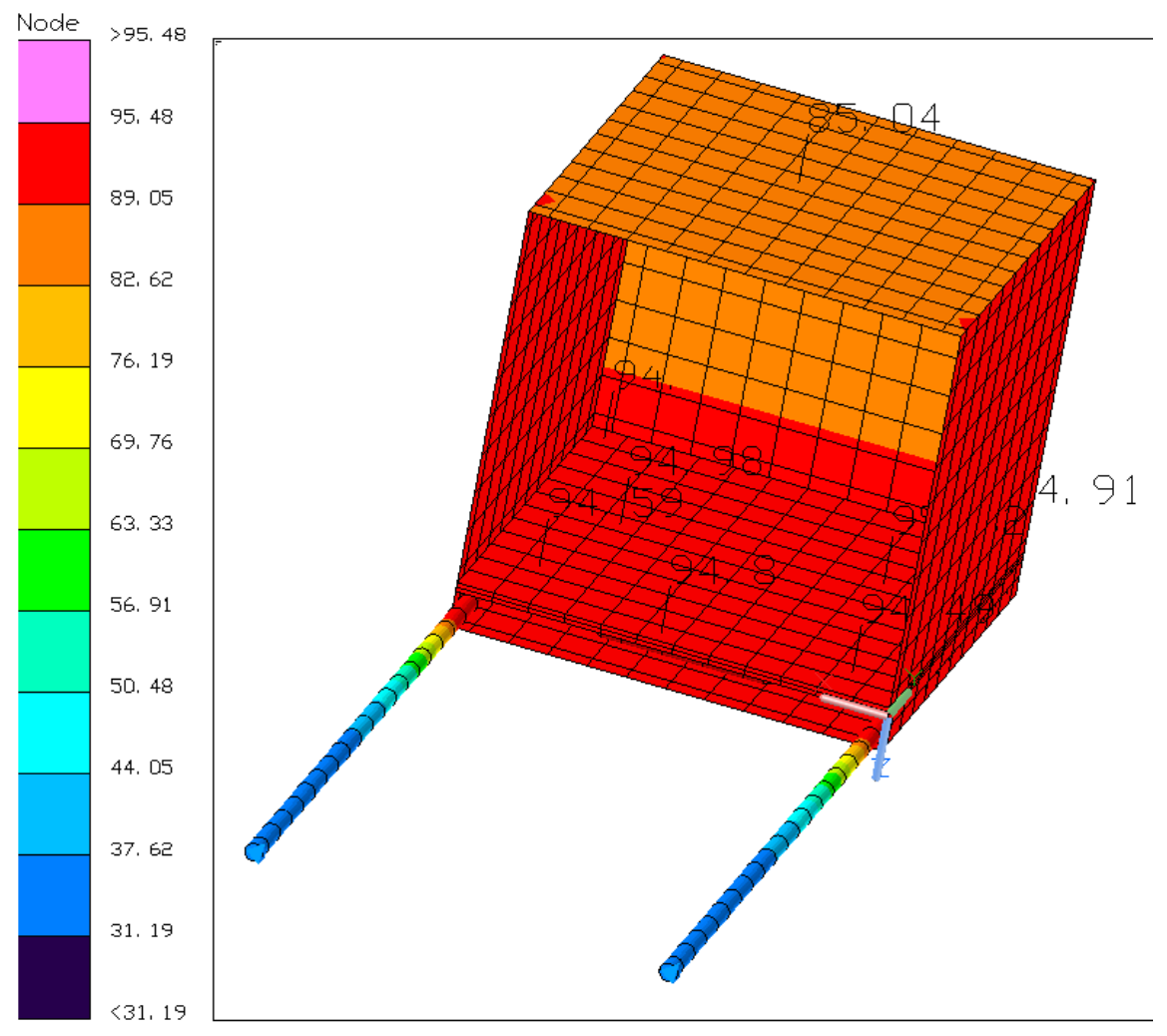

Temperature $[\mathrm{C}]$, Time $=0$ sec

Figure 56. Bake Out TD Results, Shroud and Pipes

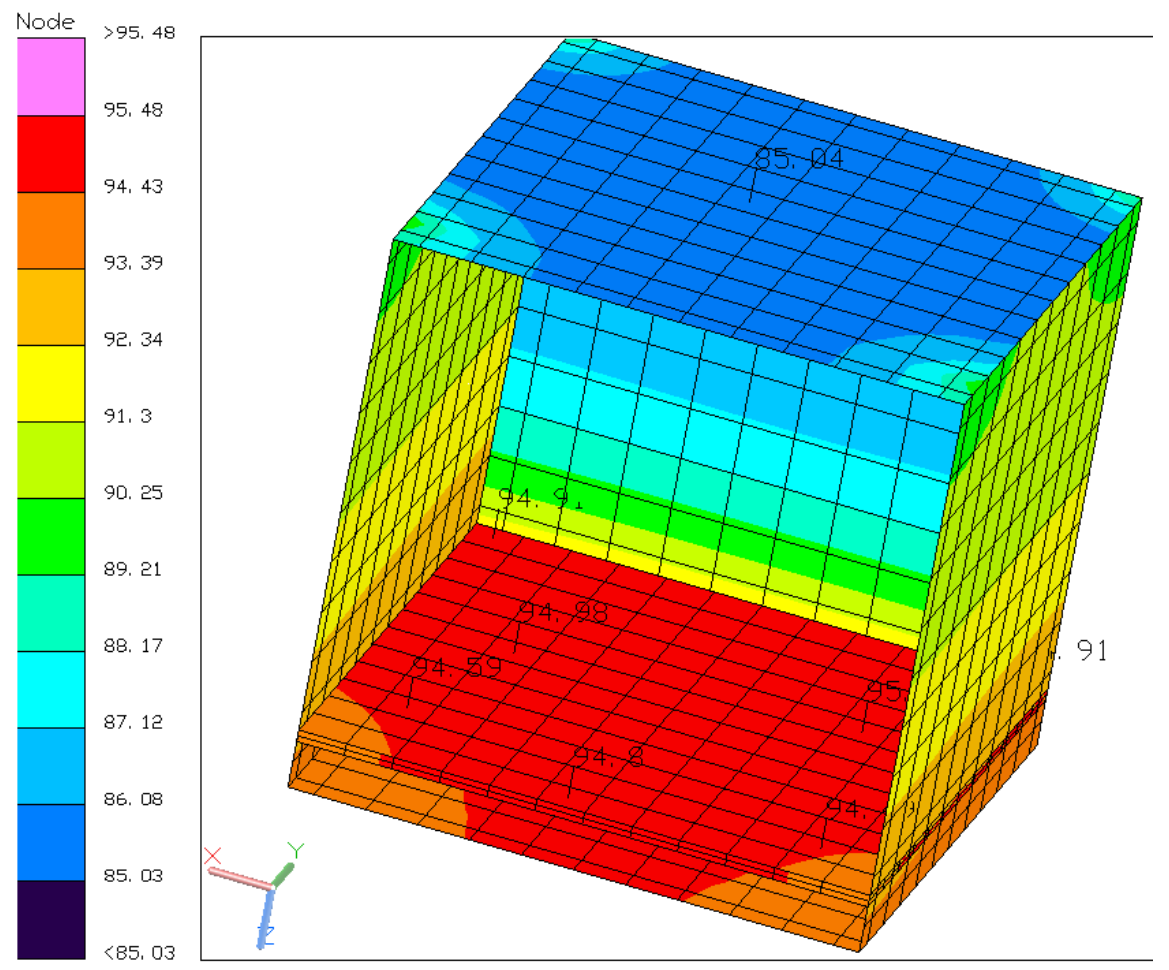

Temperature [C], Time $=0$ sec

Figure 57. Bake Out TD Results, Shroud 


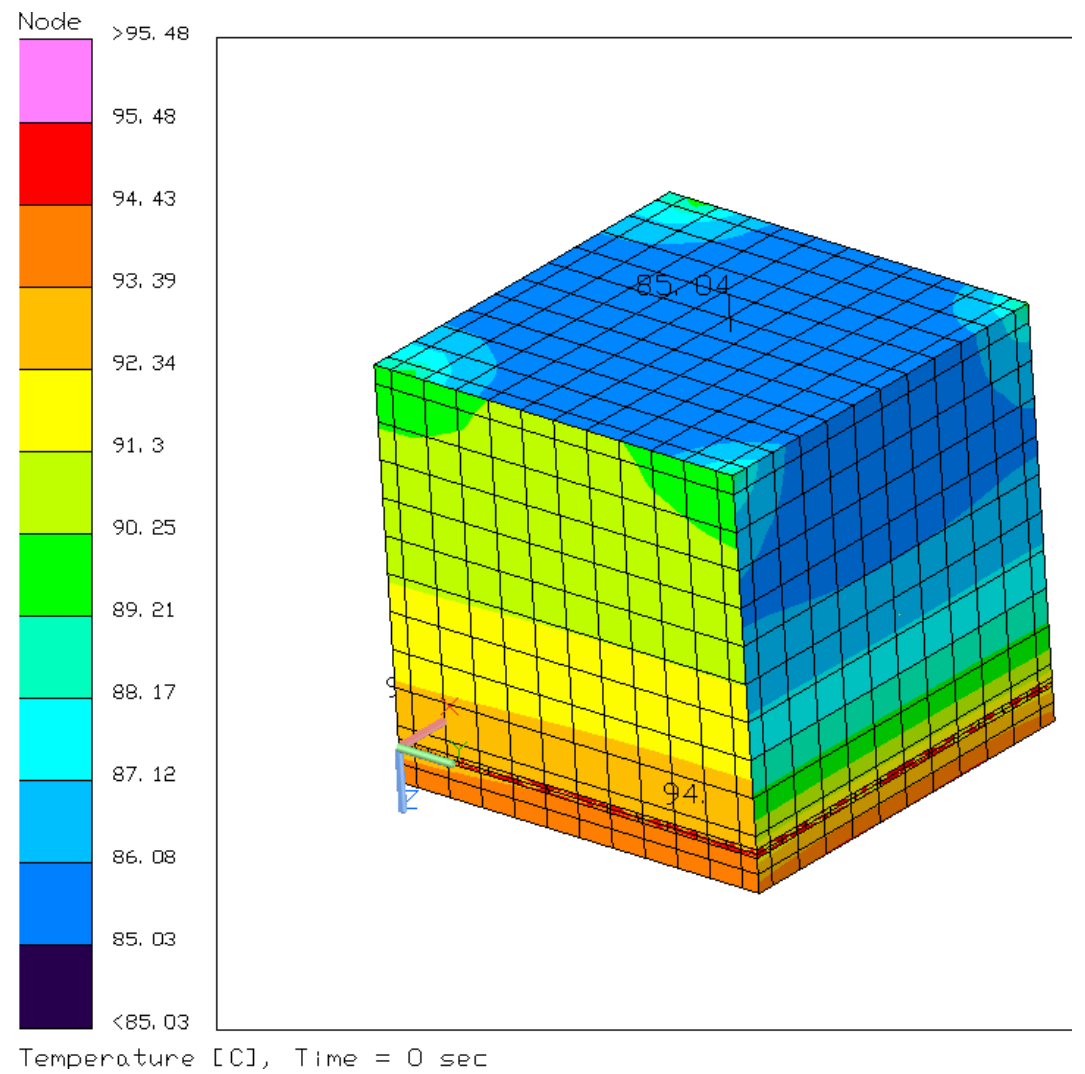

Figure 58. Bake Out TD Results, Back

The dips and valleys of the temperature plot in Figure 55 directly correlate with Table 14.

After 4.5 hours the entire heater system was turned off in an attempt to cool the shroud down faster, but the MLI insulation slows down the process. Eventually, the power was turned back on and set to $15 \mathrm{~V}$ for an overnight test. The system could have been placed at $30 \mathrm{~V}$ at that point, but multiple people were not involved in the test so shifts to watch the chamber overnight were not possible. The lower set point of $15 \mathrm{~V}$ was much safer for a long period of unmonitored time. A set point of $30 \mathrm{~V}$ had a much slower climb to steady state than $100 \mathrm{~V}$ set point. The test showed that a high voltage supply at first and then backing off could decrease time to steady state. The test was able to show how the system responds to the different voltage supplies with the MLI blanketing. Maximum bake out temperatures depend on what materials are inside of the shroud. Adjustments 
to the supply voltage change the final steady state temperature, so a diligent watch and knowing how to "kill" the heater power was important to not damage the shroud or the testing material.

The previous test that did not have a shroud was set to $80 \mathrm{~V}(133 \mathrm{~W})$ to reach $83^{\circ} \mathrm{C}$ steady-state temperatures. The shroud test was set to $30 \mathrm{~V}(19 \mathrm{~W})$ to reach similar temperatures. So, the initial start of $100 \mathrm{~V}$ with a shroud increased temperatures of the platen significantly more than the non-shrouded set up. Unfortunately, at approximately 35 hours, the temperature graph shows a change in the steady climb in temperature which did not correlate to a voltage supply change. After stopping the test and pumping down to investigate the lower temperatures it was determined that the back MLI blanket had fallen off creating a significant heat leak. The corner that fell down is shown in Figure 59. More caution was used when securing the blanket for further testing. The results were not scrapped because the bake out test still showed a long time span with temperatures over $60^{\circ} \mathrm{C}$.
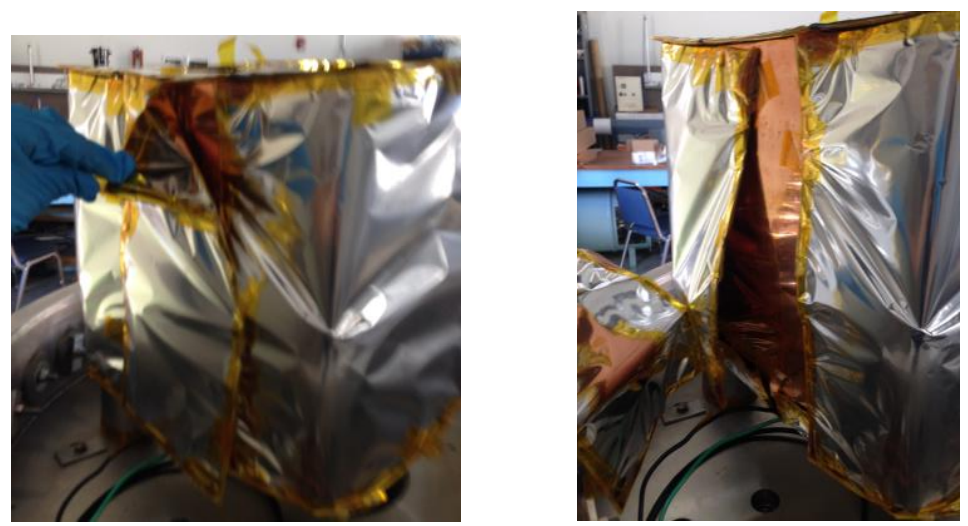

\section{Figure 59. Back Blanket That Came Off During Bake Out Test}

The MLI was able to insulate effectively because the external blanket only varied a total of $5 \pm 2.2^{\circ} \mathrm{C}$. It was a very hot summer day in the Cal Poly lab so the ambient temperature was about $32^{\circ} \mathrm{C}$, as seen in the beginning of the graph in Figure 60 . The temperatures dipped below $32^{\circ} \mathrm{C}$ at night because the ambient temperature was lower. 


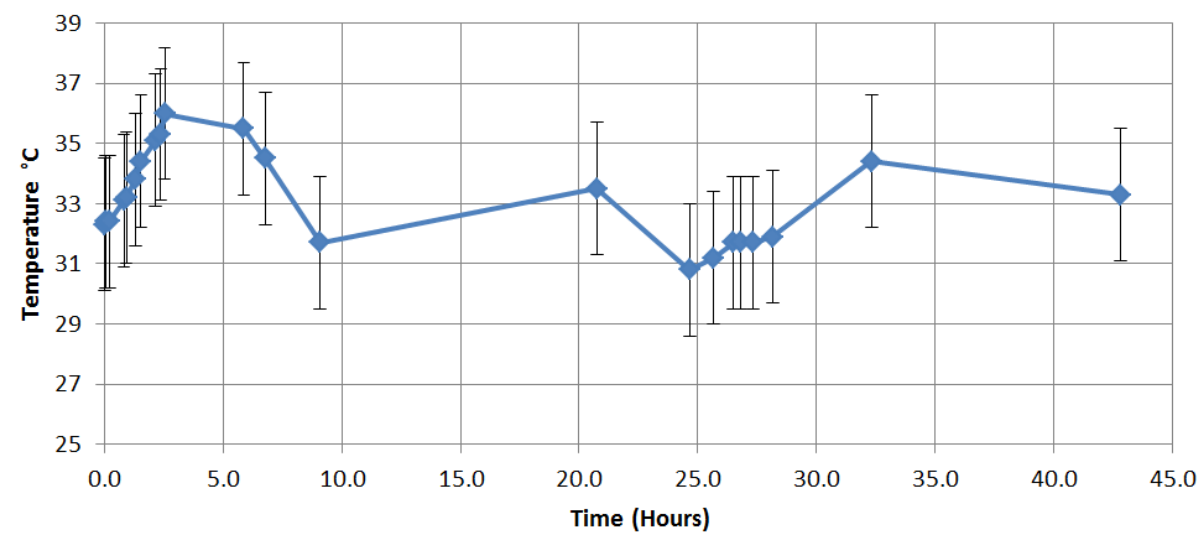

Figure 60. Bake Out Thermal Test Results of TC 13 on MLI Exterior

The bake out test was able to reach significantly higher temperatures than the cycling test or any test using the platen with the ATS Chiller. Due to the ideal gas law, as the temperature increased in the chamber, so did the pressure. For this reason, the pressure of the vacuum chamber was recorded from an ion gage throughout the bake out test in order to verify that pressures were within the NASA GEVS requirement throughout the duration of the test(below 10${ }^{5}$ Torr, see section 1.3 for more details). As can be seen in Figure 61 the pressure was well below the requirements and even went as low as $5.4 \times 10^{-7}$ Torr. After 0.1 hour of operation the chamber spiked to $1.2 \times 10^{-5}$ Torr, then one more spike occurred at 0.9 hours to $1.2 \times 10^{-5}$ Torr. Both spikes were within the first hour when the supply voltage was $100 \mathrm{~V}$ and the pressure was only just below $1 \times 10^{-5}$ Torr at the start of the test. Given enough time, the plot shows 10 hours, the pressure equalized to a low pressure without any spikes from the higher temperature. Pressure during all of the other tests was monitored, but not recorded. High temperatures in the vacuum chamber did not hinder the vacuum pump from reaching pressures below $10^{-5}$ Torr. 


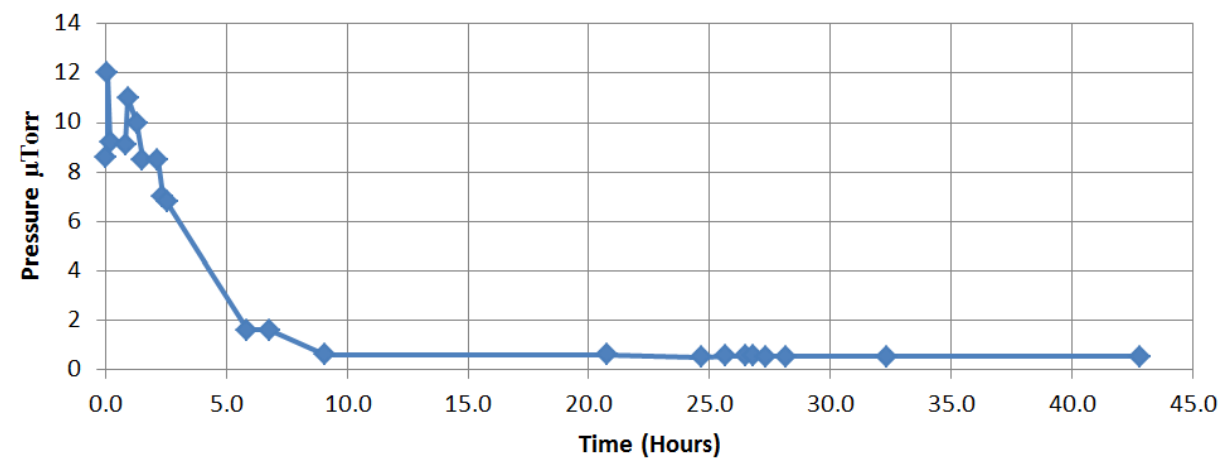

Figure 61. Vacuum Chamber Pressure during Bake Out Test

A closer look at the temperature graph in Figure 62 shows that TC1 and TC2 were cooler than the main group of TC's on the platen by $10 \pm 2.2^{\circ} \mathrm{C}$ because those TCs were at the top of the shroud. Next, TC5 was on the edge of the platen closest to the shroud opening. Without the solid copper wall to absorb heat from the heater this side of the platen leaked much more heat out through the MLI. TC4 was also cooler than the other TC's on the platen because it was also facing the front, but it was located under the platen where the heater was, so it was warmer than TC4. All of the other TC's are very close to the same temperature; $94 \pm 2.2^{\circ} \mathrm{C}$. Along the platen all TC temperatures were within error of each other. This is an improvement from the previous hot test without a shroud which had a variance of over $8^{\circ} \mathrm{C}$. The shroud proved to decrease the variability over the platen and the bake out test results shows that any instrument should be positioned at the back of the shroud closest to all copper walls. 


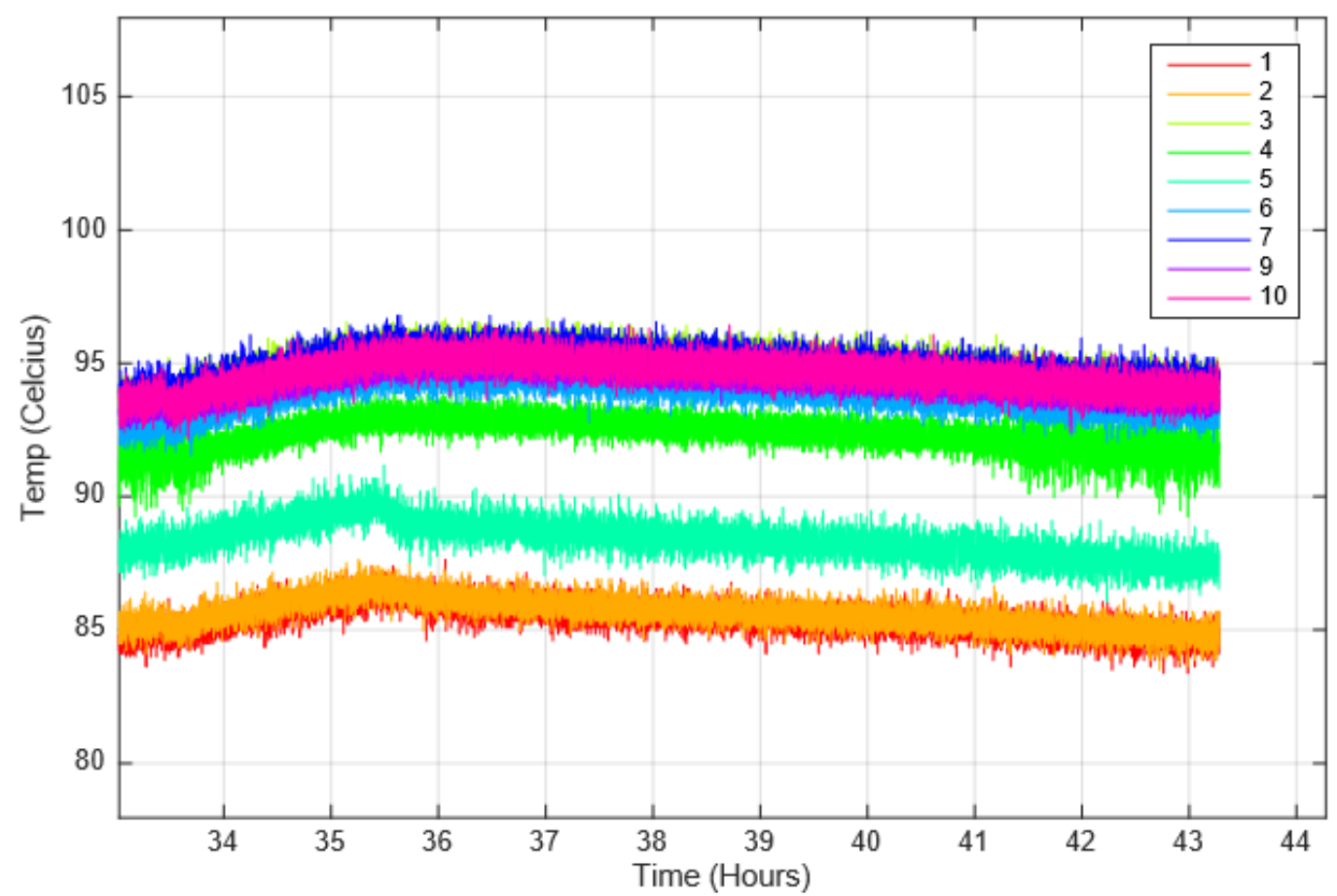

Figure 62. Detail of Steady-State Bake Out Results

\subsection{ATS CHILLER COLD TEST}

The improved shroud was tested with the ATS Chiller at the cold setting before doing the full cycling test. The test showed how much power the ATS Chiller is able to dissipate with the cooling Galden ${ }^{\circledR}$ Fluid through the pipes. Throughout the test variable set points and heater power were used. These are outlined in Table 15.

Table 15. Cooling ATS Chiller Test

\begin{tabular}{cccc}
\hline \hline $\begin{array}{c}\text { Time Since } \\
\text { Start (hr) }\end{array}$ & Set Point $\left({ }^{\circ} \mathrm{C}\right)$ & Voltage & Watts \\
\hline 0 & -20 & 0 & 0 \\
0.6 & -20 & 50 & 52 \\
0.8 & -20 & 120 & 300 \\
1.9 & -38 & 120 & 300 \\
5 & -38 & 0 & 0 \\
\hline \hline
\end{tabular}

The thermal couple locations are outlined in Figure 63. Each thermocouple is a blue circle with the appropriate number next to it. TC 4 was directly connected to the stainless steel piping. TC2 was secured to the top-center of the shroud on the interior of the copper. TC1 was 
located on the stainless steel piping for the inlet flow and TC4 is on the piping at the outlet. The rest of the TC's were distributed across the platen. Overall temperature results are shown in Figure 60 and the detailed steady-state temperature is shown in Figure 65.

Unlike the heater test, the ATS Chiller changed the temperature in minutes instead of hours. This was due to the refrigeration cycle that uses the convective heat transfer of the Galden® Fluid to quickly take heat away from the copper platen. The hot bake out test relied on conduction and radiation only. The temperature plot in Figure 64 is perfectly aligned with the voltage and set point table and the ATS Chiller was very effective in absorbing $300 \mathrm{~W}$ from the strip heater. The heater could not produce more heat dissipation than the $300 \mathrm{~W}$, but if a component is more than $300 \mathrm{~W}$ the ATS Chiller is rated for $500 \mathrm{~W}$. TC2 was always much slower to reach steady state because the location was far away from the fluid lines and the conductive path was through very thin copper sheets. As expected, when the heater was not powered on the ATS Chiller was able to reach temperatures closer to the set point. The difference between the powered and unpowered set points was $2 \pm 2.2^{\circ} \mathrm{C}$, but the difference decreases with less heat dissipation.

While the heater was on the temperature variance across the plate was $-34 \pm 2.2^{\circ} \mathrm{C}$ to $37 \pm 2.2^{\circ} \mathrm{C}$, but when it was off the platen $\mathrm{TC}$ temperatures were nearly indistinguishable, all within $-38 \pm 2.2^{\circ} \mathrm{C}$. This shows that the brazed stainless steel pipes were conducting evenly all along the copper for a very even temperature distribution. That does not mean the conduction was exactly the same along the piping. Rather, the conduction was high enough and the pipe covered enough of the platen that the temperature was evenly distributed for the test. TC4 and TC1 were the lowest temperatures when the heater was on because they were positioned directly on the pipe. Also interesting to note is that the temperature had peaks and valleys of $\pm 1^{\circ} \mathrm{C}$ on the pipe because the ATS Chiller was continuously heating and cooling the Galden® Fluid with a control loop based on the controller set point. The other temperatures do not show as much fluctuation 
because the thermal mass of the platen is large compared to the thermal mass of the pipes.. The TC closest to the opening of the shroud was the furthest from the set point compared to the other TCs on the platen. TC8 and TC10 were closest to the back of the shroud and were also the coldest across the platen. They are also positioned on top of the platen directly over the pipes. So, like the bake out test, components should be placed towards the back of the shroud.

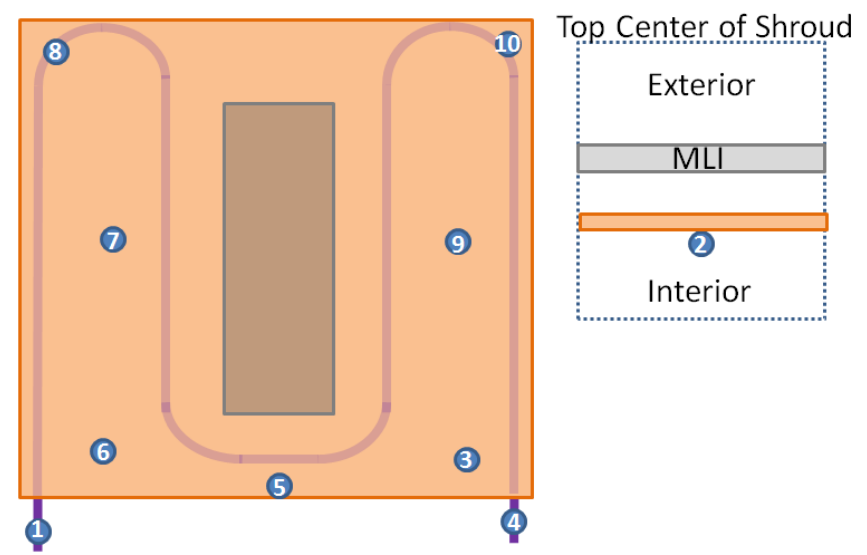

Figure 63. Cold ATS Chiller Test Thermocouple Locations

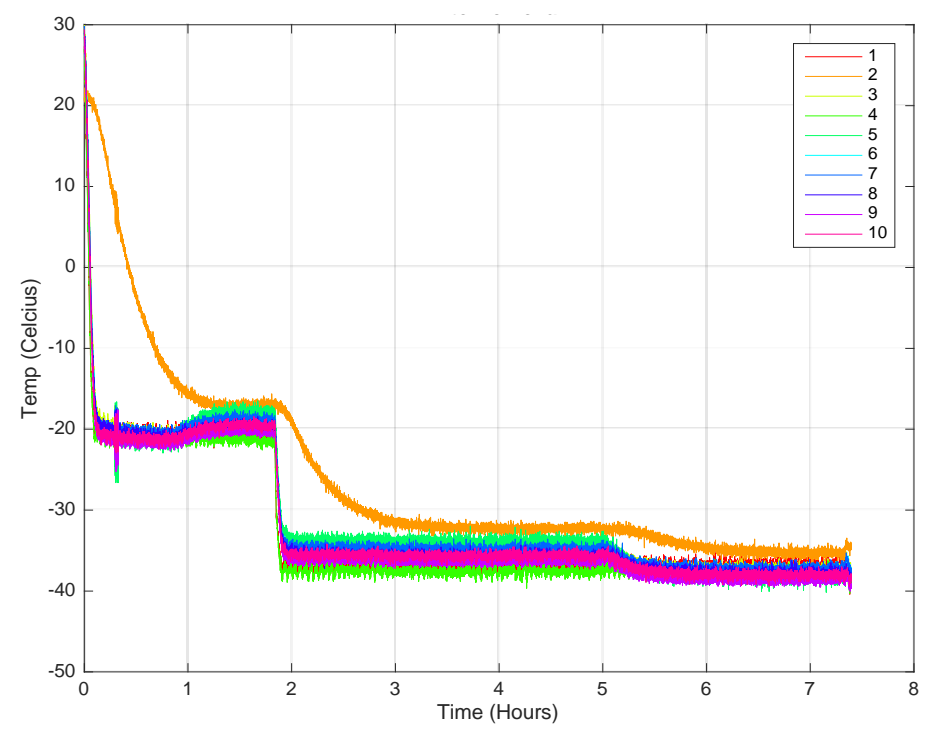

Figure 64. Cold Test ATS Chiller Results 

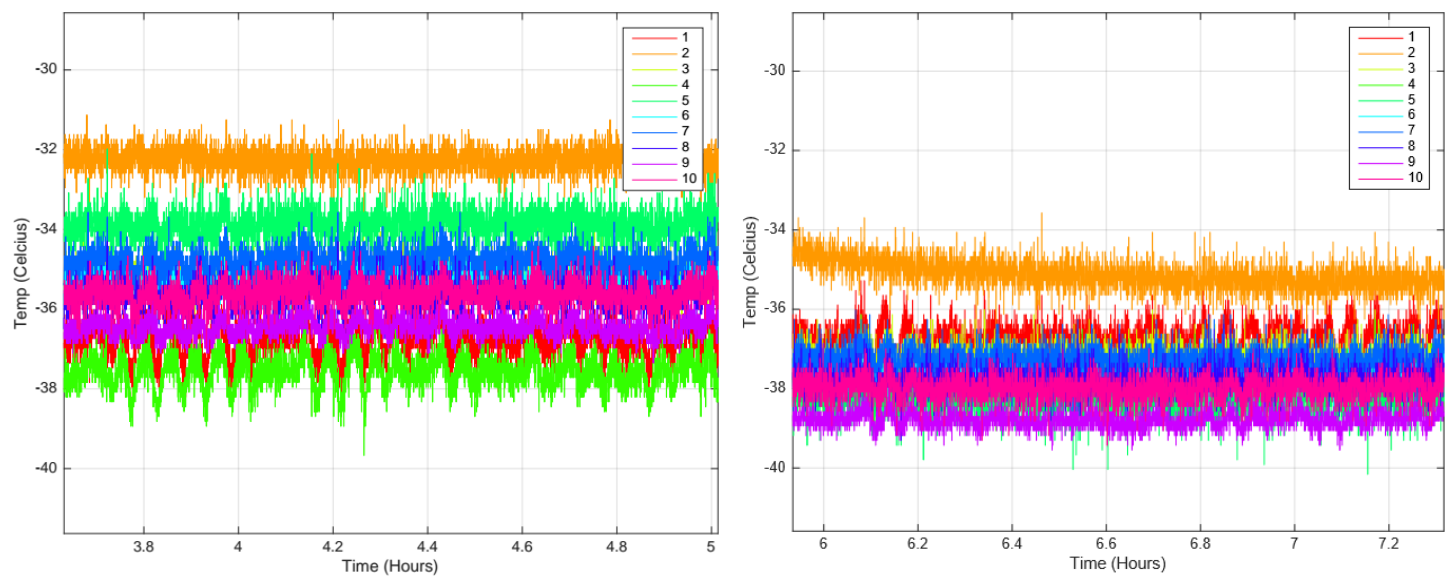

Figure 65. Detailed Cold Test Results, 300W Heater (left) and 0W (right)

\subsection{THERMAL CYCLING TEST}

The final test was implemented to prove the TVAC system was reliable over long periods of time and could be implemented for spacecraft component testing. In accordance with the NASA GEVS document, a thermal cycle component test was performed by doing three cycles where one cycle has a 4 hour duration at each extreme. Limits were set to the maximum allowable limits of the ATS Chiller $+60^{\circ} \mathrm{C}$ to $-40^{\circ} \mathrm{C}$. The heat strip was turned on to a maximum power of $300 \mathrm{~W}$ to simulate a high power component and to test the capabilities of the ATS Chiller over long periods of time. The total time of the test was 31 hours and each cycle duration is shown in Table 16. Also included in the table are the various set points that were used to cycle the TVAC chamber. For most of the test the heat strip is at maximum power, but for clarity the voltage of the power supply and expected power output are shown in the table. At the beginning of each set point change a few small temperature steps up or down were taken every 2-5 minutes to either slowly raise or lower the temperature. This was done to keep the ATS Chiller within capacity so no alarms are set off by the Watlow Controller.[23] The small temperature steps can be seen in the temperature plots, but are not specifically stated in the set point table.

During the first hot cycle the Watlow controller set point was changed from $60^{\circ} \mathrm{C}$ to $58^{\circ} \mathrm{C}$ because the pressure in the chamber was $1 \times 10^{-5}$ Torr. This is still within the guidelines, but 
to ensure the pressure limit wasn't breached the test set up was lowered in temperature by two degrees Celsius. For consistency, the heater cycles were left at $58^{\circ} \mathrm{C}$ for the duration of the test. This error could have been avoided by pumping down for 24 hours before starting the test. . The cold extreme set point changed from $-40^{\circ} \mathrm{C}$ to $-38^{\circ} \mathrm{C}$ because the ATS Chiller was flashing the warning light for "high capacity". The warning could be partly from the hot ambient temperature in the lab from both the summer weather and the vacuum chamber components. The cryopump and the ATS Chiller both expel heat during operation. The other possibility is that the ATS Chiller has difficulty reaching the maximum low temperature of $-40^{\circ} \mathrm{C}$ and must always be set to a minimum of $-38^{\circ} \mathrm{C}$.

Table 16. Thermal Cycle Test Set Points

\begin{tabular}{cccc}
\hline \hline $\begin{array}{c}\text { Time Since } \\
\text { Start }(\mathrm{hr})\end{array}$ & Duration $(\mathrm{hr})$ & Set Point $\left({ }^{\circ} \mathrm{C}\right)$ & Power $(\mathrm{W})$ \\
\hline 0 & .8 & -38 & 0 \\
.8 & 4 & -38 & 300 \\
4.8 & 2.2 & 60 & 300 \\
7 & 4 & 58 & 300 \\
11 & 5 & -38 & 300 \\
16 & 6.5 & 58 & 300 \\
22.5 & 4.5 & -38 & 300 \\
27 & 4 & 58 & 300 \\
\hline \hline
\end{tabular}

The thermal couple locations are outlined in Figure 66. Each thermocouple is a blue circle with the appropriate number next to it. TC9 and TC4 were directly connected to the stainless steel piping to capture the inlet and the outlet pipe temperatures. TC2 was secured to the top-center of the shroud on the interior of the copper. The rest of the TC's were distributed across the platen. Overall temperature results were shown in Figure 67 and the detailed maximum and minimum temperatures were shown in Figure 68. TC1 is omitted from the results because the TC fell off of the platen.

Both the hot and cold set points by the ATS Chiller set point temperatures on the platen within a matter of minutes. The Watlow Controller heats or cools the Galden® Fluid in the ATS 
Chiller to keep a steady temperature, unlike the bake out test that requires constant adjustment of the voltage supply on the heat strip. The ATS Chiller is able to heat up to $60^{\circ} \mathrm{C}$ with little monitoring which is a much more reliable system for testing. Furthermore, during the cycle test the high heat load on the platen did not inhibit the ability of the chiller to reach set temperatures. The group of TC's on the platen included TC3, TC5, TC6, TC7, and TC8. At both the hot and cold extremes the TC's on the platen only varied by $3 \pm 2.2^{\circ} \mathrm{C}$. This was a very low variability across the platen for such a large heat load. At both the hot and cold extremes TC5 was always the warmest on the platen and TC8 was always the coldest even though TC5 was close to the opening and TC8 was at the back of the shroud. This shows that the ambient temperature had little effect inside the shroud when compared to the $300 \mathrm{~W}$ heater and the extreme temperatures of the ATS chiller. As seen in the heat transfer equations it would be expected that radiation through MLI should be less of an impact on temperature than the conduction and convection through the pipes and platen.

TC4 and TC9 on the pipes were both lower in temperature by $1 \pm 2.2^{\circ} \mathrm{C}$ than the platen TC's at the hot and cold end. This was to be expected because the fluid must be colder than the platen temperature in order to absorb the heat dissipation on the platen. TC2 was on the shroud so it was slower to respond to the temperature change of the platen and it did not get as hot or as cold as the platen temperature. Based on TC2 the shroud was able to cool or heat to the ATS chiller set point to within $1 \pm 2.2^{\circ} \mathrm{C}$. 


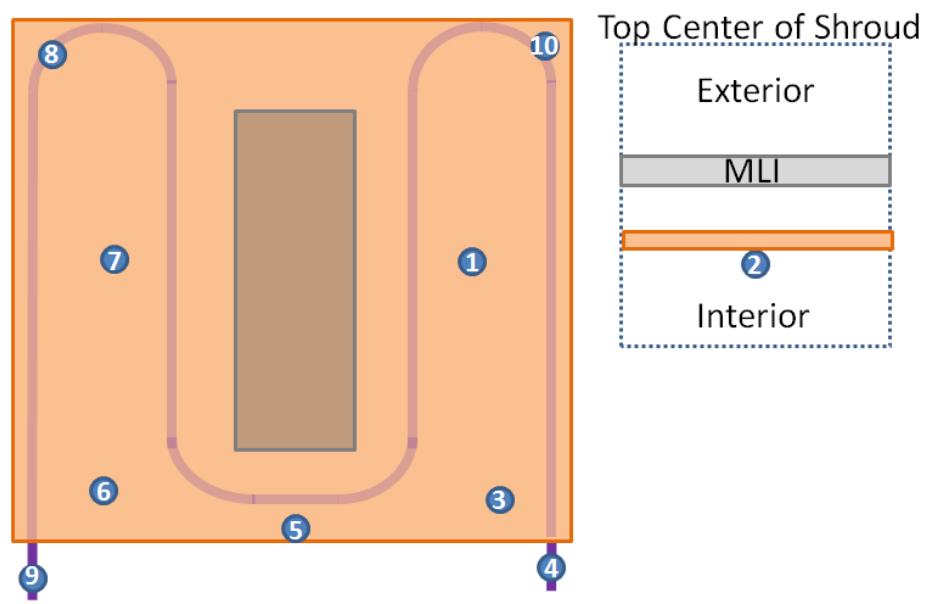

Figure 66. Cycle ATS Chiller Test Thermocouple Locations

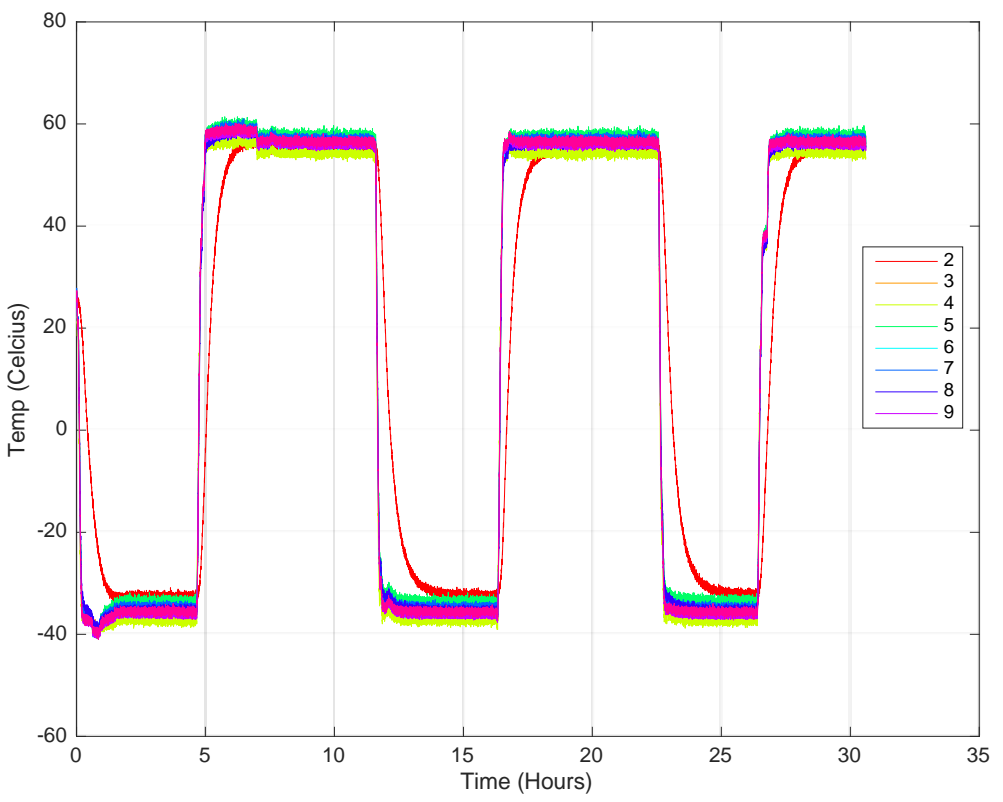

Figure 67. Thermal Cycle Test Temperature Results
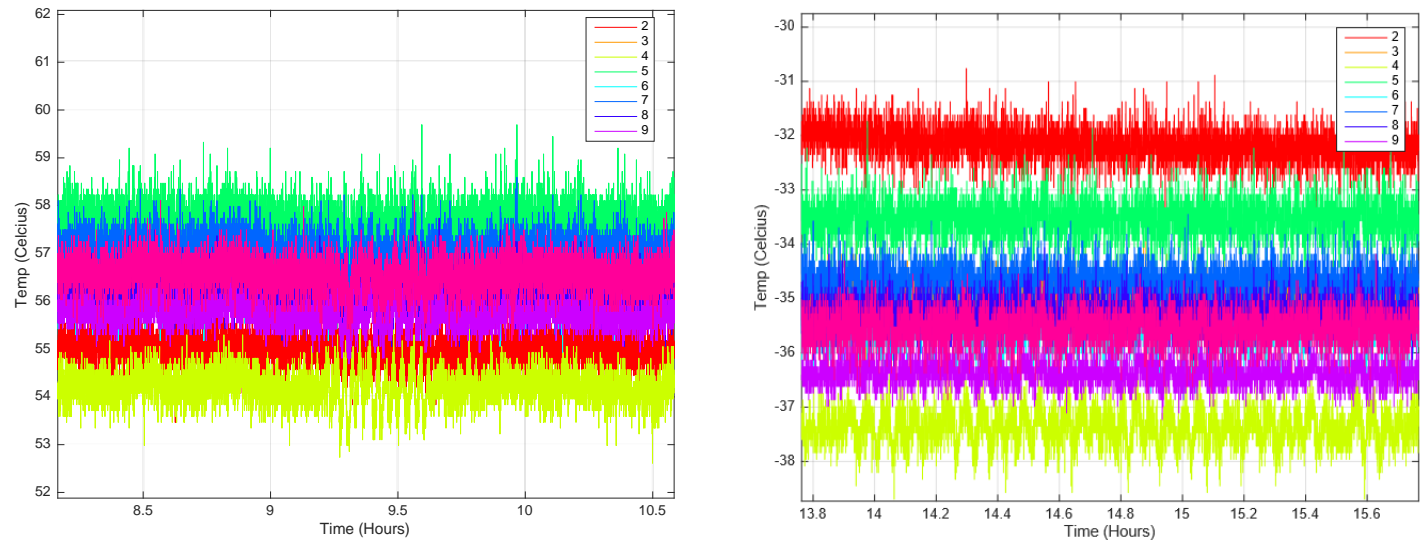

Figure 68. Detail of Cycling Max Limit (left) and Minimum Limit (right) 


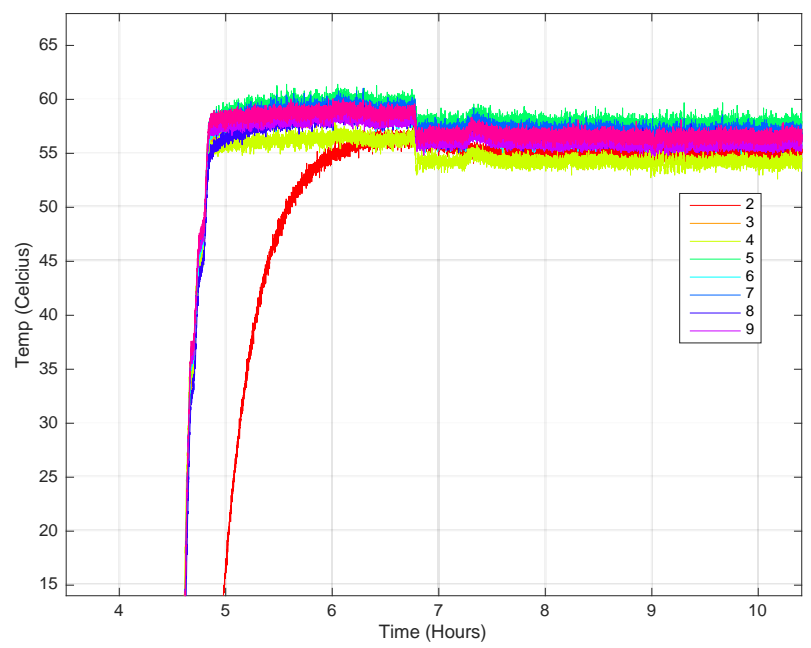

Figure 69. Step Detail Lower From $60^{\circ} \mathrm{C}$ to $58^{\circ}$

The Thermal Desktop model after correlation is shown in Figure 70 and Figure 71. Without any power applied to the heat strip, the platen is a solid, even temperature. This is the ideal state of a platen for any kind of thermal testing. The model and the test results prove the ATS Chiller is capable of providing a cold or hot platen as a temperature sink for TVAC testing.

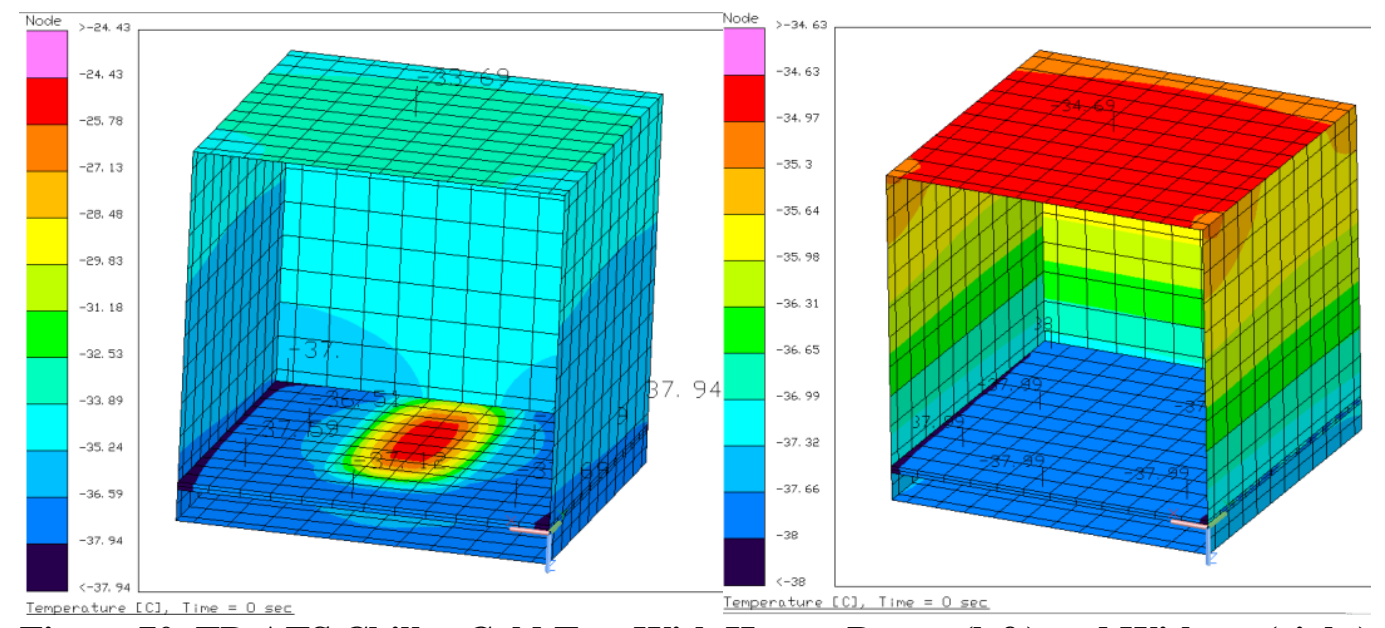

Figure 70. TD ATS Chiller Cold Test With Heater Power (left) and Without (right) 


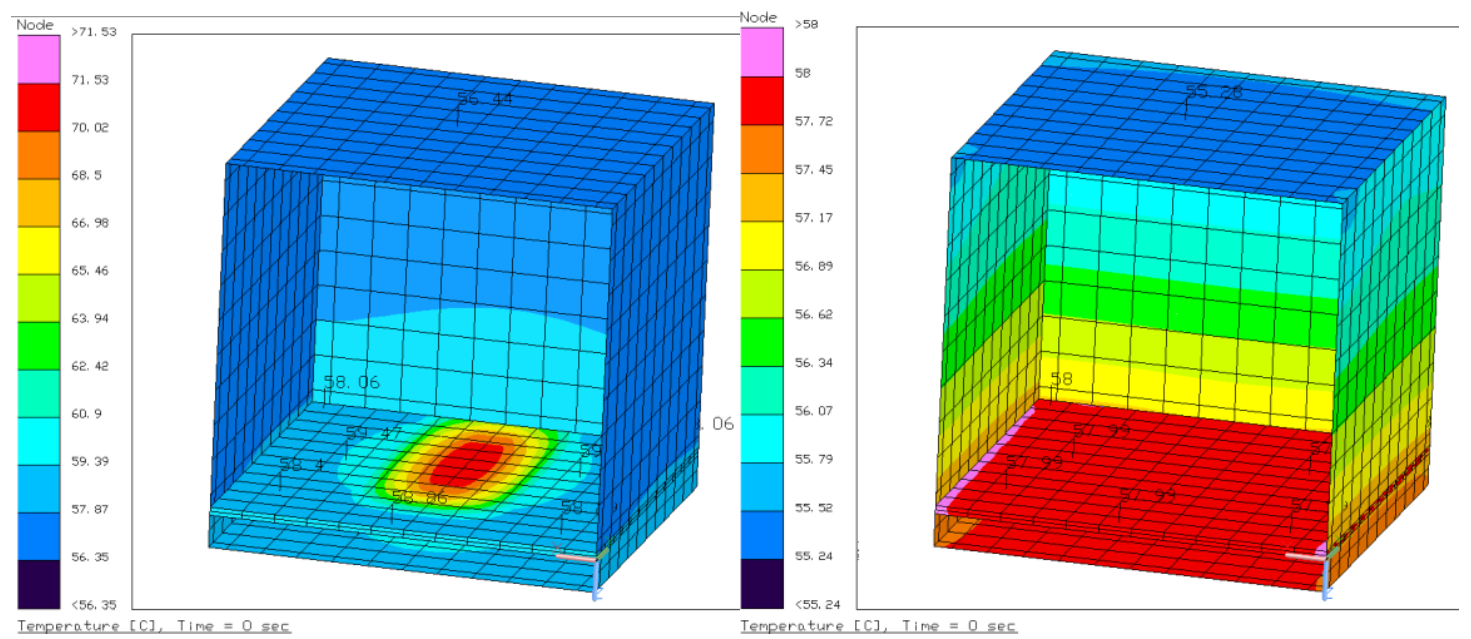

Figure 71. TD ATS Chiller Hot Test With Heater Power (left) and Without (right)

\subsection{CORRELATION}

After testing, the thermal model was correlated to match the testing results as closely as possible. For this thesis the model was adjusted to correlate within $\pm 3^{\circ} \mathrm{C}$ not including error on the TC's. Sometimes such tight requirements are not always possible primarily due to incorrect heat dissipation calculations from.[3] The correlation started by adjusting the model to match the no shroud heater test. All of the correlated thermal desktop models are shown as figures in the previous sections.

To correlate the no shroud heater test model the vacuum chamber boundary node had to be added to the piping. At the end each of the 30 inch pipes there was a $22^{\circ} \mathrm{C}$ boundary node to better capture the pipe temperature gradient from the platen to the chamber. This was only useful for the bake out cases, because during chiller operation the pipes were all at the temperature set point. The wattage was also lowered by $30 \%$ to greatly improve model correlation.. There may be losses in the electrical lines so that the full power applied to the heat strip does not equal the full heat dissipation. The heater conductor to the platen was also reduced to $0.2 \mathrm{~W} / \mathrm{C}$ to better simulate the small screw connections. The emissivity of copper was changed multiple times because there was so much variability on the polish and oxidation on the copper. For this test a 
lower emissivity of 0.2 was the best match. TC4 TC5 and TC6 on the pipes were not able to be correlated because there was not enough nodes or temperature information along the pipe to accurately compare the model to the test TCs. There was also not enough detailed information on the emittance for the TC's. It was not a critical point in the model because the main concern is the platen temperatures. To demonstrate the temperature gradient of the pipe see Figure 72 .

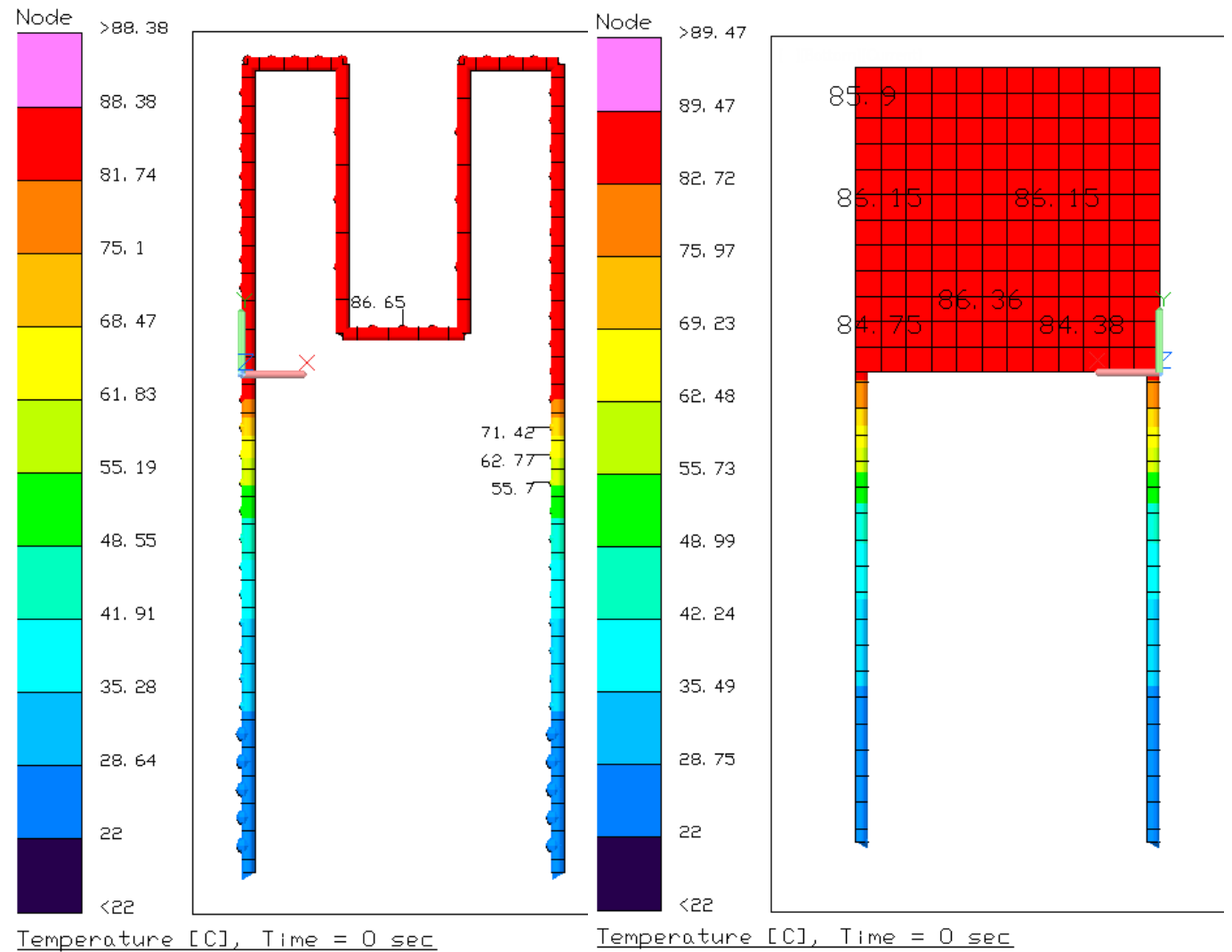

Figure 72. Piping Gradient from the Platen to the Chamber Wall

Table 17. Heater and Platen Test no Shroud Temperature Correlation

\begin{tabular}{cccc}
\hline \hline TC & Test $\left({ }^{\circ} \mathrm{C}\right)$ & Model $\left({ }^{\circ} \mathrm{C}\right)$ & Difference $\left({ }^{\circ} \mathrm{C}\right)$ \\
\hline 1 & 84 & 86.3 & 2.3 \\
2 & 82.5 & 84.8 & 2.3 \\
3 & 85 & 86.2 & 1.2 \\
4 & 80 & $\mathrm{n} / \mathrm{a}$ & $\mathrm{n} / \mathrm{a}$ \\
5 & 48 & $\mathrm{n} / \mathrm{a}$ & $\mathrm{n} / \mathrm{a}$ \\
6 & 65 & $\mathrm{n} / \mathrm{a}$ & $\mathrm{n} / \mathrm{a}$ \\
7 & 84 & 86.2 & 2.2 \\
8 & 84 & 85.9 & 1.9 \\
9 & 85 & 86.2 & 1.2 \\
10 & 86 & 85.9 & 0.1 \\
\hline \hline
\end{tabular}


From the correlation of the hot test without a shroud more modifications were made to correlate the bake out test. During the correlation of the bake out test it became obvious that the pipes were thermally coupled to the copper shroud because they were in contact at the bolted locations. The pipes, connected to the chamber wall, were acting as a heat sink to cool the copper shroud. An estimated conductance between the pipes and the bottom of the shroud was $20 \mathrm{~W} / \mathrm{C}$. This helped to correlate TC1 and TC2 which are at the top of the shroud. Emissivity of the copper also had to be as low as 0.2 in order to get a matching gradient from the platen to the shroud of $10 \pm 2.2^{\circ} \mathrm{C}$. The MLI effective emissivity had to be greatly decreased from the experimental calculation from section 5.1 which was .0014 to 0.06 . The blanket experiment was done with a small heat load and a small blanket with only one hole in the blanket for the strip heater electric wire. The shroud test had many holes for the heat to escape. The TC wires all had to go through a large hole and the heater also had a hole for the electrical wires. There were also multiple blankets that were taped together with large gaps between them. With these considerations in mind it was appropriate to increase the effective emissivity. Once again the power input was reduced by $30 \%$ or else the model was overall too hot and could not be correlated. TC5 could not be correlated correctly. The final result was a 6.8 error between model and test. The two most likely reasons for the discrepancy are that the TC wasn't fully taped down or MLI on the front had a lot more heat leaks than the other blankets. The pipes were not correlated for the bake out test model because they were determined unnecessary to the model.

Table 18. Correlation Bake Out Shroud, All Temperatures in ${ }^{\circ} \mathrm{C}$ and with $\pm \mathbf{2 . 2}{ }^{\circ} \mathrm{C}$

\begin{tabular}{cccc}
\hline \hline TC & Test $\left({ }^{\circ} \mathrm{C}\right)$ & Model $\left({ }^{\circ} \mathrm{C}\right)$ & Difference $\left({ }^{\circ} \mathrm{C}\right)$ \\
\hline 1 & 85 & 85.0 & 0 \\
2 & 85 & 85.0 & 0 \\
3 & 95 & 94.5 & 0.5 \\
4 & 93 & $\mathrm{n} / \mathrm{a}$ & $\mathrm{n} / \mathrm{a}$ \\
5 & 88 & 94.8 & 6.8 \\
6 & 95 & 94.6 & .4 \\
7 & 95 & 95 & 0 \\
9 & 95 & 94.9 & 0.1 \\
10 & 95 & 94.9 & 0.1 \\
\hline \hline
\end{tabular}


The ATS Chiller cold test was correlated next. No changes were made between this model and the bake out test model. The model is shown in section 6.3 and the correlated temperature results without the heater are shown in Table 19. The correlation with the heater on is shown in the cycle test for both hot and cold cases.

Table 19. Cold Test ATS Chiller Correlate Nodes When the Heater is Off

\begin{tabular}{cccc}
\hline \hline TC & Test $\left({ }^{\circ} \mathrm{C}\right)$ & Model $\left({ }^{\circ} \mathrm{C}\right)$ & Difference $\left({ }^{\circ} \mathrm{C}\right)$ \\
\hline 1 & -37.9 & -36.5 & 0.4 \\
2 & -34.7 & -35 & 0.3 \\
3 & -37.9 & -37 & 0.9 \\
4 & -37.9 & -38 & 0.1 \\
5 & -37.9 & -38 & 0.1 \\
6 & -37.9 & -37 & 0.9 \\
7 & -37.9 & -37 & 0.9 \\
8 & -38 & -37.5 & 0.5 \\
9 & -37.9 & -38.5 & 0.6 \\
10 & -38 & -38 & 0 \\
\hline \hline
\end{tabular}

The hot and cold extremes of the cycle models were executed with the same changes as the bake out shroud model. For this correlation the strip heater had an input power of $300 \mathrm{~W}$. No other changes needed to be made except to make the boundary nodes on the pipes either $-38^{\circ} \mathrm{C}$ or $58^{\circ} \mathrm{C}$.

Results are shown in Table 20 and Table 21 . TC5 was not within $3{ }^{\circ} \mathrm{C}$, but it was at the edge of the platen by the MLI and has the same errors associated with it as the errors discussed when correlating the bake out test.

Table 20. Hot Cycle Test ATS Chiller Correlate Nodes When Heater is On

\begin{tabular}{cccc}
\hline \hline TC & Test $\left({ }^{\circ} \mathrm{C}\right)$ & Model $\left({ }^{\circ} \mathrm{C}\right)$ & Difference $\left({ }^{\circ} \mathrm{C}\right)$ \\
\hline 2 & 55 & 56.4 & 1.4 \\
3 & 55 & 58 & 3 \\
4 & 54 & $\mathrm{n} / \mathrm{a}$ & $\mathrm{n} / \mathrm{a}$ \\
5 & 58 & 58.6 & 0.6 \\
6 & 56.5 & 58.4 & 1.9 \\
7 & 57.5 & 59.5 & 2.0 \\
8 & 57.5 & 58.1 & 0.7 \\
9 & 56 & $\mathrm{n} / \mathrm{a}$ & $\mathrm{n} / \mathrm{a}$ \\
10 & 56.5 & 58.1 & 1.6 \\
\hline \hline
\end{tabular}


Table 21. Cold Cycle Test ATS Chiller Correlate Nodes When Heater is On

\begin{tabular}{cccc}
\hline \hline TC & Test $\left({ }^{\circ} \mathrm{C}\right)$ & Model $\left({ }^{\circ} \mathrm{C}\right)$ & Difference $\left({ }^{\circ} \mathrm{C}\right)$ \\
\hline 2 & -32 & -33.7 & 1.7 \\
3 & -35 & -37.6 & 2.6 \\
4 & -37.5 & $\mathrm{n} / \mathrm{a}$ & $\mathrm{n} / \mathrm{a}$ \\
5 & -33.5 & -37.1 & 3.6 \\
6 & -36 & -37.6 & 1.6 \\
7 & -34.5 & -36.5 & 2.0 \\
8 & -35.5 & -37.9 & 2.4 \\
9 & -36.5 & $\mathrm{n} / \mathrm{a}$ & $\mathrm{n} / \mathrm{a}$ \\
10 & -35.5 & -37.9 & 2.4 \\
\hline \hline
\end{tabular}

The correlated Thermal Desktop model was created to determine the test values of the MLI and conductive paths. Adjustments were made to correlating each TC to a corresponding node resulting in new conductances. From this section the thermal paths were analyzed and changed to match test results. Each condutive path was documented and should not change unless a major rework of the shroud is done. The next reason for the Thermal Desktop model was to provide information on a modeled component. The analysis for this part of the Thermal Desktop model is discussed in the next section.

\subsection{COMPONENT THERMAL DESKTOP MODELS}

In this section the bake out model and the cycle model are adapted to analyze a component in the test apparatus. These are the two cases that could be used in future experimentation on a wide range of aerospace components. The simulated component in the model was a basic 4 inch cube aluminum brick with $1 \mathrm{~W}$ heat dissipation. The component had four nodes in the z-axis, to capture the temperature difference from top to bottom. The $\mathrm{x}$-axis and $\mathrm{y}$-axis are not divided into more nodes. Conductance from the bottom of the component to the platen was varied in order to quantify the effect of the thermal path. The sensitivity analysis includes three materials, screws for a bolted interface, putty, and Kera-therm Pink 86/50. Results are shown in Figure 73, Figure 74, Figure 75, Table 22, Table 23, and Table 24. 
Table 22. Bake Out Component Thermal Model Temperatures in ${ }^{\circ} \mathrm{C}$

\begin{tabular}{cccccc}
\hline \hline Material & $\begin{array}{c}\text { Conductance } \\
(\mathrm{W} / \mathrm{K})\end{array}$ & $\begin{array}{c}\text { Temp } \\
\text { Node 1 }\end{array}$ & $\begin{array}{c}\text { Temp } \\
\text { Node 2 }\end{array}$ & $\begin{array}{c}\text { Temp } \\
\text { Node 3 }\end{array}$ & $\begin{array}{c}\text { Temp } \\
\text { Node 4 }\end{array}$ \\
\hline 4 6-32 Screws & 1.68 & 102.6 & 102.6 & 102.6 & 102.6 \\
T-Putty 502 Series & 6.18 & 101.5 & 101.5 & 101.5 & 101.5 \\
Kera-therm Pink 86/50 & 132.75 & 101.1 & 101.1 & 101.1 & 101.1 \\
\hline \hline
\end{tabular}

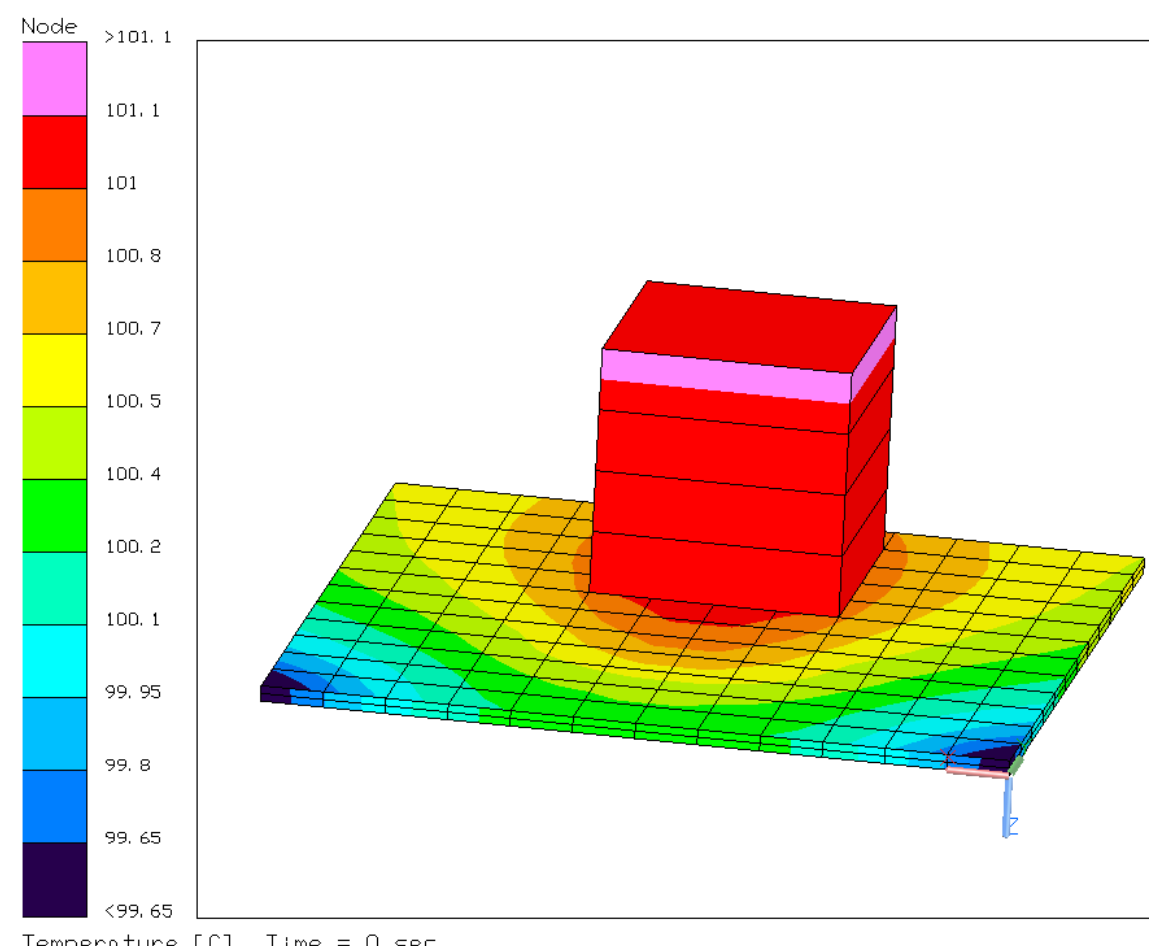

Figure 73. Bake Out Component Thermal Model (Kera-therm Pink 86/50)

Table 23. Hot Cycle Component Thermal Model Temperatures in ${ }^{\circ} \mathrm{C}$

\begin{tabular}{cccccc}
\hline \hline Material & $\begin{array}{c}\text { Conductance } \\
(\mathrm{W} / \mathrm{K})\end{array}$ & $\begin{array}{c}\text { Temp } \\
\text { Node 1 }\end{array}$ & $\begin{array}{c}\text { Temp } \\
\text { Node 2 }\end{array}$ & $\begin{array}{c}\text { Temp } \\
\text { Node 3 }\end{array}$ & $\begin{array}{c}\text { Temp } \\
\text { Node 4 }\end{array}$ \\
\hline 4 6-32 Screws & 1.68 & 58.7 & 58.7 & 58.6 & 58.6 \\
T-Putty 502 Series & 6.18 & 58.2 & 58.2 & 58.2 & 58.2 \\
Kera-therm Pink 86/50 & 132.75 & 58.0 & 58.0 & 58.0 & 58.0 \\
\hline \hline
\end{tabular}




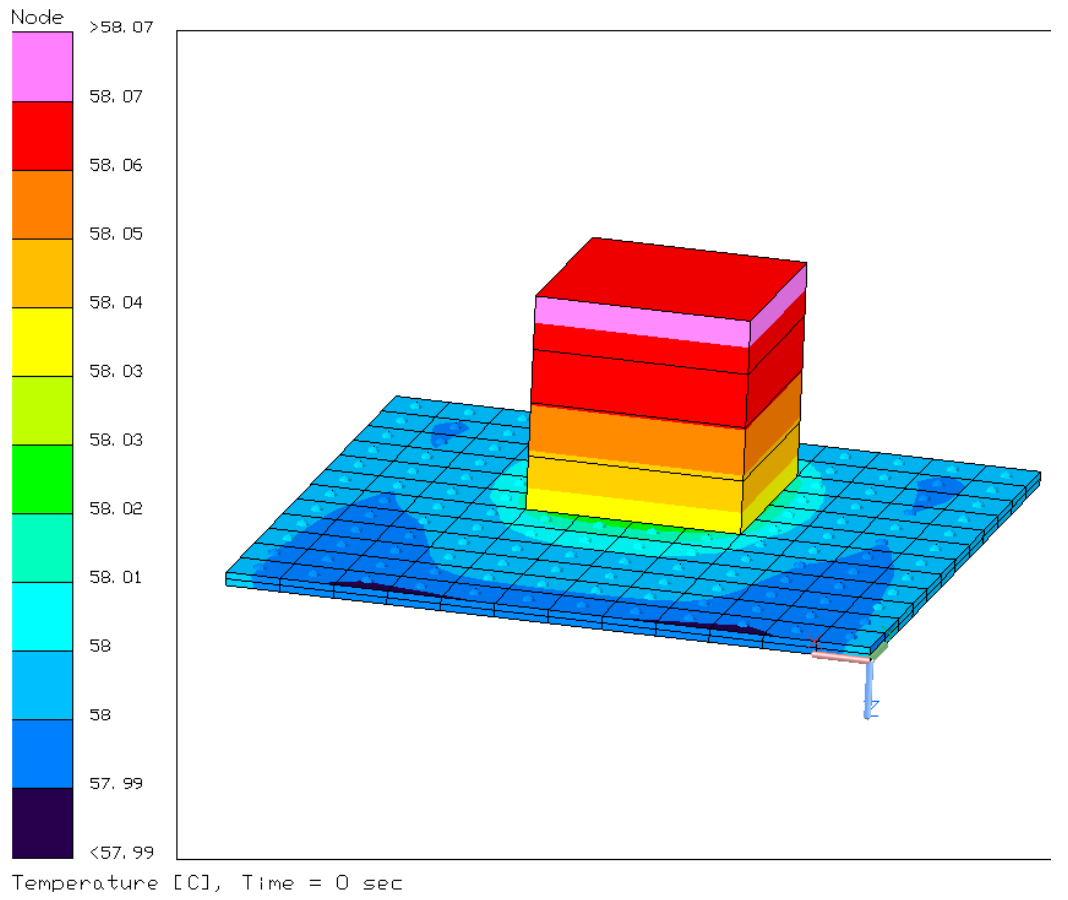

Figure 74. Hot Cycle Component Thermal Model (Kera-therm Pink 86/50)

Table 24. Cold Cycle Component Thermal Model Temperatures in ${ }^{\circ} \mathrm{C}$

\begin{tabular}{cccccc}
\hline \hline Material & $\begin{array}{c}\text { Conductance } \\
(\mathrm{W} / \mathrm{K})\end{array}$ & $\begin{array}{c}\text { Temp } \\
\text { Node 1 }\end{array}$ & $\begin{array}{c}\text { Temp } \\
\text { Node 2 }\end{array}$ & $\begin{array}{c}\text { Temp } \\
\text { Node 3 }\end{array}$ & $\begin{array}{c}\text { Temp } \\
\text { Node 4 }\end{array}$ \\
\hline 4 6-32 Screws & 1.68 & 37.3 & 37.3 & 37.3 & 37.3 \\
T-Putty 502 Series & 6.18 & 37.8 & 37.8 & 37.8 & 37.8 \\
Kera-therm Pink 86/50 & 132.75 & 37.9 & 37.9 & 37.9 & 37.9 \\
\hline \hline
\end{tabular}

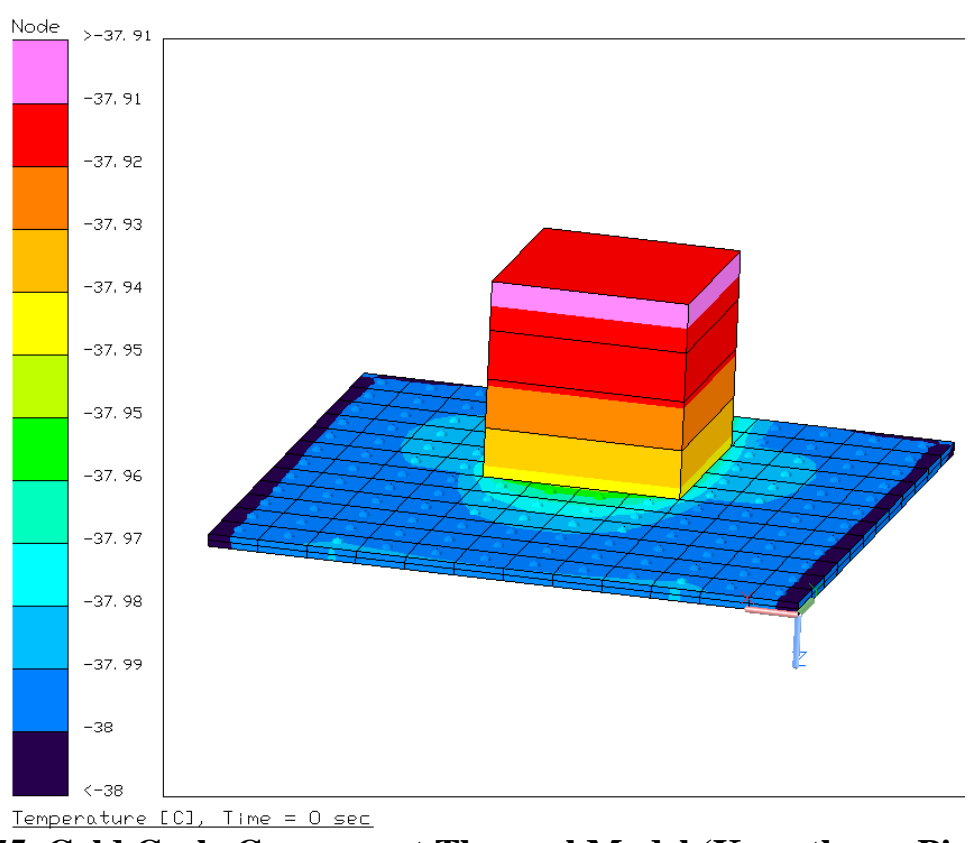

Figure 75. Cold Cycle Component Thermal Model (Kera-therm Pink 86/50) 
The conductivity material varied the temperature only slightly by at most $0.7 \pm 2.2^{\circ} \mathrm{C}$ which is well with the error of thermal modeling analysis. This is most likely due to the low wattage of the component and the even shroud radiation all around the component. From this analysis, it is concluded to be safe to bolt a component down and not have to use thermal paste. This will help to keep the component and the chamber clean without sacrificing thermal performance.

All of the tests in this section built the foundation for further testing in the TVAC chamber for either a bake out or thermal cycling test. The correlated thermal models prove that components will reach ATS chiller temperature set points within $1^{\circ} \mathrm{C} \pm 2.2^{\circ} \mathrm{C}$. Performance of the ATS Chiller was exceptional because the machine was able to keep the platen at temperature set points with little to no variability across the platen. The platen is able to mimic a heat sink in the vacuum chamber which is essential for development thermal tests and acceptance tests. 


\section{CONCLUSION}

A series of tests were performed to redesign the ATS Chiller and HVEC TVAC Chamber so that is more reliable and better understood for future use. A shroud was implemented onto the previously designed platen apparatus and the leaking in the ATS Chiller lines were fixed. The TVAC performed a bake out test with peak temperatures reaching $130^{\circ} \mathrm{C} \pm 2.2^{\circ} \mathrm{C}$ and steady state temperatures reaching $85^{\circ} \mathrm{C} \pm 2.2^{\circ} \mathrm{C}$. The shroud was designed from a copper sheet and MLI was applied around the copper to improve the insulation around the platen. The shroud reduce variable temperatures across the platen from $\pm 3.8^{\circ} \mathrm{C}$ to $\pm 2.2^{\circ} \mathrm{C}$ to temperatures within the $\mathrm{TC}$ error limits of $\pm 2.2^{\circ} \mathrm{C}$. The thermal cycle test was 3 cycles long with 4 hours at each of the hot and cold extremes. The ATS Chiller proved to absorb 300W of heat dissipation and hold temperatures on the platen between $-38^{\circ} \mathrm{C} \pm 2.2^{\circ} \mathrm{C}$ and $58^{\circ} \mathrm{C} \pm 2.2^{\circ} \mathrm{C}$. Throughout all the testing the HVEC chamber held pressures below the required $10^{-5}$ Torr.

Thermal models were created to capture both bake out and thermal cycle tests. Radiation and conduction was simulated in the model. The models were correlated to match the test data by changing copper emittance, MLI effective emissivity, and bolted conductive paths. All thermocouple nodes were within $\pm 2.2^{\circ} \mathrm{C}$ except for one TC closest to the opening of the shroud. The piping temperatures were not correlated because they were not considered critical to analyze the effectiveness of the platen.

Once correlated, the models were updated to include a small aluminum component with 1 Watt of heat dissipation. Various conductive materials were modeled to simulate the contact resistance between the component and the temperature controlled platen. Based on the results, the component can be bolted down to the platen for the thermal cycling testing. Bolts alone without thermal paste have enough conductance to create an effective thermal path from the dissipating component to the platen heat sink. Finally, from both testing temperature results and the model 
simulation it was determined that the component to be tested should be positioned as far away from the front of the shroud as possible.

The thermal vacuum chamber was proven to be effective and all processes were documented in this thesis for future students. 


\section{FUTURE WORK}

The main goal of this thesis was to thoroughly document the ATS Chiller system in the TVAC chamber in order for future work to be completed using the system. Such work includes thermal cycling instruments or components for Cubesat that can be completed alongside spacecraft testing that is in the hanger thermal chamber. A bake out test can also be done for any material or unit. The capabilities of the ATS Chiller were well documented in the testing results of this thesis. The procedure is documented in the appendix. All information presented in this thesis will aid in future TVAC operation and test. This section will outline future projects that would be beneficial so Cubesat or other clubs can use the ATS Chiller in another chamber if required. As long as the pipes have a feed through in another chamber there is no reason the ATS chiller can't be moved and used elsewhere.

A TVAC chamber is much more valuable than just thermal cycling and that's really where future work can take advantage of this system. A multitude of testing can be done in the chamber because of the large size, reliable ATS Chiller, and the low pressure of the chamber. This thesis has laid the ground work for any student looking to gain a better understanding of thermal aerospace engineering. Testing is the best way to get hands on experience with thermocouples, heating, cooling, and a radiation in a vacuum environment. As discussed in this thesis, the interface conductivity is a difficult to calculate with equations, so an in depth study on mounting materials would be a worthwhile investigation. Another study can be done on thermal blanket analysis with different layers and different materials for the layers. Verifying thermal properties of space grade materials is another possibility for future work along with testing heat straps, heat pipes, and other materials used to transfer heat on a spacecraft.

There are some modifications that can be implemented to make a better TVAC system. Most important would be implementing another cooling system to circulate the water alongside the ATS Chiller. It seems wasteful to drain the water, but in engineering there is a need to use 
resources to reach an engineering goal. To get more information Denis Webster can be reached at Denis_Webster@beaerospace.com. He has given his email to provide invaluable help on working and fixing the ATS Chiller. Fixing the first channel leak and heater may also be a worthwhile project because the both channels could then be used at the same time, either in the chamber with the second channel or in a different chamber altogether. To fix this side the leaks must be looked at once again in more detail. Unfortunately, the first students used a welding material somewhat similar to JB-Weld that is cemented onto the outer pipes. Using a hammer and chisel did not get everything off, so the leaks continued. More weld and even epoxy was attempted to be used to cover the leaks, but to no avail. It is possible the first channel is beyond repair without further damaging the pipes in the ATS Chiller, but other methods may be available that were not used for this project. Another small, but useful fix to the ATS Chiller would be to implement filters onto the Galden ${ }^{\circledR}$ Fluid line to help keep the fluid clear of particles. Due to the dirtiness of the lab and the need to salvage all of the expensive Galden ${ }^{\circledR}$ Fluid there are definitely contaminants in the fluid that will degrade the ATS Chiller over time. For a student run machine this is nothing to worry excessively about, but a filter could increase the lifespan and even performance of the machine. For more details consult the ATS Manual Figure 5-5.

Heater control on the bake out test would be much more accurate, save time, and reduce stressful possibilities of reaching critically high temperatures. A controller can be bought from McMaster-Carr that works with the current strip heater.

Another fix to the bake out test would be to use kapton heaters on the copper shroud to more evenly heat it. These, too, would need controllers. Also, connecting another thin copper sheet to the front would help to reduce the heat loss from the opening that was shown during experimentation.

Both cycling and the bake out test would benefit by coating the interior copper shroud with black paint or the black kapton blankets. The dark surface property has a very high 
emmitance when compared to the copper emittance of 0.2. This means the interior of the shroud will be closer to the same temperatures all around the shroud and the change will happen faster because the platen will radiate directly to the shroud interior.

The DAQ is well documented for future work, but there are some adjustments to make the readings more reliable. First, each of the TCs should be calibrated and tested thoroughly to understand whether they are cold or hot biased. Next, how the TCs are secured should be tested and analyzed. For this thesis the TC was secured with aluminum tape (highly conductive) and then kapton tape which is able to secure it very well. The kapton tape could have been reading from the environment. Different tape should be tested to ensure the thermocouple is reading the surface temperature, not the radiative environment. Copper tape or aluminum tape is effective.

An exciting project to improve the TVAC chamber would be to add a lamp or light bulb to simulate solar radiation. This would make the absorptance properties important and could be used to test the effectiveness of different surface properties. For example, the platen could be set to a panel temperature with a blanket covering the top. Above this blanket a solar heat source could be applied to get temperature information and calculate how well the optical properties accept or reject the solar radiation.

When it comes to aerospace thermal engineering there are many ways to test materials that will enrich the understanding of radiation and conduction. With a stable, verified ATS Chiller that can make a platen anywhere from $-40^{\circ} \mathrm{C}$ to $60^{\circ} \mathrm{C}$ many new projects are able to unfold for future students interested in thermal engineering. 


\section{BIBLIOGRAPHY}

[1] Vincent L. Piscine, The Space Environment and its Effects on Space Systems, American Institute of Aeronautics and Astronautics, Inc. , 2008.

[2] J. Wert, D. Everett, J. Puschell, Space Mission Engineering: the new SMAD, Microcosm, Inc. , 2011.

[3] David G. Gilmore, Spacecraft Thermal Control Hand Book, American Institute of Aeronautics and Astronautics, Inc. , 2002.

[4] MIL-STD 1540D, "Product Verification Requirements for Launch, Upper Stage, and Space Vehicles.” Department of Defense Standard Practice, 1999

[5] GSFC-STD-7000A, "GENERAL ENVIRONMENTAL VERIFICATION STANDARD (GEVS) For GSFC Flight Programs and Projects." NASA Goddard Space Flight Center, Greenbelt, Maryland, 2013

[6] M. Moran, H. Shapiro, D Boettner, M. Bailey, Fundamentals of Engineering Thermodynamics, John Wiley \& Sons, Inc. , 2011.

[7] Kurt J. Lesker Company, “Galden ${ }^{\circledR}$ Heat Transfer Fluids,” [Online] Available: http://www.lesker.com/newweb/fluids/heattransfer_galden_ht.cfm?pgid=0. [Accessed 20 December 2016]

[8] Advanced Thermal Sciences, 1231-CCN-GL-004 Operating Manual - Document No. 4084413 Rev. A, 2003

[9] Denis Webster personal correspondence

[10] C\&R Technologies, User's Manual Thermal Desktop Version 5.6

[11] C\&R Technologies, "Heat Transfer and Fluid Modeling Software,' [Online] Available: https://www.crtech.com/products/sindafluint. Accessed[January 10 2017]

[12] C\&R Technologies, User's Manual SINDA/FLUINT Version 5.6, May 2013

[13] C. Barlog, Divergent Plume Reduction of a High-Efficiency Multistage Plasma Thruster, San Luis Obispo: California Polytechnic State University, 2016.

[14] C. Barackman, S. Jackowski, Thermal Vacuum Integration for Cal Poly's Space Environments Laboratory, San Luis Obispo: California Polytechnic State University, 2012.

[15] L. Tebyani, Thermal Vacuum Chamber Operation and Testing, San Luis Obispo: California Polytechnic State University, 2013.

[16] B/E Advanced Thermal Technologies, Inc. , Fill / Drain Procedures For MDP Sub-Zero Chiller Document No. 4080194 Rev. A, 2003 
[17] Sanjay Jayaram Eliu Gonzalez, (2011), "Design and construction of a low-cost economical thermal vacuum chamber for spacecraft environmental testing”, Journal of Engineering, Design and Technology, Vol. 9 Iss 1 pp. 47-62

[18] Pyromation, "Type K Thermocouple - thermoelectric voltage as a function of temperature $\left({ }^{\circ} \mathrm{C}\right)$; reference junctions at $0^{\circ} \mathrm{C}, "$ [Online $]$ Available:

http://www.pyromation.com/Downloads/Data/emfk_c.pdf . [Accessed 15 January 2016]

[19] Adafruit, “Analog Output K-Type Thermocouple Amplifier - AD8495 Breakout,” [Online] Available: https://www.adafruit.com/products/1778 [Accessed 20 February 2016]

[20] The Engineering Toolbox, "Material Properties," [Online] Available:

http://www.engineeringtoolbox.com. [Accessed November 10 2015]

[21] Swagelok, "Product Catalog," [Online] Available: https://www.swagelok.com/en. [Accessed June 20 2016]

[22] McMaster-Carr, "Strip Heater," [Online] Available:

https://www.mcmaster.com/\#heat-strips/=167u2b4 [Accessed Feb 15 2016]

[23] Watlow, CLS200 Series USER'S GUIDE 


\section{APPENDICES}

\section{A. LESSONS LEARNED AND RECOMMENDATIONS}

There is no way to convey how much can go wrong in the aerospace environments lab and at the same time there is no way to convey how useful working on an experimental project can be. Day one was overwhelming, but in no time I had combed the lab so many times that I could get in the general location of every spare wire or cable in the lab. Learning to improvise with materials, learning to purchase the correct materials, and learning to put all the pieces together were essential skills the lab can teach. The most important lesson I learned was that I had to accept the overwhelming feeling of working in uncharted territory and push forward to finish the project.

More specifically, I learned a lot about the ATS Chiller and all the nuances that came with it. This section will go over some of those key lessons learned throughout the project. First, do not have the pipes full of liquid unless the ATS Chiller will be used. The manual goes over how to remove the pipes without completely draining the chiller and this should be done as a precaution. At one point the Galden ${ }^{\circledR}$ Fluid started to boil from the heater without the chiller on. Because the ATS Chiller only goes to $60^{\circ} \mathrm{C}$ cheaper Galden ${ }^{\circledR}$ Fluid can be purchased with a lower boiling point. Any Galden ${ }^{\circledR}$ Fluid can be used, as long as it's the same fluid in the chiller, i.e. do not mix Galden-110 with a different Galden® Fluid.

Swagelok's are important for many experiments and they are implemented between the chiller and the platen. No plumbers tape is necessary because the Swagelok design is able to seal the connection effectively without any other material. It is also important not to overtighten Swageloks which can be investigated further from their website and through a learn by doing process. At the same time, the Swagelok must be tightened enough so that there isn't a small (as in not visible in ambient pressure) leak in the line that will manifest when trying to pump down the vacuum chamber. 
The machines will break. They are student run and things happen in a student ran lab. The biggest lesson for this is problem is to start early and to read other students Thesis' procedures and lessons learned. This will help to not break something and to also determine if another student encountered a similar phenomenon. The procedures outlined under this section go into much more detail for the different machines used for this thesis. Other than that it takes determination, reading a ton of manuals, and a lot of trial and error. 


\section{B. HVEC CHAMBER}

The largest volume vacuum chamber in the lab is the HVEC chamber. It is used for many types of experiments that require different feed throughs. There are gas feed throughs for propulsion, 1/2 diameter swagelock feed throughs for the ATS Chiller, TC feed throughs, and electrical feed throughs. Many different experiments can be done using Big Green. Big Green requires the Mechanical Pump and the Cryo Pump in order to reach low pressures of e-6 Torr.

The procedure for pump down is listed after this guide.

Vacuum Grease: use vacuum grease along the o-ring every few months, but do not leave any "globs". Use a glove and rub it in so that there is very little on the o-ring. You shouldn't see it very well.

Leaks: The main source of leaks are the electrical feed throughs. These should all have BNC cables attached to limit the leaks. If you suspect more leaks elsewhere, then look for the leak detector procedure.

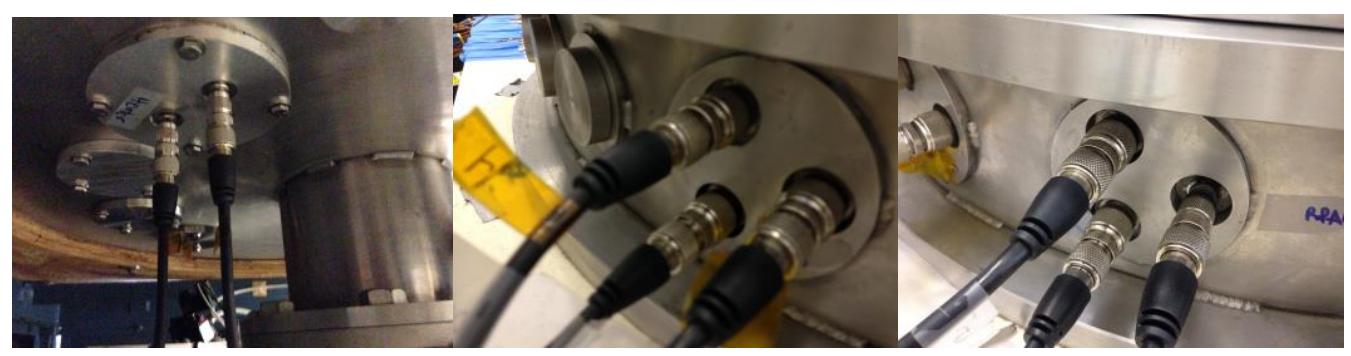

Under the chamber, and two feed throughs on the side of the chamber all need to be plugged in 


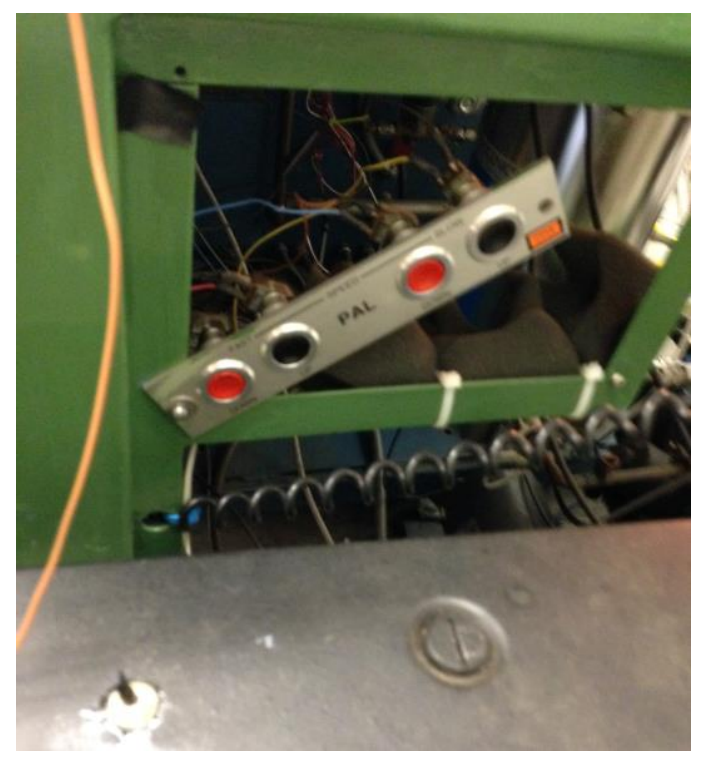

Open and Close: Only the red slow down button works do to some electrical wiring problems. There is a switch on the black power box that is used to change "up" and "down" wiring. So, just flip the switch if the lid is going the wrong direction.

When closing, the lid isn't perfectly aligned with the bottom so close it slowly and move the lid from to side to side if it is too far off. Stop descending when the o-ring hits the bottom.

If you aren't sure if it is aligned properly then lift the lid and see where the o-ring mark is, this should be faint, but it is useful for making sure the o-ring is on the metal.

Before opening check the pressure, if it isn't ambient it won't open, vent (air on), and wait until it hits 760Torr

\section{Control Panel, Gages:}

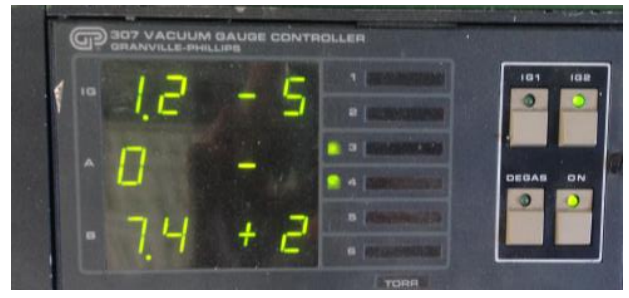

On turns on the convectron gages. $\mathrm{A}$, in the middle, is the chamber. $\mathrm{B}$, at the bottom, is the roughing line. 0 means the convectron gage is not accurate so the IG2 button can be pressed to 
turn on the ion gage. The gage will break if left on during venting! Turn off before closing the gate valve(on procedure)

\section{Procedures: (Adapted from Chris Barlog's Thesis[22])}

Two procedures are available for the Chamber system. The first is when the compressor is warm and needs to be cooled down. The second is when the compressor is on and cold, but the gate valvle had to be closed and the chamber vented. Note: Times may very depending on the amount of feed throughs are used and how many connections are made allowing for leaks.

\section{HVEC CHAMBER OPERATION, CRYO PUMP WARM}

\begin{tabular}{|c|c|c|}
\hline Steps & Time to complete & Time since start \\
\hline \multicolumn{3}{|l|}{$\begin{array}{l}\text { 1. Turn on facility compressed air supply via valve on the } \\
\text { wall }\end{array}$} \\
\hline \multicolumn{3}{|l|}{ 2. Turn on System Power switch on chamber front panel } \\
\hline \multicolumn{3}{|l|}{ 3. Turn on Mechanical Pump } \\
\hline 4. Turn on Chamber Rough & & 1 minute \\
\hline $\begin{array}{l}\text { 5. Allow chamber to pump down to } 50-100 \text { mTorr (5e-2 to } \\
1 \mathrm{e}-1 \text { Torr) }\end{array}$ & 10 minutes & 11 minutes \\
\hline \multicolumn{3}{|l|}{ 6. Turn on Pressure Override } \\
\hline \multicolumn{3}{|l|}{ 7. Turn on Rough Interlock } \\
\hline 8. Open the Gate Valve & 1 minute & 12 minutes \\
\hline 9. Wait for pressure to decrease to $50-100$ mTorr & 10 minutes(varies) & 22 minutes \\
\hline \multicolumn{3}{|l|}{ 10. Turn on the Compressor } \\
\hline $\begin{array}{l}\text { 11. Allow cryo temp to reach } 150 \mathrm{~K} \text { or lower (convectron } \\
\text { gage starts to zero out) }\end{array}$ & 1 hour & 1 hour $22 \mathrm{~min}$ \\
\hline \multicolumn{3}{|l|}{ 12. Close Roughing Valve Turn off Mechanical Pump } \\
\hline \multicolumn{3}{|l|}{ 13. Turn off Rough Interlock } \\
\hline \multicolumn{3}{|l|}{ 14. Turn on Pressure Interlock } \\
\hline \multicolumn{3}{|l|}{ 15. Turn off Pressure Override } \\
\hline 16. Allow cryo temperature to fall to $17 \mathrm{~K}$ & $\begin{array}{l}2 \text { hours } \\
(6 \text { microTorr })\end{array}$ & $2: 45$ to $3: 22$ hours \\
\hline
\end{tabular}




\section{HVEC CHAMBER OPERATION, CRYO PUMP PRECOOLED}

\begin{tabular}{|l|l|l|}
\hline & Time to complete & Time since start \\
\hline 1. Turn on Mechanical Pump & & \\
\hline 2. Turn on Chamber Rough & & $10 \mathrm{~min}$ \\
\hline 3. Allow chamber to reach 50-100mTorr & $10 \mathrm{~min}$ & \\
\hline 4. Close Chamber Rough & & \\
\hline 5. Turn off Mechanical Pump & & pressure drop to 9e-4 \\
\hline 6. Turn on Pressure Interlock & 3 min & 15 min \\
\hline 7. Open Gate Valve & 1 hour & $\begin{array}{l}9 \text { hours (depends on feed } \\
\text { throughs) }\end{array}$ \\
\hline 8. Convectron gauge zeros & 8 hours & \\
\hline 9. Allow to pump down 9e-6 & & \\
\hline 10. Get to 9e-7 & & \\
\hline
\end{tabular}

\section{HVEC CHAMBER SHUT DOWN AND VENT}

1. Turn off the Ion Gauge using IG1 or IG2 button.

2. $\quad$ Shut the Gate Valve.

3. Turn off Pressure Interlock and compressor.

4. $\quad$ Open the Vent Valve.

5. Allow the chamber to reach ambient pressure (760 Torr) then close Vent valve

6. Close the compressed air supply at the wall.

7. Turn off System Power. 


\section{CRYOPUMP/COMPRESSOR PROCEDURE}

The compressor compresses helium until the helium is 17 Kelvin on the cold head. This cold plate attracts molecules from the chamber in order to reach pressures on the order of e-6 Torr. The cold head is attached at the bottom of the cryopump(connected to the vacuum chamber) with a small grey cord. This must be attached before turning on the compressor. (Page 27 in manual for more functional description)

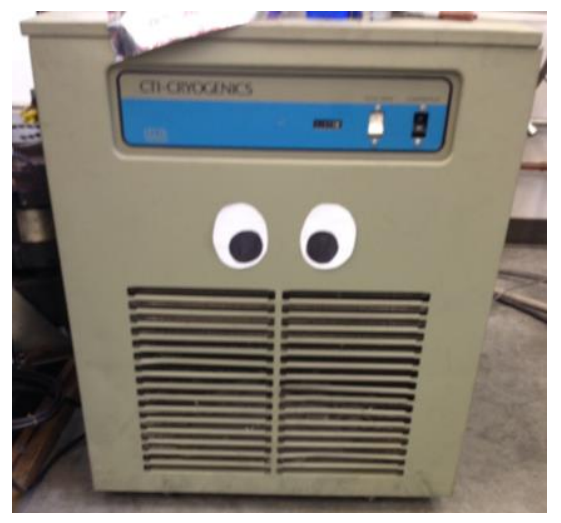

The compressor hooks up to the vacuum chamber with return and supply lines shown below.

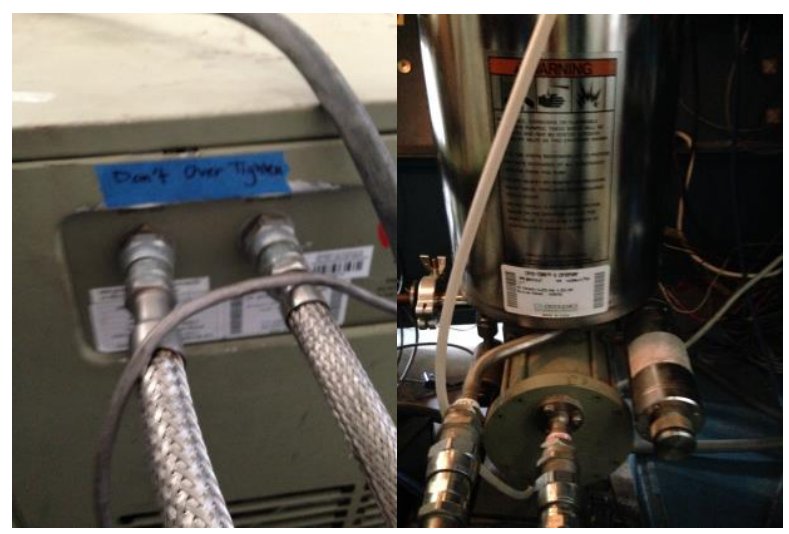

Left, compressor return and supply. Right, cryopump return and supply.

The manual has specific information, but a brief overview of common ailments will be discussed in this report.

\section{To Fill:}

Page 45 in manual for more details, if less than 30psi must do Procedure: CRYO PUMP DECONTAMINATION

1. Bring helium close to pump, attach a pressure regulator and line to the helium (wear safety glasses) 

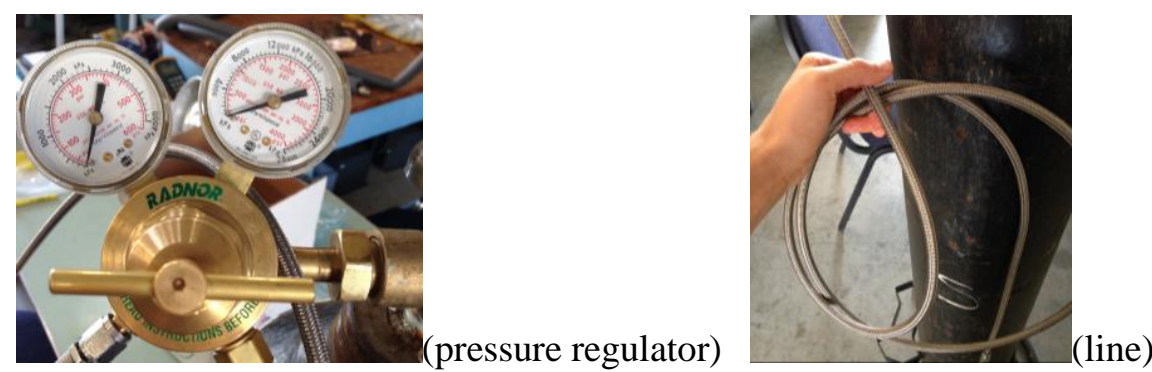

2. Make sure valve is closed, turn all the way counter clockwise until lose, but not off.

3. Turn on tank

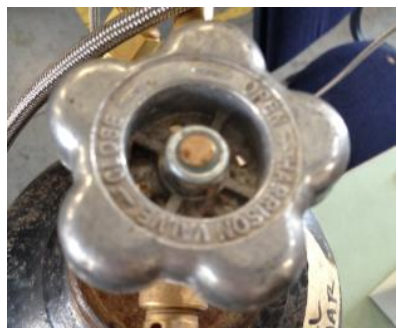

4. Slowly turn pressure gage valve clockwise until a small amount of helium can be heard. Bleed the line for 1 minute.

5. Keep the helium on and attach the line to the helium nozzle on the compressor.

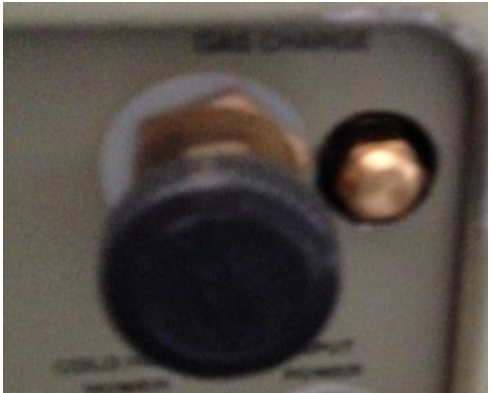

Balck knob: Charge that opens and closes to let helium pass. Right gold flare cap: where to put the gas line.

6. The left gauge of the pressure regulator should now read the pressure in the line. The right side is the tank pressure. Turn the regulator clockwise until it reaches $250 \mathrm{psi}$ on the left gauge (can be tough at the end, don't have to be gentle).

7. Open the gas charge on the compressor. You will hear the helium fill the tank. Stop at 200psi by closing the charge.

8. Close the tank valve

9. Close the regulator by rotating counter clockwise

10. Undo the line from the compressor

\section{To Drain:}

1. Take off flare cap from the gas charge fitting on the compressor, open charge (slowly).

2. Close charge at $185-200$ psi, replace cap

\section{Attaching/Removing The Lines Pg. 16}

Attach the lines in the following order, don't over tighten! Just make sure its snug: 
1. Helium return line to the gas-return connector on the rear of the compressor unit.

2. Connect the helium supply line to the gas-supply connector on the rear of the compressor unit

3. Connect the helium supply line to the gas-supply connector on the drive-unit displacer assembly(on chamber)

4. Connect the helium return line to the gas-return connector on the drive-unit displacer assembly(on chamber)

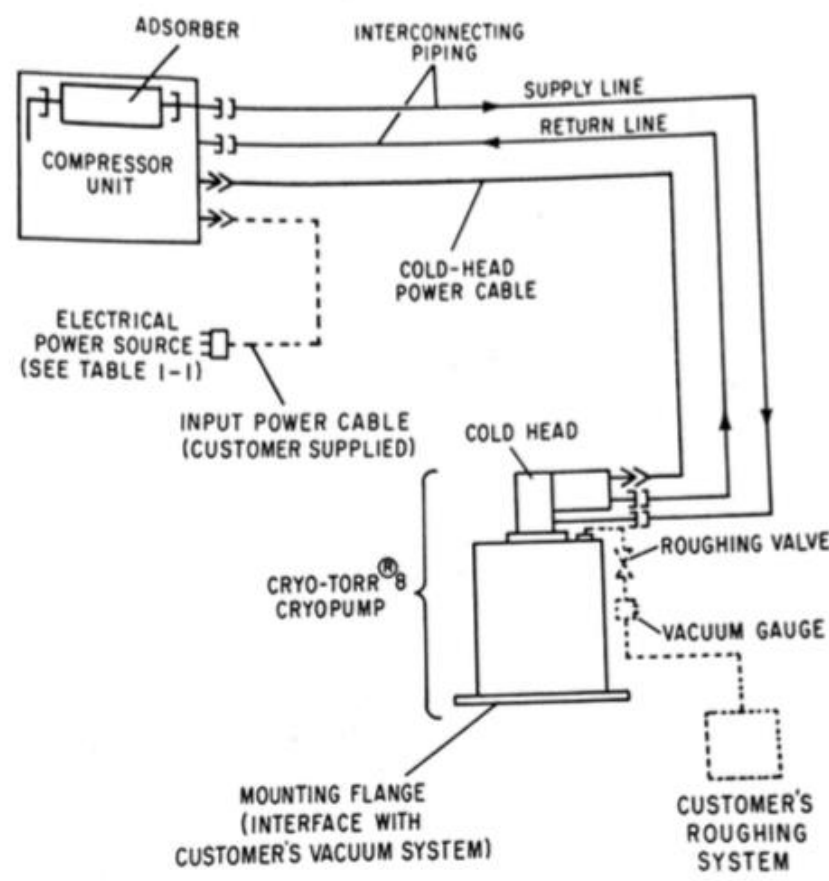

FIGURE 2-5. COMPONENT INTERCONNECTION DIAGRAM FOR THE CRYO-TORR $(R)$ \& HIGH-VACUUM PUMP

$-17-$

\section{Recurring Problem:}

After about 5 hours on two different occasions the compressor turned off completely while under vacuum. If this happens the gate valve should close after the chamber gets above $50 \mathrm{mTorr}$. The problem was with the 3-Phase cords. NOTE: DO NOT WORK ON ELECTRONICS WITHOUT ADVISOR OR CODY'S HELP. After opening the top of the compressor, the 3-Phase power cord wires ( 4 of them) can be seen attached to the electronics. In the first case the red wire blew apart at the connection, in the second place the yellow wire blew apart. In both cases the heads of the wires were replaced.

Other problems if the machine turns off.

1. pressure too high 
2. a fuse blew on big green, try to plug into the back of MAX (make sure max is getting power too)

Timing: Check Procedure for HVEC Chamber for more details in Appendix B

1. If the system was completely off. Once the mechanical pump is on, gate valve open and at $50-100 \mathrm{mTorr}$

30 min: $185 \mathrm{~K}$

1 hour: $140 \mathrm{~K}$, close rough valve and turn off mechanical pump

2h 20 min: $\quad 18 \mathrm{~K}$

3 hours: $17 \mathrm{~K}, 8.5 \mathrm{e}-6$ Torr

3. If the cryopump is already cold, but the gate valve is closed: once chamber is pumped down to 50-100 mTorr form roughing, closed roughing valve and mechanical pump is turned off.

open gate valve: $\quad 9 \mathrm{e}-4$ instantly

3 min:

convectron gage at 0

$4 \mathrm{~min}: \quad 9.3 \mathrm{e}-5$ (ion gage)

1 hour: $\quad 9.3 \mathrm{e}-6$ Torr 
D. MECHANICAL PUMP PROCEDURE

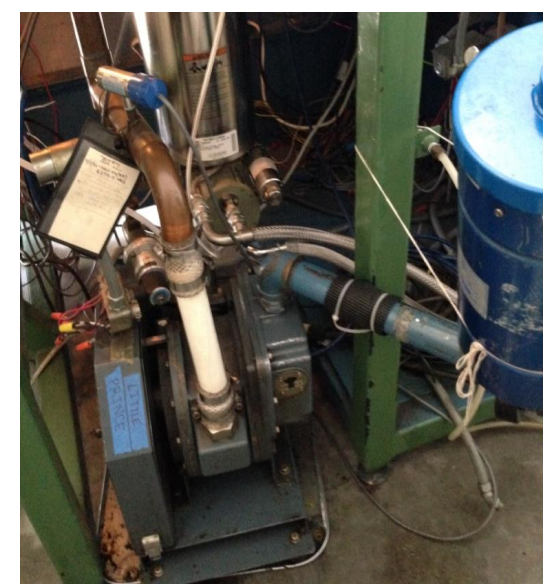

\section{Pump Operation}

When using the mechanical pump the swamp fan must be used at the same time to keep the pump cool. A string is also used to ensure the exhaust does not fall down.

* Normal operations pressure: Low $10^{\wedge}-2$ Torr to $10^{\wedge}-3$ Torr after several hours

\section{Procedure}

1. Turn on swamp fan and face it towards the pump

2. Air on

3. Main Power On (See Big Green Procedure for more details on operation)

4. Convectron gage On

5. Turn on Pump

6. Open roughing valve

\section{Timing After Opening Roughing Valve}
1. $3 \mathrm{~min}$
4 Torr, pump quiets down
2. $5 \mathrm{~min}$ 2e-1 Torr
3. $7 \mathrm{~min}$ 9.9e-2 Torr
4. $10 \mathrm{~min}$ $5.5 \mathrm{e}-2$ Torr
5. hours 6e-3 Torr

Notes: The pump is plugged directly into the HVEC Chamber. When the roughing valve is closed and the pump is off, the roughing line vents automatically. Generally, the mechanical pump is only needed to get to 50-100 mTorr for the cryopump to turn on, see Cryopump Procedure Appendix C . 


\section{Oil}

Check the oil by first getting the mechanical pump warm. Leave it on for 20-30 minutes for an accurate reading. The oil should be between the two "OIL LEVEL" lines, shine a flashlight behind the pump if it is hard to see the oil. If it is below you need to add oil, if it is above, you need to remove oil.

\section{A. Add Oil}

i. The pump must be removed from the chamber.

ii. Ensure the chamber is not under pressure.

iii. Take off string and rotate the exhaust until it comes off

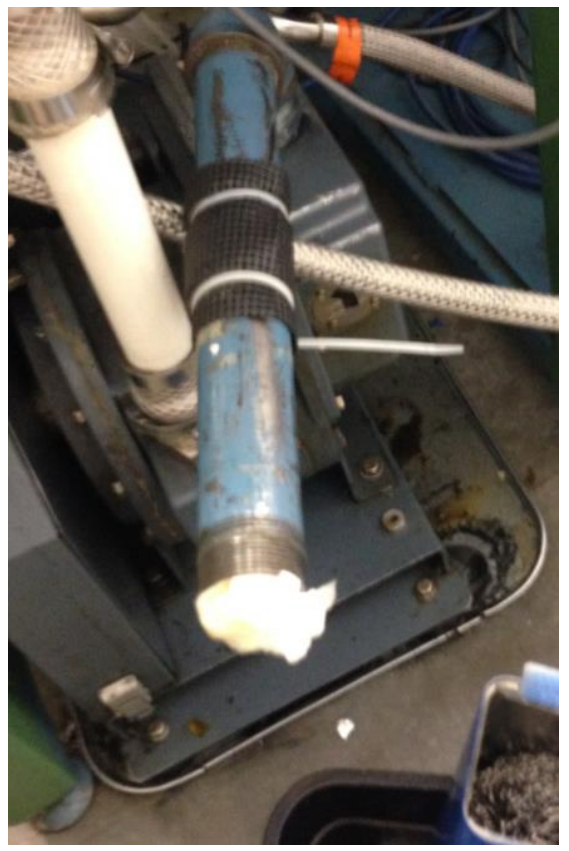

Exhaust is off and paper towels are used to stop oil dripping (mostly)

iv. Unscrew the tubing between the chamber and the pump. (below) 


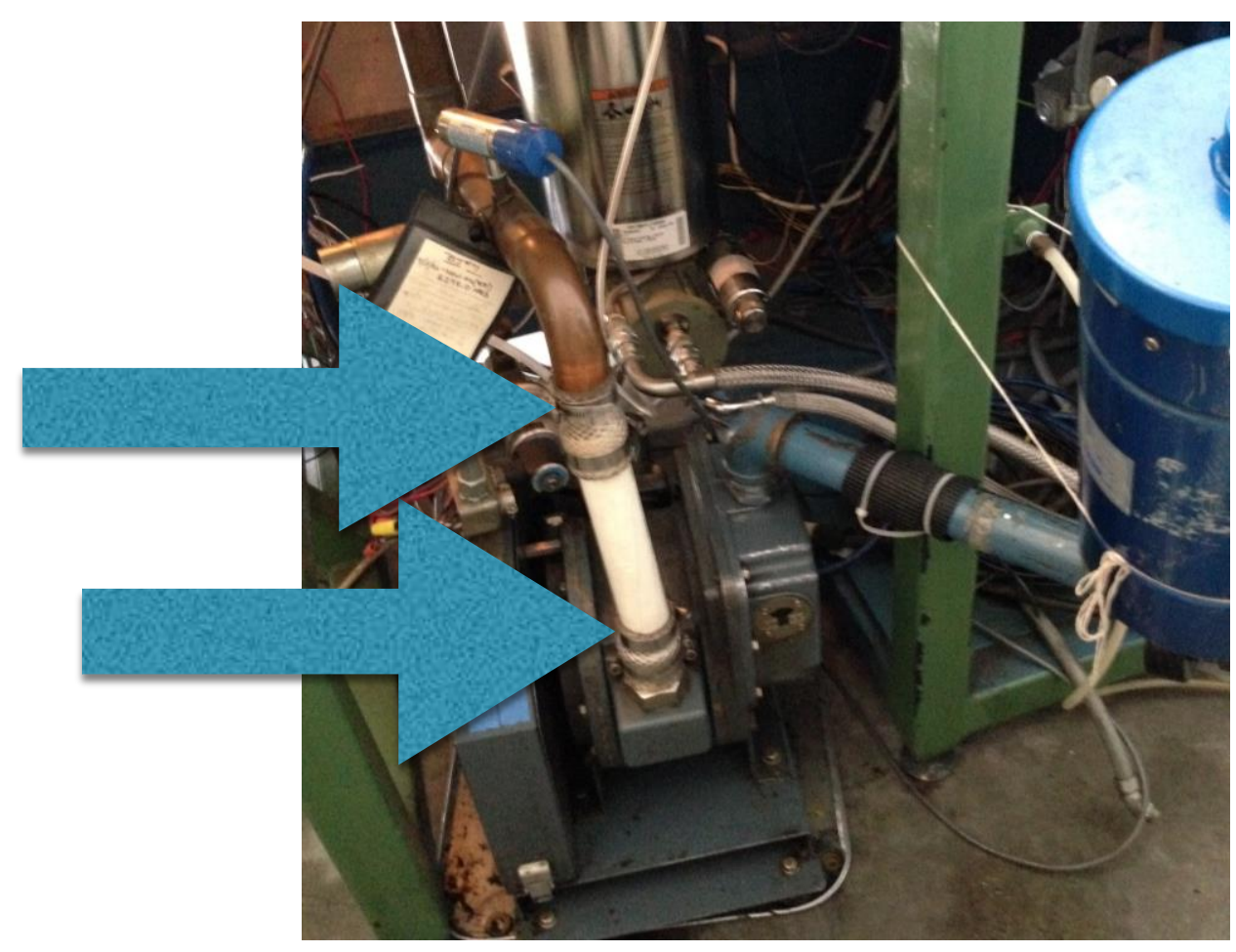

v. Pull the pump away from the chamber allowing the tubing to pull away from the roughing line. You can be tough here to make it move.

vi. Rotate the horizontal pipe counterclockwise until it comes off:

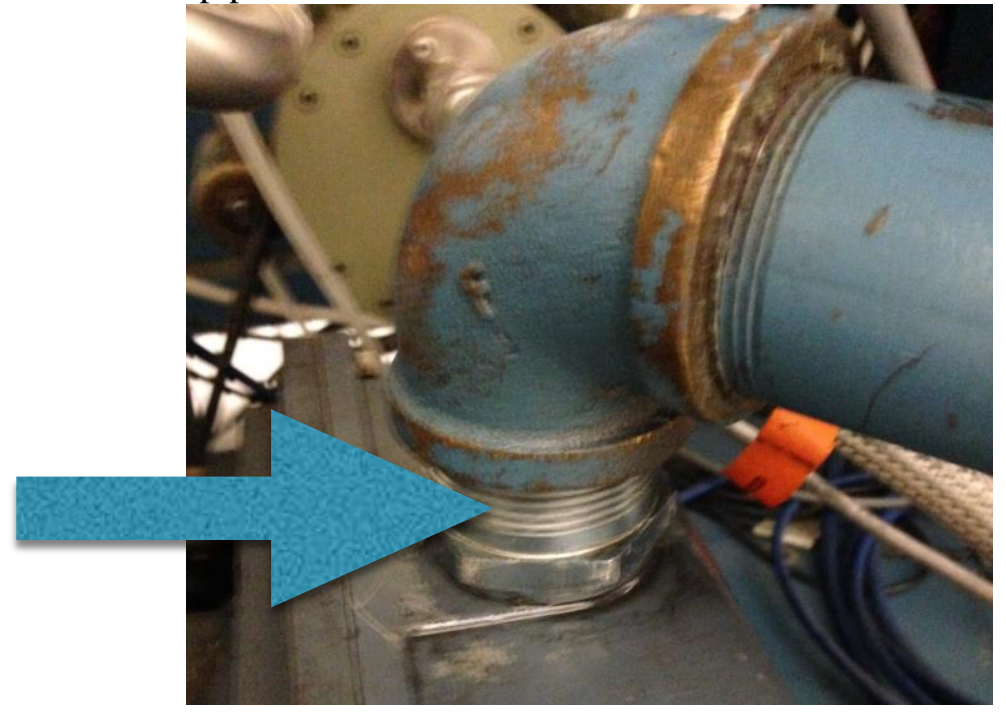

Arrow is pointing to the part that screws out of the mechanical pump

vii. Slowly add oil into the now pipe-less mechanical pump.

viii. Put the pipes back on, scoot the pump back under the chamber, and replace piping to the roughing line.

ix. The amount depends on how low the oil is, just add a cup at time. 


\section{B. Remove Oil}

i. If too much oil was added remove it with the screw at the bottom.

ii. Place a cup under the nozzle because dirty, sludgy oil will spray out.

iii. Turn the screw back to close the opening when the oil level is within the lines

\section{Remove Pump}

See the 2.Oil, A. Add Oil, section.

\section{Trouble Shooting Basics}

\begin{tabular}{|l|l|}
\hline $\begin{array}{l}\text { Won't go past 1e-1 Torr } \\
\text { Gets to 1e-2 Torr and then goes back up to 1e-1 Torr } \\
\text { and won't pump down anymore }\end{array}$ & $\begin{array}{l}\text { Add or reduce oil depending on if the oil is } \\
\text { above or below the oil line }\end{array}$ \\
Won't go past 1 Torr & $\begin{array}{l}\text { Put the fan on it, wait } 30 \text { minutes before starting } \\
\text { again }\end{array}$ \\
\hline Slow to pump down (more than 10-15 minutes) & $\begin{array}{l}\text { There is most likely a leak in the system. Check } \\
\text { all of the electric feed throughs as seen in the Big } \\
\text { Green Procedure as well as any feed throughs } \\
\text { used for the specific application. }\end{array}$ \\
\hline
\end{tabular}




\section{E. BLANKET CREATION PROCEDURE}

The blankets are created by sewing 9 layers of Mylar and 1 layer of black Kapton purchased from Sheldahl. In between each layer is a layer of Dacron netting which in this case is wedding tool from Micheal's. Nylon string is also purchased from Micheal's to sew the blanket together. A needle, gloves, and a thimble are also needed to complete the blanket. The design was modified from the Thermal Control Handbook. First, the tool must and thread must be in a student vacuum chamber for 24 hours before using in the blanket. Then the materials had to be cut to length. This proves difficult, but with patience and a sharpie sheets are cut to about the right size. The blanket does not have to be perfect, so there is some room for error. The black kapton sheet goes on the inside to better absorb and emit back the heat inside the shroud. Mylar is a typical low emissive, space grade material that is used for the rest of the blanket.

Once the layers are positioned on top of one another it is easiest to tap a small piece of Kapton tape to hold it together before sewing. There are many types of stitches, but since this was done by hand and the blankets were very thick together only one stitch was made every inch and a half. There was no back stitching. All the edges were taped with the thickest kapton tape to seal the blanket together and cover the stitching. Then, small half inch holes were trimmed along the sides every 5 inches or so to allow for air to escape. Pictures shown below as a reference.

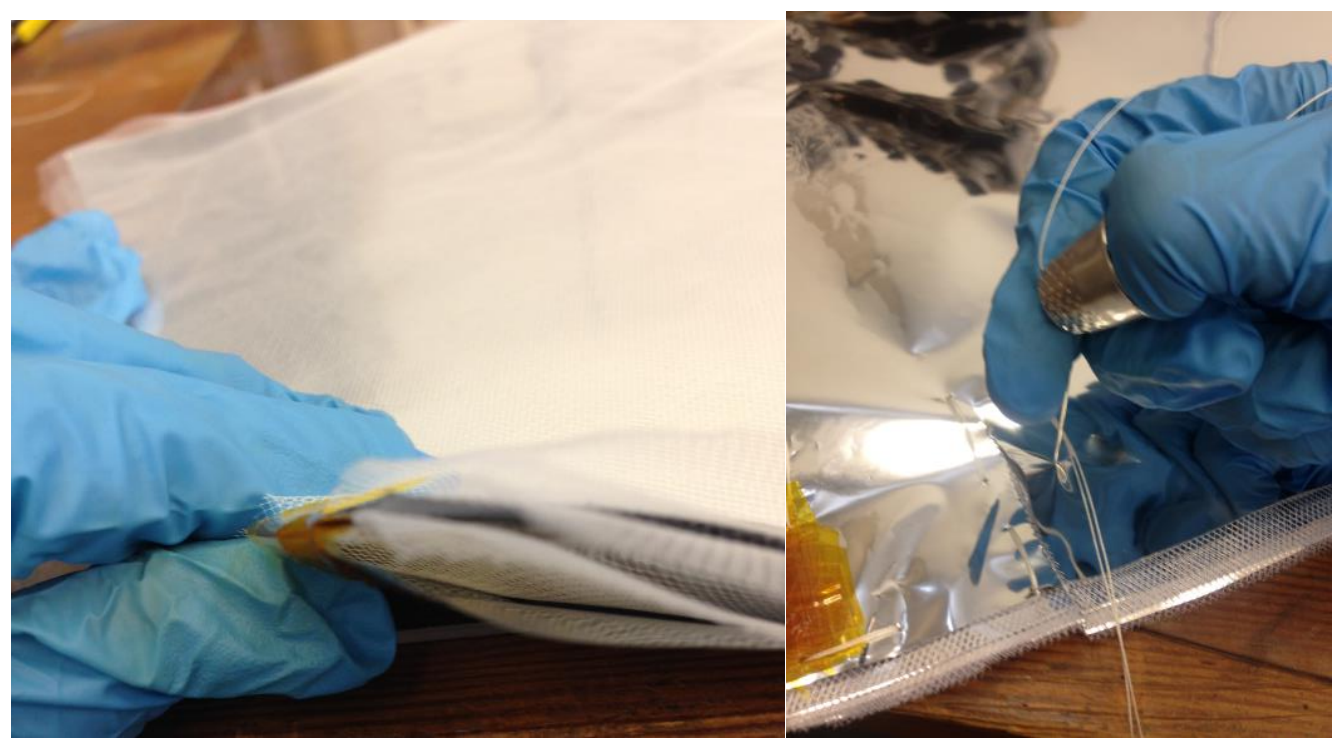




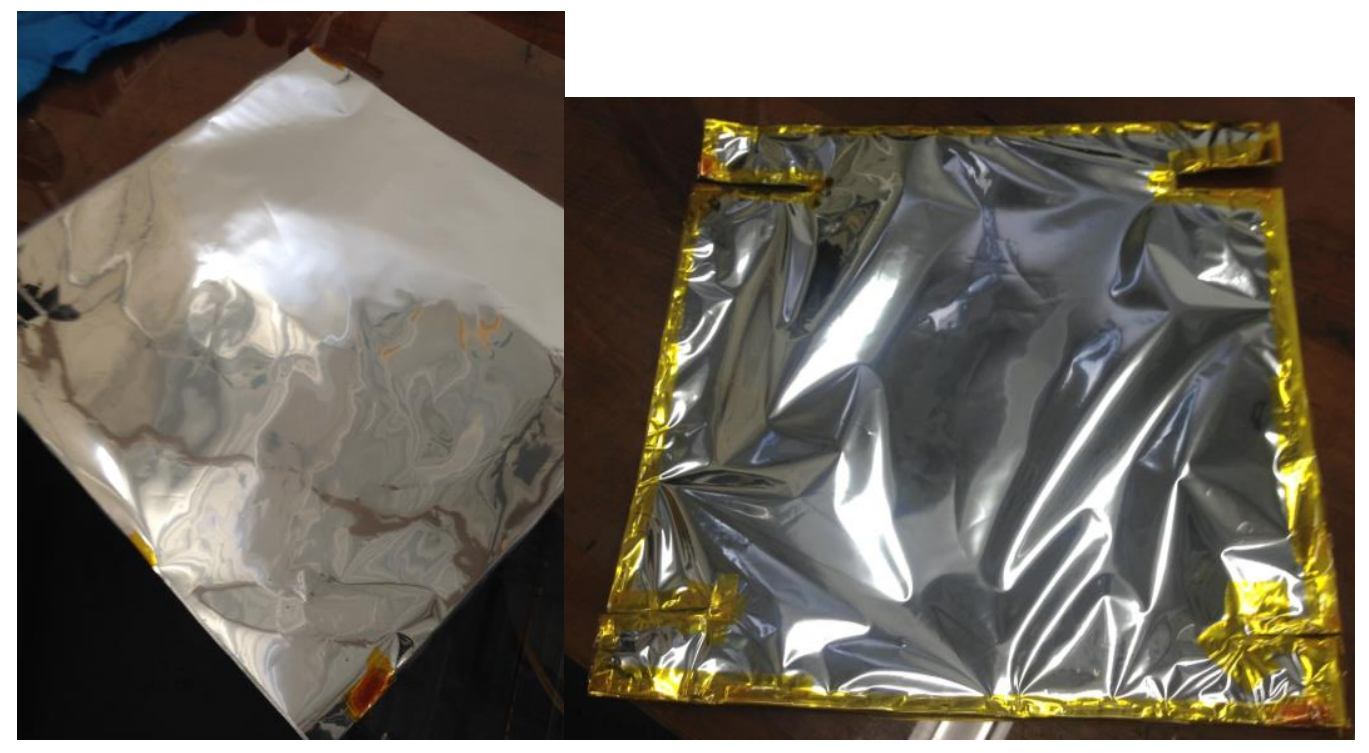




\section{F. DAP SOFTWARE PROCEDURE}

DAPStudio is installed onto the computer to be used with the DAP to output the thermocouple voltage as text file in A/D converter counts. System parameters are set as follows:

\section{CONFIGURATION: DAP0}

1) Input

a) Settings

i) Group Size: 4; Input Range: -5 5; Count/ch: 0

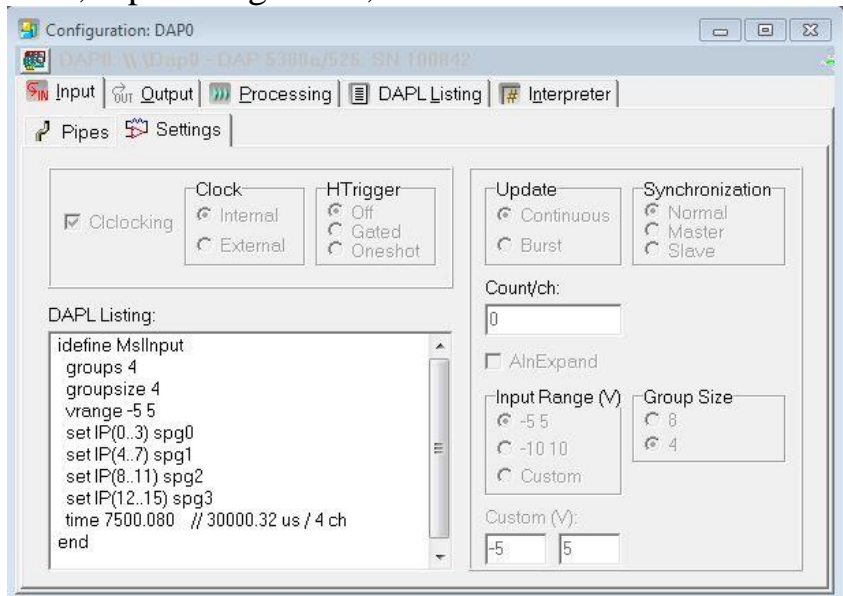

b) Pipes

i) Groups: 4; Rate, s.s.ch: 33.333; Pin: SPG0

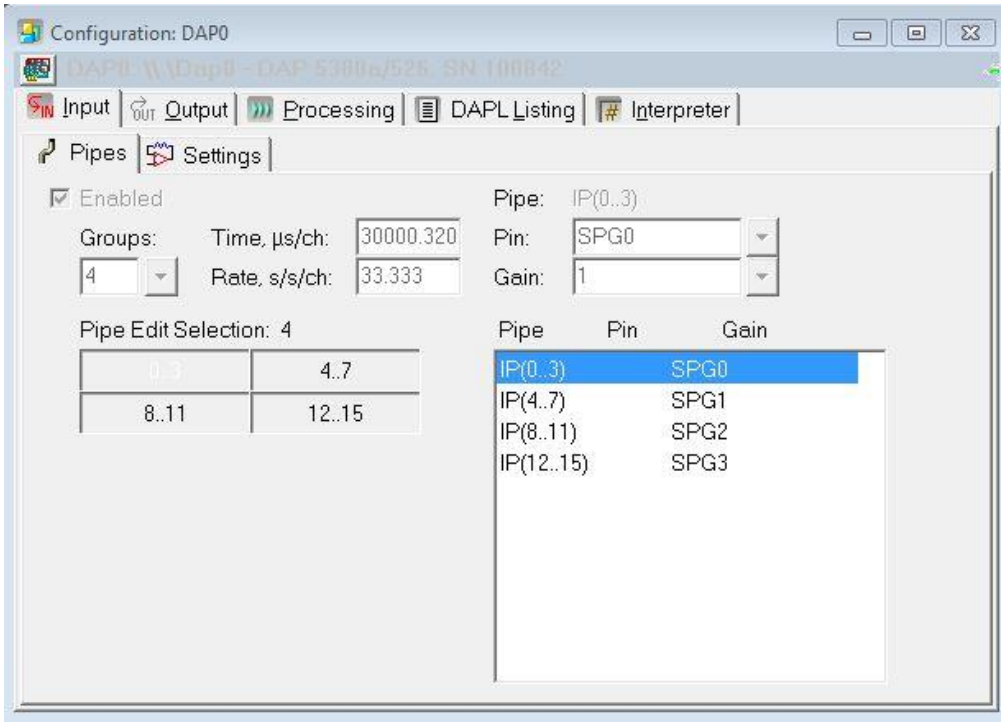

2) Output - None

3) Processing

a) Send to PC

i) Click "Select All", then uncheck IP10 to IP15, leaving the first 10 selected IP0 to IP9 


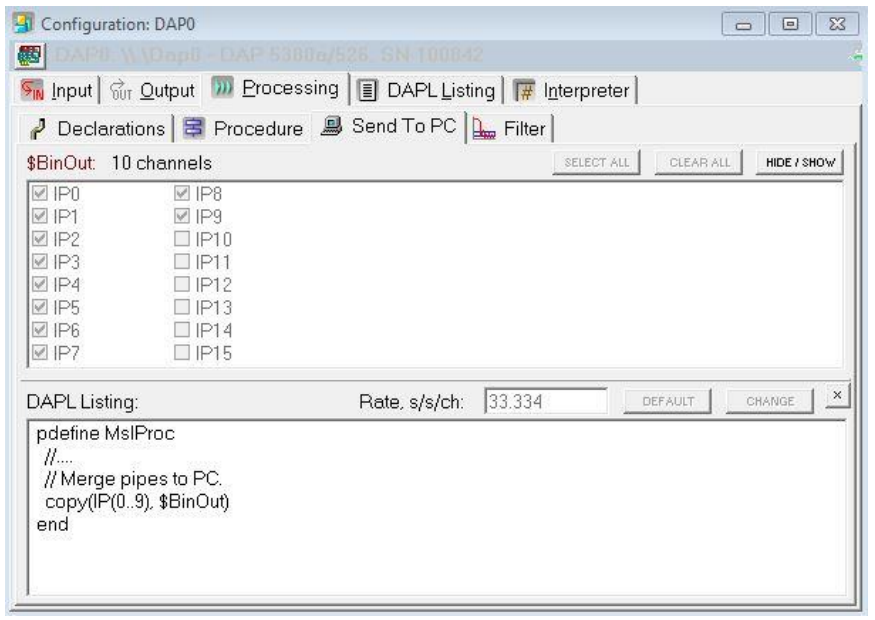

4) Window, DiskLog

a) Under "Output File:" create a file name

b) Format: Text

c) Logging Options: Overwrite confirm

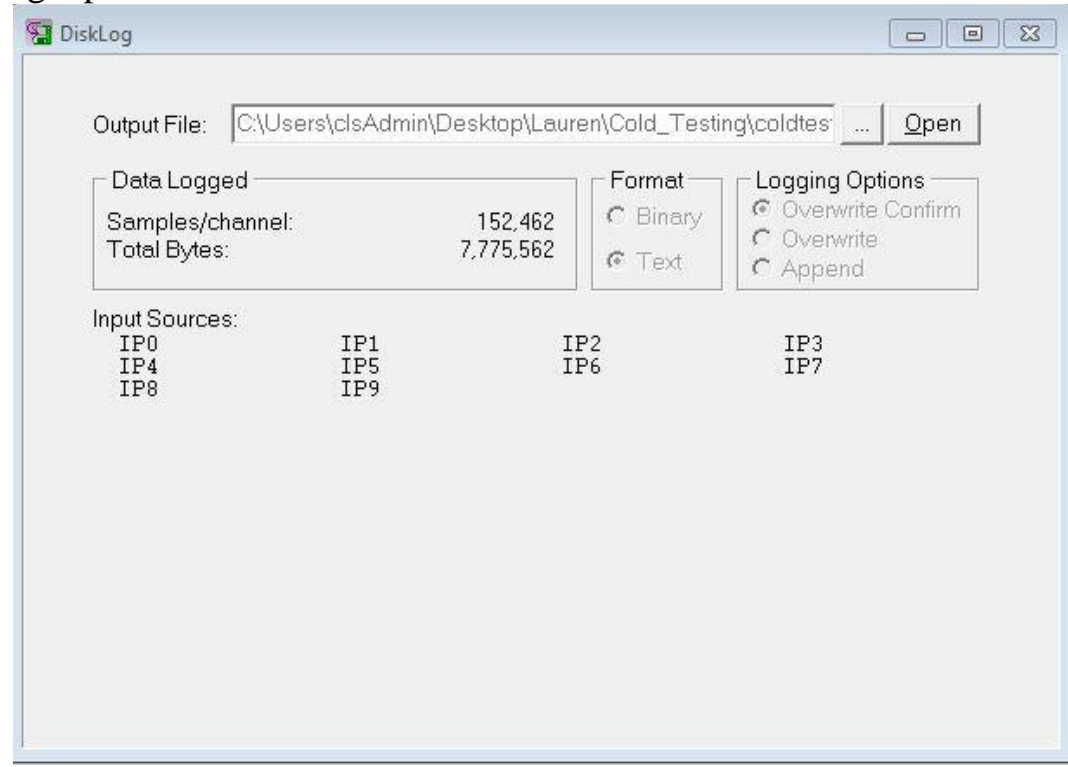

5) To view counts as the test is running:

a) Window, Table

b) Window, Graph 


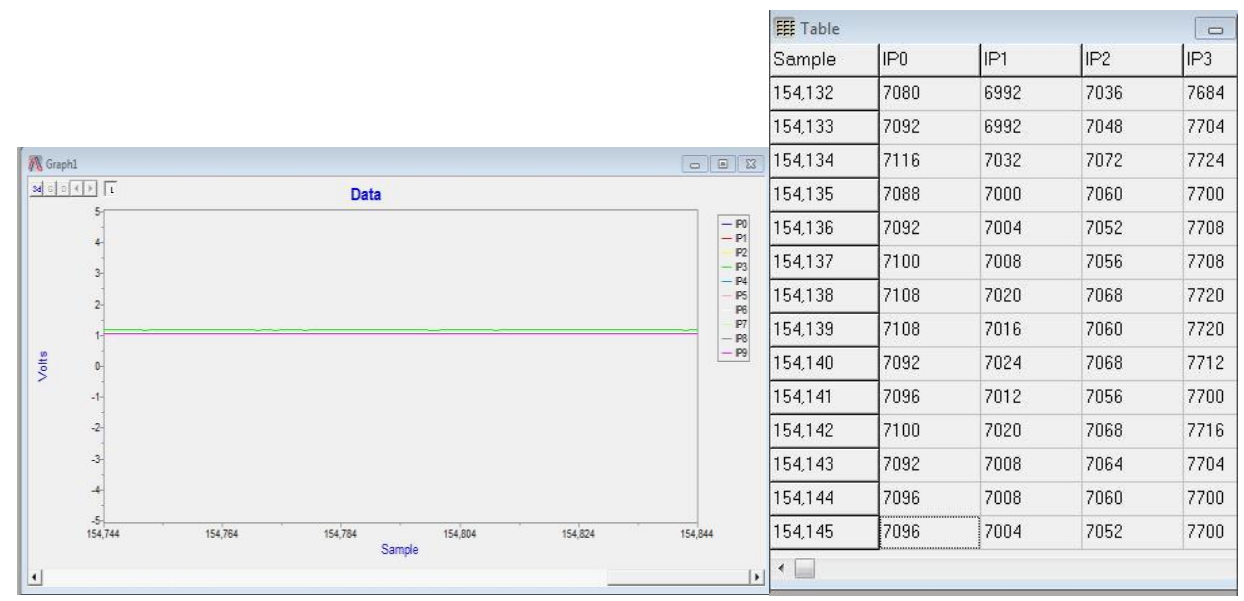

Graph and Table shown during testing in DAPStudio

Then, the text document can be read in a Matlab Script and plotted over time. The script is shown in Appendix J. Multiple text documents can be read in one Matlab script to show a full test over the entire testing time. During the test, the best way to check temperature without stopping the DAP run is to use the table counts output and convert to temperature with a calculator. 


\section{G. PLATEN INSTALLATION WITH SHROUD}

The shroud must be used for either a bake out or thermal cycle test. The bake out needs the shroud so that the heat strip does not touch the blanket. The thermal cycle test needs the shroud to insulate the component. Follow the procedure bellow to ensure proper installation of the plate with the shroud attached.

1. Wear gloves to reduce oxidation of the copper

2. Attached heat strip with two extending cables to the plate

3. Put the plate sideways and put the shroud on it as shown below

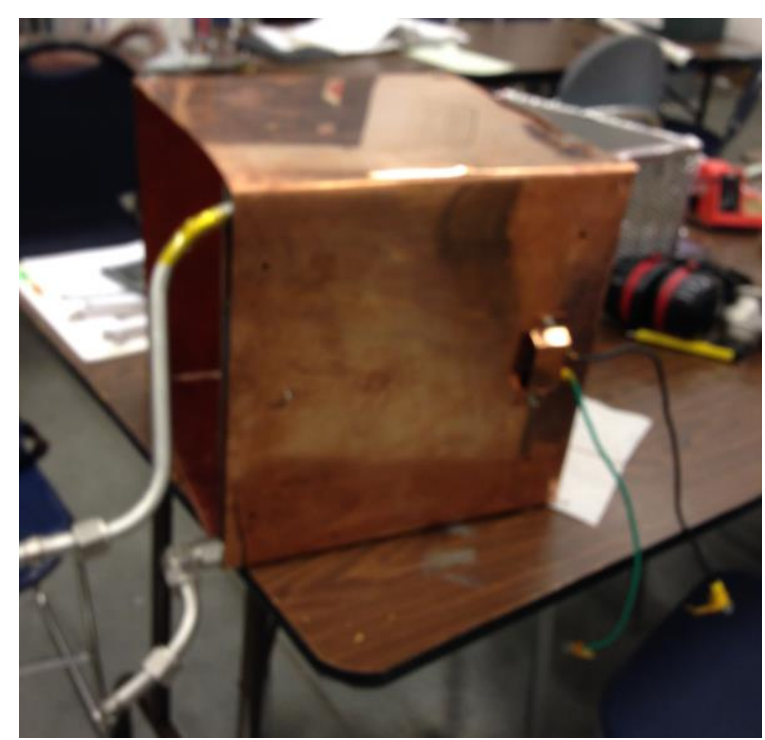

4. Start putting the heat strip screws through the holes made in the shroud

5. Continue to put in 6-32 $11 / 4$ " screws with washers on either side through the plate and the shroud

6. Make sure all screws( 2 from heat strip, 6 going through the plate) are tight so that there is contact between the copper shroud and the interior cooling pipes

7. Double check that the heater wires are tight on the heat strip 
Note: The copper shroud does not fit perfectly on the sides, there is not very good contact between the side of the plate and the shroud. The blanket helps to seal in the heat without needing conduction from the heater to the shroud.

8. Move the shroud and plate to the opened vacuum chamber and use a small support to hold it up
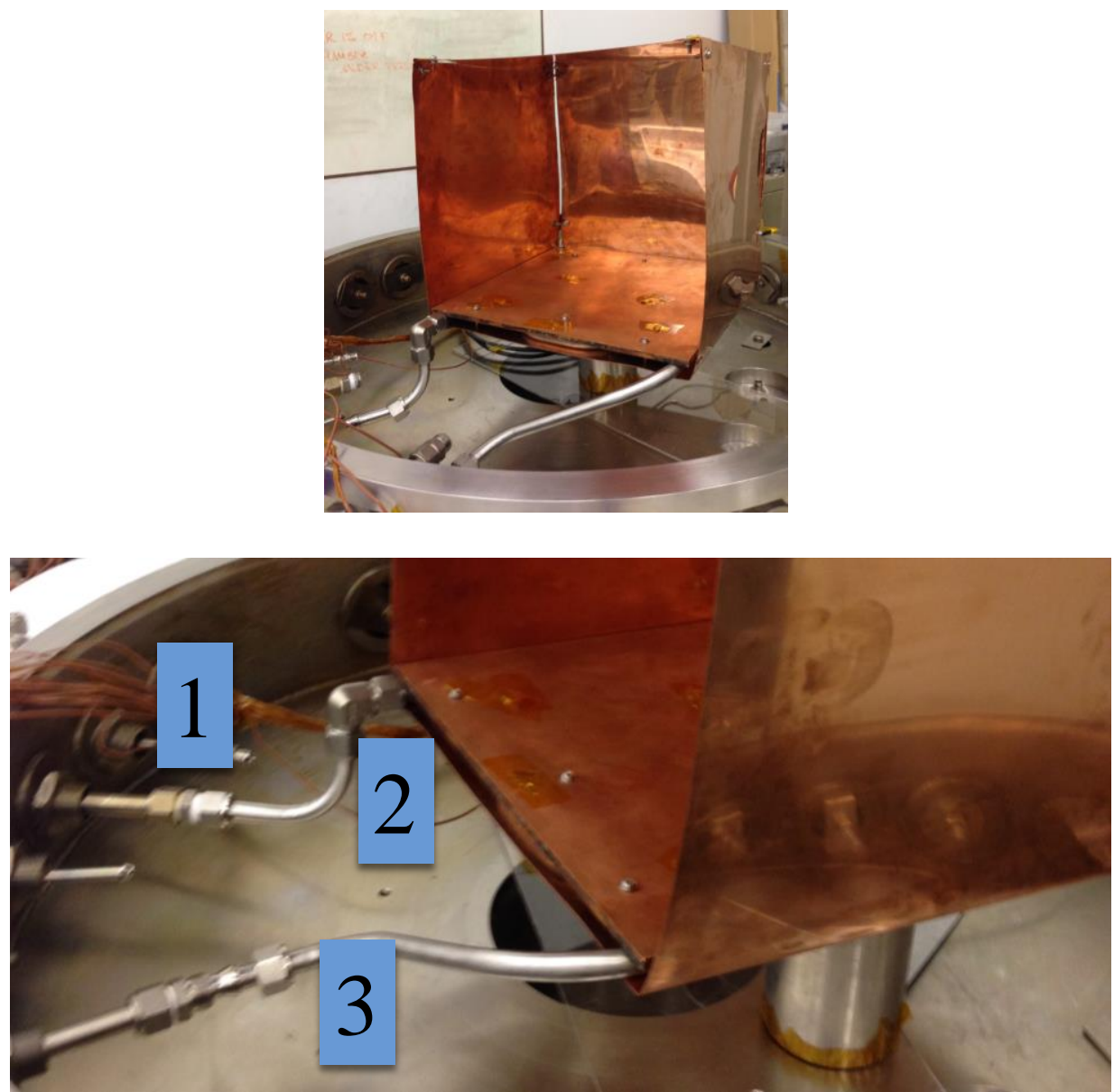

9. Attach swagelok 1 (pictured above), tightening all the way 


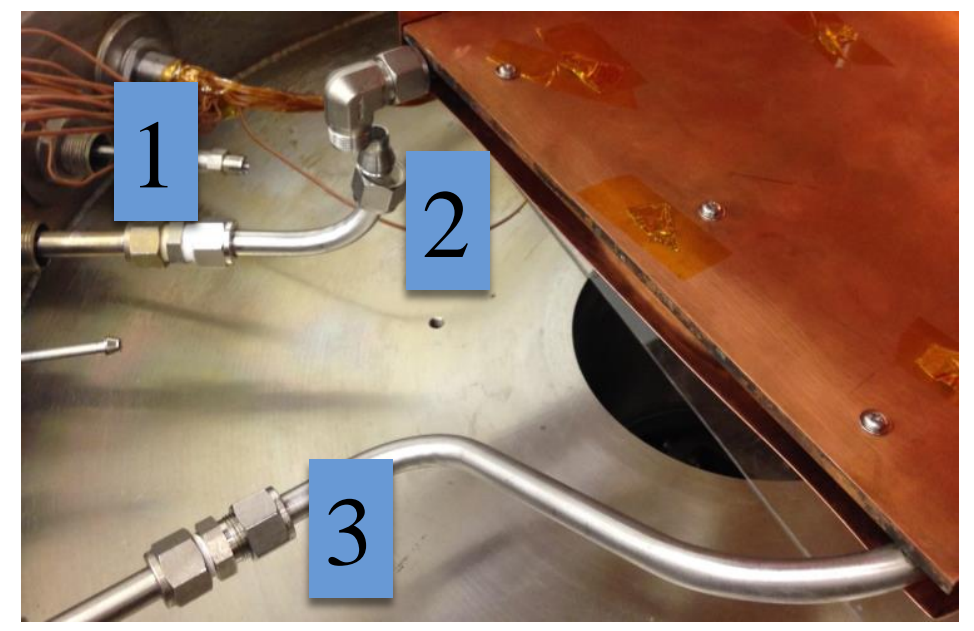

10. Detach swagelok 2 (pictured above)

11. Attach swagelok 3 (pictured below), tightening all the way. There is some resistance, but keep tightening until snug

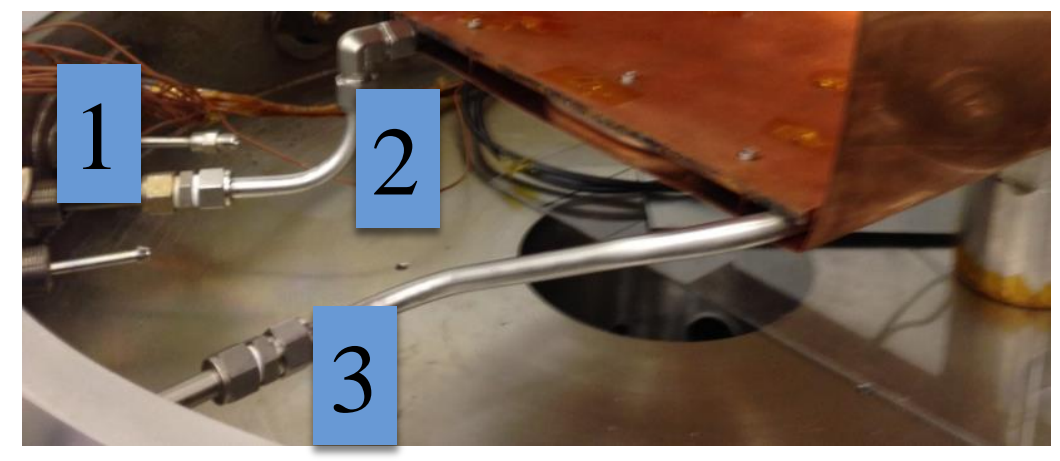

12. Attach swagelok 2

13. Double check all fittings are snug (no need to over tighten, but apply some pressure)

14. Attach wires from strip heater to a BNC cable on the inside of the chamber

15. Use a BNC cable on the outside of the chamber to connect to the DC Voltage power supply

16. Attach all TC's needed on the component or plate.

- Use aluminum tape to secure TC, the tape is conductive to better read the temperature

- Use kapton tape on top of the aluminum tape, the kapton tape is more secure than aluminum tape 
- Use kapton tape to secure all the TCs around one of the pipes. This is an opening through the blanket and can also be used for electronic wires

17. Attach the bottom blanket using kapton tape with a "Buddy Tab". The buddy tab is made at the end of a piece of tape fold over about a half centimeter or tape so that it can be easily pulled off for removal. The black kapton goes towards the plate, shiny mylar faces out. $\underline{\mathrm{DO}}$ NOT tape all along the seams! The air must be able to vent out of the shroud through the seams.

18. Attach the bottom blanket using kapton tape with a "Buddy Tab". The buddy tab is made at the end of a piece of tape fold over about a half centimeter or tape so that it can be easily pulled off for removal. The black kapton goes towards the plate, shiny mylar faces out.

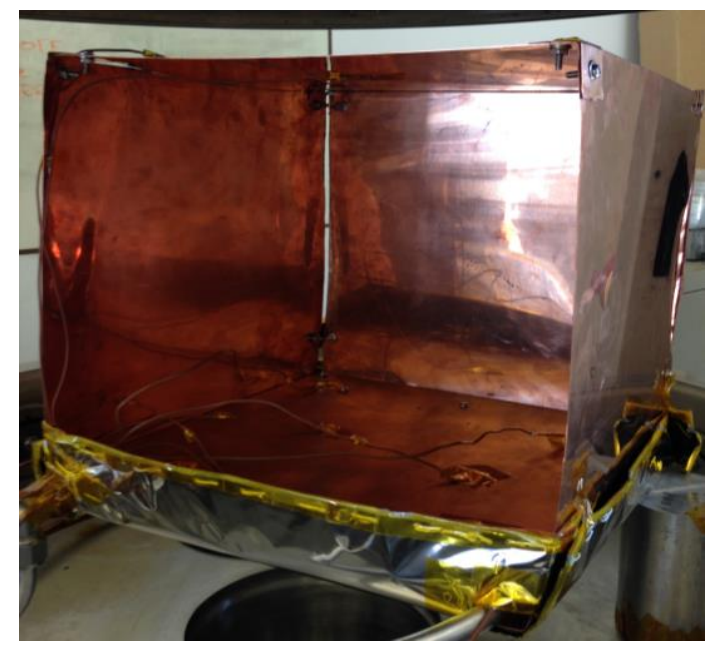

19. Attach side blanket, making sure the seam is at the back of the shroud so the front is all blanket. 


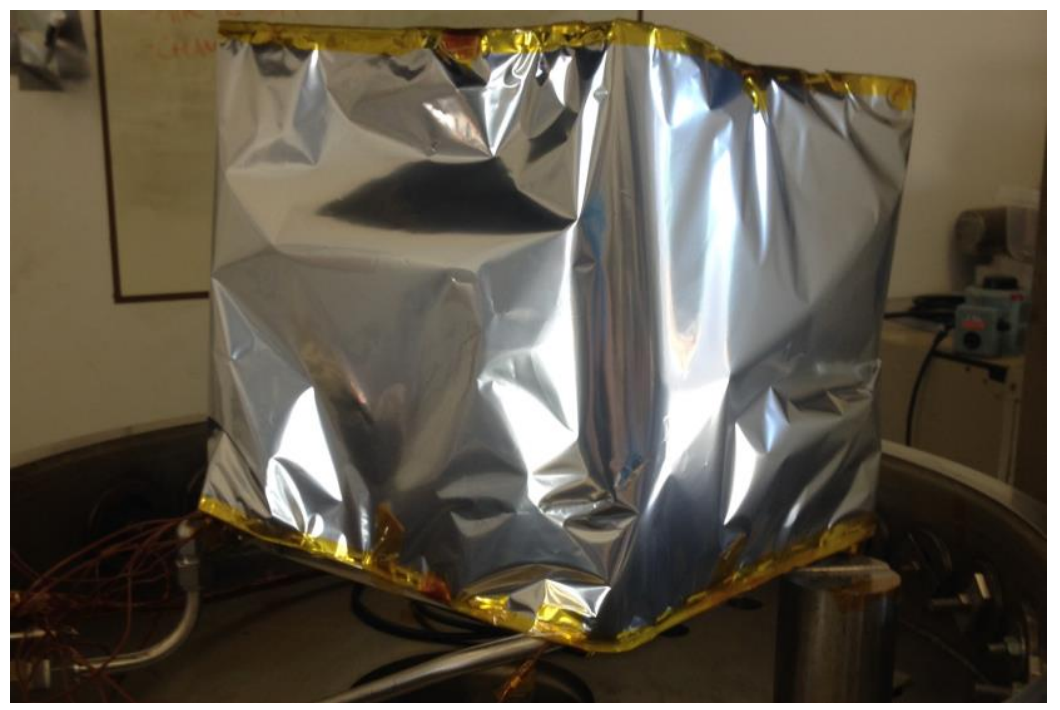

20. Attach side blanket back to cover seem. There should be a hole for the heat strip wires to come out of. The bottom should be lose enough so that the heater screw does not touch it on either side.

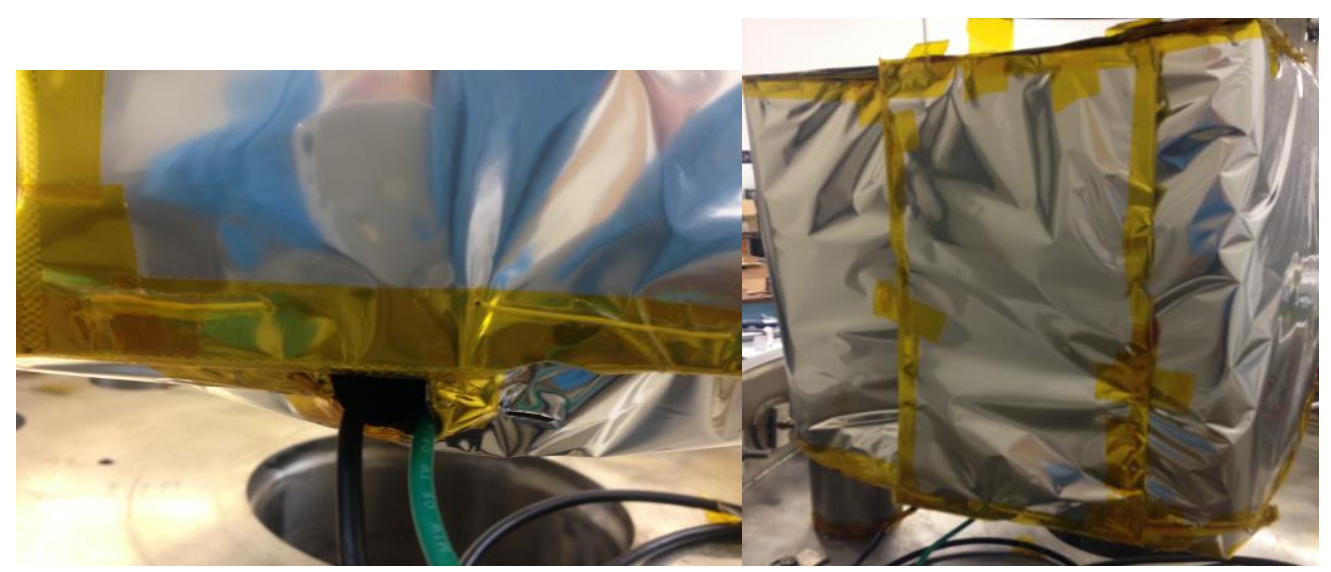

21. Attach top blanket

Note: The copper can be cleaned with vinegar, but must be put in the smaller student chambers to outgass for 24 hours (no heat necessary). 


\section{H. ATS CHILLER OPERATION}

The following instructions are adapted from Leila's project "Thermal Vacuum Chamber Operation and Testing", the fill/drain Manual, and the ATS Chiller Manual. It is highly recommended to read all of the manuals first before working with the chiller. There is repeating information between the different procedures, but each has some unique information. The Fill/Drain Procedure from B/E Aerospace Doc NO: 4080194 REV. A is particularly useful to understand how the Galden®fluid fills up the ATS Chiller at each step.

This procedure will cover the entire process to use the ATS Chiller. The chiller must be set up mechanically first. This involves attaching all the piping to the vacuum chamber and filling the machine with Galden®fluid. The refrigeration fluid is already in the ATS Chiller in a closed system. The refrigeration fluid cannot and should not be tampered with; it doesn't need to have fluid added or removed and if any problems are suspected ATS should be contacted. To fill the machine with Galden®fluid the Fill/Drain tank is used. The tank is filled with Galden®fluid first and pressurized with nitrogen. The nitrogen is an inert gas so it won't react with the Galden ${ }^{\circledR f l u i d}$. Pressurized gas is needed to properly fill up the ATS Chiller since there is no way to poor the liquid into the chiller. Also, during operation the tank is pressurized with nitrogen gas. Nitrogen and the fill/drain tank are again needed to drain the ATS Chiller. All of the steps outlined here are listed in detail below.

The fill/drain procedure from ATS instructs the user to run water through the system, then nitrogen or clean air. This was not done because it wasn't necessary for a student machine, the Galden ${ }^{\circledR} f l u i d$ was already dirty from being reused which was also 
not following the specifications, but again this was for student experimentation, not industrial regulations.

\section{I. $\quad$ Preparation and Fill}

a. Start by attaching the Swagelok piping to the ATS chiller and the chamber. The platen and shroud must be secured at this point using the procedure from Appendix G. The grey foam around the piping covering is in place to protect from accidentally touching the pipes when ice forms during cold operation.

i. Cap Channel 1 in the back, do not attach the bypass piping shown in the figure.

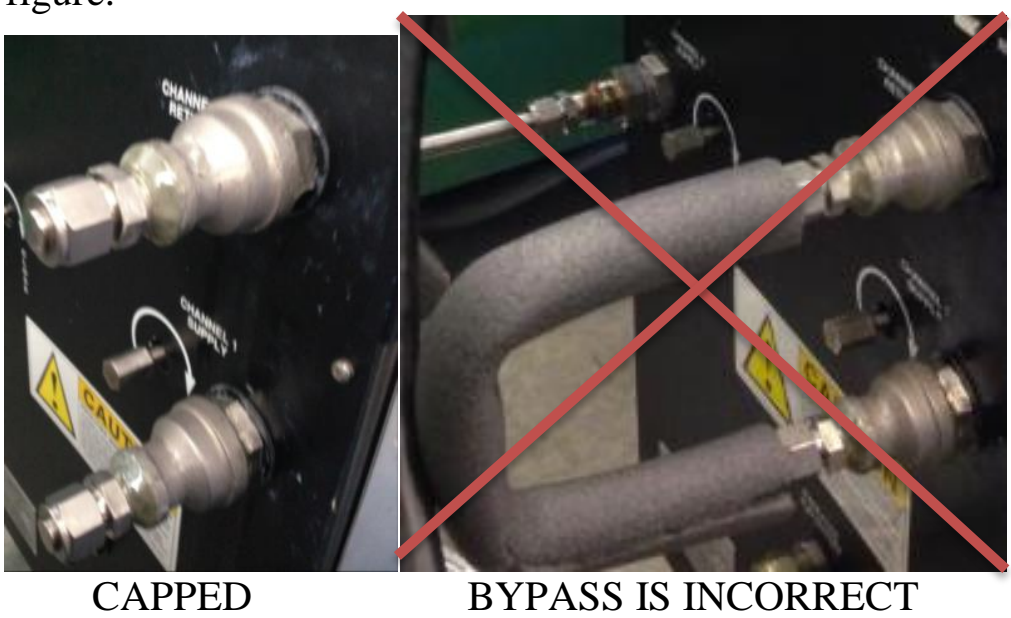

ii. Attach platen and piping securely to the vacuum chamber so there won't be any leaks. No plumbers' tape is needed in the Swagelok connection. See Appendix $\mathrm{G}$ for more details on attaching the platen.

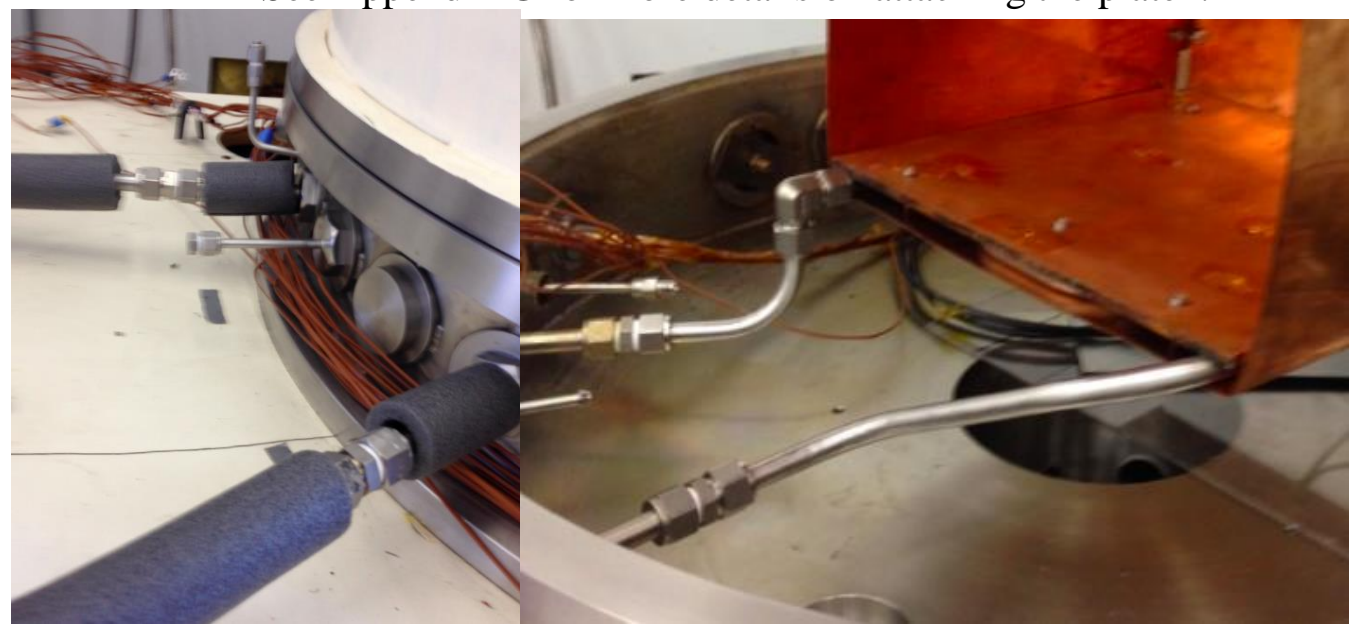

iii. Attach pipes to the back of the ATS Chiller at the channel supply and return. Use the special connector provided by ATS to convert the chiller oring connector to the Swagelok pipes. 


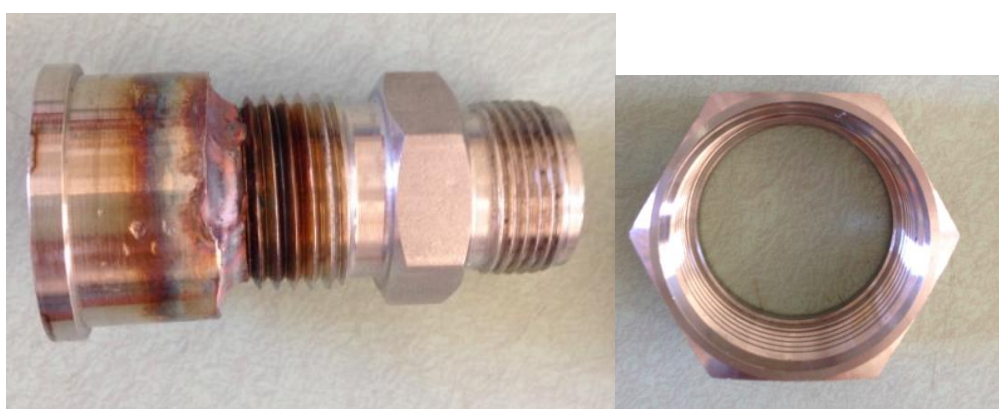

ATS TO SWAGELOK FITTING

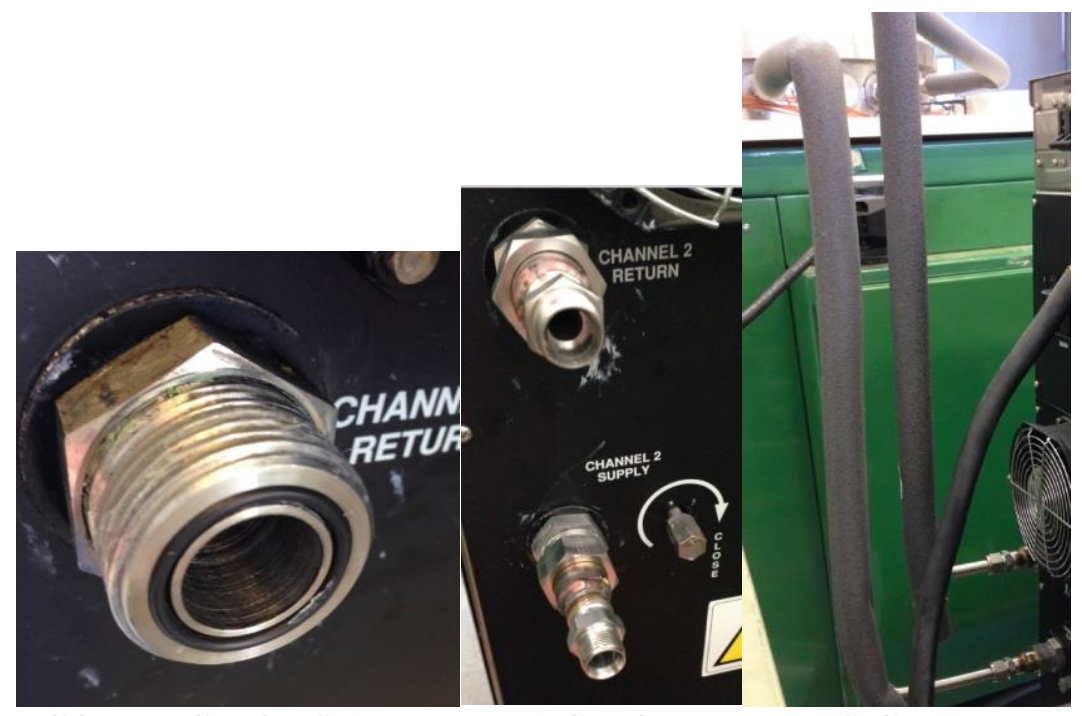

CONNECTIONS AT THE BACK OF THE ATS CHILLER

b. Fill and Pressurize the Fill/Drain Tank

i. Empty 3 gallons of the Galden@fluid into the fill/drain tank if there isn't any already in the container. The top of the fill/drain tank pops off when not under pressure with a latch at the top. NOTE: The pressure gage is broken. It reads a higher pressure than ambient.

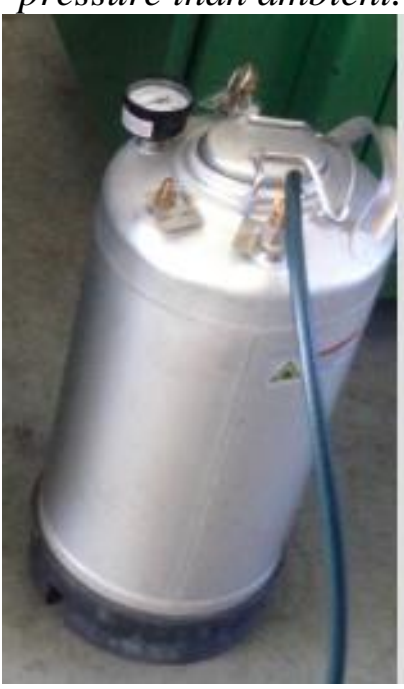




\section{FILL/DRAIN TANK}

ii. Close the lid of the fill/drain tank (notice the o-ring and make sure it is in place)

iii. Wear safety glasses when working with high pressure!

iv. Attach the Nitrogen Tank to the fill/drain tank using the pressure lines and the pressure regulator. The yellow and blue hoses are compatible with the Shraeder fittings on both the ATS chiller and the fill/drain tank. The hose has a connector at one end that is able to compress the middle nipple of the Schraeder fitting to allow pressur through. Such a fitting is not needed on the Nitrogen tank, or at one end of the hose valve. Make sure the hose fittings are pushing on the schraeder fittings for a proper connection. The series goes in the following order:

Nitrogen Tank -> Regulator -> Hose -> Hose Valve -> Drain Port on tank
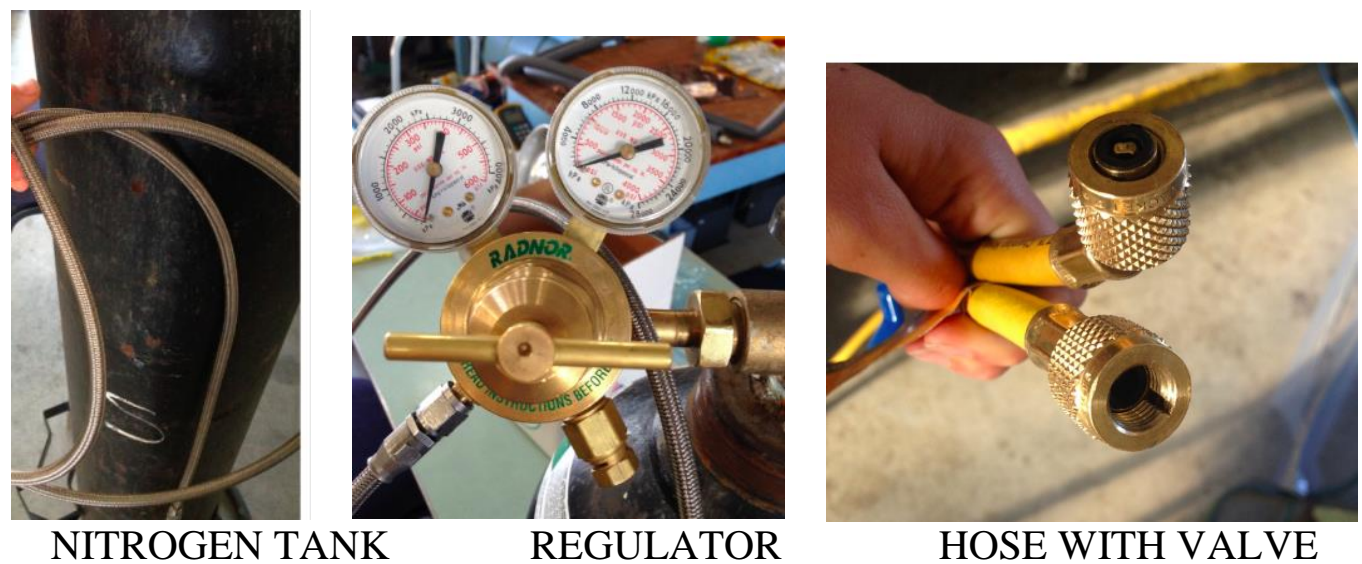

v. Make sure the regulator knob is loose by turning counterclockwise (opposite of normal screws) The knob will feel very loose, this means the regulator is closed.

vi. Close the valve on the hose, it should be perpendicular to the hose when it is closed. An open valve is in line with the hose.

vii. Open the nitrogen tank knob (counterclockwise, use force)

viii. At this point the pressure reading on the right of the regulator will show the pressure in the tank. The left pressure gage should still read ambient

ix. Slowly turn the regulator knob clockwise to open the valve. The pressure gage on the right will slowly increase. The line is pressurized between the regulator and the tank. Stop turning when the gage reads 80psi.

x. Open the valve on the hose so that the tank fills with a pressure of 40 to $60 \mathrm{psi}$ (add 40 to 60psi to what the gage originally read at ambient). This happens quickly so monitor all pressure gages.

xi. Close the valve on the hose.

xii. Close Nitrogen source (clockwise)

xiii. Close the regulator valve (counterclockwise)

xiv. Detach the hoses, some pressure will release.

Xv. Move the fill/drain tank closer to the ATS chiller 
xvi. Close the supply valve for both channel 1 and 2 (clockwise)

c. Fill the Lines between the chiller and the platen

i. Close the supply valve for both channel 1 and 2 (clockwise)

ii. Connect a hose from the "Fill Port" on the fill/drain tank to the "Fill/Drain" connection on channel 2. The hose should be closed so that liquid does not spill out before both ends are attached.

iii. Attach another hose valve to the connector above the sightglass labeled "Pressurize 80psi Max", open the valve. This valve purges the air as the Galden® fluid fills the chiller.

iv. Open the hose valve for the fill/drain port to get the set up shown below:

v. Wait until fluid reaches the sightglass and only a few bubbles are seen. There is still air in the system at this point so the elimination of air bubbles at this point is not possible, this is contrary to the manual's advice of waiting to stop filling until there are no longer any bubbles. If a LOT of bubbles start to form in the sightglass, then that means the Galden ${ }^{\circledR}$ fluid is drained from the tank and only nitrogen is being pushed through the system. The tank will need to be refilled and re-pressurized. The sightglass should not fill up at this point, because the fluid is needed in the lines, not just the reservoir. Close both valves when the first 2 lines are filled in the sightglass. Do not remove hoses.

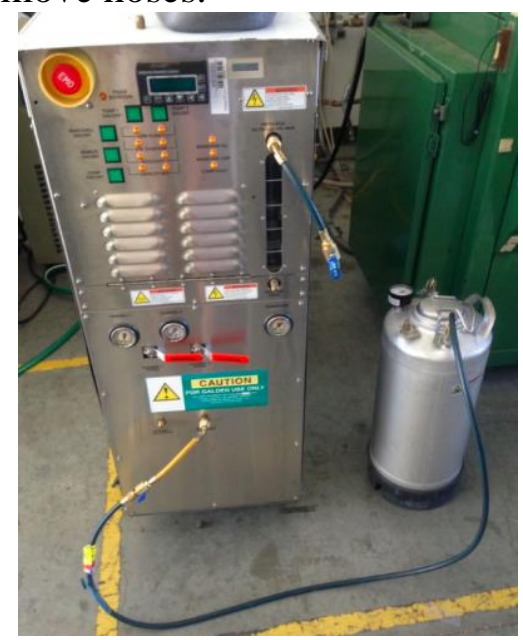

\section{FILL LINES BETWEEN CHILLER AND PLATEN}

d. Fill internal lines of the ATS chiller

i. It is possible to refill the fill/drain tank with nitrogen following part (b. iv.) if the pressure is getting low. No need to detach from the ATS Chiller at this point. If more fluid needs to be added decompress the Fill/Drain Tank by pulling on the vent. It is loud.

ii. If the tank is pressurized and full of Galden ${ }^{\circledR}$ fluid, then the channel 2 supply valve in the back of the chiller can be opened. This opens the lines to the internal pump.

iii. Open the hose valves between fill/drain tank and ATS Chiller and the one above the sightglass (shown in picture from c. v.) 
iv. Once again bubbles should start to form in the sightglass as the air is purged from the lines. Continue filling to 2 or 3 lines in the sightglass. The bubbles will not stop all the way. Later in the procedure the lines are purged to get rid of the last of the air in the lines

v. Close the valves on the hose.

vi. Disconnect the hose from the "Fill/Drain" Port at the bottom of the chiller. e. Fill the Reservoir

i. It is possible to refill the fill/drain tank with nitrogen following part (b. iv.) if the pressure is getting low.

ii. Connect the hose from the Fill port on the Fill/Drain Tank to the connector under the sightglass marked "Reservoir Drain". A hose valve should also be attached at the top of the sightglass. The setup is shown in the picture below:

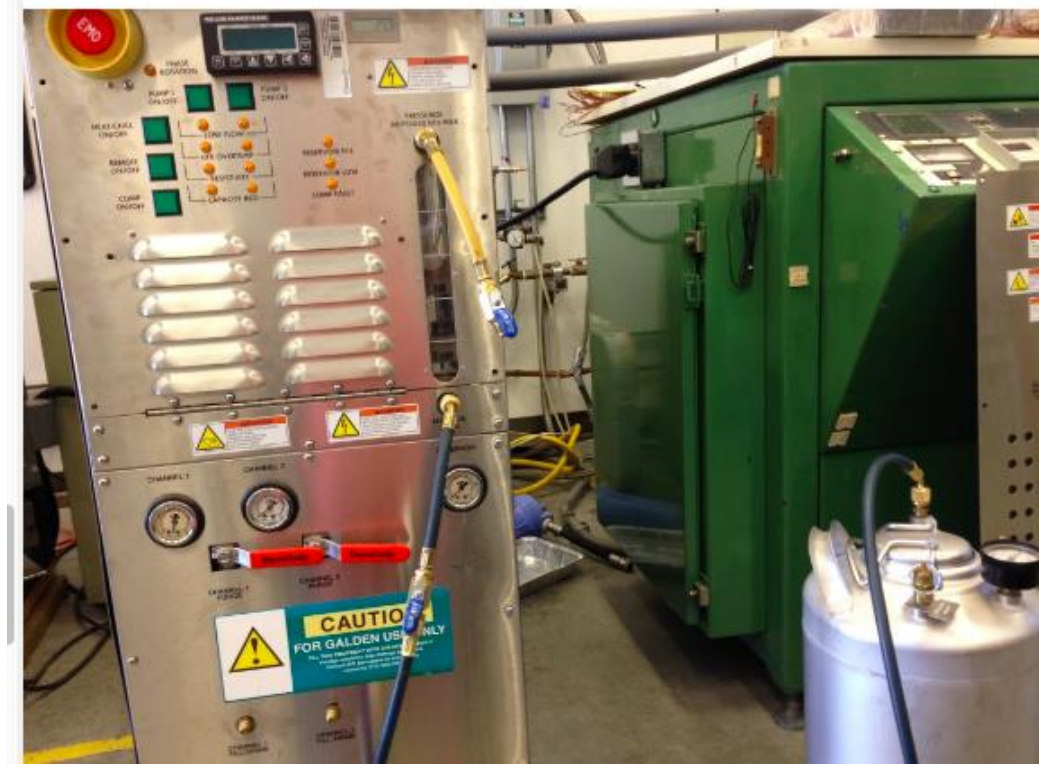

FILL THE RESERVOIR

iii. Open both valves the hoses and fill up the sightglass to the fourth line. If the Galden ${ }^{\circledR}$ fluid all drains out of the fill/drain tank, then a large amount of bubbles will form in the sightglass. This is nitrogen from the fill/drain tank going through the reservoir. The nitrogen does not go through the whole system, just the reservoir, so there is no need to refill the lines if this happens. Close the valves when the fluid in the sightglass reaches the fourth line or the Galden ${ }^{\circledR}$ fluid is emptied.

iv. Pressurize the ATS Chiller with nitrogen up to 30-40psi. Two options to accomplish this.

1. Fill the fill/drain tank with nitrogen at 60-80psi following steps from $b$. iv. Then attach a hose from the drain port on the fill/drain tank to the top of the sightglass marked "Pressurize 80psi Max". Open the valves until the pressure of the reservoir reads 30-40psi. 
2. Connect the Nitrogen source directly to the ATS Chiller. Follow steps from $b$. iv. But make sure the regulator letting in a lower amount of pressure (30-40psi) not 80psi. Fill until the ATS Chiller reservoir gage reads 30-40psi. Example Below:

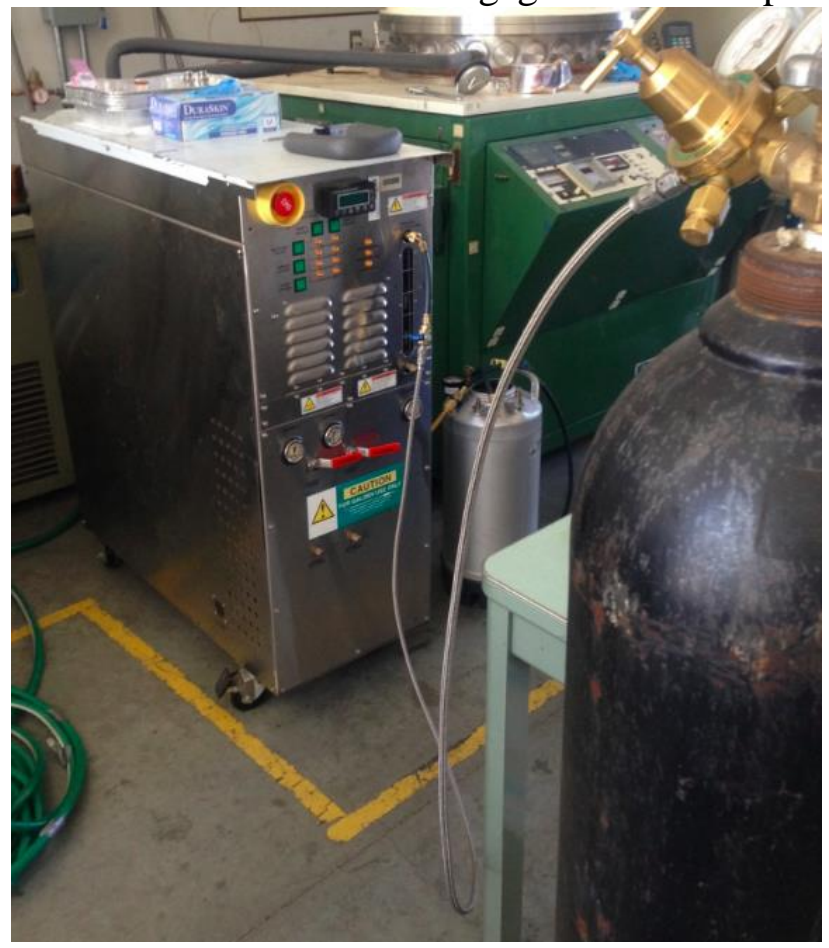

PRESSURIZE CHILLER

v. The entire system is at 30-40psi and therefore, the pressure gage for channel 2 should read a higher pressure than 0 . Channel 1 should not increase in pressure. Channel 2 pressure gage looks broken but it is not.

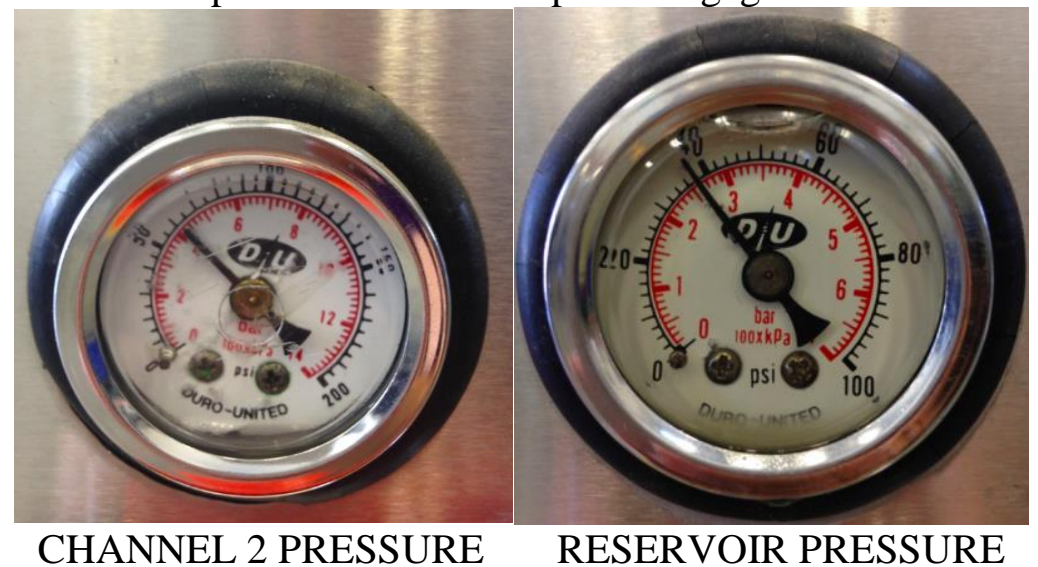

vi. Close all hoses that are attached to the reservoir and disconnect them.

\section{f. Connect the water hoses}

i. Connect the yellow hose to the water supply behind the HVEC Chamber. 
ii. Connect yellow hose to the blue filter, then the filter to the ATS hose going to the "H2O Inlet". There is a black hose that attaches to the ATS chiller "H2O Outlet" that connects to a large green hose. The green hose is fed to the lab drain in the middle of the floor. Take of the grate and put the hose inside the hole. View picture below as a reference.

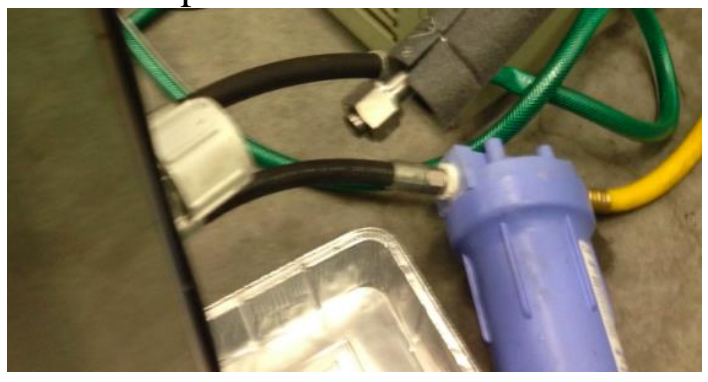

WATER CONENCTIONS

\section{Operation}

\section{a. Power}

b. Water

i. Plug in the machine into a three phase power outlet.

i. Open the H2O supply valve along the wall behind the HVEC vacuum chamber.

ii. Turn the water knob 3.5 turns clockwise to get a 10 gallon per minute flow.

c. Operate

i. Check Pump2

1. Press the button for pump \#2 and the light should come on. This checks wiring.

2. If pump 2 LED does not turn on, press "Alarm Ack" on the Watlow Controller and try turning on the machine again starting with the breaker.

3. Turn on the breaker for Pump \#2 within 10 seconds to start the pump. (On is "up", they should all be "down" before plugging in.)

ii. Only pump 2 should be on at this point and the "low flow "light should be off.

iii. Open purge valve on the front of the ATS Chiller for channel 2. Leave on for about 3 minutes, then close the valve.

iv. Turn on the breakers in the back for the Compressor and Heater \#2.

v. Turn on the buttons for the compressor and the heater \#2. The system should look like the picture below: 


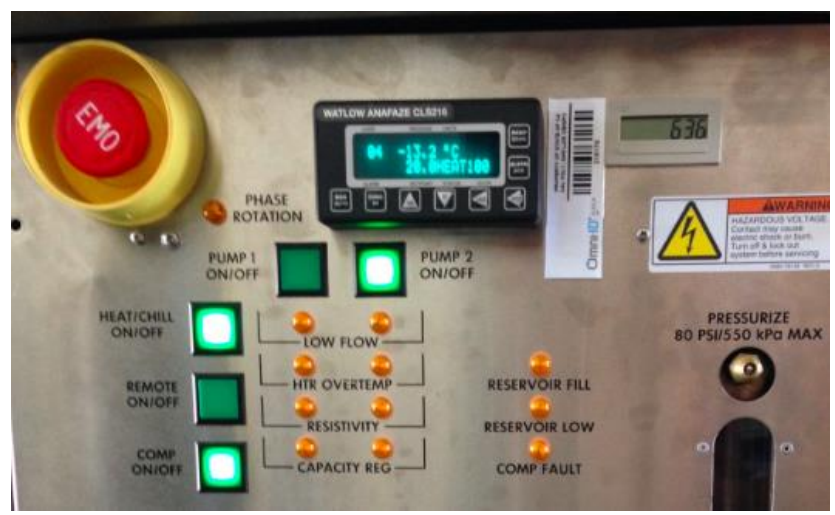

ATS CHILLER ON

vi. Note: You should not hear the fluid in the lines. If you hear fluid turn it all off, turn off water, and depressurize the ATS Chiller. Close the supply valve in the back and repeat the fill processes.

d. Watlow Controller

i. Channel 2 is controlled by Loop 4, Channel 1 is controlled by Loop 1 . Only Loop 4 is used for normal operation.

ii. Change the temperature set point:

1. Press CHNG SP

2. Press YES

3. Press Down or Up ARROW to the desired temperature (-38C to $+60 \mathrm{C})$

4. Press ENTER

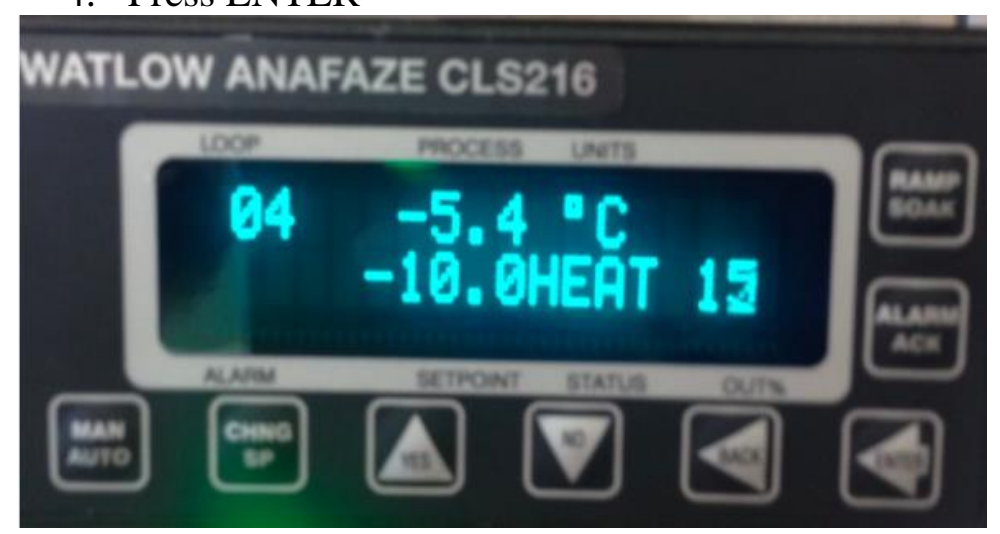

WATLOW CONTROLLER

iii. The chiller will immediately start to heat or cool the Galden®fluid to the set point. The chiller can run $24 / 7$ as long as there are no warning lights that show during operation.

e. Problems and Notes:

1. "Capacity" light turns on or flashes. In this case, raise or lower the temperature closer to ambient. After 5-10 minutes lower or raise back to the original set point. This step down or step up method was done during testing for the thesis.

2 . 


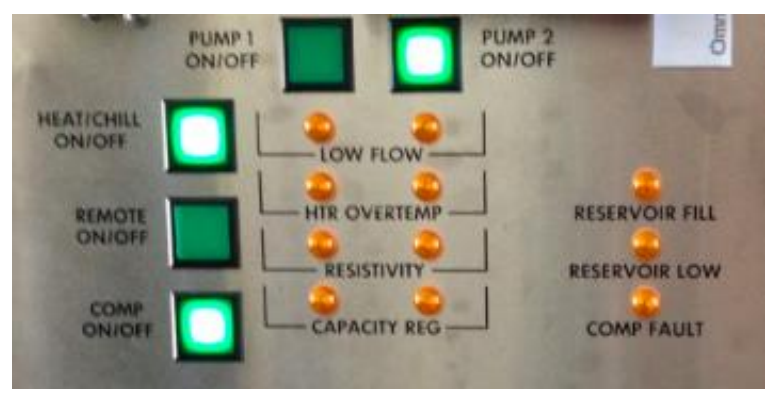

WARNING LIGHTS ALL OFF

3. "Reservoir Low" light turns on. It is allowed to run the machine with a low reservoir, but it MUST be watched more carefully.

4. "Reservoir Fill" light turns on. The machine must be powered down and depressurize in order to add Galden®fluid to the reservoir. Purging is not necessary, nor is closing the supply in the back of the chiller. Just add fluid then re-pressurize the chiller following step e.

5. Note: The machine is LOUD from the whining of the compressor and it expels a lot of heat.

6. Note: Frost is normal all along the lines during sub-freezing temperature set points.

f. Turn off

i. After testing is done set the Watlow Controller to $22 \mathrm{C}$ or room temperature.

ii. Let the machine reach steady state at this temperature.

iii. Turn off all buttons (no particular order)

iv. Turn off all breakers (down)

v. Turn off water and close water supply valve from the lab facility.

vi. Flow low pressure Nitrogen through the H2O supply and outlet using either the fill/drain tank or the Nitrogen source directly. Note: a lot of water will come out of the chiller, use a tray to catch it.

vii. Depressurize the chiller by pressing on the nozzle above the sightglass

III. Drain/Fill part of the ATS Chiller

The chiller is drained in two steps. First, the lines between the chiller and platen are drained. This allows the platen to be removed for repair and reattached. The lines can then be refilled without having to go through the entire fill process again. Second, the rest of the ATS Chiller is drained for storage.

a. Drain the Semi-Tool lines (where the platen is)

i. Depressurize the chiller by pressing on the nozzle above the sightglass.

ii. Close the supply channel for channel 2 at the back of the chiller. Don't forget!

iii. Connect the Nitrogen supply to the "fill/drain" port under channel 2 and connect the hose to the top of the sightglass and to the drain port on the fill/drain tank. (Picture below) Open the regulator to 25-50 psi. Open the valves in the hoses. Allow nitrogen to go through the lines for about 1 
minute. The lines won't be completely drained, but most of it will be pushed out of the lines and into the reservoir or fill/drain tank. Close the valves, close nitrogen supply.

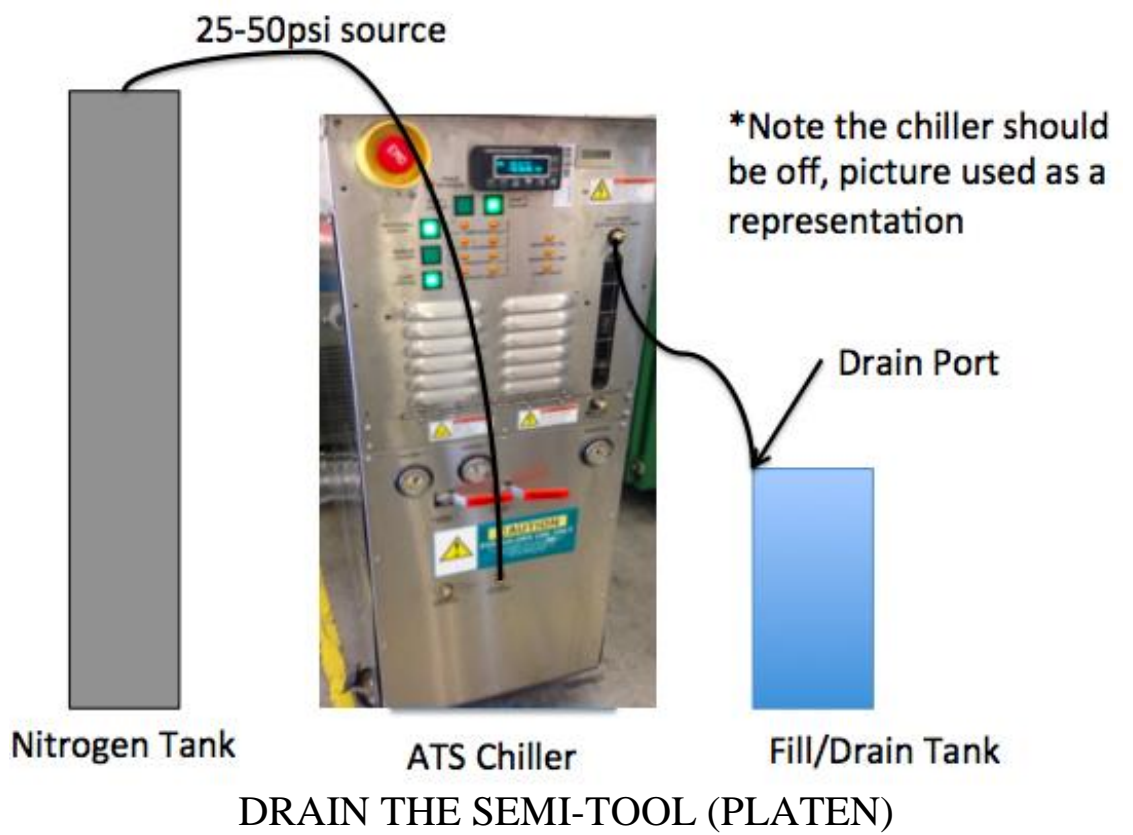

iv. Remove the Swagelok pipes from the outside of the thermal vacuum chamber. Have a tray to catch the fluid.

v. Run Nitrogen through the pipes that are on the inside of the vacuum chamber (not the pipes still connected to the chiller). More fluid will come out.

vi. Cap the pipe feed throughs of chamber and remove the platen to fix it or allow others to use the chamber. The ATS Chiller is no longer connected to the chamber at all.

vii. Drain some of the reservoir so that the liquid can be reintroduced into the pipes after the platen is put back in place. Connect Nitrogen source to the connector at the top of the sightglass. Connect hose from the connector at the bottom of the sightglass to the drain port on the fill/drain tank. (picture below) 


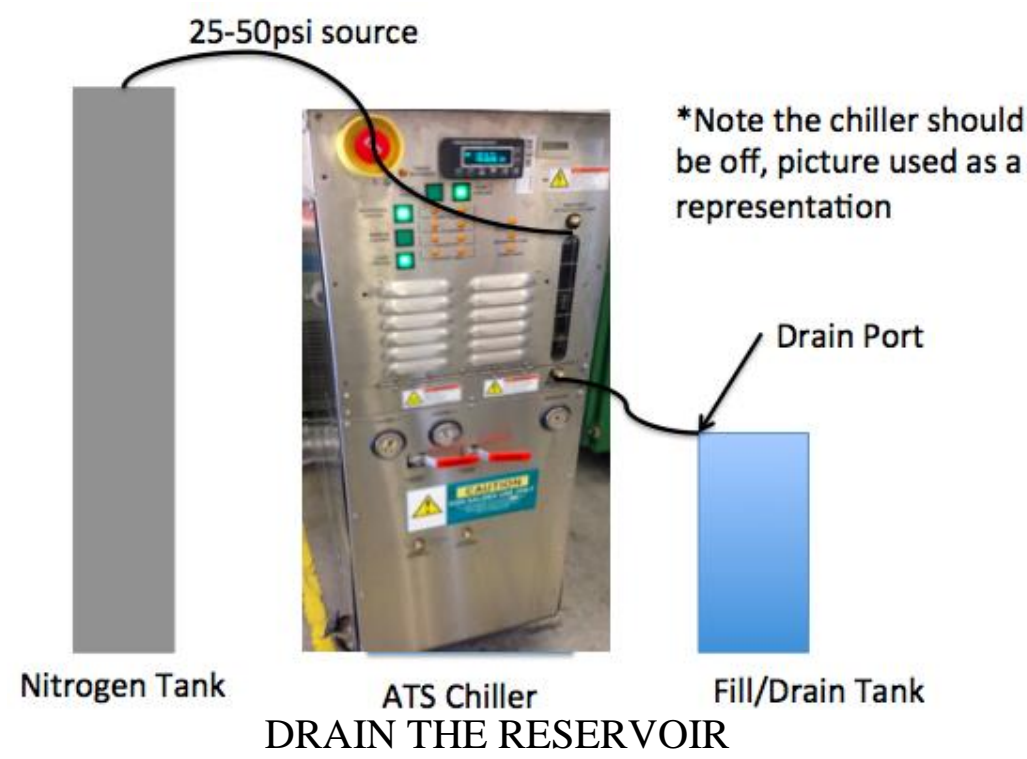

b. Fill the Semi-Tool Lines (where the platen is) after draining/removing the platen (Part III. a)

i. Attach the platen to the chamber. Attach the Swagelok piping from the ATS chiller to the chamber.

ii. Close supply valve (should already be closed if part a. was done correctly) If the valve is open then the entire fill process will need to be done from part (XXX)

iii. Pressurize the fill/drain tank to 60psi. It should already be filled with Galden ${ }^{\circledR}$ fluid from part a.

iv. Connect hose from fill port on fill/drain tank to the ATS Chiller Channel 2 "Fill/Drain" connection. Connect a hose valve to the connector above the sightglass (Picture Below)

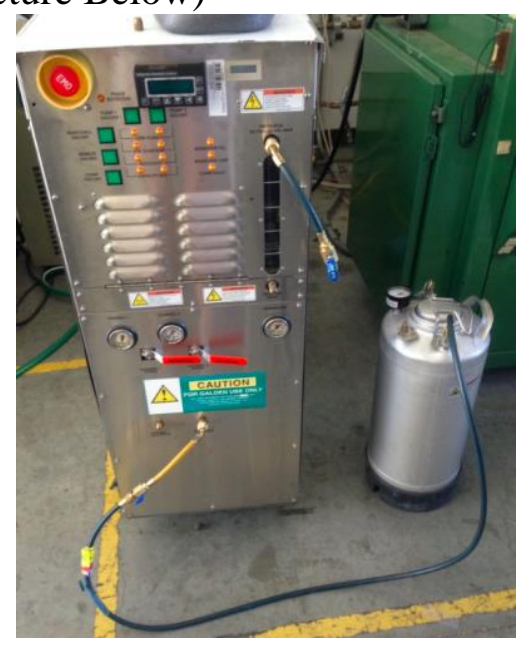

FILL SEMI-TOOL

v. Open valves. Watch until NO bubbles are seen in the sightglass.

vi. Close the valves. 
vii. Open supply valve for channel 2.

viii. Open valves on the fill/drain tank again. Internal lines are already filled so the sightglass should fill up quickly within 20-30 seconds. Don't let nitrogen back in the system by accidentally emptying the fill/drain tank of Galden ${ }^{\circledR}$ fluid.

ix. Close valves

$\mathrm{x}$. Pressurize the reservoir to 30-40psi (follow section $\mathrm{xx}$ for more details)

c. Drain for storage

i. Drain the semi-tool according to section III. a.

ii. Take off the Swagelok pipes that are on the ATS Chiller. More fluid might come out so have a tray available to catch the fluid.

iii. Cap the supply for channel 2 using the white face seal cap.

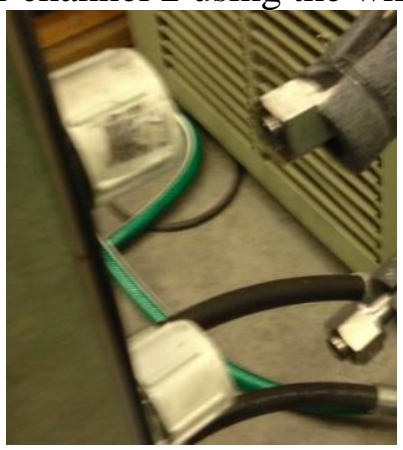

CAPS ON SUPPLY AND RETURN OPEINGS

iv. Open the supply valve in the back of the chiller.

v. Attach hoses as shown in the picture below. Open hose valves to allow nitrogen through the entire system. When no more Galden ${ }^{\circledR}$ fluid is filling the fill/drain tank close the valves. NOTE: it is possible that channel 1 has some fluid in it. Open the supply for channel 1 and drain the same way as channel 2.

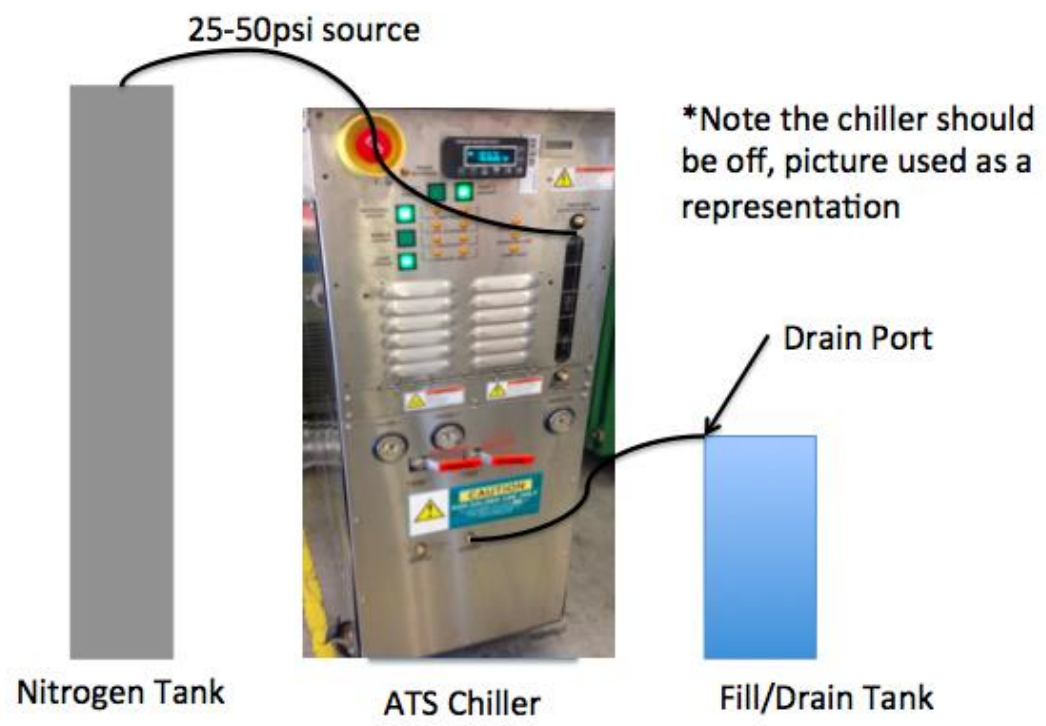




\section{DRAIN THE CHILLER}

vi. Cap everything and make sure all the hoses have had nitrogen ran through them, purging all of the Galden ${ }^{\circledR}$ fluid.

vii. The system can be put in storage. 


\section{THERMAL DESKTOP/SINDA OVERVIEW}

This is only a brief guide covering only some of the basic essentials needed to run a thermal desktop. To get access contact Cindy Beer at Cindy@CRTech.com and request a student license for a specific project. SINDA and TD programs come with manuals and tutorials that are very valuable for learning how to use them. In this appendix will walk through the steps taken to create the model used in the thesis.

SINDA

If it is impossible to get Thermal Desktop(TD), then the next best thing is SINDA/FLUINT. Even if TD is available, understanding how the solver works is important. This can help debug pp.out file or the .cc file that is created after a TD run. The key difference when using SINDA directly is that the user must evaluate all of the capacitances and conductances for each node and each conductor. TD is able to take a model and solve for those values, decreasing the amount of hand-calcs significantly.

The point when modeling is to make a thermal network with various types of nodes and conductors in order to simulate the design. Even very basic models can provide input into a system. Even a single node for the exterior of a spacecraft and a single node for the interior can help to start the spacecraft design process.

SINDA is written in a text file using the SINDA format from the manual. The txt file can be saved as a inp file. Open sinda, browse to the input file, and run. There is no visual representation of the model, just temperatures at steady state. Nodes, submodels, and conductors are explained here. For more detail, consult the manual and work through the tutorials.

\section{Nodes}

Before typing the format for a node, the header block must be written first. This header tells SINDA what the submodel name for the node is. Multiple submodels/headers can be written to better organize the many different nodes.

HEADER NODE DATA, SUBMODEL

- Diffusion Node: Normal Capacitance Node\#, InitialTemperature, Capacitance 
- Arithmetic Node: No capacitance

Node\#, InitialTemperature, -0

- Boundary Node: Infinite capacitance, temperature does not change (space node/panel node) Node\#, InitialTemperature, 0

\section{Conductors}

Before typing the format for a conductor, the header block must be written. Also, the node to be used should already be defined. This header tells SINDA what the submodel name for the conductor is. Multiple submodels/headers can be written to better organize the many different conductors. The node submodel and conductor submodel do not have to be the same. $G$ is the conductance $(\mathrm{W} / \mathrm{K})$ between the nodes.

\section{HEADER CONDUCTOR DATA, SUBMODEL}

- Linear Conductors: Used to conduct between two nodes

Conductor\#, Node1, Node2, G

Ex) 1, PLATEN.1, PIPE.1,100.0

- Radiation Conductors: Used to radiate between two nodes

-Conductor\#, Node1, Node2, G

Ex) -1, PLATEN.1, SHROUD.1,5.0

\section{Source}

Before typing the format for a source, like a solar node or a heater, the header block must be written. Also, the node to have heat applied to should already be defined. This header tells SINDA what the submodel name for the source is. Multiple submodels/headers can be written to better organize the many different sources. The node submodel and source submodel should be the same. $\mathrm{Q}$ is the value of the source in watts.

\section{HEADER SOURCE DATA, SUBMODEL}

- Source Format

Node\#, Q

Note: Be careful with floating points and variables. The node\# and conductor\# are integers, but the values of sources, conductors, and capacitance are floating and need $a .0$ if it is a whole number value.

\section{THERMAL DESKTOP}

These are the steps to get a thermal model running.

1. Open Autocad, click on the thermal tab, press F7 to remove grid (optional).

2. Add in the Optical Properties and the Thermophysical Properties for the model. These options are found in the Thermal Tab.

3. If using radiation create the radiation submodels in Thermal>Radiation Analysis Groups. Add as many groups as necessary. The groups are used to put surfaces that are in view in a group. 
Surfaces that are not in the same view should be in separate groups. Just create the groups for now.

4. Choose a surface or solid depending on the object to be simulated

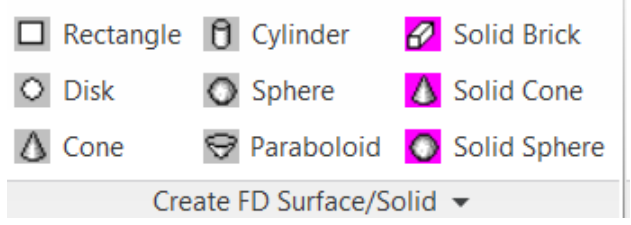

5. Once created (follow prompts at the bottom of the screen) a pop up editor box shows up. More parameters can be added to make the surface/solid the right material.

a. Subdivision - How many nodes in each dimension

b. Numbering - Choses submodel and node starting number

c. Cond/Cap - Material property and submodel

d. Radiation - Choose radiation group on what part of the surface. Multiple radiation groups can be used for the different surfaces. Use material radiation optical properties

e. Contact - can be used instead of conductors (later). Any other model that is "physically" touching this surface/solid will have a conductor automatically created.

f. Advection $-\mathrm{n} / \mathrm{a}$

g. Insulation - Used for MLI. Note, a thermophysical property must be chosen, optical properties are used in the radiation tab.

h. Parameters - Size

i. Trans/Rot - not normally used

6. Repeat Step 4 and 5 for all of the materials that need to be modeled. This includes boundary nodes.

7. Set up Conductors. These can be contactors (surface to surface), conductors (node-node) or a node-surface conductor.

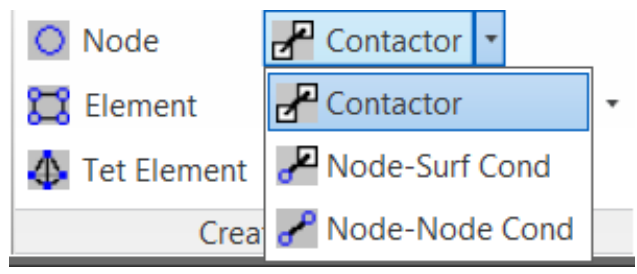

The conductance per area can be used or the absolute conductance can be used for the contactor. Only absolute conductance can be used for conductors.

8. Apply heat loads. Right under the Contactor (shown above) is the heat load button. The heat load can be put on a surface, solid, or single node.

9. Use the tips and tricks section below to check pieces of the model.

10. Open Case Set Manager
a. Double Click case
b. Radiation Tab $>$ Add $>$ Pick group to add $>$ Radk Output $>$ Space Node Temperature $=$ set to the proper temp, repeat for multiple groups. Press okay to go back to case set options.
c. Advanced Setting. Check Run in User Defined Directory and name a folder for the ouput files to go into (optional, but helps to check output files when there is a lot of cases made)
d. Okay to go back to Case Set Manager
e. Run 1 Selected Case
f. If it fails open the pp.out file and search "errors" if this doesn't work make sure there is a boundary node in the model.
g. Examine Results (Only Steady-State For this Review, consult TD Manual for Transient Cases)




\title{
Tips And Tricks
}

\author{
Editor
}

This button is extremely useful for changing nodes, surfaces, solids, and conductors.

\section{Model Browser}

Use this to navigate to everything that has been modeled. It can be used to show nodes by submodel, heatloads, conductors, and at the bottom of the window it shows what layers these are modeled in and if they are visible. Submodels can be turned on and off from the model browser, making it easy to navigate around the model. Becoming familiar with this piece of TD is invaluable for time savings.

Move, Rotate, Duplicate (picture to right from top to bottom) These three icons are very useful to quickly create a model. Duplicating already created solids is handy because all the material properties are saved. The node number is also the same, so that should be changed.

$>$ Views: Undo visibility change, Off, On, Name Off, Name On (picture to right) Being able to "turn off" pieces of the model is very useful when applying conductors to two very close nodes. Seeing the node number is also useful for some applications. Experimenting with these ribbons can help to have a clean model while adding surfaces/solids. If something is invisible just open model browser and select the large "A" at the top and everything will be set to "Visible"/"On"

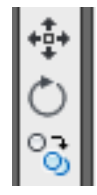

\section{Layers}

Layers are not needed, but are another easy way to "turn off" pieces of the model. If a submodel is large, layers can be used to break it up. The layers used for this thesis are shown below. They are color coded and can easily have the visibility turned on or off. The layers do not affect the output of the model, they are purely for the user to have a clean workspace.

\begin{tabular}{|c|c|c|}
\hline 影犆 & 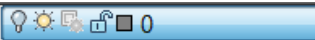 & 7 \\
\hline rent] & 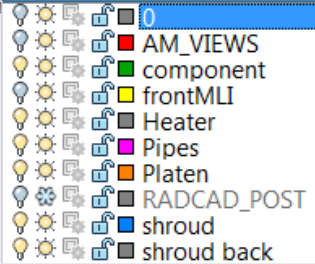 & $\rightarrow$ \\
\hline
\end{tabular}

Edit Active Side/Display Active Side (Picture to the right)

These are somewhat more advance utilities, but also essential to check the model for accuracy. The "Edit Active Side" on top is used to choose what you want to see. This can be a certain radiation group, or the top side of surface, or area contact, or insulation nodes. These things just described are difficult to see in the model, so the editor can be used to show them clearly. When "Arrows" are used it is very easy to see the top side of the surface/solids in order to verify what is the top and bottom. This is very important when grouping the surfaces into radiation groups! The "Display Active Side" is used to display it on the screen. Then, to clear the display press "Reset TD To Model Space"

\section{Check Contact Between Surfaces}

Before running the model it is important to click on a contactor and then go to >Thermal> Model Checks> Show Contactor Markers or Show Contact Markers (depending on which was used) 
A yellow line from each surface should show the contact. Then, to clear the display press "Reset TD To Model Space" 


\section{J. MATLAB CODE: CONVERT OUTPUT TO TEMPERATURE}

$\%\{$

Lauren Glenn

Power 300W set temp -38C goal.

Description: Cold Test, Test performance on dissipating heat load

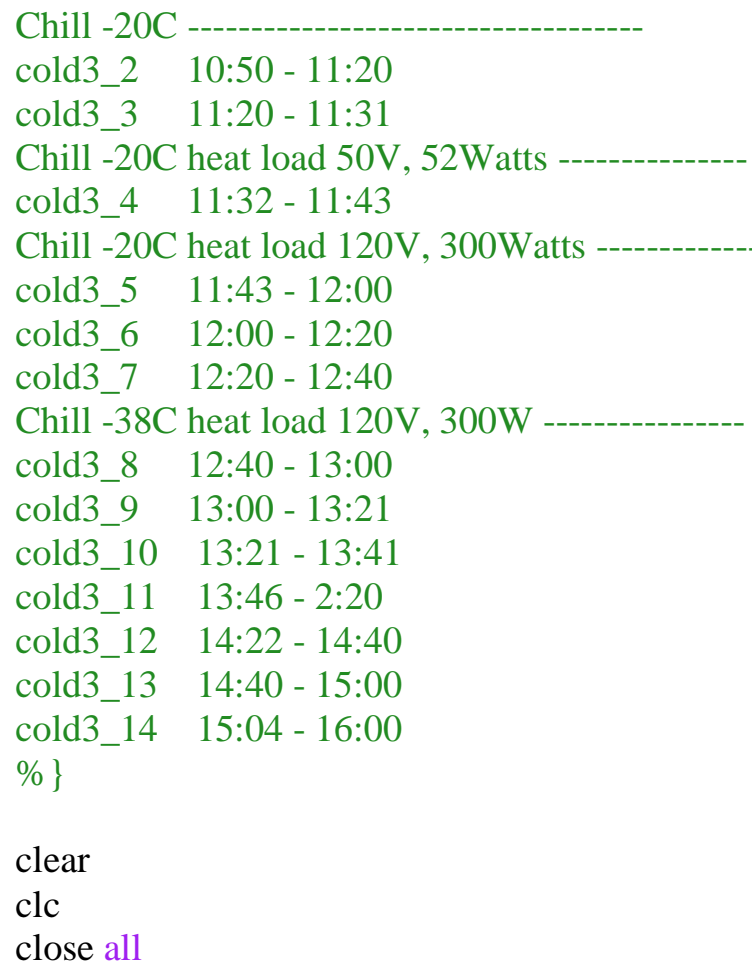




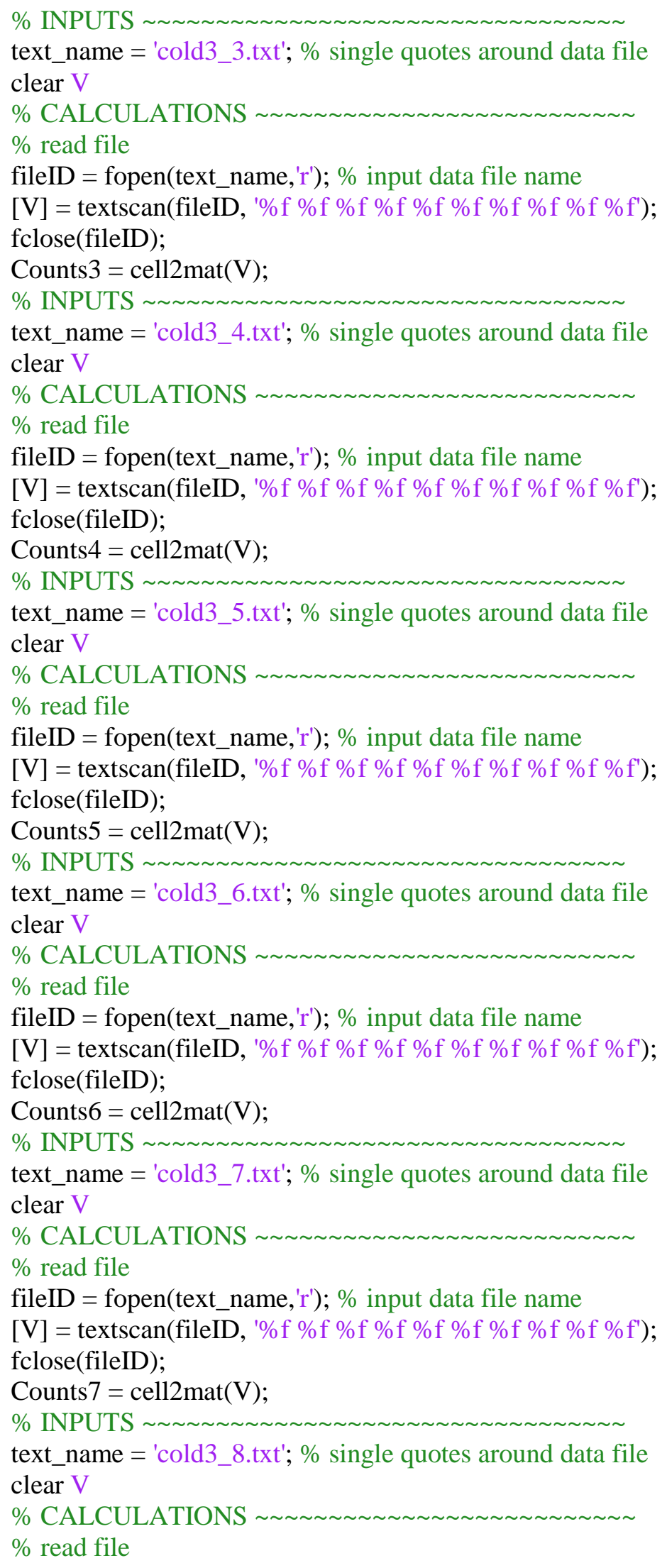


fileID = fopen(text_name, 'r'); \% input data file name

[V] = textscan(fileID, ' $\%$ f \% $\%$ f $\%$ f $\%$ f $\%$ f $\%$ f $\%$ f $\% f^{\prime}$ );

fclose(fileID);

Counts8 = cell2mat $(\mathrm{V})$;

$\%$ INPUTS

text_name = 'cold3_9.txt'; \% single quotes around data file clear $\mathrm{V}$

$\%$ CALCULATIONS

$\%$ read file

fileID = fopen(text_name, 'r'); \% input data file name

$[\mathrm{V}]=$ textscan(fileID, ' $\%$ f $\%$ f $\%$ f $\%$ f $\%$ f $\%$ f $\%$ f $\%$ f $\left.\% f^{\prime}\right)$;

fclose(fileID);

Counts $9=\operatorname{cell} 2$ mat $(\mathrm{V})$;

$\%$ INPUTS

text_name = 'cold3_10.txt'; \% single quotes around data file clear $\mathrm{V}$

$\%$ CALCULATIONS

$\%$ read file

fileID = fopen(text_name, 'r'); \% input data file name

[V] = textscan(fileID, ' $\%$ f \% f $\%$ f f $\%$ f $\%$ f $\%$ f $\%$ f $\%$ f');

fclose(fileID);

Counts $10=\operatorname{cell} 2 \operatorname{mat}(\mathrm{V})$;

$\%$ INPUTS

text_name = 'cold3_11.txt'; \% single quotes around data file clear $\mathrm{V}$

$\%$ CALCULATIONS

$\%$ read file

fileID = fopen(text_name,'r'); \% input data file name

$[\mathrm{V}]=$ textscan(fileID, ' $\%$ f $\%$ f $\%$ f $\%$ f $\%$ f $\%$ f f $\%$ f $\%$ f $\%$ f');

fclose(fileID);

Counts $11=\operatorname{cell} 2 \operatorname{mat}(\mathrm{V})$;

$\%$ INPUTS

text_name = 'cold3_12.txt'; \% single quotes around data file clear $\mathrm{V}$

$\%$ CALCULATIONS

$\%$ read file

fileID = fopen(text_name,'r'); \% input data file name

[V] = textscan(fileID, '\%f \%f \%f \%f \%f \%f \%f \%f \%f \%f');

fclose(fileID);

Counts12 = $\operatorname{cell} 2 \mathrm{mat}(\mathrm{V})$;

$\%$ INPUTS

text_name = 'cold3_13.txt'; \% single quotes around data file clear $\mathrm{V}$

$\%$ CALCULATIONS

$\%$ read file

fileID = fopen(text_name, 'r'); \% input data file name

[V] = textscan(fileID, ' $\%$ f \% f $\%$ f $\%$ f $\%$ f $\%$ f $\%$ f $\%$ f f');

fclose(fileID);

Counts $13=\operatorname{cell} 2 \operatorname{mat}(\mathrm{V})$;

$\%$ INPUTS 


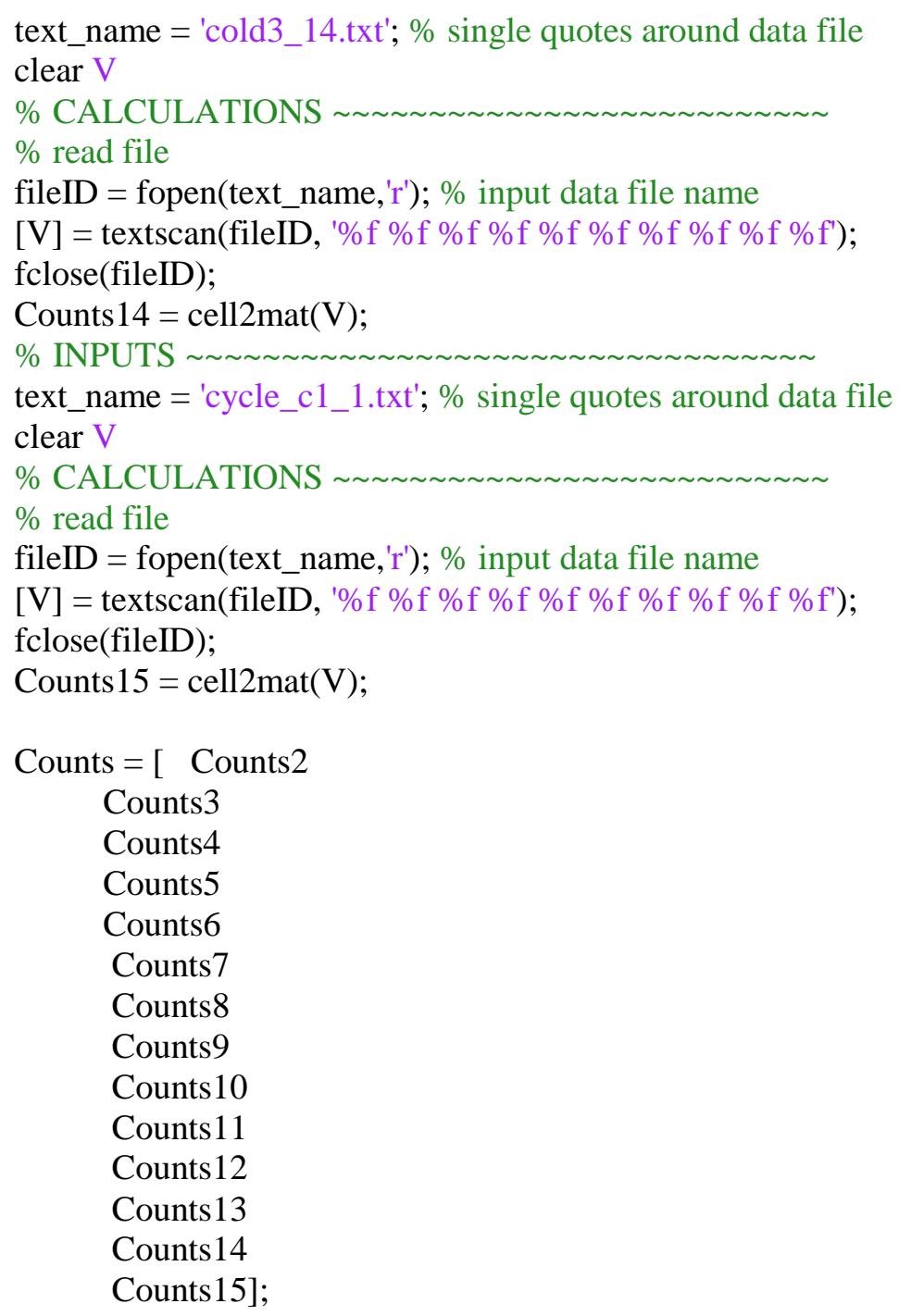




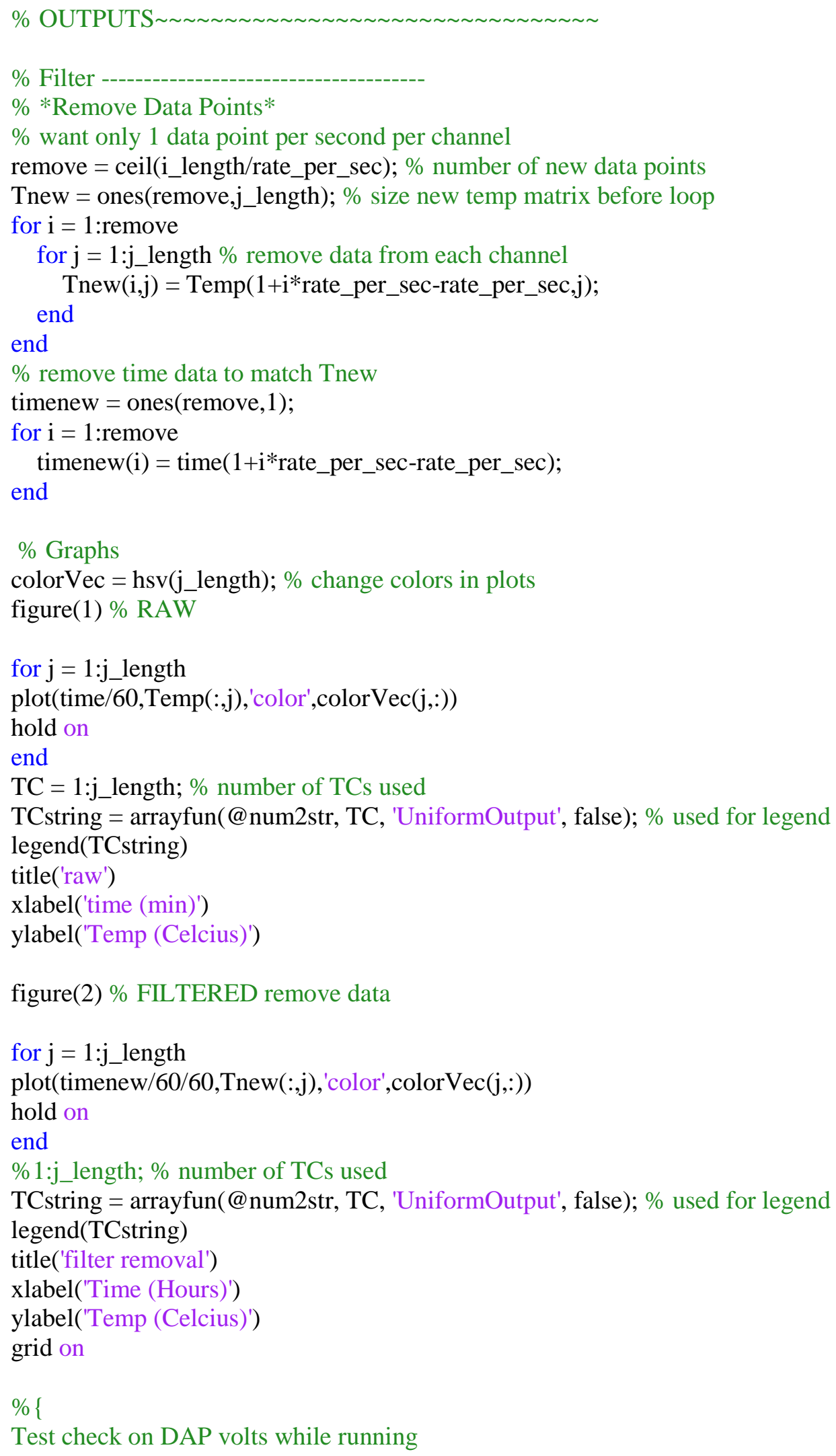


reading $=11000 ; \%$ Plug in approximate voltage on DAP screen in TABLE

Vtest $=$ reading $* 10 / 2^{\wedge} 16 ; \%$ Equation based on DAP resolution and voltage range

Ttest $=($ Vtest -1.25$) / .005$

$\%\}$ 